\title{
Technology's arrow : developing information networks for public administration in Britain and the United States
}

Citation for published version (APA):

Wyatt, S. (1998). Technology's arrow : developing information networks for public administration in Britain and the United States. [Doctoral Thesis, Maastricht University]. Datawyse / Universitaire Pers Maastricht. https://doi.org/10.26481/dis.19981105sw

Document status and date:

Published: 01/01/1998

DOI:

10.26481/dis.19981105sw

Document Version:

Publisher's PDF, also known as Version of record

Please check the document version of this publication:

- A submitted manuscript is the version of the article upon submission and before peer-review. There can be important differences between the submitted version and the official published version of record.

People interested in the research are advised to contact the author for the final version of the publication, or visit the DOI to the publisher's website.

- The final author version and the galley proof are versions of the publication after peer review.

- The final published version features the final layout of the paper including the volume, issue and page numbers.

Link to publication

\footnotetext{
General rights rights.

- You may freely distribute the URL identifying the publication in the public portal. please follow below link for the End User Agreement:

www.umlib.nl/taverne-license

Take down policy

If you believe that this document breaches copyright please contact us at:

repository@maastrichtuniversity.nl

providing details and we will investigate your claim.
}

Copyright and moral rights for the publications made accessible in the public portal are retained by the authors and/or other copyright owners and it is a condition of accessing publications that users recognise and abide by the legal requirements associated with these

- Users may download and print one copy of any publication from the public portal for the purpose of private study or research.

- You may not further distribute the material or use it for any profit-making activity or commercial gain

If the publication is distributed under the terms of Article $25 \mathrm{fa}$ of the Dutch Copyright Act, indicated by the "Taverne" license above, 


\section{TECHNOLOGY'S ARROW}


(6) 1998 Sally Wyati, London. England ISBN: $90-5278.240-7$

Printing: Datawyse/Lniversitaire Pers Matsiricht 


\section{TECHNOLOGY'S ARROW}

\section{Developing Information Networks for Public Administration in Britain and the United States}

\section{PROEFSCHRIFT}

ter verkrijging van de graad van doctor aan de Universiteit Maastricht,

op gezag van de Rector Magnificus, Prof. dr. A.C. Nieuwenhuijzen Kruseman volgens het besluit van het College van Dekanen, in het openbaar te verdedigen

op donderdag 5 november 1998 om 16.00 uur

door

Sally Wyatt

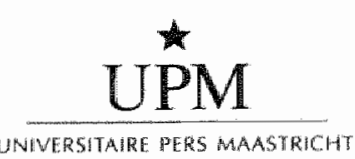


Promotor:

Prof.dr.ir. W.E. Bijker

Beoordelingscommissie:

Prof.dr. L.L.G. Soete (voorzitter)

Prof.dr. A. Rip (Universiteit Twente)

Dr. R. de Wilde 


\section{CONTENTS}

List of Tables

The Elephant and Jupiter's Monkey

Preface

Introduction

1, Technology \& Society - A False Dichotomy

Introduction 4

Models of the relationship between technical and social change 9

Conclusion $\quad 24$

2, Information Technology \& Public Administration

Introduction 25

Information technology $\quad 28$

Public administration $\quad 35$

IT in public administration 37

Policy issues raised by the use of IT in the public sector 39

Approaches to studying information technology and public administration 46

Conclusion 51

\section{3, Studying the Society-Technollogy Relationship}

Introduction $\quad 53$

Interdisciplinarity: Seamless webs or unfocused microscopes $\quad 55$

Portraying technology as a linear process $\quad 59$

Symmetry in accounts of science and technology 63

Scale: Small may be beautiful but big is hard to define 66

Conclusion $\quad 69$

\section{4, The British Operational Strategy}

Introduction $\quad 70$

A very short history of social security in the UK 71

The Operational Strategy: The cast $\quad 75$

Relevant social groups - problems and interests 79

The development of the Operational Strategy: Part 1, 1977-86 81

Interpreting the story of the Operational Strategy 85

The development of the Operational Strategy: Part 2, 1987-91 87

Closure 91

Next steps in the Operational Strategy 93

Conclusion 94 


\section{5 , The tyranny of structurelessness}

Introduction $\quad 96$

Prologue $\quad 98$

The Government Data Network: The cast 107

The FTS2000: The cast 109

Social groups - relevant for whom? 110

The Government Data Network $\quad 112$

The Federal Telecommunication System for the year 2000

Reciprocal invisibility: Malleability and technological frames 125

Conclusion 133

6, Conclusion: Technological determinism is dead;

long live technological determinism

Introduction

Pink, white or gray elephants? Illusion, vainglory or reality in building information networks

The three Ps: Privacy, primacy and privatisation $14 \mathbb{1}$

The elephant and the rhinoceros: Rules of combat 143

Technological determinism: Elephants live for a very long time 150

\section{Appendices}

I Abbreviations 156

II Map of the UK 158

III List of Interviewees 159

$\begin{array}{ll}\text { Bibliography } & 162\end{array}$

$\begin{array}{ll}\text { Summary } & 176\end{array}$

$\begin{array}{ll}\text { Samenvatting } & 182\end{array}$

$\begin{array}{lr}\text { Curriculum Vitae } & 188\end{array}$ 


\section{LIST OF TABLES}

2.1 Summary of issues raised by public sector use of IT 41

2.2 Models of the relationship between technical change \& social change 48

3.1 Linear models of technological change 61

3.2 Principle of symmetry 65

4.1 Computerisation of social security: chronology of main events 73

4.2 Projects in the Operational Strategy 83

5.1 GDN: The Government Data Network: Chronology 113

5.2 Departments which signed access agreements for the GDN 118

5.3 FTS2000: Chronology 122

5.4 Characteristics of the GDN and FTS2000 127

6.1 Extending the principle of symmetry 149

6.2 Varieties of technological determinism 154 


\section{THE ELEPHANT AND JUPITER'S MONKEY}

The elephant and the thinoceros, having collided

In a difference of opinion

Over their respective precedence and the boundaries of their dominion

Decided

To settle their quarrel by combat, hand-to-hand.

The greal day came round as planned.

When someone dashed up to announce

That Jupiter's winged monkey, wand in hand,

Was about to land -

A simian named Gille, by all accounts.

At once the elephant, assuming he'd been sent

In the role of ambassador to investigate

The grandeur of the elephantine state

And basking in the glow

Of this glorious thought, waited for the envoy to present

His credentials, and found him somewhat slow

in appoaring.

At last Mr Gille called by, casually, to salute

His Elophantship, who was all ready to grant a gracious hearing.

This monkey, however, vemained mute: Not a word about the dispute, No mention

Of the great topic which the king thought claimed the god's' attention.

(Elephant or fly - To them what does the difference signify?)

Seeing he had no choice

But to be first to use his voice,

The Elephant began: 'Soon my cousin Jupiter will enjoy the sight

Of a tremendous fight. From his supreme throne, all his court

Will witness a fine soort.'

'What fight?" asked the monkey with a solemn face.

'Good gracious, haven't you learned

The news? The rhino has challenged my pride of place.

And the tusked people are at war with the one-horned race.

Surely you've heard of our country - it's not without fame."

I should be wnchanted to be informed of its name:

Mr Gullo returned. 'In our vast celestial hall

Matters the this are hardly discussed at all."

The olephant. lost in amazement and shame.

Said. What are you doing then, in the land of the elephants?"

've conne to apportion a blade of grass among some ants.

There is nothing on which the gods don't lavish care:

Large and small are equal in their eyes.

As for your affair, it still hasn"l been mooted in the skies."

La Fontaine, $1621-1695$

La Fontaine, Selected Fables. New York: Viking Press. 1979. (trans. Jarnes Michie) 


\section{PREFACE}

Perhaps this book is best understood as a very belated response to Keith Pavitt's accusation that I am an 'intellectual gadfly'; maybe he intended it as a compliment. My interests are indeed wide-ranging. During the 1980s, my work not only allowed but required an ability to engage in diverse areas of research. I worked on a variety of research contracts, at the Science Policy Research Unit (SPRU), University of Sussex; the Programme for Information and Communication Technologies (PICT), Economic and Social Research Council and at the Centre for Business Research (CBR), Brighton Polytechnic. At SPRU, $I$ worked on the measurement of innovative activity and British competitiveness; on gender and domestic technology; on the ways in which multinational corporations protect their technological advantage; and, on the transfer of technology to China s offshore oil industry. Joining PICT forced me to pay attention to information technologies and at Brighton Polytechnic I extended that to the public sector. All of this work was collaborative. The variety and the opportunity to learn from others was the great strength of this lifestyle. Its downside was the short-termism; constantly having to find one's own and others' salaries and always feeling that more work could have been clone.

In 1990, I applied for a permanent teaching position with the Department of Innovation Studies, University of East London (UEL). The position was for someone with a knowledge of innovation theory and its application to information technology. After adjusting to the demands of a new teaching job, I decided the time had come to do a long piece of work, by myself, that would enable me to synthesise some of these diverse interests and to demonstrate there was some coherence to my own intellectual work. What follows is that piece of work. I have not managed to include everything, although the footnotes do provide clues to some other pursuits. At a very general level, I have always been concerned with the role of technology and technological change in the economy and society more widely. As I became more aware of the more sociologically-informed science, technology and society (STS) literature, the relationship between that literature and the economics of innovation, with which I was more familiar began to pre-occupy me. That is part of the sub-text of this book.

I began writing this book in 1994 , while I was a Pellow-in-residence at the Netherlands Institute of Advanced Study (NIAS). I am extremely grateful to the Dutch Royal Academy, to the then Director of NIAS, Professor Dirk van de Kaa and to all of the staff for their various roles in creating such an academic idyll. I returned to NIAS for three brief weeks in April 1997, to begin the end of this book. I am especially grateful to Wouter Hugenholtz, Executive Director of NIAS, both for his kindness during some difficult moments in 1993-94 and for his facilitation of my 1997 sojourn.

NIAS endures as a wonderful environment. But each year it takes on a diverse set of characters from around the world with an even more diverse set of interests. The companionship and friendship of the habitués of my eponymous bar made 1993-94 a 
companionship and friendship of the habitués of my eponymous bar made 1993-94 a personally and intellectually fascinating year. I hope that Christopher Brown, Jeroen van den Hoven, Mayke de Jong, Douglas Lewis, James Tracy and Marek Zvelebil will approve of their traces which, with the exception of Jeroen, fall well outside their usual concerns.

The research on which this book is based began much earlier, in 1988, while I was working at the Centre for Business Research. Howard Rush and Joanna Buckingham contributed a great deal to what appears in Chapter 5 . One of the interviews, which must remain unnamed, that Howie and I did together is one of the highlights of my life as a researcher.

Versions of some chapters have been presented in the usual academic settings, including the Universities of Brighton, Brunel, East London, Edinburgh, London (UCL), Maastricht, Manchester and Sussex. The European Group on Public Administration and the Large Technical Systems conferences have also provided stimulating fora for discussion. I am grateful for the opportunities and the feedback.

Maastricht is the intellectual home of this book. It took a while to find its way there. Wiebe Bijker agreed to become my 'promotor' in 1994 in unusual circumstances. I am extremely grateful that he had the confidence (in me and himself) to take me on at a time when I was certainly not at my best. The physical distance between us could have been a problem, but the wonders of modern telecommunication and air transport eased many of the potential difficulties. Discussions of drafts took place on occasional visits each of us made to London and Mastricht, but also in the corners of conferences elsewhere in Europe.

Maastricht was also my temporary, physical home on two occasions. In 1995, Rein de Wilde and I exchanged houses so that I could write Chapter 4 and he could visit the British Library. Not only did I complete Chapter $4, I$ also learned to enjoy the music of Dvorak. In 1997, Jessica Mesman generously allowed me to stay in her house while she was on holiday, On both occasions, I was reminded of the dangers of taking domestic technologies too much for granted.

Without he demands placed by my colleagues and students at the University of East London, this book would, without a doubt, have been finshed much sooner. However, my life, and this book, would have been poorer without them. Arriving at the Department of Imovation Studies in 1990 felt like coming home. Working there with our students, travelling bewween the financial centre of London and one of the nost deprived boroughs of Lordon, where UEL is located, constantly remind me of the importance of my subject.

Wiebe Bijker and Hans Redder both worked on the translation of the summary into Dutch. This will be the only ocession in my academic career when I can disclaim all responsibility for my errors. However, have complete confidence in them both and an 
very grateful for their help. I would also like to thank Jessica Mesman and Gillian Perkins for their help in preparing for the final stages of the presentation of this book.

There are a few people who do not fit neatly into the narrative offered above. David Albury, Flis Henwood, Alvaro de Miranda, Dave O'Reilly and Hans Radder all kindly read earlier versions of some chapters. I am grateful to each of them, for their comments and for their friendship.

This book is for three of my friends - Flis, Mayke and Tine. In their very different ways, they have given me so much fun, love and intellectual stimulation over the years. Most importantly, they demonstrate that it is possible to live one's life creatively, if not always easily. 



\section{INTRODUCTION}

This book has three purposes: to tell the fascinating stories of three information systems developed during the 1980s in Britain and the United States; to demonstrate why it is necessary and important to follow both actors and analysts; and, to retrieve technological determinism from its ignominious position as the bête noire of 'enlightened' scholars of science, technology and society studies. All of these can be subsumed within an overarching objective which is to contribute to the development of an interdisciplinary perspective for understanding the complex process of socio-technical change.

Chapter 1 outlines the general technology-society problematic. How can we make sense of a world inhabited not only by people but also by the artefacts we and our ancestors have created? The reader is introduced to technological determinism, neutral technology and a range of constructivist approaches to understanding technology. While the latter is given most attention, I suggest that there are reasons why technological determinism continues to endure, not least because it is the explanation which fits most people's experience of technology most of the time.

Chapter 2 narrows the focus by examining the role of information technology (IT) within public administration. This represents an attempt to redress the balance in the evergrowing literature on the development and use of $\mathrm{TT}$ which focuses on manufacturing and private services. Some of the issues posed by IT are simillar for government, but there are others which are specific to the public sector. The public sector is an important player which needs more analysis. Not only is it a major user, it is also involved in the development of IT through its other roles as, inter alia, regulator, standard-setter. Three key issues are identified which I have termed the 'three PS': privacy, privatisation and primacy (of the legislative process). All of these affect the nature and direction of the systems described in later chapters.

Three government information systems provide the empirical focus for this book. The first, in Chapter 4, concerns the second attempt, called the Operational Strategy, by the British Department of Social Security (DSS) to develop a computer-based system for administering the huge volume of social welfare benefits for which it is responsible and which had hitherto largely been administered by the movement of vast quantities of paper. How was it possible to bring huge numbers of people with very different interests together with even larger numbers of rules for deciding and processing benefit claims? What was the role of technology in this process? The DSS had attempted to do something similar in the 1970s. Why did it work this time? 


\section{2 introduction}

The other two systems, described in Chapter 5 , were developed by the central administrations in the UK and the US. The British attempted to develop a data communication network; the US attempted to develop an integrated voice, data and image communication network. Both of these were to be shared by different government departments and both were to be provided by a third party supplier. Both are very odd stories. The British Government Data Network is the story of a single data communication infrastructure to be shared by departments in a country where exchange of data between departments is forbidden by law. The US Federal Telecommunication System for the year 2000 is the story of how a single integrated network to be shared by government departments became two incompatible networks. How did the people behind these systems convince so many others that these were practicable ideas? In what sense could they be considered successful?

Chapter 3 provides an introduction to some of the methodological problems encountered. How do you define scale; is largeness an objective fact? How can we reconcile the limits of linear approaches with our experience of historical time? Why and how do we conduct interdiscplinary research? Is it possible and desirable to extend the principle of symmetry yet again? Occasionally, Chapters 4 and 5 are interrupted to reflect on what the stories illustrate about these and other methodological concerns. Chapters 4 and 5 attempt to intertwine two narratives - the case studies mentioned in the preceding paragraphs and the methodological issues introduced in Chapter 3. Readers interested in only one of the narratives should be able to follow their inclinations by using the sub-headings.

The major methodological contribution of this book is that actors and analysts can learn from one another. If we simply followed the actors, which some authors suggest is what the new sociology of technology advocates, we would end up with very partial accounts of technological change. In two of the case studies presented here, we would have missed the users, both those people who use the systems to do their paid work and also those people whose livelihoods depended on the systems. We occasionally found images of users being deployed, but not always even that. Yet, anyone with even a cursory knowledge of the economics and management of innovation literature, will know that users are important to the success of projects. These case studies only become comprehensible when the invisibility of users by other social groups is taken into account. Equally, analysts have something to learn from the concepts used by some of the actors. In these cases, it is technological determinism, a mode of explanation used to both justify
courses of action and mobilise other resources.

The major theoretical and practical contribution of this book is that technological determinism needs to be treated with more respect and subtlety than has been done hitherto. Berating it as a reductionist and inadequate explanation is not enough. 
Technological determintsm lives! It persists in the actions taken and justifications given by many actors; it persists in analysts' use of it to make sense of the introduction of technology in a variety of social settings; it persists in manifold theoreticall and abstract accounts of the relationship between the social and the technical; it persists in the responses of policy-makers and politicians to challenges about the need for or appropriateness of new technologies; and it persists in the reactions we all experience when confronted with new machines and new ways of doing things. Chapter 6 concludes with a mapping of the varieties of technological determinism found in the words of analysts and actors. Four types are identified: justificatory, explanatory, methodological and normative. Taking technological determinism seriously in this way is important for 'big' and 'small' politics. In order to be able to intervene in the familiar big politics of public life, we have to understand how technological determinism is used by some aciors. An understanding of the types of technological determinism will also help us in the politics of knowledge, to anallyse how the dualisms of internal/externat, social/technical. are produced and reproduced.

If you have read even this far, it is likely you do not need to be convinced of the importance of including technology within our analyses of social change. I want this book to be read by a number of different audiences; including people involved in the development and use of IT systems in the public sector and elsewhere and my colleagues in the science, technology and society community. In addition, perhaps there will be a few readers as yet unconverted who read this and become convinced that social studies of techrology are interesting. Maybe technology's arrow will pierce the hearts and minds of a few of those who continue to study the social world as if it was inhabited exclusively by humans. 


\title{
CHAPTER 1
}

\section{TECHNOLOGY \& SOCIETY - A FALSE DICHOTOMY?}

\begin{abstract}
Airlines seek EC inquiry into Galileo ${ }^{1}$
This headline was not introducing what would otherwise have been a front-page story about the return of the Inquisition. Rather it was a small item at the back of the paper in the business pages about the challenge from five smaller airlines to British Airways' control of the airlines' reservation system, called Galiteo, which is accessed by travel agents. The concern of the smaller airlines was that British Airways was charging them too much to put their own schedule details on the system and, moreover, was abusing its position of ownership by designing a system that ensured its flights appeared on the screen first, thus reinforcing its dominance of the air passenger travel market.
\end{abstract}

\section{Cinemas challenge consumer choice}

Automated ticketing and seating systems are used by cinemas to impose their views of the 'best seat". Being told you have been assigned the best available seat raises the hackles of anyone schooled in science, technology and society studies and contrary people every where. How could they possibly know the preferences of all cinema goers? People vary in their preferences for the front or the back, the aisle or the centre.

This book examines the attempt to develop three large information systems by the British and US governments. As with the systems described above, these government systems promised to improve the quality of service, reduce costs and improve the quality of the working lives of civil servants. The stories behind these government systems are interesting about the pleasures and perils of large-scalle, government-funded projects. Moreover, they provide stimulating fodder for those contrary people, including myself, who try to understand why technologies take the form that they do, regardless of whether they are large scale systems like those of British Airways or the British and US governments or smaller scale systems like those of film distributors.

\section{Introduction}

Wild claims are frequently made about the revolutionary potential of the new technologies of information and conmunication, those 'things' that incorporate microprocessors and are connected to one another with wires or cables or via satellites. Such claims usually reflect cheeringly optimistic or despairingly pessimistic visions of the future. The utopian view depicts a future in which we are freed from routine, tedious work in order to enjoy the
infinite variety of entertainment and education that is beamed into our homes. The
dystopian version emphasises the potntiat of dystopian version emphasises the potential of the technology to increase surveillance and

\footnotetext{
The Independen, 31 March 1994, p.37.
} 
control over every aspect of our lives, not only at home but also at work, in the marketplace and in our dealings with the government.

These claims and counter-claims are repeated in many discussions about the nature of contemporary society, including debates about whether or not we are atready living in, or are on the threshold of, an 'information age', a computer society' and whether or not we are experiencing the 'post-modem condition'. Much of the popular and academic literature on the subject, which itself is no small part of the information explosion, bases its claims about revolutionary social changes on the widespread availability and use of computing and telecommunication technologies, what I will term information technology (IT). But questions about the actual extent of the use of IT and the nature of the technology itself are rarely raised.

The development of microcomputers in the early $1980 \mathrm{~s}$, with its promise of massive processing power on individual desktops, highlighted the debate about centralised or decentralised patterns of use and control. This was overtaken with the development of electronic networks, again seemingly offering the capability for both centralised and decentralised pattems of work organisation and service delivery. This tension between centralisation and decentralisation accounts for much of the confusion about whether or not the technology will be used for good or bad; and is thus at least part of the reason for the wide gulf between the utopian and dystopian visions.

IT is not the first technology to have such apparently contradictory possibilities. The printing press has been described as both an instrument enabling the dissemination of a variety of political and religious views and one allowing the rise of the modern nation state through the wider geographic distribution of printed codes of law. More recenly, television has been welcomed by some for providing a window on the world and extending our horizons, and reviled by others for transmitting tawdry scenes of sex, violence and mass consumerism. This suggests the problem is not simply a function of the extent of centralisation but also derives from the interests of those who use technologies.

What these apparenty contradictory analyses share is a view that the technology itself is inherently neutral and whether it has good or bad effects in the world depends entirely on the choices people make regarding how to use it. Such a view is not confined to those technologies of information and communication as in the above examples. Simple material objects such as the ubiquitous textbook brick can be interpreled in a similar manner. In the hands of a skilled mason, a brick is an essential part of a walled Persian rose garden. In the hands of a disaffected youth, a brick can be used to smash windows. Belief in the neutrality of material objects and the concomitant prinacy of human action is aptly expressed in the slogan of the US National Rifle Association, 'Guns don't kill people, people kill people:"

\footnotetext{
2 In his rewiew of Hubert Buier's autobiography, John Banville makes a similar point in relation to the Holocaust. "The fact is, "science" did not destroy the Children of Drancy 14051 children deported 10 Auschwily in 1942 fhoughth the transit camp at Drancy near Parisl. Nor did technology, which Butler hails to distinguinh from heoretical science. The techneal means of transporting the millions of Europern Jews to the campas were primitive. Even Zyklon $\mathrm{B}$, the gas used in the killing rooms requind no great scientific skill lo produce. No: in the camps, as in every murder site, what killed people was people. Buller, guoting Francois Marriac, helieves that "the cightechth
} 
This book explores why information technologies are often considered to be value neutral, why this view is mistaken and how this affects our understanding of the world in which we live. The either/or analyses found in many discussions of IT arise from the fact that computers can do very different things. The very same collection of circuits in a plastic box can be programmed to do entirely different activities - play games, manipulate words and numbers, control production processes, communicate share prices. Unlike the printing press, which admittedly could be used to generate lots of different texts, the ways of using the press itself to generate a printed page were quite limited. The uses for guns are even more circumscribed - you can use them as paperweights or hang them on your walls but all you can really ' $\mathrm{do}$ ' with them is shoot people, other living creatures and inanimate targets." If the uses for relatively "fixed" artefacts can be explained by recourse to notions of the neutrality of objects and the importance of human choice, then the possibilities for the naive analyst to use such notions to highlight the ambiguities of IT are even greater. The argument I shall develop in later chapters, through the telling of three stories about government IT systems, is that the malleability of IT said to arise from its programmability is illusory. While the malleability is a feature promoted in order to sell IT, for the technology to be used it has to have a purpose that is both fixed and clearly recognisable to its intended users. Thus, for a system to be used, malleability has to be excluded during the process of development. During this process of exclusion, social relations are reflected in the design of the technology. Moreover, as we shall see in Chapters 5 , if they are not reflected, if indeed the technology is too malleable, it will not be used, even if it works, because people will not recognise it as part of their world.

The other feature of IT highlighted in the claims about the ways in which IT will change the world, for good or bad, is its pervasiveness. What makes IT a revolutionary technology is the fact that information processing is at the heart of all human activities and therefore IT can be used in all spheres. Paradoxically, this ubiquity can equally be seen to contribute to the essentially conservative potential of the technology. As mentioned in the preceding paragraph, later in the book we shall see how a network technology has to incorporate existing patterns of human interaction in order to be used, thus playing a significant role in reproducing long-standing sets of social relationships. In this way, large technical systems can be said to be hard, obdurate and even autonomous.

I hope that this book will be of interest to a number of different audiences. At first glance, a book which takes as its central object three government IT networks may appear to have al readership limited to those people in government and the IT industry who are trying to

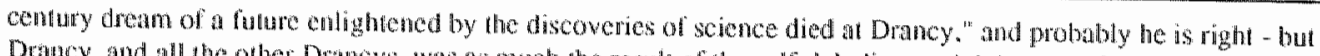
Drancy, and all the other Drancys, was as much the result of the selfodeluding sociat drams of the Enhghenment

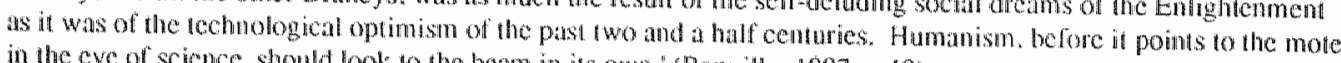

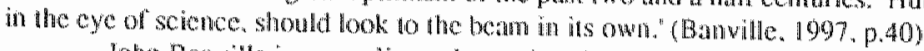

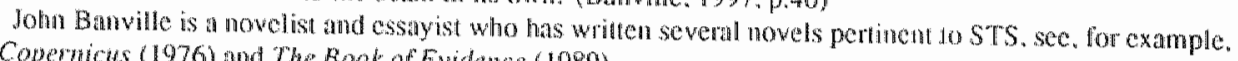
Docha Copernichs (1976) and The Book of Evideme (1989).

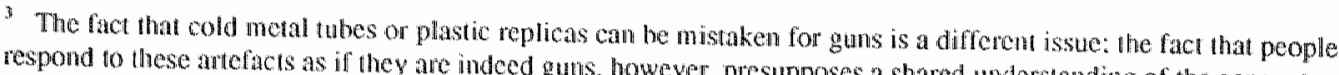
respond to these whefacts as if they are indeed guns. how ver. presupposes a shared understanding of the concept
and reality of a gun. 
sell, develop or use public sector IT systems. What follows is not a how to' manual enabling ever greater levels of efficiency to be realised but rather an analysis of some of the recurring difficulties there have been in developing networks for public sector use. In most industrialised countries, public administrations have come under pressure to reduce costs in recent years. These highly politicised debates have tended to ignore the role of technology in the process, yet the technical means for recording information have always had a vital place in the development of nation states, not to mention monasteries and city states. Political power, administrative power and the technical means for achieving them are a single process. The stories recounted in Chapters 4 and 5 offer some insights into this process, but this book is not aimed exclusively at either a political science or public administration audience.

I would like this book to be read by my colleagues in the social sciences and humanities, particularly those who have so much to say about the nature of the society in which we live but who rarely mention the role and place of technology or, when they do, simply make assumptions about its availability. For some reason, technical artefucts are not subjected to the same rigorous analysis to which other social phenomena are subjected as a matter of course. Scholars in the humanities and social sciences have shown a widespread disregard for the place of technology in human affairs, yet artefacts and combinations of them play an important role in conditioning how individuals, organisations and political institutions conduct their daily activities. We live in a world inhabited not only by other people but occupied also by the material objects we and our ancestors have created. Sometimes we respond with awe and wonder at these feats of human ingenuity and creativity ${ }^{4}$ more often we take them for granted and do not subject them to critical scrutiny. Perhaps the disregard shown by those usually concerned with the vicissitudes of social life stems from the separation, begun over 200 years ago, between, broadly speaking, scientific and artistic pursuits. Perhaps it results from the extraordinary success of scientific method and rationality, which convinces most people most of the time of the internal logic, dynamics and, ultimately, autonomy of science and technology. Perhaps the disregard arises from the indubitable successes of science and technology in improving the human condition. Since the rise of modern science, there have been voices critical of the products of scientific and technical endeavours and their dehumanising potential; but, with a few exceptions, it has only been in the latter hatf of the twentieth century that the social nature of the production of scientific and technical knowledge and artefacts has received sustained and critical attention.

Sustained attention has come from that small group of colleagues from at wide variety of disciplines who come together under the umbrella heading of 'science, technology and society' (STS) studies and who will be both the most sympathetic and the most critical audience. They will recognise the political and theoretical concems which underlie this book. I hope to contribute to the ongoing and lively debate about how better to describe, understand and intervene in the relationship between lechnical change and social change. Over the past fifteen years, this debate has been increasingly informed by an approach

4 For an interesting discussion of the "technological sublime". see Nye (1994). 
labelled the 'social construction of technology' (SCOT). In particular, I want to explore the possibilities for extending the social constructivist analysis to include both large technical systems ${ }^{6}$, as opposed to stand-alone artefacts which have been the major focus hitherto, and revolutionary technologies ${ }^{7}$, such as IT. The study of any particular technology, especially one as important as IT, is bound to highlight where some of the concepts we are using require further clarification and elaboration. These will be explored as they become pressing in the following pages.

I do not want to contribute only to the scholarly debates. Drawing on the stories I tell in Chapters 4 and 5 about the development of large IT systems for government use, I shall. return to the traditional questions underlying the STS 'project' in the final chapter. This book confirms what is a truism within STS, but one still not widely shared: social relationships and structures do not exist through human activities alone but are mediated through the wide variety of material artefacts which have the function of stabilising everyday life. Understanding how machines and people make history and contemporary life, together with exploring the possibilities for effecting change in the social order via intervening in the socio-technical systems that make up our world are both part of the STS project. Over the past decade, the emphasis has been firmly on the former. It is now time to return to the latter.

Despite fashionable commentaries celebrating the fragmentation of cultural and economic life, we live in a world increasingly connected by physicall means - roads, railways, air routes, different sorts of waves, wires, pipes and cables for sending and receiving energy and data. There is some space for local variation, but it is a diminishing space.

Supranational rules govern the operation and trade of the output of these increasingly large and complex technical systems. If these systems are to remain controllable, accountable and subject to human intervention not only by their direct users but by all citizens and their representatives, we need to understand the dynamics of their development and use and learn what that might mean regarding the possibilities for and limits to action. We need to comprehend the difference between technical imperatives and social choices, and how the former are constructed to justify the latter. One way of doing this is to look inside the lechnology to reveal the social processes within.

These diverse audiences, spanning $\mathrm{CP}$ Snow's (1959/1993) 'two cultures', present the author with the particular difficulty of finding a language we can all understand. It imposes on me a responsibility to reverse the politicians' dictum, "never apologise, never explain'. I shall try to explain all of the jargon, whether it is technical, social scientific or bureaucratic. I shall apologise only once. For some of you, some of the time, these explanations will be trivial: for that, my apologies.

\footnotetext{
\$An early. oft-cided version of this approach can be found in Pinch and Bijker (1984). A more elaborated version is presented in Bijker (1995).

"Other atempts have been made: see the collections editcd by Maynz and Hughes (1988) and Summerion (1994),

${ }^{7}$ Revolutionary technologies are those which have the potential to alter all cconomic sectors and our understanding of the conmon sense way ol doing things. This concep is discused more fully in Chaper 2.
} 
In the next sections, I shall introduce the three main approaches for understanding the relationship between technical and social change in order to set the scene for my criticisms of them in the final section of this chapter. The three approaches are technological determinism", "technology as neutral" and 'social constructivism'.

\section{Models of the relationship between technical and social change}

\section{The march of the pots}

"Tools and instruments are so intensely worldly objects that we can classify whole civilizations using them as criteria." (Arendt, 1958, p.144) Not only can we, but frequently we do; thus, we speak of the 'stone', 'iron', 'steam' and 'computer' ages. ${ }^{8}$ We also characterise nations by reference to technologies in which they have played a prominent developmental role or which are highly symbolic of the culture: Holland and windmills, the USA and cars, Japan and microelectronics. Robert Heillbroner (1994b) argues that it is the availability of different machines that defines what it is like to live in a particular place and time. Examination of the material objects of a society is a good place to start studying an unfamiliar society. Lewis Mumford (1961) suggests that the tendency to associate whole millenia or entire nations with a single material artefact has arisen because the first academic disciplines to treat technological change seriously were anthropology and archaeology which often focus on non-literate societies for which material artefacts are the sole record.

$[T]$ he stone or pottery artifact came to be treated as self-existent, almost selfexplanatory objects... These tools, utensils, and weapons even created strange technological homunculi, called "Beaker Men", "Double Axe Men", or "Glazed Pottery Men"... The fact that such durable artifacts could be arranged in an orderly progressive series often made it seem that technological change had no other source than the tendency to manipulate the materials, improve the processes, refine the shapes, make the product efficient. Here the absence of documents and the patucity of specimens resulted in a grotesque overemphasis of the material object, as a link in a self-propelling, self-sustaining technological advance, which required no further illumination from the culture as a whole even when the historic record finally became available. (p.231)

Those of us concerned with more contemporary societies have no similarly convenient excuse for such reductionist thinking. Yet the linguistic habit persists, of naming whole historical epochs and societies by their dominant technological artefacts. This habit can be witnessed frequently in museums, schoolbooks, newspapers and on telewision and radio. It is difficult to predict for which of its many new technologies the twentieth century will

\footnotetext{
8 The novel Texaco by Patrick Chamoiseau (1997) explores the le gacies of slawery and colonialism for the Caribbean island of Martinique. The shaty tow which spring up around the refinerics of the company which gives the novel its title are called the age of crate wood'. "Of asbestos" and 'of concrene'.
} 
be remembered five hundred years from now ${ }^{9}$ yet the habit of thought and language of ascribing simple catuse and effect endures as the statements below illustrate:

* In the twentieth century, the car became widely available, leading Americans to move to the suburbs and providing us all with a symbol of freedom reflected in many American road movies, books and songs.

The invention of television caused the decline of the cinema and a deterioration of children's reading abilities.

The development of the contraceptive pill resulted in the sexual permissiveness of the 1960 s and a reduction of family size.

This way of thinking about the relationship between technology and society has been 'common sense' for so long that it has not needed a label. But its critics, of whom more later, have termed it 'technological determinism', which has two parts. Logically, the first part is that technological developments take place outside of society, indlependently of social, economic and political forces. New or improved products or ways of making them arise out of the activities of inventors, engineers and designers following an internal, technical logic that has nothing to do with social relationships. The more crucial second part is that technological change causes or determines social change. ${ }^{10}$

\section{Technological determinism is imbued with the notion that technological progress} represents social progress. Historically, it means that each generation produces a few inventors. Their inventions appear to be both the determinants and stepping stones of human development. Unsuccessful inventions are condemned by their failure to the dustheap of history. Successful ones soon prove their value and are rapidly integrated into society, which they proceed to transform. In this sense, a technological breakthrough is claimed to have important social consequences.

The simplicity of this model is, in large part, the reason for its endurance. But it is also the model which makes most sense of many people's experience. For most of us, most of the time, the technologies we use every day are of mysterious origin and design. We have no idea from whence they came and equally little idea of how they actually work. We simply adapt ourselves to their requirements and hope that they continue to function in the predictable and expected ways promised by those who sold them to us. It is because technological determinism conforms with a huge majority of people "s experience that it remains the 'common sense' explanation.

\footnotetext{
9 The systematic use of the term 'Industrial Revolution' was not introduced until the 1880 s. by Arthold Toynbee (1884) in a serics of lectures at Oxford, almost a hundred years after the "events". Sec also Bruland and Smith (1981).
}

10 Misa (1988) and others suggest that what I bue presented here as two parts ot the whole of technological

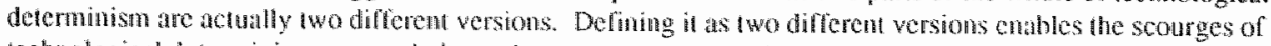

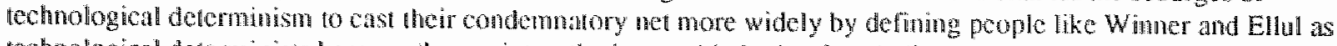
technological deternimists because they point to the incxorable logic of capitalist icchnologicall mitionality. This is to confuse theit matioralism and tealism with detcrmism. If they are to be accused af any son of determinism. cconomic deteminism is the more appropriate charge. I shal folow Mackenrie and Wajcman 1985 in defining techrological dederminism as taving wo paris. Wom of which are necossary. 
The problem with technological determinism is that it leaves no space for human choice or intervention and, moreover, absolves us from responsibility for the technologies we make and use. This serves the interests of those responsible for developing new technologies, regardless of whether they are consumer products or power stations. Technological determinism allows all of us to deny responsibility for the technological choices we individually and collectively make and to ridicule those people who do challenge the pace and direction of technological change. At the very least, we have choices about whether or not we use technologies, and if we choose to use them, we also have choices about how we do so.

\section{Using the pot}

In an earlier section of this chapter, I suggested that one reason why opposing claims are sometimes made about the same technology is that technological artefacts are considered to be intrinsically neutral. The implication of adopting such a notion is that the effects technologies have on society are entirely a result of how we choose to use them. Recall the two parts of technological determinism outlined in the preceding section: the technology as neutral position accepts the first part, that technologies follow an internal, technical logic of their own which is independent of social factors; but rejects the second, that technologies then proceed to affect society in a unilinear fashion.

Evidence to support the view that the ways in which technologies affect society is a more complex process with various possible outcomes than technological determinism would lead us to expect can be found by examining both historical and contemporary technologies more closely. In a classic study of technological change in medieval Europe, Lynn White Jr. (1962) presents an essentially technologically determinist argument about both the rise of power in northern Europe and the spread of feudalism across continental Europe. He explains the shift of power and weat th from southern to northem Europe which occurred during the tenth and eleventh centuries in terms of the development of a heavy plough, suitable only for the rich soils of northern Europe. Northern peasants were able, as a direct result of using the plough, to achieve higher levels of productivity than their southern neighbours and produce surplus food. This led to urbanisation because some peasants were no longer needed on the land."

White also suggests that feudalism was caused by the invention of the stirup. Using a stirrup meant that Frankish warriors were less likely to fall off their horses during batule and so were better positioned to conquer and redistribute land. In an oft-quoted remark. White does recognise that, 'a new device merely opens a door'; it does not compel one to enter (1962, p.28). Northern peasants could have used the productivity gains arising from their use of the plough to redistribute labour enabling them all to stay on the land. Mounted warriors could have gone off to the Crusades. Moreover, it may also have been necessary for other doors to have been open at the same time. The Anglo-Saxons also used the stirrup, but not in the way the Franks used it to support a new type of warfare.

1 Hilton and Sawyer (1963) offer a devastating critique of Whites thesis arguing that open-liceld agriculture Existed for centuries in Europe prior to the invention of the plough. Perduc (1994) builds on this in his discussion of lechnological detemimism in angraian socicties, arguing against single factor theorics, such as rechological determinism. 
Wholescale societal changes cannot be reduced to a simple change in riding tack. It is also important to know about patterns of land ownership and the economic conditions which made it worthwhile to fight over land; but knowing that would force one to start questioning the first part of technological determinism, which will be done in the next section.

In the twentieth century, radio broadcasting has been used in different ways in various times and places. In both Britain and the United States, radio was developed to transmit signals to individual homes where people could make their own choices about the programmes to which they would listen. There was nothing intrinsic in the technology which made this inevitable. In Nazi Germany, receivers were placed in the streets so that the National Socialist Party could ensure everyone heard Hitler's speeches via organised compulsory listening groups. Other totalitarian regimes have attempted to use radio in a similar way. Even in Britain and the US where private listening was the norm, the organisation of broadcasting was different in the two countries. In the US, small, private, local radio stations were typical. Prior to the election of the Thatcher government in 1979, the state-owned British Broadcasting Corporation (BBC) had a monopoly over radio transmission. Rarely has this been overtly abused by the government of the day ${ }^{12}$, nonethelless part of the $\mathrm{BBC}$ 's mandate is to contribute to the cultural cohesion of the nation. Consistent with her commitment to private enterprise, then Prime Minister Margaret Thatcher oversaw the opening of the airwaves to commercial radio. In the US, it was ever thus (Aitken, 1985).

An even more recent technological development than the radio illustrates the individual choices we can make about how to use technology. The microwave oven has been condemned for contributing to a decline in family values. Because it can be used to heat pre-packaged meals in a matter of minutes, some families use it to enable different family members to eat what they want when they want; not only destroying shared family meal times but also causing a decline in nutritional standards. Other families use it precisely to make it possible for people to eat home-cooked food together. Food can be prepared at weekends, stored in the freezer and heated quickly when everyone has returned from work or school. It can also be used to prepare fresh fish and vegetables, with texture, taste and nutritional value superior to that offered by convection cooking methods. Depending on our particular circumstances - including family size, income, work patterns and food preferences - we can incorporate the microwave oven into our living arrangements in a variety of ways. ${ }^{13}$

This conception of technology as a neutral instrument which people can use as they want challenges the second part of technological determinism, that technologies have straightforward social effects. This is altogether too simple an explanation given the wide

\footnotetext{
The independence of the BBC was sewerely challenged during the General Strike. May 4-12. 1926, following a lock-out of miners. The BBC allowed neither Labour nor pro-Libour speakers. The Conservalive Government felt the BBC could have been even more supportive of the Govermment's supposition, but woted on May II not to assume complete control of the BBC. (Briggs. 1985. pp.96-106)
} 
variety of situations in which technologies are introduced. To comprehend fully the development of European feudalism, one also needs to grasp the complexites of trade and patterns of land ownership of the time. In the case of radio broadcasting, political and military considerations were important in configuring the technology for individual or group histening. Social and geographic considerations also played a role. There would have to be an over-riding need for political control to create a single broadcasting company in a country the size of the US, of nine million square kilometres with five time zones. Such a political need did exist in the former Soviet Union and the post-World War 11 Socialist Republics of eastern Europe, but not in the United States nor Canada.

The advantage of the 'technology as neutral' model over technological deterninism is that it gives a prominent place to people, individually and in groups, making choibes about how they want to use technical artefacts. Technological determinism allows no room at all for what is usually a very messy process of change, involving not only new technical artefacts but also a range of broadly social factors, including struggles over political, economic and cultural control within and between countries, organisations and households. "Technology as neutral" begins to create a space in which complex and usually conflict-ridden historical processes can be explored. Once we start to investigate that space, however, we soon realise that the processes by which technologies themselves are created are just as riven with choice and conflict as any other historical process. In other words, the first part of technological determinism, that technologies simply follow an intarmal, technical logic free of social forces, also requires closer examination. Doing that will begin to reveal the limits of the "technology as neutral" approach."

\section{Looking for the kiln}

At the end of the mineteenth century, the radical left Parisian city council wanted to begin construction of the underground railway system, the metro. The council wanted the métro to remain in public ownership and control and, therefore, it needed to find a way of excluding the private railway companies - not just in the short tem which the council

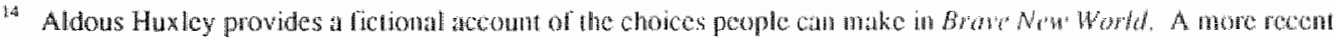

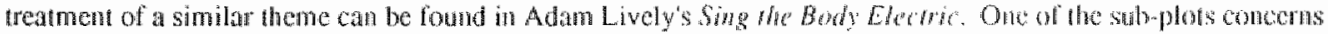

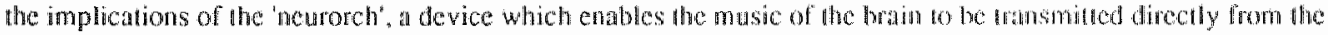
unconscious. Should this be used to democratise music, making it possible tor people will lub fom ant musical traning go create their own music? Should is use be restricted because of fears of deationing cacophony: only to be wsed by professional composers? Or. in the words of the Peoples Form for Free Aceses to the Neturoreth, should it. "he an instrument of revolution and liberation, not a means of propping up clapped-rut. atchite ast forms"? (1994. p.322)
}

is In social psychollogical studies of aggressiont. exidence can be found to tefte this notion of the neutratly of objects. This is a diflerent argument to the one I will be developing but noncheless a valuable and fascinating insight into the ways in which objects inflenec ou consciousness. In a 1967 study by Berkowitz and LePage. US college students were made angry. Some were made angry in a room in which a gun was left casually in a condet. Others were made angry in al room in which a badminton racker was left. The studetus were then given the opportunity to administer electric shocks to a fellow student. Those students who had heen in the room with athe gun administered more shocks thall did those left in the presence of a batminion racke. "Alangry person can pull the trigger of his gun if the wants to commit violence: but the trigger can also pull the finger" iciled ill Aronson. 1980. pp. 184-5). I am grateful to Cigdem Kagitçibasi lor bringing this study to my attention. 
could engineer but wo in the long term, in the event a rightist city council was elected. At first, they wanted to use narrower tracks for the méto, different from those used for the overground trans. But they were persuaded by the military that this would be a threat to national security. Instead, they retained the track width but reduced the width of the coaches themselves; this enabled them to make the tunnels too narrow for conventional railway coaches. As the métro expanded its reach, the practical feasibility of its potential take-over by private railway companies diminished. ${ }^{16}$

The fin de siecle Paris council did not simply choose to develop the méro as a public transport system rather than to turn it over to the private raillway companies. Nor were the widths of the track, coaches and tunnels necessitated by the technical knowledge of railways of the time. Rather the council seized the opportunity to set in stone and concrete, literally and metaphorically, its political commitment to public ownership of mass transport making it wery difficult for future city councils to reverse that commitment.

This story challenges both parts of technological deterninism. It illustrates how political beliefs infuenced the size of railway tunnels, almost a 'fact of nature', something most of us would rarely even notice, much less question. It also illustrates how choices for future generations can be constrained. Once the narrow tunnels were built, the métro could not be transferred easily between public and private ownership because of the massive investment a private railway company would have had to make in the special narrow coaches. A century later, the Paris metro still bears the marks of late nineteenth century Parisian politics."

The essence of the social constructivist argument is that technologies are artefacts, objects made by people. They are not separate from but rather are constituted by political, economic and cultural processes. If we look closely at any technology, we will find that it is marked by the conditions of its design, production and use. Whereas technological determinism presents social change as being the result of technological change, social constructivism explains technologies as being actively shaped by different social groups. Moreover, the latter sometimes regards the distinction between soctety and technology as an arbitrary one, albeit sometimes an analytically and practically useful distinction.

There are three ways in which technologies can be said to be social constructions: ${ }^{18}$ * technologies are the material embodiment of the values and interests of particular social groups on classes;

16 Daumas (1977) cutco by Latour (1988. p.36\%.

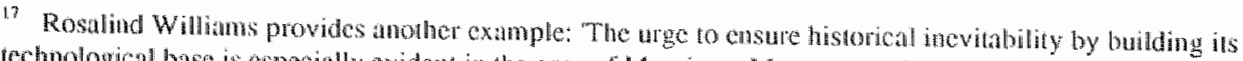

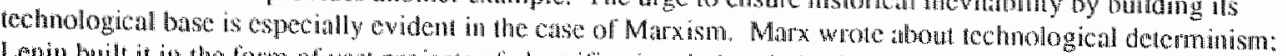

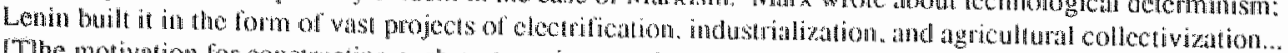

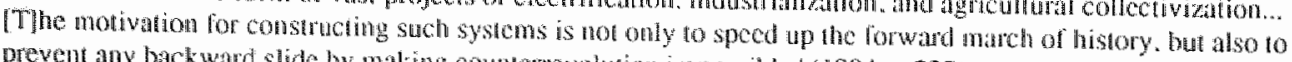

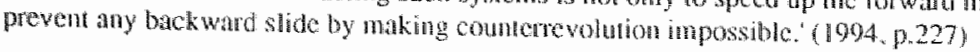

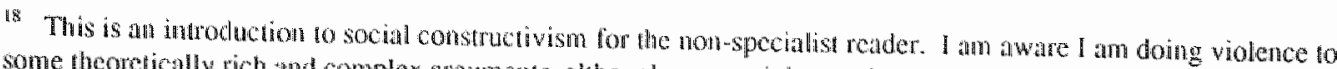

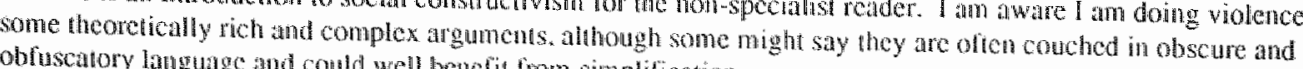
obluscatory language and could and benefit from simplitiontion. 
technologies are elements in our language and in our symbolic universe: and technologies are the outcome of negotiation between individuals, groups and institutions.

The first version is illustrated by the brief tale of the Paris métro above. Things, machines, technologies are not just things, machines and technologies that peiform useful functions. They are also ideas made real. Designers, engineers and their managers and financiers have values, goals, assumptions and even prejudices that get built into technologies.

Technologies can embody social and cultural values as well as economic interests and, as a result, can reinforce or reproduce those values and interests. That is what happened in the Paris métro and it is also what happened with the New York City roads, a more frequently cited example. ${ }^{19}$ Two hundred overpasses on Long Island have the exceptionally low clearance of approximately nine feet (2.7 metres). This is because Robert Moses, city planner from the 1920 s to the 1970 s, wanted to restrict access to some of the parks and beaches. The predominantly white, automobile-owning middle-class had no difficulty in using the roads to reach the more desirable area of Long Beach with all of its amenities. Black and working-class people however, dependent on buses which could not fit under the overpasses, could not reach Long Beach. Moses reinforced this exclusion by vetoing a proposed extension of the railway.

Both examples illustrate how material artefacts physically embody political views. The Paris métro is a materialised commitment to public ownership of mass transport. The Long Beach overpasses reproduce class and race relations. Recall the earlier example of radio broadcasting in Nazi Germany. Not only did the Nazis choose to place receivers in the street but in the radios they manufactured for private household use, they deliberately curtailed the receiving capacity of the sets so that people could not listen to the $\mathrm{BBC}$. In response, the $\mathrm{BBC}$ increased its own transmission capability. Current technical features of radio transmission and organisational features of the world broadcasting industry can be traced back to the role of political propaganda in World War II.

The second general form of social constructivism is informed by the work of Pierre Bourdieu (1984). The social and cultural meanings we give to technical artefacts are emphasised. A car is not simply an internal combustion engine with seats and a radio in a steel casing on wheels. Whether or not we own a car at all and, if we do, its make, age and colour all provide meaning for ourselves and others about who we are and what our values and aspirations are. This is not only the case for individuals; production technologies used by a private company indicate to its competitors something about its commitment to modernisation and about its attitude to its workers. At a national level, weapons systems are not merely collections of warheads and missile launchers; they provide a country with a sense of prestige and give signals to other nations about intentions and capabilities.

39 Wimer (1980); reprinted in Mackenzie and Wajcman. eds. (1985) and Wirner (1986). For a crithical discussion of the (mis)use of this paradigm case in STS. see Joerges (1997). 
In this sense of social constructivism, technologies are not primarily material objects but are an arena for contesting meaning. The physical capabilities of the artefact are not paramount; rather the cultural meanings we try to give to them or read into them are important. Because these meanings are contested and fought over by different social groups, the same artefact will be understood differently over time and across cultures. ${ }^{20}$

The third general form of social constructivism is more akin to the first, although the construction of meaning predominant in the second also has an important role to play. It differs from the first in that the contingent nature of technological change is stressed. The notion in the first that technologies physically embody political or other values can be as reductionist as technological deterninism. The causality is simply reversed. Instead of technological change causing social effects, the dominant social values result in some sorts of technologies being developed rather than others. This third form of social constructivism differs from the second in that the process of stabilising meaning is central to the process of creating the artefact and does not occur only after the artefact enters a wider world of consumption and use.

The history of bicycles, as told by Wiebe Bijker (1995), draws on insights from each approach. It is a fine example of how the same artefact - an identical collection of rubber, metal and wood - was understood differently by various social groups. The high-wheeled Ordinary bicycle, patented in 1870, had a very large front wheel, a back wheel of only a quarter of the diameter of the front and a saddle above the front wheel. Many people regarded this as an 'Unsafe Bicycle'. It was very difficult to get on and off and if one succeeded in mounting it, one could easily topple off of it. Other people regarded the difficulty and danger as an integral part of the bicycle's attraction because, to ride the Ordinary, one needed to possess athletic skill and physical courage. For this second group of people, the Ordinary was not an 'Unsafe Bicycle', it was a 'Macho Machine'. From this single artefact, two different paths were followed. Some people sought to address the safety problem by, for example, equalising the diameters of the wheels and moving the saddle to a more central position. Those who enjoyed the thrill of the 'Macho Machines accentuated the skill required and the danger involved by making the front wheel even larger. Eventually, safety considerations prevailed but the high-wheeled "Unsafe Machine' left its mark. It had required the development of stiffer spokes which were subsequently incorporated into the designs more familiar to us today. The association of a certain sort of masculinity with various forms of two- and four-wheeled vehicular transport has also
endured.

As the bicycle example illustrates, the process by which different interpretations of a single artefact stabilise around a single meaning is not a well-organised process during which the relevant parties sit down together to arrive at some mutually acceptable solution.

\footnotetext{
Lockwod"s reminder ss a useful corrective to analyses which siress the symbotic walue but neglect the materiality of artefacts. 'I is in any case sociology gone mad to assume that because people wath goods of this kind washing machine. (1960, p.257) Such grithem as status symbols. A washing machine is a washing machine is a in people"s alonestic lives.
} 
The stabilisation of the bicycle took time. A more recent example is provided by the case of the video cassette recorder (VCR). Mitsubishi developed a VCR which did not record the advertisements which appear during commercial television broadeasis. Advertisers did not like this because fewer people would be exposed to their products. Broadcasters did not like it because it would probably result in the loss of advertising revenue. The advertisers and broadcasters agreed to scramble the television signal so that the video recorder would not work properly. Mitsubishi, Japanese broadcasters and advertisers had different interpretations of what the VCR should do, derived largely from their economic interests.

I introduce below my own very general approach to social constructivism which will be more fully explored in the remaining chapters. Some of the terms in italics may be unfamiliar but hopefully some idea of their meaning will be conveyed from the context or from earlier examples; or, if they are familiar, they will be recognised as contentious. All of them will be discussed, clarified, criticised and expanded when it becomes necessary to do so in later chapters.

Technologies are social constructions, the outcome of negotiations between relevant social groups. To explain technological developments we need to identify who is involved and what their interests are. In any innovative effort, actors form alliances. A project often has a certain interpretative flexibility, when there exist competing meanings. The selection of one of many possible solutions is also a social process. Often there is a key actor/ entreprenew who is instrumental in enrolling other actors and defining the scope of the technological frame. A successful mobilisation of arguments, interests or resources may result in closure: the artefact becomes stable and enters a wider world. But risers of technical artefacts and systems also possess a degree of what could be described as interpretative flexibility, what I have termed earlier as malleability. New artefacts may or may not work, and may or may not be used. Some might fail or be used in unforeseen ways. If the technology fits within the technological frame of its wider community of users, it might acquire momenrum. In this way, shccessful technologies give the appearance of autonomy.

As already mentioned, this matter-of-fact summary conceals a number of theoretical concerns internal to the social constructivist programme, most of which have implications for wider theoretical and political debates. These will be explored later. In the remainder of this chapter, I want to highlight one fundamental problem, not only for social constructivism but for social and political theory generally; namely, how is it that actors are not only shaped by but also involved in shaping the world in which they live, where that world includes material objects and artefacts. This is not merely of theoretical interest; it is also profoundly important for understanding how and where we can participate in the construction and use of technical artefacts.

\section{Problems of the reciprocity berween people and pots}

The social constructivist literature has provided us with many accounts detailing the messiness of both the content and context of technological change. These accounts have demonstrated repeatedly that technical artefacts could have been otherwise; choices were 
made, some paths were followed, others were abandoned. In the enthusiasm to provide evidence to challenge widely held notions of the inewitability and naturainess of technical developments (namely, technological determinism). questions about the ways in which these technicall developments become part of the world in which we live, and subsequents condition or even structure our daily activities have been neglected. Technological determinism thas been so rewiled and discredited within the constructivist literature that it has becone almost impossible even to suggest that some technologies, some of the time. influence the ways in which we live and work. Also, in stressing the social nature of the process of technical design and choice, the notion that "anything is possible" has taken hold. Little space has been left for exploring the social and technicallimits to what is indeed possible.

Let me summarise the three types of explanation of the relationship between technical and social change which I have presented so far. Technological determinism assumes technical artefacts atre the way they are because they are based on the application of irrefutable laws of nature. They are imposed on an unsuspecting world and then have effects on individuals and organisations. Technological neutrality does not problematise the origins of artefacts but does suggest their effects are not simple, singular or inevitable. We have choices about how we use them. These human choices will influence the effects technologies will have on individuals, organisations and society as a whole. Social constructivism focuses on the development of artefacts - the processes of invention and innovation during which choices are made about the final shape of the artefact. Who makes these choices and why? What other possible outcomes could there have been? But little has been said by social constructivists about the 'effects' of these artefacts. Or, in the words of Thomas Misa, '[i]n the last two decades, historians [and social scientists] have contributed impressively to our understanding of how society shapes technology but have nearly absindoned the urgent task of understanding how technology concurrently shapes society." (1994, p.116)

All three of these explanations have resonance and strength. The first two - technological determinism and technological neutrality - remain the explanations which make most sense of our own everyday experiences and they continue to appear in popular accounts of technology. As we shall see later, technological deteminism continues to be deployed by policy-makers at all levels. The social constructivists are correct to point to the social 22 nature of the production of technology. All artefacts are the result of human endeavour; they are created by people with personal, professional and institutional goals and objectives - be it the promotion of an individual or the establishment of a particular technical approach or the securing of the profiability of a private company. All of these factors, and others, have a role to play in influencing the shape of the technical artefacts presented to consumers to buy and use.

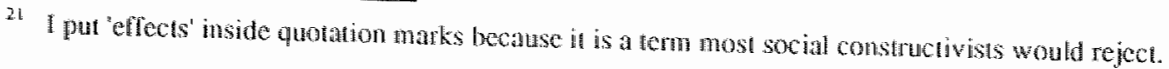

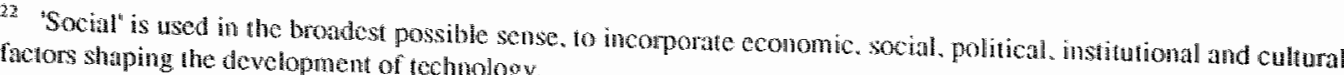
factors shaping the dewclopronen of techwology.
} 
Before proceeding to discuss the fundamental problem of the extent to which the construction of technical artefacts constrains people, not only in the way they relate to the objects but also in the ways they relate to one another, it is now time for a brief digression on the distinction between 'social' and "technicall. So far, I have been deploying these terms casually, relying on a common sense distinction. But, of course, much of the import of social constructivism is to challenge that common sense. Within that literature, it is almost a cliché to say that because technology is socially constructed, technical and social phenomena should not be opposed. This is not useful analytically. Even if technologies are socially constructed, what sorts of social constructions are they? Do they differ from everything else that is socially constructed (and within social constructivism everything else is)?

Bijker and Law (1992b, p.201) identify two approaches to the distinction between 'social" and 'technical' within social constructivism, namely the seamless web approach and the interactive approach. The more radical is the 'seamless web' approach which regards the social/technical distinction as itself a social construction, and one that is not stable. In continuing to use social and technical in a common sense way, moreover, we participate in the reproduction of the notion of the naturalness and inevitability of techmology and in its reification as something different.

My own preference is for the less radical interactive approach which does assume there is a stable and matter-of-fact distinction which can be made between the social and the technical. However, the reductionism of either social or technical determinism is avoided by accepting that there is an interaction or exchange between the two. Indeed, by the end of the book, after another application of the principle of symmetry (discussed more fully in Chapter 3), a guiding tenet in the philosophy and sociology of technology since its appearance (Bloor, 1976), we may even be able to return to the certainties offered by classical realism.

Returning to the three different sorts of explanation presented earlier, technological determinism and technological neutrality emphasise the effects technologies have, but the latter allows space for human choice in use. Social constructiwism emphasises the origins of technical artefacts. But a lacuna remains between these types of explanation. One reason for this gap is the technological scale commonly invoked. Technological determinism often deploys images of 'big technology' - transport, power generation, communication, weapons. These are often what come to mind when we think of technology. Because of their size and complexity, both technically and organisationally, they can appear to be out of human control. But precisely because of the complexity of these big technical projects and systems, it is not surprising to learn that many people and groups with different interests will have been involved in their development. Yet, as these big technologies stabilise and acquire momentum, they give a very good impression of being autonomous and determining and beyond control. Discrete, simple technical artefacts, such as bicycles and microwave ovens, however, are often open lo greater variability in their use, but the possibility that their design and production have been social processes is less obvious. Many social constructivists have concentrated on these 'hard cases', unravelling the complex social processes behind the development of even the most 
mundane of artefacts; this has meant that questions about the autonomy and power of technology have received relatively lithle attention.

Two routes out of this lacuna between those explanations emphasising use and effects and those focusing on the processes of invention and innovation suggest themselves. The first concerns the scale of the empirical object. We need to turn our attention to larger, more complex technical systems because, as suggested above, with larger technical systems, we can explore both the process of their construction and whether or not they become integrated with other social processes and achieve a degree of autonomy. Also, we live in a world that is increasingly connected and dominated by politically, economically and technically complex systems. In Chapters 4 and 5 , I will analyse the histories of three large government information technology systems, and I will also explore the concept of scale in more detail. But shifting the empirical focus does not help us with the conceptual problem of reconciling invention and use, or design and effects, or agency and structure.

Marx expected that changes in the means of production, a not inconsiderable locus of technological innovation, would undermine the social order. David Noble (1977), in his study of American capitalism, wonders why this has not happened. Rapid technical change in the means of production occurred throughout the twenticth century in the United States, but social structures were left largely undisturbed. Noble suggests this is because capitalists have learned to manage technical change for their own ends. Unlike Marx, Noble recognised that technology was not an atonomous force which would wreak havoc with the social order, but rather that technology was an integral part of society, both actively constituted by and constitutive of society.

\section{Anthony Giddens' structuration theory (cf. 1979 and 1984 ) provides a way of reconciling} the tensions between social constructivism, emphasising the contingency of the process of technological change, with the apparent autonomy of technical systems, highlighted by technological determinism. The essence of structuration theory can be captured by paraphrasing Marx and Engels, people make history but not in circunstances of their own choosing. ${ }^{27}$ Giddens is concerned to explain social change, but like many other social theorists he does not pay a great deal of attention to the role of science and technology in the production and reproduction of social relations. ${ }^{24}$ Moreover, as is common in highly abstract social theory, the references to science and technology reflect a highly deterministic viewpoint. ${ }^{25}$

\footnotetext{
2. History is nothing but the successon of the separate generat ioms, each of which exploits the materials, the

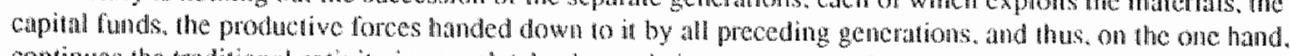
continues the maditom activity in completely changed circumstances and. on the other, modities the old

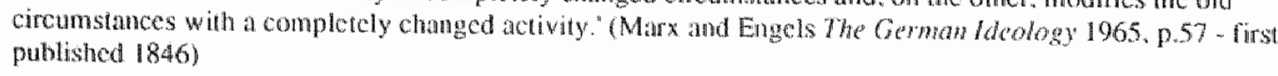

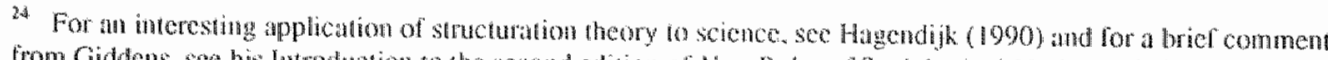

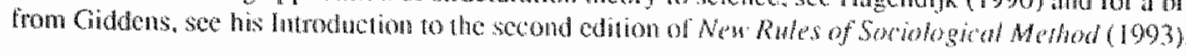

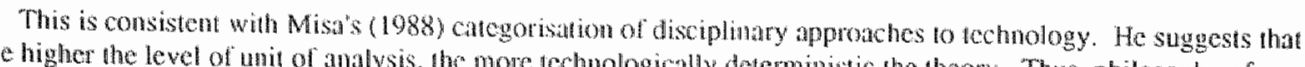
the highor the level of unit of analysis. the nore techologically deteministic the theory. Thus, philosophy of

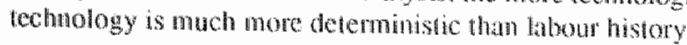


The fundamental question underlying Giddens' work is how to explain the patterned or recursive character of social practices. This is a very general question which can be asked of many different sorts of practices. Why do we brush our teeth before we go to bed? Why do the British drive on the left-hand side of the road? Why do industrial workers go to their factories at particular times of day and, once there, repeatedly perform the same task?

Giddens suggests that in order to enact a social practice, participants must draw on a set of rules which structure the practices they help to organise. This requires the active involvement of skilled actors who are themselves dependent upon the structuring properties of rules. The reciprocity between the ways in which individuals' repetition of social activities contributes to the reproduction of broader social structures and, conversely, the ways in which social structures condition how individuals perform those acts is what Giddens means by structuration. He claims his is not an objectivist notion of structure: it has no reallity except insofar as people have internalised the rules. We brush our teeth every night because for years our parents told us to do so before we went to bed, until it was no longer necessary to tell us. Every time we brush our teeth we contribute to the reproduction of good dental hygiene practice.

Internalisation is not the only way to reproduce rules, however. Technology also functions to reproduce rules and structure our daily activities, a possibility not explicitly acknowledged by Giddens. Hannah Arendt (1958) expresses very well this aspect of all material artefacts, not just technology, "the things of the world have the function of stabilising human life, and the objectivity lies in the fact |that people|, their ever-changing nature notwithstanding, can retrieve their sameness, that is, their identity, by being related to the same chair and the same table.' (p.137) The British drive on the left not simply out of habit; they are reminded to do so every day because road signs are put on the left and steering wheels on the right. Driving on the left is made possible by the geographic reality of Great Britain being an island (at least until 1994 when the Channel Tunnel was completed); at the same time, this difference with continental Europe contributes to the cultural and political perception held by the British that they do indeed live on an island.

Similarly, hotel guests are reminded to leave their room keys at the front desk because hoteliers are more and more frequently attaching awkwardly shaped weights to key rings (Latour, 1991). Alternatively, hoteliers are switching to electronic locks and keys, in which case it does not matter if the guests walk of with the key because the lock can be re-programmed subsequently in order to keep them out of the rooms.

For factories to run efficiently, according to the factory owners' notion of efficiency, workers have to follow the time schedules clictated by the needs of industrial capitalism. In agricultural societies, the ordering of tasks is dictated by conditions of light and temperature. Religious rituals have their own time frame. In the early days of the Industrial Revolution, workers had to learn industrial discipline. Clocks were rare, and workers were suspicious that the new capitalists were adjusting the clocks in order to lengthen the working day. Workers began to buy their own watches so they too could 
monitor the passing of time, of course, this had the effect of improving their own timekeping and thastening the spread of time-discipline. ${ }^{26}$ Once workers have arrived at the factories, they need to perform specific tasks at regular intervals - a process simultaneously facilitated and reinforced by the technique of assembly line production, introduced much later than clocks. ${ }^{27}$

The key to analysing social order is not in understanding the process of internalisation of rules to which Giddens refers ${ }^{28}$, but rather in comprehending the shifting relations between the production and reproduction of social life by human actors. In a more recent book, Giddens suggests that, the process of reproduction begins with and depends upon reproduction of material circumstances of human existence' (1993, p.102, my emphasis). ${ }^{29}$ Peter Weingart, amongst many others, recognised this a decade ago. "Technology is thus also a social product and part of a social system. From a simple tool to a complex system of machines and their infrastructure it is constituted by and structures action: (1984, p.116)

Technology generally (the particularities of information technology will be discussed in the next chapter) has an important role to play in structuration, I will argue. "Technology is social relations", is a rather opaque catchphrase of the STS community, conveying the ways in which technologies reflect and reinforce the needs and interests of those who design and own them. ${ }^{30}$ The concept of structuration provides one way of understanding it. Technologies govern the reproduction of social relations through their incorporation of existing social relations. If we accept that technologies are the outcome of more or less. overt negotiations between actors, we can accept that technologies incorporate elements of the social relations between those actors. Every time the technology is used, that set of social relations is invoked and reproduced.

This helps us to understand how machines make history. Law and Bijker (1992) suggest that understanding how technical artefacts are stabilised will bring us closer to understanding how the social order is secured. Bijker's concept of 'technological frame' attempts to provide a way of understanding precisely that. 'Technological frame' is not dissimiliar to Giddens notion of structuration, but it keeps our attention on the role and place of technology. The danger of adopting a grand social theory such as structuration

25 EP Thompson (1967), in his wonderfut aticle on the energence of time-discipline and capitalism, recounts a

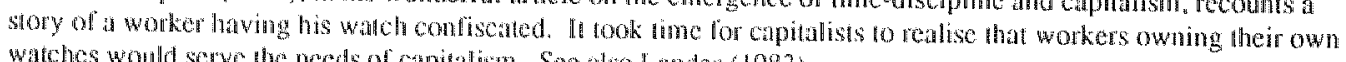
watches would serve tho needs of capitalism. See 64 to Lindes (1983).

23 The introduction of the asscmbly line is usually attributed to Henry Ford: however, there is evidence in was introduced in the nincecnth century in both Britian and the US in other industries, including food processing.
(Erenner and Glick, 1991 )

$8 s^{3}$

The study of "internatisation' is more properly the domain of prychologists.

This quole sthould not be interpreted as undermining my carlicar claims about Giddens lack of attention to science and rechology. He has begun ion incorporate more awatysis of scicnec and tochnology in his work. but it
occupies a very minor role. 
theory is that we might lose sight of the technology; and, as the discussion above indicates, Giddens is primarily concened with reconciling structure and agency, the social with the individual, not the social and the technical.

Technological frames are located between the actors and groups involved in the development of an artefact, and include all of the aspects that influence interactions within and between social groups. Elements of a technological frame include goals, key problems, problem-solving strategies, theories, tacit knowledge, testing procedures, design methods, users' practice and the perceived substitution function of the new artefact. Technological frames are applicable to all social groups, not only engineers. ${ }^{31}$ (Bijker, 1995, pp.123-4)

Bijker recognises the similarity between technological frames and structuration, in that technological frames are themselves created through the interactions of groups and individuals but they also guide future interactions. Structuration focuses on the mutually constitutive relationship between individualls and wider social structures. The notion of technological frame has two advantages. First, it has space for organisational actors, for social groups, whereas Giddens focuses on the individual. Second, it draws attention to the material world neglected by Giddens. Merely to say that it draws attention to the material world is misleading, however; because one of the main purposes of the concept of technological frame is to elucidate the single world of social groups and technical artefacts. Accepting that the world is both social and technical, and that they are mutually constitutive, does not mean one has to accept the seamless web approach mentioned earlier. Another purpose is to provide an analytically robust concept for describing this single world.

"IT]echnological frame" will be helpful in transcending the distinction between hitherto irreconciliable opposites: the social shaping of technology and the technological impact on society, social determinism and technical determinism, society and technology. "(Bijker, 1995, pp. 195-6) Yet, Bijker does not go far enough in extending the concept to the latter, to the impact of technology on society. There is no a priori reason, however, why this could not be done. The element of 'user's practice' within a technological frame is primarily deployed by Bijker to analyse how relevant social groups involved in the process of innovation perceive users' practice rather than how people actually utilise technical artefacts. The former, perceptions of users' practice, can be used to explore how ideas about users, including ideas about their needs and relationships, are involved in the construction of artefacts. The latter, how people actually utilise technical artefacts, can be used to explore how artefacts are involved in the creation and structuring of social relationships.

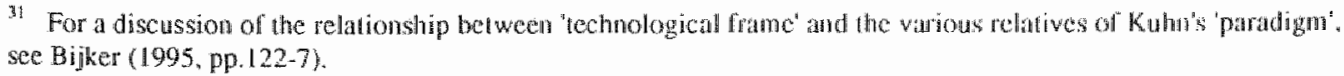




\section{Conclusion}

In this chapter, I have begun to outline my own approach to understanding the relationship between technical change and social change, largely through a description of the major lines of thinking on the subject that dominate not only the academic literature but also more popular accounts of 'technology and society'. There is 'technological determinism', in which technologies emerge as if from nowhere and then proceed to affect the society in which they land. 'Technology as neutral', for all intents and purposes, also has the technology emerge from nowhere but people choose how they want to use it. "Social constructivism' emphasises the origins and development of technology, demonstrating how people are involved in the creation of technical artefacts, not only in how they are subsequently used.

In the latter part of this chapter, the notions of 'structuration' and 'technological frame' were introduced because they will be valuable in reconciling how technologies can be both socially constructed and at the same time appear as autonomous forces in many people's lives, one reason for the title of this book. So far, these ideas have been explored at a very general level, drawing on examples of very different artefacts from different times and places. In the next chapter, I will begin to focus on information technologies of the late twentieth century, particularly as they are used by the public administrations of two industrialised capitalist democracies. Chapter 3 returns to some of the methodological concerns raised here and explores in greater detail how we can study large technical systems such as information networks. Chapters 4 and 5 present three stories of attempts to develop such networks by the UK and US administrations, interspersed with further theoretical reflection. Finally, in Chapter 6 , we return to the general questions underlying this book: how do people and machines make history and why does technological determinism continue to have such a powerful hold over both actors and analysts involved in making and understanding history? 


\section{CHAPTER 2}

\section{INFORMATION TECHNOLOGY \& PUBLIC ADMINISTRATION}

\section{Introduction}

Accounts of the contradictory potential of information technology (IT) for social change are legion. On the one hand, IT offers us a limitless choice of entertainment, having already freed us from boring, repetitive work. On the other hand, technologies can monitor whatever work we do and also record and control the types of programmes we choose to watch. These extremes can also be found in discussions about technology more generally and those concerned specifically with IT in public administration, which has been a major promoter and user of information technology at least since the end of World War II. The prospect of increased reliance on technology for information processing and communication, which is at the heart of so much of public administration, can be an emotive issue for citizens, public officials and politicians.

Debate about the potential of IT in political life are also polarised. At one extreme is the utopian vision of IT unleashing human creativity, in which people have unlimited access to information which they utilise fully in order to participate more actively in public life. The case of an ethnic minority pressure group in Amsterdam illustrates how publicly available information can be used to put pressure on the municipal authority. The Dutch keep very detailed population and housing registers. When these are combined, with the help of IT, it is possible to draw conclusions about the relative deprivation of ethnic minorities, based on comparative statistics about occupancy rates, state of repair, average waiting period for a house, level of subsidies for home improvements. The pressure group used this information in order to support its claims that members of the ethnic minority were disadvantaged, both in the reality of their housing and in their treatment by the authorities. (Meyer, 1993)

IT can also be used to enhance local democracy by devolving government activities and information. Since the mid-1980s, the city of Santa Monica in California has been developing a public electronic network (PEN), with the following three major components:

A 'read-only' link allows citizens to access city information, such as agendas for council meetings and information about city services, and to access the public library"s catalogue.

* A 'mail room' allows citizens to send messages to their elected representatives, to officials and to each other. Citizen enquiries are forwarded to the appropriate city council member or employee who then responds directly.

* A 'conference' feature allows all users both to read and to participate in computer conferences on a wide variety of topics related to the ruming of the city. (Dutton and Guthrie, 1991) 
A third liberating possibility is improved quality of service as IT facilitates the delivery of public services tailor-made to individual needs and eliminates routine, tedious information processing tasks, freeing people for more personal interactions. In Denmark, prior to 1987 , local municipalities had discretion in allocating social security benefits. The Social Assistance System (SAS) was developed following a change in the law in 1987 which fixed the basis for calculating benefit payments across the country. The SAS has two parts: calculation and payment. The calculation part holds the legislation on benefits, containing all the rules about entitlement. Data is automatically retrieved from the population register, regarding the claimant's marital status, number of children, address; data about income and previous employment status is obtained from other relevant databases. Combining these various pieces of personal data with the rules-based legislation enables the claimant's entitlements to be calculated. Details about the amount to be paid are transferred to the payment part of the system which automatically disburses the appropriate sum at the time interval requested by the claimant - one-off, weekly, fortnightly, etc. - and in the desired monetary instrument - cash, cheque, bank transfer. (Hoff and Stormgaard, 1991)

This type of IT application has a number of advantages for citizens. First, the removall of discretion from officials ensures that all citizens are treated in the same manner and that people in similar circumstances receive the same level of benefits. In other words, greater integration of data and rules allows higher levels of equity to be achieved. Second, the process is hastened, meaning people do not have to wait so long before receiving the payments to which they are entitled. Third, automatic payment via bank transfer reduces the constraints imposed by office opening hours and physical location of offices, and it minimises the risk of loss or theft of payments sent through the post. Finally, and perhaps most importantly, staff are freed from routine data processing and are able to devote more time to caring, social work type activities.

Contrasted with these possible emancipatory applications of IT is the dystopian view that IT is an instrument for centralised state control. The power of IT to link previously disparate information raises anxiety about privacy and civil liberties. For example, in the Netherlands a lateral-thinking public official matched water consumption, which is metered, with social welfare payments. Households with unusually high levels of water consumption were investigated. Many home-based hairdressers who had not been declaring their incomes were discovered.?

The use of IT to process decisions in state-citizen interactions raises fears about a decline in human contact and loss of sensitivity to individual needs. Contrary to the Danish example above, Adt Scheepers (1992), in a detailed study of the introduction of IT into Dutch social security offices, finds that the increased use of JT reduces staff autonomy, Following the introduction of IT systems, staff are much more likely to observe

\footnotetext{
It is not clear, however. to what extent this has happened in the Danish example cited, as of course such routinisation could be used to rationalise work.
}

This cximple was given by Frmb Kutenbrouwer in his inaugural hecture, University of Utrecht. February 1990. 
standardised procedures and much less likely to exercise discretion in their treatment of clients. He found that the use of a computer during client interviews promoted behaviour in which staff dissociated from individual clients.

Greater emphasis on electronic information provision and communication raises the spectre of an 'information poor', excluded from full participation in the democratic process. As information increasingly becomes available only via new media, some people will become disenfranchised from the democratic process either because they are unable to afford the new gadgets or because they do not know how to use them. Peter Golding (1990) mounts a robust attack on the optimistic notion that we shall all share equally in the proliferation of information. Using data from the British Family Expenditure Survey, he demonstrates that spending on consumer technologies increases in both absolute and relative terms as household income increases. In 1986, the top $20 \%$ of households, in terms of income, spent 5.6 times more on media than the poorest $20 \%$. For the latter, this represented over a quarter of their average weekly expenditure; for the wealthiest group, it was less than $5 \%$. Similar conclusions can be drawn from a 1995 US Census Bureau survey which found that white households with incomes of more than US $\$ 75,000$ are three times more likely to own a computer than households with incomes between US $\$ 25,000$ 30,000. Asian and Pacific Is landers are most likely to own computers, followed by white households. Computer ownership is least likely in black households. Less than $5 \%$ of households headed by someone without a high school education have a computer. ${ }^{3}$ For the rich, acquiring the latest technology involves an insignificant outlay; for the poor, it is a difficult trade-off between alluring new products and the necessities of food, clothing and housing.

Ownership of media technologies, including televisions, telephones and video recorders, declines as household income falls. Growth in the ownership of video recorders and home computers has been very unequal. In the past, new domestic technologies, for example televisions and washing machines, followed a 'trickle down' pattern. Wealthier households were the first to acquire new products, establishing patterns of use and the viability of the market. Subsequently, poorer households were able to buy them when mass production began and prices fell. This pattern may not be repeated. One reason is that the last period of rapid technological change in consumer products was during the $1950 \mathrm{~s}$ and $1960 \mathrm{~s}$ when there was virtually full employment and rising disposable income. The chances of such favourable economic conditions reappearing seem increasingly unlikely. Another reason is that the new generation of information technologies, such as video recorders, home computers and interactive compact disk players require constant additional expenditure if they are to be used efficiently. Software, in the form of computer programs and audio or visual compact disks, and access to online databases are expensive, recurrent expenditures. Golding and the US survey remind us that the possibilities offered by new technologies are not open equally to all; in other words, access to information and the means for

3 This study was reported by Ken Cotrinl. "The Poverty of Resources', The Guadian, 30 March 1995. Online section, p.5. 
receiving and transmitting it are both very much conditioned by people's class, race, education and income,

This introduction has illustrated how debates about the effects of IT on political life are often polarised, with one side emphasising the emancipatory potential of IT-enhanced local democracy and the other side raising the spectre of centralised, totalitarian control. Before challenging this type of thinking through a closer examination of three government IT systems in Chapters 4 and 5, this chapter will begin to narrow the focus. One of the flaws in the type of analysis presented above is that very different technologies are being invoked. One of the lessons of STS is the importance of being precise and specifying the technical artefacts being deployed in argument. In the previous chapter, many teclunologies from different historicall periods were used to illustrate four approaches to understanding the relationship between technical change and social change, namely technological determinism, technology as neutral, social constructivism and my own effort to reconcile the insights offered by social constructivism with the apparent autonomy of large technical systems. To begin to narrow the focus in this chapter, I shall explore the nature of IT itself in greater detail and also what II understand by the term 'public administration'. Only then will it be possible to outline an approach for examining the history of IT in public administration. I shall then return to some of the questions raised earlier in this introduction, outlining some of the public policy issues raised by the increasing use of IT in the public sector in order to set the scene for later chapters, in which these issues are mobilised by different groups during the development of large IT systems. Drawing on the approaches to understanding the relationship between technical change and social change outlined in Chapter 1, I shall outline how these approaches have been used to analyse the role of IT in public administration.

\section{Information technology}

At the end of the previous section, I suggested that one of the lessons of STS is to be specific about the technology; it is one way of taking technology seriously. In Chapter $\mathbb{1}$, I used a variety of technical artefacts as examples, including horse stirrups, radios, bicycles and the Paris mérro. In the introduction to this chapter, I began to focus on IT, but IT is a term that can be used to cover everything from pocket calculators to super computers, from mobile telephones to satellite broadcasting, from domestic washing machines to computer-integrated-manufacturing systems. The image of IT that probably comes most frequently to mind is that of the networked microcomputer - the games machine or PC

\footnotetext{
"Concen about the incrasing concentration of media ownership is a different issue. not addressed directly by Golding. I would agree. howewer, with Murdock (1990). Gambam (1990) and others that romantic notions about, for example. the democratic potential of local video obscure the ever growing concentrat ton of the ownership of mass media in the hands of a few world-wide congilonerates.
}

\footnotetext{
Golding is also concemed to challenge the domunam direction of media and cultural studies since the mid-1980s which emphasises the construction of meaning open to all recipients of meda images. sounds and words but which neglects socio-economic stuctural barriers to access. This is not entrely dissimilar to debates within 'science. technology and society studies.
} 
(personal computer) - which can be used to process words, manipulate numbers, create pictures, and send any of these to friends and collewgues down the hall, across the road or on the other side of the world. It is the device that most clearly conforms to the common definition of IT - the convergence of computing and telecommunication made possible by the ever-growing power and ever-declining cost of microelectronics. IT treats data in a digital form, representing data as a series of ' $O$ 's and 'l's, thus facilitating the process of convergence because digital data can be processed by many different devices. As a result of the declining cost and reduced size of microprocessors, they can now be incorporated in the controls of newer versions of traditional products, including calculators and washing machines; thus it becomes possible to connect them to other devices and communicate information from one to another. Pocket calculators incorporate small storage devices so that calculations can later be transferred to a desktop microcomputer. The often bewildering array of rinse, wash and spin cycles on a washing machine is controlled by a microprocessor. Prototypes exist which demonstrate how different household appliances can be connected to one another, making it possible for them to be controlled from the comfort of the living room or from outside the home."

The connection of different domestic appliances into some sort of network is similar to the more widely used integrated systems, found not only in the production of IT itself - the socalled heartland of the new technologies - but in manufacturing and service industries more generally. It is no longer a question of computer numerically controlled (CNC) machine tools or dedicated word-processors; or of separate machine shops with a few CNC tools or separate data-processing departments. Computer-integrated-manufacturing and office automation which integrate all of an organisation's activities - from $R \& D$, design, production, marketing and stock control - became the leitmotiw of IT during the 19805

IT makes it possible to process, communicate and respond to information much more rapidly than previously. Organisations are able to respond mone quickly to changes in demand and to customise their product designs, regardless of whether they are selling automobiles, clothing or life insurance policies. No longer are the techniques of mass production used to achieve economies of scale; now the flexibility oftered by integrated IT systems makes it possible to achieve economies of scope. IT is not simply a new product nor a new technique radically changing the production process in a single sector, it is a technology that is applicable to all sectors of the economy with the potential for radically altering the way things are done everywhere, not just in the economy but also in the home, schools and government bodies. Because of this pervasiveness, It has been labelled anew techno-economic paradigm."

\footnotetext{
"Such sysiems are variously called home autoniation', 'smart liouscs". 'home infomatics'. Sece for tample. Beng (1991). Miles (1988). Robins and Comford (1990) for a variety of STS-informed perspectives on their dewelopmen.

This is sometimes referred to as a shift from Fordist to post-Fondist produclion pratices. Fuller claboration can be found in, amongst many others. Carnoy at al (1993) and Harvey (1989), allhough Harvey prefers the tem "flexible specialisation".
}

"This work follows in the tradition of Joseph Schumpeter and long wave theory. Sice. for cxample. Perco (1983). Freeman (1987) and Dosi ef al (1988). 
Christopher Freeman (1987) identifies four types of technical change:

* Incremental technical change occurs more or less continuously in response to specific technical problems.

* Radical innovations are the result of deliberate R\&D activities, and thus occur on an irregular basis.

* New technical systems are clusters of innovations, both technically and economically related.

* Changes of techno-economic paradigm give rise to whole new sectors (the heartland) and affect all other sectors of economic activity.

Changes of techno-economic paradigm do not happen frequently. Previous examples include the host of technical and economic changes associated with the steam engine or electric power. Changes of techno-economic paradigm involve the creation of whole new products and sectors as well as fundamental changes in existing sectors. With a new techno-economic paradigm, there emerges a new key factor of production with, "clearly perceived low - and descending - relative costs; unlimited supply for all practical purposes; potential all-pervasiveness; a capacity to reduce the costs of capital, labour and products as well as to change them qualitatively.' (Perez, 1983, p.361) In other words, a new techno-economic paradigm, such as IT, alters relative costs of inputs and outputs and thus the conditions of production and distribution for both old and new products. In more qualitative terms, however, it involves the emergence of a new 'common sense', a new best-practice set of rules and customs for designers, engineers and managers which differs fundamentally from that established for the previous paradigm. It can take many years for the benefits of the new paradigm to be realised as the process of learning and adaptation takes place in the myriad of economic and social institutions which together constitute economies and societies.

Freeman, Perez and others argue that we are in the midst of a change in techno-economic paradigm, one based on the low costs of storing, processing and communicating information made possible by economically and technically related imovations in computing and telecommunication. These new information technologies permit far more precise control in real time of all production processes and of stockholding and distribution; and offer great potential for cost savings in labour, capital, energy and materials. But these productivity gains have not been fully realised because institutions, management styles and market structures are still geared to the old paradigm based around mass production and cheap energy. The economic difficulties experienced by most national economies since the late 1980 s is thus seen, from this perspective, as a period of prolonged adaptation to the new IT-based techno-economic paradigm.

This might appear as a rather technologically determinist wiew, in that no attention appears to be paid to the origins of the technology and the onus is on individuals and organisations to respond to the changed circumstances dictated by the new techno-economic paradigm. Suggesting it is technologically deferminist does a disservice, however, to the economic sophistication and complexity of the argument. There is nothing inevitable about the emergence of a new techno-economic paradigm; a new one is likely to emerge only if 
there is a decline in the rate of return and profitability of the old because only then will entrepreneurs search for new innovations which will enable them to enjoy higher profits. The problems of structural adjustment, especially unemployment, are also not inevitable: not something to be endured stoically as we await the golden age of a new paradigm's economic upswing and boom. Govermments can intervene to create jobs or provide training, for example. One advantage of this type of explanation is that it offers a way of examining economic discontinuities arising from technical change, in its own economic terms of changing cost structures and production functions. But there is nothing in it which enables us to say anything about technological or wider (than economic) social discontinuities."

Neo-Schumpeterians, such as Freeman, simultaneously emphasise the revolutionary potential of new techno-economic paradigms and at the same time point to the ways in which different techno-economic paradigms are the same. In other words, differences from and discontinuities with past technologies are highlighted, otherwise the radical change in products, production techniques and best practice would be neither possible nor necessary. At the same time, similarities between different techno-economic paradigms are also emphasised; similarities in terms of the economic conditions necessary for their emergence and similarities in terms of their revolutionary potential. Yet neither the technology itself nor the wider social conditions are given due attention. In a report focusing on the employment implications of IT, Freeman and Soete (1993) do, however, refer to the importance of 'time-saving' in all process innovations ${ }^{10}$. Saving time was important in directing the nature of technical changes made in the British cotton industry in the eighteenth century. (von Tunzelmann, 1993) It was also crucial in the development of mass production systems early in the twentieth century. The 'just-in-time' system developed by Japanese automobile manufacturers during the 1960s and '70s was initially an organisational innovation, aimed at reducing the need to warehouse parts or finished goods, necessary for coping with the high costs of land in Japan. This macle batchprocessing, with its concomitant need to store both components and finished cars, prohibitively expensive. The time-saving feature of this organisational innovation is now embodied in those integrated manufacturing systems which automate not only the flow of materials but also the flow of information by linking together product schedules, purchasing and inventory control. Time-savings are also achieved by multinational companies which use IT to link together their R\&D and design teams from different parts of the world. One common thread running though many technological innovations since

\footnotetext{
It woud be unfair to single out the neo-Schumpeterians for filling fo deal adcquatcly with questions of continuily ws. discontinuity in technological change. It is a perennidil question which aflicts cweryone who adopts any kind of historical analysis. which fends to emphasise coningency and conninuity. Indecd. as Law and Bijker (1992) suggest, it is important that. "the new sociotechnology starts to address these changes. (in order to begin to obtain purchase on some of the fundamental historical and sociological questions about power, class, incquality, sociall chatage. and the formation of the modern world. (p.305)
}

20 Process innovations are changes ili the ways in which goods and services are produced. Product immoations are new goods and services. 
the Industrial Revolution is 'time saving' and, of course, saving on capital and labour costs as a resull."

James Beniger (1986) highlights the social and economic continuities which have been in place since industrialisation. Although he suggests that IT is technically different from what has gone before and that its application will radically transform the cost structure of economic activities. He argues that as the technical developments during and since the Industrial Revolution allowed the scale of production and distribution to increase, the die was cast for a 'crisis in control'. He sees IT as a response to problems posed by advanced industrialisation; problems resulting from the increased capacity, in both speed and volume, to process material flows. Ways needed to be found to control the information flows associated with the increased scale and complexity of the production of goods and services. Part of the response came in the form of changing organisational structures, i.e. the growth of public and private bureaucracies. Part of the response has also come from the development of technical means to increase the scale and complexity of information flows to match the growth of materials processing.

By drawing attention to the time saving and control aspects of IT and earlier technical changes, I have been attempting to suggest that there are enduring social and economic reasons for hastening the movement of people, goods and information; reasons essential to the maintenance of capitalism. Nonetheless, as Beniger recognises, there can be technical discontinuities. Just as railways could not have emerged by connecting together many stagecoaches; neither could IT have emerged from a collection of abaci. In the remainder of this section, I want to suggest some of the ways in which IT is different, in which it does represent a discontinuity with previous ways of processing information.

The very term 'information technology' suggests how we should think about it. Usually, parallels are drawn with other terms, such as 'information society' in which emphasis is placed on the growing importance of information itself in economic and social life. For axample, information becomes a major source of competitive advantage, even in those sectors where information is not itself the commodity. (In financial and media industries, the efficient transfer of information has always been a major source of competitive advantage.) More and more people work in jobs where information processing is the primary task. ${ }^{12}$ From this point of view, IT is a technology that processes information. One does not need to adopt the wilder claims of IT theorists that this is somehow unique in human history; nonetheless, it is true that IT does make the information processing aspects of human activity more transparent.

In what ways is IT different from earlier technologies used for manipulating information? One way of concentrating upon what is different about IT is to explore the changing relationship between technology and information. This differs from those involved in

\footnotetext{
11 Many domestic technologics are also sold with the promise of saving time. There has been a liwely debate about the extent to which this thas happened. See Wajoman (1991) for an infoductory overview of the debate.

12. For a futler discussion of the debates surrounding the "in Lombation society". see Bell (1973), Lyon (1988). Webster (1995) and Castells (1996).
} 
debates about the emergence and shape of the 'information society', who concentrate upon the increased importance of information in economic activities. But there are other ways of thinking about information. Information is an integral part of all technologies. Technologies are not simply artefacts. They have a material form, but they also include the information involved in their production and use, such as technical drawings and manuals; and the information embodied within them, which is why reverse engineering is often a successful method of obtaining technical information.

Technology and information share the public good characteristic of being costly to produce but relatively costless to reproduce. But there are limits to this generalisation. It may be the case that it is very expensive to develop a new drug, and once the formula has been tested and published, it is relatively straightforward for anyone with a secondary school knowledge of chemistry to make the drug. For electro-mechanical technologies, however, it may be very difficult to codify all of the information that went into their production. The extent to which information has this public good characteristic has changed over time. Prior to the introduction of the printing press, the reproduction of written information was costly and time-consuming. IT enhances the public good characteristics of both information and technology. With IT, the costs of reproducing all soris of information are almost zero. Software, a vital part of IT, can itself be cheaply and easily reproduced. This growing ease of reproduction of both information and software means it is more and more difficult to appropriate the economic and intellectual benefits historically associated with being the first to create something. And yet, despite the growing ease with which information can be reproduced, more and more information is subject to commodification. ${ }^{14}$

Another distinctive feature of IT, at least as claimed by enthusiastic sales people, is its malleability. Past technologies have been relatively dedicated objects. A typewriter could be used to place uniform characters on pieces of paper, or as a paperweight, or bits could be removed to be used in other ways, thus rendering it useless as a typewriter. A microcomputer, however, can be used to type words onto paper, to manipulate all different sorts of symbols, to play games and music. Moreover, the crucial driver - the softwate can be changed and copied with no detriment to the functioning of the original program. By virtue of being programmable, IT is regarded as much more malleable than other technologies.

A third feature of IT is raised by the blurring of the common sense distinction alluded to above, between technology and information. Although the informational dimensions of technologies are acknowledged, previous technologies were defined largely by reference

\footnotetext{
13 "Reverse engineering" is the name given to the process whereby oxistung arcelicts ane taken apan int an of for to understand how they were made. It can be an importan source of technical knowledge. especially in ancechanical engineering industries.
}

14 See Masco (1996) lor an interesting discussion about the diferences between intensive and cxtensive commodification. The former is used to refer to those activities which add value co existing sources of ubormathon, for example people's purchasing habits. The later refers to the expansion of commodity relations into areas such ass llie arrs. 
to their materiality. When we tak of cars, whe think of their material fom, even though the manuals, the highway cocle, the tax and license papers are also part of what makes the car "work'. 'Pure' information products, however, are recognised by and derive their value from their unique symbolic content. All books look much alike; our interest is in the unique collection of symbols on the pages. Software products have a common material form - etched onto circuit boards or captured on pieces of plastic and metal. Like information products, the walue of software comes from its symbolic content. Moreover, when combined with more conventional material artefacts, sof ware can be used to effect change on both materials and symbols.

Finally, because of the convergence of computing and telecommunication, IT can integrate previously disparate people and processes. This integrative, networking feature of IT, to which I have already alluded many times, is one of its key features. It is, of course, not the first technology to allow the transmission of unformation across distance and in short periods of time. Postal services, the telegraph and telephone use different combinations of people, artefacts and rules to convey information from one place to another. IT, however, can transmit different sorts of information simultaneously and very rapidly. It is these features which permit speculation about and experimentation with new forms of work organisation in which people can be physically distant from one another and from the object of their labour, and about new forms of industrial organisation in which companies, their customers and suppliers are electronically linked together. It is because of this integrative aspect that the relationship between users needs to be considered carefully; and it is for this reason that information networks can be defined as large technical sytems (see Chapter 3).

In this section, I have begun to be more specific about the central objects of study which will be discussed in the remainder of the book. I have outlined some of the special features of IT. First, its potential ubiquity and possibilities for altering the common sense way of doing things are two of the distinguishing characteristics of a new technomeconomic paradigm. Secondly, even though there may be common motives behind the development of IT and previous technologies in terms of wanting to save time and exent control over the production of goods and services, IT itself challenges many of our notions about tochnology and information. IT makes it easier to reproduce not only information but also IT itself. Because of its programmability, it is less fixed in its functionality than many older technical artefacts; and its material form is less important than its ability to manipulate infomation. Finally, its communication and integrative aspects bring to the fore the ways in which social relationships might be reflected in its development and reinforced in its use. In Chapters 4 and 5 , we shall see how some of these features might actually work against the successful introduction of a new IT system. But now I shall outline some important considerations raised by focusing on public administration as a site of use before examining one approach to understanding the history of IT in public administration in the subsequent section. 


\section{Public administration}

So far, the terms 'public administration', 'public sector', 'public services' and 'politics' have been used interchangeably. "Public services' covers a multitude of activities, which can be divided into two broad groups: the delivery of services, such as welfare, health and education in which the most important contact is person-to-person, even though the management of these services includes formalised information activities; and public administration, involving administrative and clerical work across many different areas, in which the information content of the work is very luigh and which includes the mass of statistics collected and processed by the state.

Information is important in both service delivery and administration. The role of information in the formation and activities of nation states is considered by Giddens (1985). He argues that the administrative power of the state could not exist without the information base that is the means of its reflexive self-monitoring. In other words, government statistics are not simply representing an objective social world; they are constitutive of our social worlds. The act of keeping records about taxation, economic production and unemployment is itself a means of securing social order. This has been accentuated by the rise of 'moral statistics', i.e. data about divorce, suicide, juvenile crime and children at risk of physical and sexual abuse. Giddens emphasises the surveillance and social control aspects of data collection. On the other side is the 'Enlightenment' view, that more information necessarily contributes to better policy-making and the more equitable execution of policy decisions. ${ }^{15}$ Returning to the examples presented in the introduction to this chapter, the linking of water consumption and welfare payments is an example of the state using information at its disposal to control the population. The ethnic minority pressure group in Amsterdam, however, was able to use data collected by the authorities to attempt to make more transparent and equitable the basis on which housing was allocated and maintained.

Both the delivery of services and the information processing aspects of public administration deal with the creation and execution of decisions that affect peoples lives; decisions which are made in the name of the national, regional or local populace, sanctified by law, tradition and practice, and for which public resources are used. In this section, I shall briefly explore two distinctions commonly made in both political and academic discussions, between 'policy' and 'administration' and between "public' and 'private'. Both of these are relevant for analysing the role of IT in public administration, as we shall see in later chapters.

The first distinction is between 'policy', the determination of political ends; and "administration", the execution of legislation in a neutral and competent manner. This dichotomy, originally formulated by Woodrow Wilson in $1887^{16}$, has been the source of

15 For further discussion of these issues. see Irvine. Miles and Evans (1979) and Davidson and White (1088).

th 'Public administration is detailed and systematic execution of public law. Every panticular application of general law is an acr of administration.' (Wilson. 1887, p. 197: cited in Harmon and Maycr. 1986. p.34) 
much debate. Most public administration theorists, practitioners and politicians now accept the normative nature of public administration, nonetheless, attempts to separate politics from administration emerge from time to time. For example, the availability of IT has suggested the possibility of separating policy-making from administration, both geographically and organisationally. Following unification of the former German Democratic Republic and the Federal Republic of Germany in 1991, the German parliament decided to explore the possibilities of using new technology to distribute parliamentary and government work between Bonn and Berlin. One model under consideration is to divide ministries, 'into a political core which will move to Berlin and an administrative sector which will remain in Bonn.' (Hoschka et al, 1992, p.270) ${ }^{17}$

The second distinction is between 'public' and 'private". The nomative basis of public sector decision-making mentioned above is one of the ways in which public sector organisations can be distinguished from those of the private sector, in which profit is the driving force. Jens Hoff (1992) summarises attempts to grapple with the increasingly blurred boundary between 'public' and 'private': it is no longer possible to make a clearcut distinction between those activities organised and financed by national or local governments and those provided by private organisations. It is becoming more difficult because public organisations are contracting-out many of their activities to the private sector and because many private organisations are more and more subjected to national and international regulations. ${ }^{18}$ One way of dealing with the fuzziness of the public/private boundary is to reject the common notions that 'public' should refer either to the legal status of the organisation or to the nature of the goods and services produced. Rather, 'public' should be used to refer to the extent to which political authority guides the organisation.

In many European countries, debates about the role of government have been at the forefront of political discussions. For our purposes, it is sufficient to remember three things: first, information processing is central to public administration; second, public administration is subject to many experiments in management and organisation; third, technology is important to both information processing and the organisation of public administration.

\footnotetext{
I" For a fuller discussion of this and other proposals for redistribuing the work of the federal German goventment, see Hoschka ef al (1992) and my own comments regarding the very technicist manue of the proposals (Wyat. 1992). Sec also Robischon (1994) for an interesting discussion of how corporate and political interests shaped the united German telephone system.
}

is There has been a massive increase in the number of global organisations to regulate inter alia trade, fishing rights, Outer space, the allocation of the madio specrum. In 1905. there were approximately 200 such organisations. By 1984, there were more than 5000. (Helld, 1989, p.196) 


\section{IT in public administration ${ }^{19}$}

The most common approach to the history of computing specifically and IT generally is what Andrew Friedman and Dominic Comford (1989) term the 'hardware generations approach".

The history of computers is divided into a series of generations of computer hardware technology, each marked by major changes in the basic components of computers. The first generation was based on valve technology, the second on transistors, the third on integrated circuits and the fourth and fifth on larger and larger scale integrated circuits. (p.15)

Each generation represents a major advance on previous generations in terms of speed, reliability and equipment. Between the second and third generations of components, there was also a shift in terms of the physical size of the hardware, from mainframes to minicomputers and later to microcomputers.

Such an approach places neat descriptive labels on important moments in the rechnical history of computing. There is an implication in such labelling that even if improvements in computing did not directly cause other technical changes - in hardware and software design, in systems development techniques - as well as broader social and organisational changes, they certainly created the conditions in which such changes could occur. In other words, the hardware generations approach is squarely within a technological determinist perspective. ${ }^{20}$ In addition to the general problems of attributing social change to technical change, Friedman and Cornford also point to the danger inherent in any approach which focuses on a single determining factor. The danger is that one becomes insensitive to changes in the relative importance of that factor. The speed, reliability and cost of components was important in constraining the avallability of computing during the $1940 \mathrm{~s}$, '50s and '60s. Only organisations with massive resources were able to afford those large machines. One of the first computers, ENIAC ${ }^{21}$, was used by the US military to calculate shell trajectories. Other early machines were designed to help process US census data. Since the development of integrated circuits and their mass production, however, other factors - such as the availability of software, the needs and skills of users, as individuals and organisations, and the legal and institutional relationships between organisations have been much more important.

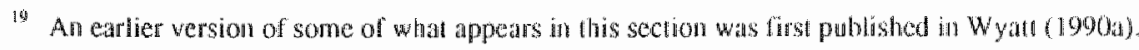

20 Friedman and Comford (1989) recognise the limits of this brand of technological detcminism. but do acknowledge its heuristic appear. They go on to explore two olber less common but still widespread aphoaches organisation stages and labour process - before devaloping their own approath, which drans on all of these but emphasises the importance of technical and socia constrants at diferent periods.

21 ENIAC (Elcetronic Numerical Integrator and Calculator) contamed 18.000 valculan tubes and occupied 1800 squire feet of lloor space. 
Chapters 4 and 5 present attempts to develop IT systems for public administration, a significant part of the service sector of the economy. ${ }^{22}$ Richard Baras (1986) combines a notion of technological generations, as outlined above, with some idea of the particular conditions in which service sectors operate. He argues that the innovation process in services can be characterised as a "reverse product cycle", in which process innovation precedes product innovation. ${ }^{23}$ This is because service industries tend to be users of technologies developed in manufacturing sectors, and it is these technologies which act as catalysts to changes in the range and nature of services available.

During the first stage of service innovation, technologies developed in other sectors are used to increase the efficiency of delivering or producing existing services. In the second stage, new production systems allow improvements in service quality - in the frequency and volume of information provided or in increased availability of the service. The third stage is characterised by the production of new services, usually after it becomes clear that the data being processed can be put to other uses. ${ }^{24}$

In terms of public services, some of the most important post-war innovations have been organisational, for example, the establishment of the welfare state in the UK. Nonetheless, central and locall government have been major computer users for decades. Like any other large organisation, early applications were in areas of large-scale data processing, such as payroll and other adninistrative functions. Systems were also developed for reconding and processing information on passports and pensions, for plamning and managing housing systems and for processing the myriad of government statistics on economic output and social trends. These were done using mainframe computers, and were applied to activities that could be easily standardised. In many ways, they were similar to the uses to which mainframes were put in private services.

22 The three basic sectors of the economy are:

Primary - extraction of raw materials. e. mining and agriculture:

Secondary - transformation of raw matriats into goods; includes manuficturing as well as infrastructure and utillies such as water and clectricity:

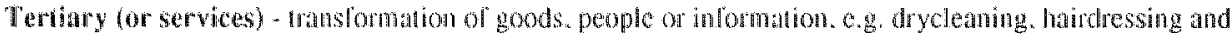
accountancy.

23 "This is in contrust will the now stundard economic concept of prodtact cycles" (Vemon. 1966) applicable to manufacturing activilies, in which product innovation precedes process imovalion. New products are developed: if they become successful, new machines (new processes) are dewcloped lo produce them on a larger scale.

24 Barras's work has ben a waluable contribution to understanding service innowation. Miles (1987) does. however idenify two limiations. First. Barnas implies that serwices are relatively passive recipients of imnovations developed by manulacturing companies. Many service innovations have been more organisational than technological (i.e. supermarkets): service companies have. however, heen imovators in the production and use of tochmological artelacts. Many large sarvice compinies do the ir own R\&D. particularly in software production and network security. Second. the distinction between product and process innowation is not as clear as in is in manufacturing. In services, sny process change may involwe product change. For example, the introduction of attomatic bank telling machines ws motivated by banks" desire to reduce data inpul costs. For the customer, it is an improwement in service quality beciuse the serwice became avalable outside taditional banking hours. 
The early generations of computer equipment were cumbersome and ill-equipped for dealing with individual needs. During the second phase of the reverse product cycle, microcomputers are bought by individual offices or departments, and are used, for example, to define personal insurance policies or to help claimants understand and complete their benefit application forms.

The third phase, wider networking of systems, brings together the isolated computers being used in different locations. Not only is this dependent upon the development of a new telecommunication infrastructure, incorporating microprocessors and fibre optics; but also upon the development of centralised or relational databases. ${ }^{25}$

In Chapters 4 and 5,1 focus on three attempts by public administrative bodies to develop networks, the technology characteristic of Barras third phase. Such data communication networks are not themselves radically new, but rather they are a more or less novel combination of existing technologies. In each case, new communication networks are often associated with new ideas about how best to deliver public services; thus the political context in which the development occurs is particularly important; and some important policy issues are introduced in the next section.

\section{Policy issues raised by the use of IT in the public sector}

There is a relative paucity of research exploring the role of IT in the public sector, compared with the huge and growing volume of work focusing on manufacturing industries and private services. Enough work has been done, however, to indicate some of the major policy areas. Table 2.1, 'Summary of issues raised by public sector use of IT", presents an overview of these issues, drawn from a review of public sector IT applications in Europe and the United States (Wyatt, 1994).

Information processing and communication are central to the functioning of public administration. Thus, increased reliance on databases, decision-support systems and networks raises many issues regarding relationships within public administrations, between public administrations and citizens, between public administrations and other organisations and, to a lesser extent, between national administrations. Some of these were touched upon in the introduction to this chapter. The ethnic minority pressure group in Amsterdam, the Santa Monica public network and the post-1987 Danish social security system are all examples of how new information technologies can be used to alter relationships between citizens, public servants and politicians. The case of the Dutch hairdressers illustrates some of the dangers to individual privacy posed by the linking of databases. The introduction of computers into both Danish and Dutch social security

\footnotetext{
25. In public administration, the latter include object. sector and control systems. Object systems are essentially registers of the population of legal entites such as enterprises. foundations and associations, of vehiclios and of immovables such as land and buildings. Sector systems contain batse registrations of actors and their transactions in a particular sector of public administration such as social security, health care, police. transport: making the free exchange and linkage of data possible throughout a whole sector. They can allso be used in the construction of simulation models. Control systems monutor the atlocation of finandint, human and physical resources.
} 
offices highlights concems about the ways in which the use of IT can result not only in more codified and rigid legislation but also in a reduction of personal contact.

Three issues which appear in Table 2.1 will become important when we examine the development of three IT systems in later chapters. The issues are privacy, contracting-out and the relationship between systems development and the legislative process. As we shall see in Chapters 4 and 5, privacy, privatisation and the primacy of the political process are used by a variesy of group in their efforts to steer the development of IT systems. 


\title{
TABLE 2.1: SUMMARY OF ISSUES RAISED BY PUBLIC SECTOR USE OF IT
}

\section{Integration of service provision}

\author{
- faster, more accurate and more convenient delivery \\ greater equity of treatment \\ mules based systems become simplified and rigidified \\ reduced discretion in applying rules \\ less personal contact \\ change in bureancratic competences demanded of citizens \\ theat to individual privacy
}

\section{Restructuring of the internal organisation of public administration}

increased capacity to exploit labour marhets across a wider geographic area loss of shared knowledge of localiry in official-public interaction greater electronic monitoring of staff performance if management located remosely

\section{Restructuring of external relationships with the private sector}

rendency to externalise government IT with possible increase in costs and decline of public sector skill base

development of administrative databases to be used by both public and private sector. organisations with concomitant thear of lock inlerchsion if compatibility required; and further threat to individual privacy

\section{Accessibility of public information}

changed criteria for access to information: increased emphasis on techwical competence of citizens: whi-directionality inhibits communication flows from cinzens to officials 'one stop shops offer greater comenience to penblic but place greater demands on staff greater avalability of information can be wsed by ciningus to exerp pressure on PA

Public policy issues

data protection

- individinal becomes collection of data to bo processed by state

differences in data protection legislation betwecn conwhies inhibit development of commercial walle added services.

commercialisation of goverment data hindered by differences in data definition and relecommunication infiastructure

PA better able to compete with private sector in the provision of services, such as pensions public sector in danger of losing its abiliry to be informed buyer and user of $1 T$ all benefits threatened by separation of IT and 'core business' strategies primacy of political decision-making threatend as legistation becones embedded within IT systems 


\section{Privacy and data protection}

Many of the attempts to improve the quality of service to citizens involve the integration of personal data historically held by different parts of the state administration and which, prior to IT, had been logistically extremely difficult to integrate. Networks and relational databases open up many possibilities for the integration of data.

The integration of information systems holding detailed, personal information is the source of George Orwell's 1984 nightmare in which a state uses its survelllance capabilities to monitor and control its citizens, resulting in a loss of individuality and human dignity. Such nightmares of totalitarianism could begin with three more mundane privacy issues which arise when government-held information is integrated. Matching, front-end verification and profiling are outlined briefly below. ${ }^{36}$

Computer matching involves the electronic comparison of two or more sets of personal records. It can be used to check for individuals who shiould not appear in two separate databases; e.g. people above a certain income level in the tax register should not appear in the database of people in receipt of social welfare payments. Conversely, computer matching can be used to look for individuals who should appear in two databases; e.g. in countries with compulsory military service, men over 18 who have already registered can be matched against men over 18 who are in possession of a driving license. Problems arise when the efficient management of government programmes comes into conflict with individuals' rights to privacy. Data protection or privacy legislation in many countries, including the US, UK and Germany, requires that information collected for one purpose cannot be used for another purpose.

Front-end verification is similar to matching. Whereas the latter involves comparing data after an individual is in receipt of government benefits or services, front-end verification is used to certify the accuracy and completeness of personal information at the time of application for government services, through comparison of data held in different places. For example, if someone is making a claim for social welfare payments, other sources of official data will be consulted to verify whether or not the person has children. Extensive use of front-end verification results in the creation of 'virtual' national databases and again raises questions of due process.

Proliling is rather different. It refers to the derivation of classes of individuals most likely to be involved in activities of interest to the state. These classes are constructed from wholesale matching in order to identify, for example, the profile of tax evaders. If it is found that dentists avoid paying their taxes more than other professionals, all dentists will subsequently be scrutinised more closely. Again, this raises questions of due process because some inclividuals are selected for special attention and treated differently from

26. Fon a fuller discussion of daa protection and individual privacy, see Bennetl (1992), van den Howen (1995) and US Congress (1986). 
others simply because they fit a statistical profile, not as a result of any actions of their own. ${ }^{27}$

Integration of databases need not stop with government-held data. Private sector organisations hold data about individuals of interest to government bodies. For example, the mass non-payment of the Community Charge (aka poll tax) in Britain in the late 1980 s led the government to consider requiring employers to deduct outstanding tax from their employees. The employers federation refused to become involved in what it perceived to be the proper task of government, namely the collection of an unpopular tax. In this case, the private sector did not participate in tax collection, nonetheless the possibility could be considered because of the availability of information systems. Private companies in the UK have agreed, however, to deduct child support payments from fathers in their employ who have neglected to make such payments, and to convey the information and money to the relevant authorities. Considerations of data protection and individual privacy arise. Do employers need to know, indeed should they have the right to know, if any of their employees are not paying taxes or child support? As employers become more and more involved in the direct provision of information needed by the state to execute its own policies, these sorts of questions will become more widespread and urgent.

\section{Privatisation and contracting-out}

The growing commitment in many industrialised countries since the early 1980 s to improve public sector efficiency and to reduce its size, together with the technical capabilities of advanced IT, have raised possibilities of wery different relationships between the public and private sectors. An increasingly popular possibility is privatisation and/or contracting-out government IT. It is seen as a way of inter alia reducing costs, externalising conflicts with trade unions and resolving skills shortages.

In a review of contracting-out IT in OECD member countries, the Public Management Committee of the OECD reached the following conclusions:

* The most common reason for contracting-out is to increase cost-effectiveness.

Formal evaluations of contracting-out experiences have rarely been conducted. US experience suggests savings can be as much as $20-30 \%$, even if the service is retained in-house and simply bench-marked against contracted-out costs.

* Difficulties in measuring cost-effectiveness can be a barrier. It must be done on an equivalent basis, including overhead and contract management costs.

* Contracting-out needs to be supported by a good contract, specifying performance requirements, the responsibilities of both parties and a procedure for changing the terms.

\footnotetext{
27 I was living in the Netherlands when I was writing the first draft wi this cthapter. Like all foreiguresidems. I was required to register with the police and: like all residents. regardless of uationality, I was also required to present myself together with my passpont and birth centicate at the town batl so that detuils about me could be recorded on the Dutch poptlation register. During the lime I was living thete. I did not visul a medical doctor but I did celebrate my $35 \mathrm{~h}$ birthday. Exaclly one week latter. I received a letter from a private medical hahoratory suggesting that I arrange to have a cervical smear tes. All 3,5 year old women receive such a reminder. This is also an example of profiling.
} 
Contracting-out is not appropriate for very new technologies as there is a greater danger of becoming locked-in to a single supplier.

* Contracting out can provide a means of accessing the skills and experience of the private sector.

* The impact on staff needs to be considered carefully. On the one hand, contractingout rowtine operations can free internal staff for more interesting tasks. On the other hand, internal staff morale may suffer if people working for the private company do earn, or are perceived to earn more money. (OECD, 1992, pp.16-8)

Somewhat paradoxically, contracting-out IT services may not lead to reductions in costs. IT professionals operate in an external labour market very different from that of cleaners and caterers. Contracting-out IT services aimed to solve the problem of attracting and retaining highly qualified IT professionals at public sector pay rates. But, contracting out IT services can actually result in an increased salary bill. ${ }^{28}$ Unlike cleaners, the wages of IT professionals are not downwardly flexible. Extenal staff were used extensively during a large computerisation project at the British Inland Revenue in order to compensate for internal staff shortages and delays resulting from industrial action. Overall expenditure increased in both real and nominal terms. (Dyerson and Roper, 1992)

One of the major concens regarding contracting-out is the threat to the public sector skill base. In April 1990, the UK Department of Social Security (DSS) announced the creation of the Information Technology Services Agency (ITSA). All DSS IT staff moved to ITSA. on terms more favourable than those available to internal DSS staff. This has exacerbated a situation in which IT expertise has been kept on the periphery of the DSS. Margetts and Willcocks (1992) argue that although the technology has been brought into the heart of the DSS in terms of providing services, "[the resistance of DSS management to the training of in-house staff means that integration of TT into the management, improvement of IT project management skills and the overcoming of shortages in IT specialist staff may never happen." (p.341) The contract governing TSSA services allows the DSS to look for another supplier if it becomes dissatisfied, but if all technical expertise has been moved outside of the DSS itself, it is not at all clear whether or not it will be in a position to judge whether or not it is even dissatisfied, much less be in a position to recommend alternative solutions.

Separating core business from IT services, moreover, runs counter to recent experience in the private sector. In financial services, for example, it is extremely difficult to distinguish between corporate strategy and IT strategy. The experience of the IT Division of UK Customs and Excise illustrates this: there was a sufficient volume of work and a constant shortage of suitable permanent staff to justify entering into long-term partnerships with both a private software house and a consultancy firm offering project management support. It was soon realised that much greater integration between the groups was

28. In May 1994, the British Court of Appeat ruled that the worsening of enploymen conditions, following conmacting-out, contravened Earopetan Union legislation. In future, companies laking on new contracts in order to provide services to gowennent will be obliged to mainain the pay and conditions of existing stafl. This challenged the objectives of the policy of the then Cotservative Govermment in its privatisation of government services. (The Guawlion. 20 May 1994, p.8) 
needed. Internal staff did not know how to utilise the skills and experience of people from the private companies and the staff from the software and consultancy firms did not fully understand the 'core business' of Customs and Excise. (Whittington. 1990) In order to use IT to improve the operation of the public sector, it may be necessary to combine the TT and business strategies rather than contracting-out the former to the private sector.

\section{Systems development and the legislative process}

The possibilities for integrating data raise concerns about individual privacy, as outlined above. But questions about how such integration affects the legislative process also arise, and these questions have received less attention. The Danish tax and customs authorities realised they held data on many of the same legal entities. Private individuals do not have much confact with customs authorities, but self-employed people and private corporations have extensive dealings with both tax and customs, particulary as the latter is responsible for the collection of value added laxes. Much of the same data was being held in two different places. Integrating the data of two organisations with different structures, training policies and IT strategies was a challenge but one which provided a way into amalgamating the two authorities in order to achieve the primary objective of creating a single, revenue collecting authority. ${ }^{* 0}$ For that primary objective to be achieved, however, it was necessary to simplify the tax system so that the IT system conld be developed on schedule and within budget.

It has also been suggested, as shall be discussed more extensively in Chapter 4 , that changes in legislation were necessary in the development of an intra-departmental system. The Operational Strategy of the DSS is based on a single, centralised database containing one record for every person living in the UK. It also required the codification of the social security rulles. The massive cost increases the project incurred in its early years are, in part, attributable to the technical difficulty of codifying a discretionary social welfare system. The 1987 Social Security Reform Act replaced the discretionary system with a more rigid rules-based income support system; necessary to ensure the survival of the Operational Strategy. The social security reforms aded the shon-term computerisation of the benefit system, but possibly at the expense of its longer-term flexibility. The Department of Social Security is now locked into a rules-based system.

These two examples raise serious questions regarding the primacy of politics in the legislative process. There will, of course, be problems in maintaining a strict separation between developing IT systems and developing policy. Some policies might require very complex and/or very expensive technical solutions; and it is undoubtedly preferable for all concerned to know this sooner rather than later. Two basic problems are associated with the computerisation of legislation. The first arises because it is perceived to be much easier to re-write legislation than to alter technical systems. (Of course, this perception arises because of the widespread acceptance of technological determinism and of the autonomy and immutability of technical artefacts, as discussed in Chapter 1.) Thus, there

\footnotetext{
29 This massive re-structuring of gowermment agencies wis not wibhou ins cmployment inplications ti bas been quite a bloody affuir, remarked one observer. A fulter account of the integration of Danish tax and customs authorities can be found in Westerbers (1989).
} 
is a danger that technical requirements will dictate the direction of legislation and that once a particular technical path has been chosen, the possibilities for radical legislative change are curtailed. The second problem is one of final responsibility. Who has the authority to define and specify the final details of legislation - legislators or technical experts? In the past, the importance of such delails may have arisen years after the legislation was implemented but, with IT, they have to be resolved immediately if the details are to be codified and incorporated within the information system. Previously, exceptional cases would probably have been left to subsequent juridical interpretation; now, technical exigencies might dictate the legal interpretation.

In later chapters, we shall see how these public policy debates regarding data protection and privacy, privatisation and political primacy are not simply the consequences of the introduction of IT, for which political solutions have subsequently to be found. Rather, different positions in each of these debates are adopted by groups involved in the development of the IT systems and thus are essentiall to understanding the way in which technology is constructed. This takes us back to the models of the rellationship between technical change and social change outlined in Chapter 1. In the remainder of this chapter, I shall examine how these models can be used to organise the research that has been done about the use of IT in the public sector.

\section{Approaches to studying information technology and public administration}

The previous section clearly indicates that the growing use of JT in public administration raises many issues of concern. Despite this, the volume of research exploring the use of IT by public administration is relatively sparse, especially when compared with the volume of research focusing on manufacturing industries and private services. To the extent that the IT literature does grant a role to the public sector, it is as a regulator or sponsor of the technology. There is a vast English language literature on the privatisation and re-regulation of telecommunication, following the break-up of AT\&T in the US in $1984^{30}$ and the partial privatisation and re-regulation of British Telecom in $1984^{3 !}$. Similarly, the Japanese government-sponsored Fifth Generation programme not only prompted US and European governments to develop their own advanced IT R\&D programmes, it also prompted much academic research regarding the role and nature of government-supported R\&D. But the actual development and use of IT systems for public administration itself have received relatively little attention.

Within the conventional public administration literature, the role of IT is also given a very marginal role. Christoper Hood and Helen Margetts (1993), in a review of British research in the field, suggest the reason for this marginalisation is to be found within the

\footnotetext{
30 The consent decree was gramed in January 1982, The actunl divestilure of the Bell Operating Companies did not take place unil early 1984.

31 What is now BT was split from the Post Orfice in 1981 . Mercury. the firs competitor in the area of woice traffic. was created in 1982. BT shares were first sole in carly 1984. The regulator. the Orfice of Telecommunication (Oficl), was also established in 1984 .
} 
particular UK tradition of public administration scholarship. One problem with that body of scholarship is that it has no real intellectual centre; work on public administration tends to be very fragmented, focusing on particular sectors such as social, education or health policy. A second problem is that academic public administration within Britain falls within the political science tradition, thus focusing on traditional political science issues of accountability and interest groups. In such a tradition, there is very little space for exploring the ways and means by which public services are actually administered and delivered. As a result, the academic public administration community has been illequipped to contribute to the highly-charged debates within Britain in which the delivery of public services is very much on the political agenda for both major political parties. This is despite the fact that new information technologies are very much involved in this redefinition of how best to deliver public services, resulting from the possibilities for using IT to reduce costs, tailor service delivery and monitor individual and organisational performance. 'Public administration in the 1980s and since has become a contested institution rather more than it has been a contested intellectual arena.' (Taylor and Williams, 1991, p.174)

There is, nonetheless, a small body of work within Britain which attempts to explore the role of IT in public administration. However, it comes from people working within different disciplines, primarily political science and organisational sociology; and no single coherent intellectual framework has yet emerged. In a review of this work ${ }^{32}$, Lawrence Pratchett (1993) identifies the main themes which were covered. With two exceptions, all are concerned with the impacts of the technology or with ways of making its implementation and management more effective. Impacts include more rational decision-making, shifting power relations from policy groups to technical groups, greater attention to performance measurement and cost savings. The inability of public administration to reap the benefits of IT is attributed to out-moded organisational structures and lack of responsiveness on the part of management.

The two exceptions Pratchett identifies derive from government's other responsibilities, such as for technology policy and privacy protection. By virtue of its size, government has the possibility to influence national IT policy through its procurement activities. Because of the huge volume of personal data held by public administration, it also has a particular responsibility to protect its citizens privacy. Decisions taken by relevant actors around these issues have the potential, of course, to influence the shape and direction of the technology and of data protection policy. Pratchett seems unaware of the relationship between these two exceptions, even though the authors of the papers do mention the "shaping" role of public procurement (Buckingham and Wyatt, 1992) and of data protection policy (Raab and Bennett, 1993).

\footnotetext{
32. Between 1991-3. the Economic and Social Research Council lunded a series of seminars on the fortad theme of Information, Communication and New Technology in Public Administration during the course of which 17 papers were presented. Most of the researchers aclive in the field participated in one or more of the seminars: 36 different people were inwolved. Pratchetf prepared a rewiew of the whole seminar series for a mecting hold in December 1993.
} 
Outside of Britain, especially within the United States and continental Europe, especially Germany and the Netherlands, there has been considerable research dating back to the 1970 s. Before discussing some of that work, it is time to recall the three models of the relationship between technological change and social change introduced in Chapter 1: technological determinism, technology as neutral and the social construction of technology. All of these models can be found - albeit disproportionately - in literature about IT and the public sector, they are summarised in Table 2.2 .

\section{TABLE 2.2: MODELS OF THE RELATIONSHIP BETWEEN TECHNICAL CHANGE \& SOCIAL CHANGE}

\section{Model - View of Technology}

Technological determinism defining, autonomous rechnology

Technology as neutral . controllable rechology

\section{Social Implications}

- need to know the characteristics of the technology as they will determine the effects

- need to know goals and strategies of actors controlling the introduction of technology; 'effects'

are the 'intended outcomes' of such actors

- not possible to talk of effects

given technology is both cause and consequence, determining and determined, context and content
Technology as social constructinteraction berween society and technology

Source: adapted from van de Donk (1993, Table 1).

Much of the work done over the past 25 years has tended to adopt a "technology as neutral perspective; largely because, as mentioned earlier, work within a political science traditio tends to focus on the activities of particular groups and their efforts to secure their own sphere of power and influence. For the most part, IT is simply regarded as a tool to help public administrations do what they have always done, perhaps more quickly and cheaply Struggles over the definition and use of $\mathrm{IT}$, when considered at all, are regarded in the same way as other power struggles. The technology is not found to be neutral; it is assumed to be neutral from the outset. Rather than determining organisational structure o decision-making practices, the use of IT is more likely to be determined by the character of the institutions into which it is introduced. Kenneth Kraemer (1991) suggests that IT has not really had any noticeable effect on organisational structure and where it has, it ha: reinforced existing structures, i.e. greater centralisation of already centralised organisations. Danziger (1986) came to a similar conclusion, '[IT has] not revolutionized 
politics. Overall, computing has amplified the configurations of capabilities, interactions, orientations and especially the value distributions that preceded the widespread penetration of the technology into government and politics. (p.186) He goes on to suggest that the results of empirical studies have been inconclusive regarding the effects of IT, leading him to conclude that the technology itself is both neutral and rather insignificant. At most, computers have proved to be useful tools but the political rationality guiding public administration remains paramount.

In recent years, a different approach to studying IT has emerged, one which emphasises the role of technology as an autonomous, defining source of radical change in public administration. Comparisons are frequently made with the Industrial Revolution: since public administration processes large amounts of information, IT will be as significant for public administration as the Industrial Revolution was for manufacturing.

New ICTs [information and communication technologies], specifically modern computer networks, establish facilities through which both efficiency and effectiveness gains are being made in Britain's public administration. More profoundly still, computer networking is beginning to provide a set of new technological and informational infrastructures as a consequence of which longestablished organizational structures and processes are being challenged. A new public administration is being forged and new information flows, and the computer networks which facilitate and mediate them, are fundamental to that innovation process. (Taylor and Williams, 1991, pp.171-2)

This process takes time and can involve a long period of experimentation and adjustment. Paul Frissen ei al (1992) use the term "informatisation ${ }^{.33}$ to capture that process of adaptation which includes the following phenomena:

* introduction of IT to shape and handle the information retrieval process;

* rearrangement of information flows and information relationships;

* adjustment or change of organisational structure;

* development of information policy as distinct area of policy making; and, * introduction of specific IT expertise.

\footnotetext{
33 This awkward and ugly neologism has culered English from Frenclh. In their repont to the President of France. Nora and Minc (1978) use iaformatsation to convey the rewolutionary potential of IT. The 1980 English version translated informansarion as 'computerisation. 'Informatisation' is beginning to take hold within English. Zulboff (1988) also uses the nerm "informate' to convey the value-added aspects of information processing using IT. She contrasts this with 'automate', in which TT is used simply to substhte for the means by which information wats previously processed. She also conveys a sense of the revolutionary potential of IT. cmiphtsising the positive benefuts for individualls and organisations.

Blackburn. Coombs and Green (1985) are much more precise in their concept of "mechanisation", in which they distinguish the following types:

* primary-mechanisation of transformation of raw materials:

* secondary - mechanisation of the transfer of raw materials from onc part of the production system to another: and.

* tertiary - mechanisation of control of both of the above.
} 
A sense of progression is clearly conveyed - the technology is introduced and, as a result, the structure of the organisation changes, new areas of policy and expertise are introduced and relationships are altered.

In the 'Editorial' of the first issue of the only journal to deal exclusively with the topic, Informatization and the Public Sector, Ignace Snellen and John King (1991) leave no doubt regarding the profound impact IT will have on public administration:

[D]uring the past decade, the use of information technology has begun to revolutionize the public sector. And the prospect of even greater change looms large .... $[$ []nformatization"...encompasses not only the underlying artifacts of information processing, but the consequences of widespread use of information made available by these artifacts to alter the relations among people, government, industry, commerce, education and other social irstitutions....

|T|he applications of information technology have already brought significant changes in the character of public programs, in the nature of public administration, and in the relationships between government and the people. (pp. 1-2)

In the paragraph which follows (not reproduced here), they confess that the precise nature of these significant changes remains 'vague' in their minds. Of course, this is partly because the public sector has been relatively neglected in terms of research. I suggest it is also partly because insufficient attention has been given to the origins, to the creation, to the process of development of IT systems for public sector use. At the beginning of this section, I suggested that despite the many public policy issues raised by the use of IT in the public sector, research into the precise nature of the uses was scarce, especially compared with the volume of research concerned with the use of IT in manufacturing and private services. Now I wish to go further and suggest that one of the reasons the results of the research that has been done remain inconclusive and vague is that too little attention has been paid to the technology itself and the process by which it has been constructed for public sector use.

There is a third reason why the research conducted to date on IT and public administration has wavered between a technology as neutral perspective and technological determinism. Much of the work is rooted in the Weberian tradition of "ideal types". Stylised notions of both the present and future are invoked, but no attention is given to the process of change from one to the other. Instead of focusing on the actuality of the present and attempting to understand how it incorporates elements of the past and how it might be projected into the future, radical forecasts are made on the basis of changes in single factors. In other words, an historical approach is required, one which can be sensitive to elements of both continuity and change. The ways in which this might be approched will be explored in greater detail in the next chapter. 


\section{Concllusion}

In this chapter, I have begun to be more specific about the technologies and their site of development and use so that in later chapters we can examine the particular cases of the development of three government IT systems. The scenarios presented in the Introduction confirmed the need to be precise; otherwise wild and contradictory predictions about the future of democracy are made on the basis of a few examples of different technologies used in different times and places. Focusing on the nature of both IT and public administration suggests some areas for further consideration.

Even if one information processing device is different from earlier information processing devices, it does not follow that public administration or society generally will be radically different in the future as a result. Not only are there many social continuities mitigating against radical social change; there is also a danger of overstating the technical discontinuities if the social conditions in which the technology is developed and used are ignored, or of mistaking technical revolutions for social ones. Nonetheless, IT includes physical objects which have particular characteristics, all of which need to be considered seriously; including their ability to reproduce both their own software and the information processed by them, the possibility to perform many different functions and the capacity to connect together different devices incorporating microprocessors. Together these characteristics indicate that the technology can be widely used in many different settings and that previously discrete and even geographically remote information processing activities can be connected to one another. More than ever it is important, therefore, to consider the social and spatial relationships between different elements of the system.

Public administration is an interesting and important site of use. Information processing is central to the conduct of public administration; thus, there are many possible ways of using the technology. One is to redefine the ever arbitrary and blurred boundary between politics and administration, between policy-making and execution. Another is to redefine the also shifting boundary between public and private spheres. These issues are on the political agenda of most industrialised democracies; but when discussing the role of IT, they can also be turned around. Then the question becomes, as we shall see in Chapters 4 and 5 , how are perceptions of these issues used to justify or redirect or stop the development of public sector IT systems?

Similarly, many public policy issues have been raised by the greater use of IT by governments, including personal privacy, privatisation of govermment services and political primacy in the legislative process. To understand these as political problems pushed into public view following the introduction of new technologies is only part of the story. Another part is that perceptions of these problems and how best to resolve them are also used to justify technical choices. That part of the story is rarely told, but it will be later in this book.

The history of IT cannot be reduced to the history of ever-cheapening microprocessors and ever-increasing bandwidth. This aspect of the history does serve to explain, at least partially, the pervasiveness of IT into many areas of society but it does nothing to explain 
the particular configurations of IT networks connecting together different people and organisations.

These points about the nature of $1 \mathrm{~T}$, the nature of public administration and the political climate in which it exists suggest that neither a simple "technology as neutral" nor a technologically determinist perspective will capture the richness and complexity of the development of IT systems for use in public administration. Nonetheless, such ideas are used frequently by some of the actors involved in developing IT. Earlier in this Chapter, I suggested that one of the problems with much of the research in this area is that it has neglected questions about the process of development. In the next chapter, I shall begin to outline in more detail the issues one needs to consider in order to provide a rich account of a complex and dynamic process of socio-technical change such as the development of an IT system for public administration, before offering three such accounts in Chapters 4 and 5 . 


\section{CHAPTER 3}

\section{STUDYING THE SOCIETY - TECHNOLOGY RELATIONSHIP}

\section{Introduction}

Studying science and technology is sometimes seen as simply another way of studying society. This is particularly the case if one accepts the aphorism mentioned in Chapter 1 that technology (and/or science) is social relations. Then, studying science and technology becomes another way, for example, of examining gender, class or race relations or of exploring differences in firm or national competitiveness. The scenarios presented at the beginning of Chapters 1 and 2 about the ways in which technology generally and IT specifically might affect society can be recast as questions about the distribution of material and cultural resources within our societies, about access to more or less meaningful jobs for individuals and nations, about access to leisure and information. Sometimes debates about 'big' technologies in particular - such as power stations, roads, railway tunnels or information superhighways - are portrayed as social conflicts, unrelated to the particularities of these material artefacts. Thus, debates about the siting of roads or of power stations are not about the features of these large, complex technologies but rather are about who has the right to live in peaceful surroundings and who has the resources to fight for these rights. Similarly, negotiations about workplace technologies become another arena for workers and management to redefine their rights and responsibilities. Debates about new reproductive technologies are yet a further opportunity for women and men to negotiate responsibilities for contraception and childcare.

It is essential, of course, to pay attention to the wider cultural and social aspects of technical decisions. But there is a danger of reweaving technology back into the seamless web of history, and thus of the STS community losing its object of study. There is also a danger of reducing technologies to just another form of cultural expression. Struggles over the meaning and representation of technologies are important but it is equally important to struggle over the technologies themselves; in other words, following Durkheim, to turn from the images of things to the things themselves (Joerges, 1988), so that we do not miss the opportunity to further our understanding of the role of technology in structuring human experience, and thus to increase the scope of our potential for intervention and action.

In a very useful overview of different disciplinary approaches to studying the technologysociety relationship, Thomas Misa (1988) concludes that there is a connection between a discipline's usual level of analysis and its affirmation or refutation of technological. determinism. For example, labour historians, through their focus on the workplace, are well aware of both the social interests behind the introduction of new technologies and the ways that workers can and do act to mitigate potentially negative impacts. They are thus well placed to refute both aspects of technological determinism, namelly that technology is independent of society and that its effects are inevitable and unilinear. Philosophers, on the other hand, with their extreme 'macro' focus are the most committed technological determinists, although they are often wery pessimistic about the impact of 'technics' on 
humaniy.' The 'Machine' is a powerful metaphor used both by philosophers and by historians to impose a structure on the past. As already discussed in Chapter 1, technological determinism renders people as the passive recipients of autonomous technology and imposes a flatness and direction on historical processes that were characterised by conflict over alternatives not chosen and choices imposed.

Misa also bemoans the way in which technological determinism, "hamper|s] integration between "macro" and "micro" levels' (1988, p.321), for the same reason that I do in Chapter 1. Technological determinism obscures the messiness of the past and renders it impossible to reconcile the 'micro' actions of individuals or groups with 'macro' structures, of which technology is one example. Scholars engaged in 'science, technology and society' (STS) studies are attempting to find a way of grappling with the heterogeneous nature of technology, heterogeneous in that it is simultaneously sociall and material. $\mathrm{A}$ focus on larger, or at least middle range, technologies, such as those described in the following chapters, that are not only the outcome of social processes but are also used to enable diverse groups of people to communicate with one another are a good vehicle for reconciling the micro with the macro; or, in the more apt terminology of social theory, reconciling agency with structure; or, reconciling empirically rich case studies with thoeretically sophisticated abstractions.

Misa (1994) proposes an alternative way forward. He too argues the desperate need for a middle range theory, one which brings together the social shaping of technology thesis with the technological shaping of society antithesis. He suggests that one way to do this would be to studly middle range actors, such as manufacturers' organisations, engineering consultants or standards bodies. ${ }^{2}$ Mansell and Silverstone (1996) also identify this need. They too argue that a middle range theory is woefully lacking in the economics of innovation literature, which has more vigorously pursued evolutionary theories of change, based on metaphors of ecology and game playing. In their introduction, Mansell and Silverstone (1996) suggest that middle range theory allows the innovation process to, 'be treated as a dialectic in which power is exercised in the production and use of technological artefacts as well as in the institutionalization of behaviour." (p.7) This challenge is pursued further here, not in the study of middle range actors as such, although they do appear, but in the analysis of middle range teclnologies, such as government information systems.

In this chapter, I want to outline some of the methodological decisions that have informed my study of three government IT systems, described in the following chapters. Three of these decisions have already been alluded to in Chapters 1 and 2 and will be discussed here in greater detail: the notion of technological development as a linear process; symmetry in accounts of the relationship between technical and social change; and, the

\footnotetext{
"Sce, for example. Ellull (1964. 1980). Winner (1977) and Borgmann (1978). This work is within the tradition of the Franklurt school, and is concerned with the prevalemee of instrumental or technacal rationality in sociall life.
}

2 This is a challenge laken ap by Schmidt and Werle (1998) in their analysts of standards-making in broadcastung and communication technologies and by Hawkins (1996) in his analysis of telecommunication wetworks. 
concept of technological scale. But first, I shall briefly explove the interdisciplinary nature of this project and STS more broadly, and what that means in terms of research practice.

\section{Interdisciplinarity: Seamless webs or unfocused microscopes}

Studies of "science, technology and society" are necessarily interdisciplinary. John Law (1991) refers to the 'genius' of STS, its recognition that social structures do not exist only in and through the actions of people, but that ' $(t)$ hey exist in a network of heterogeneous material arrangements' (p.16). To understand how a collection of disparate things people, artefacts, knowledge about how to make, build, use and maintain artefacts, organisations, regulations - forms a unitary whole performing complex operations repeatedly; and furthermore, how this whole is implicated in the reproduction of social order is a challenging task. It is a task which requires assistance from the conceptual repertoires of many disciplines, including economics, cultural studies, sociology, history. geography, politics, science and engineering.

Road transport, a major twentieth century technological development, illustrates the importance of an interdisciplinary approach. It is possible to study the development of a system of mass personal transportation using private cars from a purely economic viewpoint. An economist might analyse the changing cost structure of producing cars which resulted from the introduction of mass production techniques such as the assembly line; and would perhaps find that the capital-Jabour ratio had increased but marginal costs of production had declined. Industrial sociologists might focus on the implications of mass production for different groups of workers and the changed possibilities for trade union organisation. Cultural studies scholars might explore the symbolic meaning of the car through a study of popular media, including advertising, film and music. Geographers might have the task of considering the urban, inter-urban and rural planning issues associated with road building. Political scientists might examine the relationship between the large automobile manufacturers (the economic performance of which is often invoked as an indicator of national economic strength - new car sales are regarded as a sign of consumer confidence), energy producers, politicians and civil servants. How do car manufacturers influence industrial, energy and environmental policies? Engineers will be interested in fuel consumption and acceleration. To grasp the full complexity of the evolution of automobile transport over the past century, however, all of the above issues need to be taken into account; moreover, one can only comprehend design features which permit $0-100 \mathrm{~km}$ acceleration in ten seconds or maximum speeds of $250 \mathrm{~km}$ if one appreciates how and to whom cars are marketed. It might be sensible to introduce draconian measures to reduce car traffic in order to reduce pollution and alleviate urban congestion. But to grasp why such measures will not be introduced requires an appreciation of the economic and political importance of the automobile companies and also the deep symbolic meaning many people attach to driving a car. The policy trick will be to convince people to buy cars but not actually to drive them. ${ }^{3}$

${ }^{3}$ On January 1. 1997 , is became compulsory in Britain for new drivers to putss a written test before being allowed bethind the wheel of a car. Test applications dropped by $50 \%$ in the first lew monlts of 1997 , comparca with the 
It is because of the complex interplay of many different factors that history as a discipline has such an important contribution to make to the study of technological change. What I shall be doing in subsequent chapters is best understood as "historical sociology." In a very lucid exploration of historical sociology, Philip Abrams (1982) defines it as a project which involves, 'superimposing structure on history with a view to recovering the way history superimposes structure on us.' (p.335) Giddens also calls for an end to the separation of sociology from history:

The exclusion of time on the level of the durée of human agency has its counterpart in the repression of the temporality of social institutions in social theory - a repression effected largely by means of the division of synchrony from diachrony. On the basis of this division, sociologists have been content to leave the succession of events in time to the historians, some of whom as the ir part of the bargain have been prepared to relinquish the structural problems of social systems to the sociologists. But this kind of separation has no rational justification: with the recovery of temporality as integral to social theory history and sociology become methodologically indistinguishable. $(1979, \mathrm{p} .8)$

A straightforward history of technology, in other words, an internalist account of technical change, will be limited in its explanatory power. It is not enough to explain technology in terms of technology, ${ }^{5}$ although it is clearly important to grasp the technological trajectories pursued by firms and industries. Technological knowledge does have a cumulative aspect. For example, chemical companies, building on their experience and knowledge of chemistry, are more likely to develop new chemical compounds and possibly new ways of producing them but are less likely to invent a new mode of transport. ${ }^{6}$ There are many factors to be considered when explaining the development of new technologies - for example, the meanings ascribed by different groups, relationships of power and economics; and intellectual and personal affinity within and between groups.

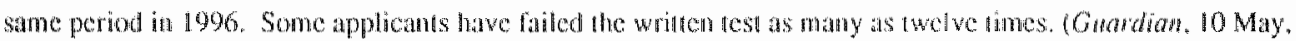
1997. Money/13) Many would be drivers are fatling to demonstrate their grasp of the complex, systemic nature of road transport which requires both tochnical competence and understanding of the social rulcs governing it.

4 One could, of course, hawe an historical sociology of deviance he family or social movennents. As far as I am aware, the only person 10 use the term in relation to STS issues is Donald Mackenzic (1990) who, in that book, is concened with techological knowledge generally and with nuclear missile guidance in particular.

I do not propose to review the debate berween historians and sociologists of technology which recurs from time to time. For those readers who are interested, please refer to Rurup (1974), Staudenmeicr (1985). Misa (1988) and issues of Techmology \& Cultwre - artickes by Butke, Danicls and Laylon (1970): and by Buchanan, Law and Scranton (1991).

3 This is despine Hobstawm's (1968) paralle entreaty that economic phenomena should be cxplained in economic terms. Single factor explanations of any social process ate rarcly adequate.

Economists of inmovation refer to this as 'path dependency" sce. for example. Tece (1988). 
I would also reject an account of technological change that focused exclusively on relations of power and domination, because then, as mentioned in the introduction to this chapter, the study of technology would collapse into general history. And, as Constant (1984) warns, ' $[t]$ he danger in these broader formulations of technological practice and change, of course, is their breadth: they lose precision by becoming too inclusive, weaving technology once again into the seamless web of history.' (p.42) As I have already suggested in Chapter 1, historians have tended to neglect the role of technology in their general accounts, regarding the history of science and technology as distinct, specialist topics. ' Yet, it is difficult to imagine how one describes the history of the United States without reference to the development of the transport infrastructure or of mass production $^{8}$; or the history of National Socialism with scant regard for the role of science and technology not only in military preparation but also in the propaganda directed at civilians and in the Holocaust itself?

The treatment of technology by historians can be inadequate; both the internalist, technicist accounts by historians of technology and the neglect by more general historians who render science and technology invisible through taking them for granted. I am not arguing only for the inclusion of technology into historical narratives, although weaving technology back into the seamless web of history would, undoubtedly, enrich our understanding of history. Historians (and, to be fair, most social scientists) have fallen prey to what David Noble (1977) identifies as the false notion that society contains all that is human and that technology must be something different and thus not human. It is important to reintegrate this mystified and mistaken conception of technology with the sociall activities from which it has been abstracted. But there is allso a need for studies of technologies - past and present - in which technology is indeed the central object. Such studies need to adopt the inclusive and narrative style of history but also need to be informed by what are generally regarded as the substantive and enduring concerns of the social sciences, questions about social structures of power and their reproduction.

Taking technology as the central object of analysis does not necessarily mean that I am privileging technical knowledge and material artefacts nor does it mean that I am denying the social nature of their construction. That technologies are socially constructed is, in fact, the starting point of my analysis of three government information systems, described in the following chapters. Thus, 1 am already convinced that technological knowledge is social through and through. Questions about how science and technology retain their

\footnotetext{
"Sometimes, in order to work up some righteous indignation. J look through ho wadoxes of history books in my

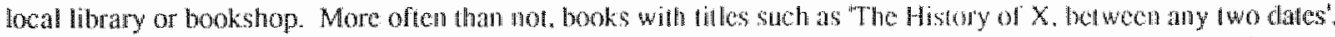
will have no reference to science or techwology at all. For example. Stanky Ekins and Erice Ackillrick (1994) in then 925 page book about ihe lasi decade of the 18 h century in the United States fand the first decade of the American Constitution) mention the cotton gin once and El Whithey not all all. Given the importance of such innovations for liberating the North from the slave system of the South. a fow pages devoted to the lopic might not have gone amiss.
}

8 Noble (1977) and Braverman (1974), however, do address these lopics at considerable lengh.

"Similarly, the book ediled by Rennebergand Walker (1994) does address these issues. 
cognitive and social hegemony and why the knowledge claims of science and technology are so rarely challenged will be left to others. I am interested here in the question of how technologies are not only constituted by but also contribute to the reproduction of social relations. Many questions are subsumed within this formulation, including:

*

Which actors are involved in different stages of the innovation process?

How do positions of dominance shift over time?

How do different actors define 'users' and relations between them?

How are these definitions mobilised in the process of defining and designing the capabilities of the technology?

Are 'real' users involved?

Are there possibilities for changing the technical system as it moves from its design phase through implementation and use, i.e. during the process of enactment?

What material artefacts are involved? How large and complex are they?

What predictable, complex and standardised functions are performed?

What social processes and norms govern and legitimate the operation of the system?

What other social processes depend on the reliable functioning of the system? What types of closure strategies are used and by whom?

Are different strategies deployed for closure in the machine and social systerns? What is the relationship between them? How is closure maintained? Is it translated into momentum or inertia?

Finding answers to these sorts of questions will enable me to attempt to answer my central question about how technologies are both socially constructed and able to attain the authority of autonomous technology, constraining and enabling different sorts of social relationships. Later in this chapter and in subsequent chapters, I will deploy a number of social scientific concepts in order to organise and analyse the answers to these questions. However, narrative history - notwithstanding the criticisms above - remains the only way of doing justice to the richness and complexity of the 'stories ${ }^{10}$ themselves. The stories I will be recounting in later chapters are about three government IT systems. I hope they are of interest in their own right. But government is a major user of IT and therefore its choices influence the nature and direction of the technology more generally; and, the ways in which governments choose to process, store and communicate information affect us all, as so much of that information is about us personally. In order to tell these stories, I have interviewed participants from different branches of government, from industry and trade unions; I have consulted govermment and private company documents. One of the advantages for the analyst of studying the public sector is that within democratic societies the public sector is accountable, not least for its treatment of citizens and its expenditure of tax revenues. As a result, much information is in the public domain. Such information would often be restricted on grounds of commercial sensitivity if it pertained to similar systems in the private sector. Private companies were involved in the development of the

10 I am not using 'story' in a pejorative way. Nor do I wish to convey, by my usc of the word. an commitment wo the post modem turn in which the world is seen as a collection of stories, each as walld as the next. By 'story' 1 simply wish to convey the notion of an account that is both readable snd colverent. 
government IT systems so it was not always possible to obtain some information, given the recentness of ewents and the commercial stakes involved. Also, the British government has less of a tradition of and commitment to openness than its US commerpert. OF course, there are also gaps in people's memories and in the published documents but it is possible to piece together a not quite complete but nonetheless coherent and consistent account: different interviewees accounts can be checked against each other and against the documentary evidence; the artefacts themselves and their attendan documents also have much to contribute to the construction of the story.

In this section, I have introduced my general approach to studying technology in this case three large govemment IT systems. I am not proposing any major methodological innovations: I shall simply be telling the best story I can, drawing on a wide range of sources. But this narrative account will be driven largaly by number of questions which owe more to the social sciences than to history for their expression and formulation. I do not wish to weigh the reader down with too many of these conceptual discussions all at once, so they will be woven into the stories when necessary. But first it is necessary to explain three decisions which have informed and guided all three of the accounts linearity, symmetry and scale - and to which I shall return in the Conclusion.

\section{Portraying technology as a linear process}

Simple linear models are widespread in the literature on technological change. Table 3.1 presents some of them, including Barras" reverse product cycle and Friedman's stages of IT development, both of which were discussed in Chapter 2 .

Bijker (1992) and Pinch and Bijker (1987) are critical of the use of linear models for understanding the development of technical artefacts. In his study of the development of fluorescent lighting, Bijker (1992) argues that stages cannot be distinguished and that even in what is commonly referred to as the diffusion stage, processes of innovation continue. In his conclusion, he states that, "ft]o understand the design process of technical artifacts, we should not restrict ourselves to the social groups of design-10om engineers or laboratory personnel.' (p.97) Indeed - but it was social construcivists themselves (of whom Bijker is a prominent member) who chose to concentrate on the early stages of the process of technological development in their concern to illuminate how facts and artefacts emerge and are stabilised. Many constructivist studies have neglected the ways in which users appropriate artefacts and how these appropriations inform subsequent developments." Realising that the construction of artefacts continues beyond the early stages of their development is not enough to justify the abandonment of linear, timedependent heuristics. On the contrary, recognition of the post-development, on-going construction of artefacts can be a valuable extension of constructivism.

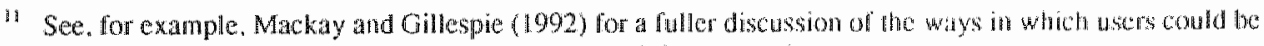
incorporaled within social shaping and social constactivist appraches. 
Pinch and Bijker (1987) criticise linear models on three other grounds. The first is that such models suggest that technology is applied science - no more, no less. This is particularly true of the Schumpeterian models summarised in Table 3.1. The idea that technology is merely applied science is also part of the explanation for the fact that the philosophy of technology is much less developed than the philosophy of science.

Philosophers focus on science - what they perceive to be the epistemological basis of technology; and therefore do not treat technology as a distinct phenomenon requiring philosophical scrutiny. ${ }^{12}$ It is now widely recognised that the relationship between science and technology is not so simple and straightforward ${ }^{13}$ but that is not a sufficient reason to discard linear models. The revelation, for some, that technologies are not only the result of applying scientific principles does not mean that linear models are no longer at all useful.

Pinch and Bijker's second criticism is that accounts of technological developments which use linear models ignore the technical content of the artefacts themselves. Again, this is not the result of adopting a linear model per se; rather it is the result of the concerns of those (economists and historians) who use linear models to explore the implications of technological change for patterns of economic growth and decline.

2 'There are, of course, philosophers concerned with technology. Some - such an Ellul and winner - have already been mentioned. Theve are others: for a review see Mitcham (1994). However, philosophy of technology does not share the lengthy indellectual hisiory nor the institutional authorily enjoyed by philosophy of science.

13 New observations in scicnce require the creation of new pieces of experimenal cquipment fior example. 


\section{TABLE 3.1: LINEAR MODELS OF TECHNOLOGICAL CHANGE}

\section{Simple linear model \\ invention $\rightarrow$ imnovation $\rightarrow>$ diffusion $\rightarrow>$ effects}

\section{Schumpeter I*}

exogenous science \& invention $>$ entrepreneurial activities $>>$ innovative investment in new technology $\rightarrow$ new production pattern $\rightarrow>$ changed market structure $\rightarrow>$ profits from imnowation (or losses) ( which feed back into entrepreneurial activities]

\section{Schumpeter II*}

exogenous science \& technology

1

endogenous science \& technology (mainly in-house $R \& D$ ) $\rightarrow>$ management of imnovative invesiment $\rightarrow$ new pattens of production $\rightarrow$ changed market structures $\rightarrow>$ profits (or losses) from innovation (which feed back into endogenous science \& technology and management of innovative investment ]

\section{Hughes (1983)}

invention $\rightarrow$ development $\rightarrow$ innovation $\rightarrow$ transfer $\rightarrow$ growth $\rightarrow$ competition $\rightarrow>$ consolidation

\section{Gükalp (1992)}

initial phase $->$ accelerated development $->$ stabilisation $\rightarrow>$ decline

\section{Mayntx \& Schneider (1988)}

new combination of existing artefacts $>>$ experimentation \& consensus building $>>$ routine operation $>>$ momentum (or not)

\section{Product Cycle Theory, Vernon (1966)}

radical product innovation $->$ incremental innovations to initial product $\rightarrow$ process innovations to enable mass production of now standardised product

\section{Reverse Product Cycle, Barras (1986)}

products imported from other sectors to improve efficiency $\rightarrow$ improvements in service quality $\rightarrow$ new services developed

\section{Intermalist history of IT}

valves $\rightarrow$ transistors $\rightarrow$ integrated circuits $\rightarrow>$ larger and larger scale integratted circuits

\section{Friedman and Cornford's history of IT (1989)}

hardware constrains -> software constraints $->$ user relations constraints $>>$ organisation environment constraints

\footnotetext{
* from Freeman (1982, pp.212-3). A distinction is usually made between the early Schumpeter (1912) and the later Schumpeter (1942). Following developments in the early part of the 20th century and Schumpeters own move from Europe to the United States, his later work gives nuch greater prominence to the in-house scientific and technical activities of large corporat ions.
} 
The third, and most serious, criticism posed by Pinch and Bijker is that linear models contribute to the teleological fallacy of unilinear technical rationality and progress. Again, I would suggest, and Pinch and Bijker themselves hint at this, that this is not the result of adopting a linear model but is a consequence of the overwhelming tendency to use such models to describe and explain the development of technical successes. Therefore, linear models can be used to reinforce the notion that the history of technology is the history of human progress. As Pinch and Bijker emphasise, it is how artefacts come to be regarded as successful that requires explanation. There is no a priori reason why linear models cannot also be used to organise accounts of technical failures, as we shall see in Chapter 5. This highlights the issue of symmetry, of accounting for success and failure in similar terms, which is the subject of the next section. Before leaving the issue of linearity, however, two points need to be clarified.

First, another advantage of narrative history, in addition to those outlined in the previous section, is that it provides a way of describing the unfolding of events over time. There is an implicit recognition of the story being a moment in a process, isolated neither from the past nor the future. The social sciences have an unfortunate tendency to isolate and abstract their stories from their historical and wider social context. Sometimes this helps to isolate issues of particular concern, but in the process the complexity and richness of human affairs is lost. Social scientists worry about 'the dereliction of method that results from excessive attention to detail' while historians worry about 'the dereliction of scholarship that results from excessive attachment to theoretical generalisation". (Abrams, 1982, p.260) The notion of 'structuration' introduced in the first chapter forces social scientists to deal seriously with time - the production and reproduction of social structures are processes in time.

Second, the linear model in Table 3.1 which best captures most of the complex, albeit time-dependent reality of the tales of developing large government IT systems recounted in the following chapters is that of Renate Mayntz and Volker Schneider (1988). This is perhaps not surprising because their approach derives from their account of the development of public videotex systems in Germany, France and Britain; systems not dissimilar from large data communication networks. Their model has the advantage of emphasising the element of bricalage involved in the creation of such systems - the novel combination of existing elements. It also includes an extensive process of experimentation and consensus building which Mayntz and Schneider attribute to the public nature of the systems. Their third stage of 'normal operation' allows for the possibility of either success or failure in achieving momentum, an important methodological advantage, because of its adherence to the symmetry principle which is discussed more extensively in the next section and because of its implicit recognition that diffusion is not an automatic and smooth process. 
Diffusion is generally used at a 'macro' level and therefore it is difficult to use it to convey 'micro' level choices and decisions. ${ }^{14}$ Diffusion also conveys a sense of pussivity and inevitability; of new technologies dispersing throughout society - some perhaps more slowly and with less ease than others - but irrespective of people's actions. It is this feature of most linear models which might be the source of Pinch and Bijker's dissatisfaction with them. Being constructivists, they are keen to emphasise the agency of people. Combining elements of the Mayntz and Schneider linear model with a more explicit sense of the difficulties of diffusion will facilitate the organisation of material in Chapters 4 and 5 about the development of large government IT systems in a manner which allows for both the unfolding of events over time and the duality of agency. Thus, my approach to understanding the development of technology, outlined at the end of Chapter 1, is becoming more elaborated as we move towards the accounts of these government IT systems.

Despite ny avowed commitment to linear narratives, I indicated in Chapter I that various conceptual and theoretical considerations will have to be introduced in later chapters. This will be done overtly - disrupting the narrative flow of the case studies presented in the next two chapters. It is necessary to place one's conceptual cards on the table and not let the excitement of the story obscure theoretical vagueness or sloppiness. Narrative contains and is contained by analysis - in part, this is my justification for accepting linear models of technological change. But sometimes one is forced to agree with Abrams when he says that, "the function of narrative...is to carry - in a highly persuasive way not accessible to intellectual scrutiny - those bits of the argument the author does not choose to make available for direct critical examination on the part of his (sic) readers.' $(1982$, p.307) Making one's arguments available for critical scrutiny remains an essential part of any intellectual enterprise.

\section{Symmetry in accounts of science and technology}

An important, albeit unresolved, methodological tenet of STS studies is, as mentioned in. the preceding section, Bloor's (1976) principle of symmetry. In the sociology of science, this means that knowledge claims which are accepted as true and those which are regarded as false are both amenable to sociological explanations; moreover those explanations must be given in the same terms. Belief in the earth's rotation around the sun and belief in the existence of unidentified flying objects must both be explained by reference to the ability of different groups to marshall political, economic and religious resources 10 support their claims. Nature itself must not be used to justify one claim rather than another: 'nature' is the result of something being accepted as true, not the cause.

It is perhaps less challenging to our learned common-sense notions of the fixity and inevitability of nature to utilise the principle of symmetry in relation to technology. In the

It I have used the terns "macro' and 'micro' here because they are part of the wocabulary of diffusion studies. Generally, however, I have tried to avoid these ferms because within STS they are, or whould he, meaningless. The point of STS is to transcend these distincions. 10 incorporate and move between content and context. 
case of technology, the principle of symmetry suggests that successful and failed machines or artefacts need to be explained in the same, social terms. Very often, asymmetrica] explanations are employed: Successful innovations are the result of their inherent and natural technical superiority; failures are the result of inadequate government support for the project or poorly targetted marketing or ignorance and prejudice on the part of consumers. Such asymmetry is not only analy tically inadequate, it is also not sustainable by reference to the historical record. Unless one adopts Bloor's symmetry principle, it is not possible to understand how steam power was known by the ancient Greeks but not widely utilised until the eighteenth century. Steam power as a means of locomotion did not become any more technically superior in the intervening centuries but the socioeconomic conditions of trade and production did change. The battle between alternating current (AC) and direct current (DC) in the distribution of electricity at the end of the nineteenth century was not won or lost on technical grounds. Despite the early lead of direct current and the unorthodox (and unsavoury) attempts by some of Thomas Edison's associates to win public and political support for DC by demonstrating the dangers of $A C$ via the public execution of animals, alternating current eventually prevailed. ${ }^{15}$

\section{Bijker (1995) provides a useful summary of the different positions found in the STS} literature on the symmetry principle, reproduced in Table 3.2. This book is concerned with technical systems, therefore it is appropriate to concentrate on the second and third columns. Michel Callon's extension of the symmetry principle has a certain playful appeal. In his version, it is no longer possible to distinguish between the social and the technical: neither determines the other. When we talk of machines or artefacts, we should be aware of the social relations involved in their construction. Equally, we should be aware of the technical and material aspects involved in the construction and maintenance of families, occupations, organisations and governments. But the price to be paid for this symmetry is high. Humans and non-humans are also treated symmetrically. Such an approach highlights our tendency to anthropomorphise machines and technomorphise ourselves (Latour, 1987); but abandoning the distinction between human and non-human means it is impossible to further our understanding of the ways in which technologies achieve obduracy; of how our world is constituted by and through the interplay of material and social relations. As Bijker (1995) indicates, this is the greatest price to be paid. Adlopting Callon's general principle of symmetry enmeshes us once again in the seamless web of history where it is only possible to recount incomplete and partial narratives. No longer will we be able to ask questions about why socio-technical ensembles take on the character that they do nor about how people can change them. ${ }^{16}$

\footnotetext{
is See Hughes (1983) for a much fuller discussion of the history of electrification. On the "butlle of the systems" see in particular. Chapters IV \& $V$

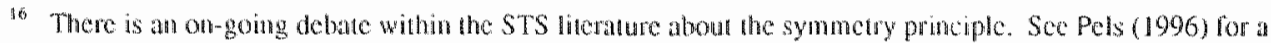
review. logether with his own assessment of the implications of successive extensions of the principle of symmetry for both public politics and the politics of knowhledge. I concentate here on the implieations of symmetry for the methodology of studying techology.
} 
This leaves us with Pinch and Bijker's (1984) interpretation of the symmetry principle, with its emphasis on the explanation of success and failure in technological innovation. Although not expressed in such terms, this principle lies behind many economic studies of innovation. For example, the first phase of Project SAPPHO ${ }^{17}$

\section{TABLE 3.2: PRINCIPLE OF SYMMETRY}

Bloor on science
$(1973,1976)$
Impartial to a
statement being
true or false
Symmetrical with
respect to explaining
truth and falsity
"Nature" is the result,
and not the cause, of
a statement becoming
a true fact

Bloor on science $(1973,1976)$

Impartial to a statement being true or false

Symmetrical with respect to explaining truth and falsity

"Nature" is the result, and not the cause, of a true fact

\section{Pinch \& Bijker on technology (1984)}

Impartial to a machine being a success or a failure

Symmetrical with respect to explaining success and failure
'Working' is the result, and not the cause, of a machine becoming a successful artefact

\section{Callon on socio- technology (1986)}

Impartial to an actor being human or nonhuman

Symmetrical with respect
to explaining the social
world and the technical
world
Distinction between the
"technical' and the "social"
is the result, and not the
cause, of the stabilisation
of socio-technical
ensembles

Source: adapted from Bijker (1995, p.275)

examined twenty-nine pairs of innovations - similar artefacts in each pair but one succeeded and the other failed. Success was defined in commercial terms, whether or not a market was established and profits earned. The purpose of the research was to identify the factors contributing to success or failure. The single most important factor distinguishing befween success and failure was whether or not user needs were understood by those developing and promoting the innovation. This is a recurring theme in studies of innovation. Awareness and comprehension of the needs of users is crucial.

In the following chapters, I too will be seeking reasons for success and failure of different government IT systems, and I will adopt Pinch and Bijker's injunction that these reasons

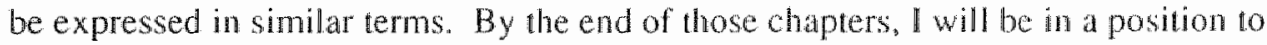

\footnotetext{
17 Project SAPPHO was one of the first projects conducted an the Scicnec Policy Research Unit (SPRU), Universily of Sussex. in the 1970s. A summary can be found in Frem man (1982).
} 
elaborate on their point that 'working' in the sense of an artefact performing pre-defined functions, effecting change on people, materials or information, is the result and not the cause of a machine becoming a successful artefact. I will argue that it is misleading to conflate 'success' and 'working' in the way that Pinch and Bijker do. The notion of 'use" will have to be introduced to make the distinction clearer. Learning the lessons of Project SAPPHO, I too will pay attention to system builders' understanding of user needs in the early stages. The innovations studied in Project SAPPHO were discrete, stand-alone artefacts; I shall be looking at large, inter-connected systems of artefacts. Both, of course, involve networks of social relations within which they are embedded. It is no longer a simple question of system builders understanding individual user needs but, when examining systems consisting of many artefacts connected together, it becomes a rather more complicated question of their appreciation of the relationships between users. But although it is more complicated, it is also more satisfying analytically. A study of larger, inter-connected artefacts brings us closer to the question of the ways in which technologies are involved in structuration. This brings us to the notion of 'scale', the final methodological consideration to be introduced in this chapter.

\section{Scale: Small may be beautiful but big is hard to define}

There may be widely shared notions of the distinction between 'Jarge" and 'small' that are used in everyday discussion and in environmental groups' critiques of technology ('small is beautiful'), but the distinction is not obvious in social scientific terms. If notions of scale are to be used in a descriptive, explanatory or prescriptive sense then greater precision is required.

Recall the parable of the four people in a dark room with a very large object. They are required to determine what this object is. The first cleclares, "It is a rapier, I can feel its smooth hardness and sharpness in my hand.' The second says, 'No, it's a pillar, I'm leaning against it." The third exclaims, 'You're both wrong. It is at rope - can't you hear it swishing back and forth?' 'The fourth shouts from on high, having made the greatest leap in the dark, "It's a very high table. I'm sitting on it." All are describing the part of the elephant which is closest to where they are standing.

Adopting the lesson of this parable, one way of defining scale would be to rely on the perceptions of the actors. Joerges (1988) illustrates both the applicability of the parable for studying large technical systems, and its inadequacy, using the example of the telephone system. As domestic users, we might experience the telephone as a small device in the corner of our living rooms or hanging on the kitchen wall. We might not even recognise it as a technical artefact, much less as part of possiblly the largest functioning technical system in the history of the world. Telecommunication engineers might recognise its vastness and technical complexity but not its social and political significance.

18 Like most parables. this one raises more questions than it answers for the literal-minded. How does one get an dephont to stand still in al dark room with four strangers? 
Politicians, particularly since the break-up of AT\&T and the westem privatisation craze of the 1980s and 1990s, will be aware of the regulatory and competitive complexities but only dimly aware of how their national telephone system actually works. Each of these actors, if asked, would assess the scale of the telephone system very differently.

Another approach would be to define scale in terms of the size of the dominant organisations involwed in the operation, maintenance or regulation of the technology. But that would raise the economists' perennial. problem of how best to define large and small organisations: by market share? number of employees? tumover? Continuing with the example of the telephone system, the US system would apparently have become smaller following the legal and organisational dismantling of AT\&T.

A thind approach would be to focus on externalities ${ }^{19}$ - the scope of a technology's impacts on social and/or natural environments. The awailability of telephones has affected company's location decisions and maybe family members decisions to move away from home. How does this affect our understanding of the scale of the telephone system? Moreover, what are externalities, but poorly defined impacts or impacts for which no one accepts responsibility?

Another approach, related to the above and implicit within some of the public debates about "big technologies", is to equate large scale with riskiness, especially environmental risks. Technologies of power generation and transpont are most susceptible to this approach. Arguably, the environmental risks of the telephone system are relatively insignificant ${ }^{20}$, but is that sufficient reason to define it as a small technological system?

Joerges (1988) argues that all of these approaches on their own are unsatisfactory. Furthermore, there is a danger of conflating different aspects of "largeness" which need to be kept separate in order to distinguish between different sorts of systems. Each aspect of scalle has a role to play in understanding the dyamics of processes of technological development and change. He suggests that it is necessary to relate largeness to the technical core, and thus equates scale with the complexity, speed and rate of growth of the activities performed by the technology and with the quantity of the social processes needed to perform them. The latter includes, for example, the legal regulations and technical norms governing their operation and use. Joerges defines large technical systems

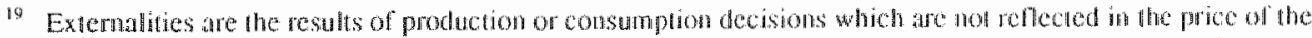

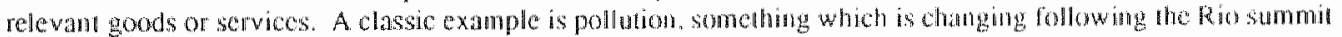

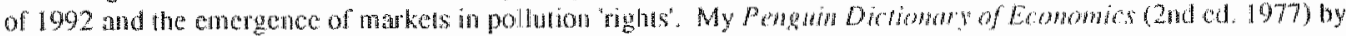

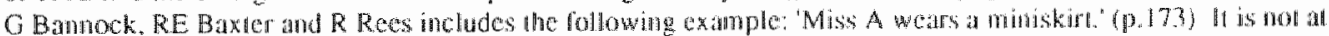

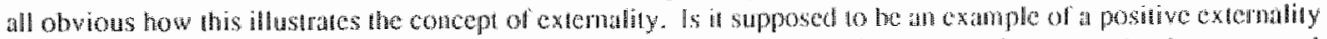

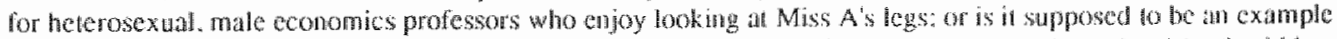

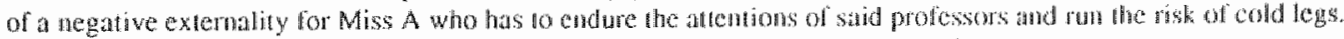

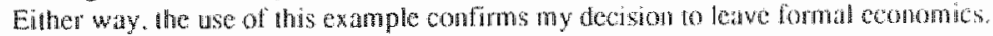

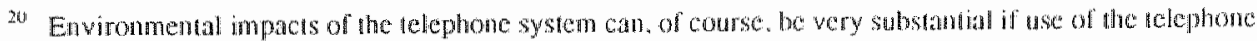

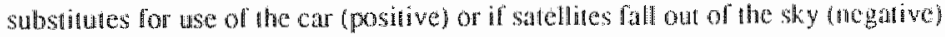


as, systems of machineries and frestanding structures performing, more or less reliably and predictably, complex standardized operations by virtue of being integrated with other social processes, governed and legitimated by formal. knowledge-intensive, impersonal rationalites. The guiding idea in determining the scale of such systems would then be to determine (a) the relative quantity (complexity, speed, rate of growth, etc.) of activities materialized in such systems, and (b) the quantity (complexity, speed, rate of growth) of other social processes necessitated by (a) in order to function. (1988, pp.23-4)

There is a hint of technological deteminism, of autonomous technology in this definition, which comes through in the ordering and wording of (a) and (b). Nonetheless, it remains a useful defintion, not least because it draws attention to the social processes involved in the functioning of the technical systems, if not explicitly to those social processes involved in their development.

Joerges goes on to offer examples of what he does and does not regard as a large technical system. $^{2}$ Fol example, he suggests that water supply, telecommunications, and military defense systems are large technical systems, but manufacturing technologies, arms production and administrative IT systems are not. Nor are the Channel tunnel and the Sizewell nuclear power station large technical systems, although they could be called large technical projects, and when complete they become part of the large technical systems of, respectively, road/ rail transportation and electricity supply.

The UK Department of Social Security's 'Operational Strategy', the focus of the next chapter, was ofen referred to as the largest civilian IT project in Europe. It was rarely specified in precisely which sense it was the largest I do not propose to offer a neat definition of technological scale, I have simply attempted to indicate that there are a variety of ways of so doing. In the next two chapters, thee government IT systems will be described. The scalle, in several senses of the term, of these systems is important for understanding their development and use. In the following chapters, different notions of scale will be used to describe the thee IT systems. By the final chapter, It will be able to clarify sone of the ambiguities of the concept as I have discussed it here. Only then will we be able to explore the implications of targe and growing technological scalle for other social phenomena, including for the specific social practices in which the technologies are both constituted and constintive.

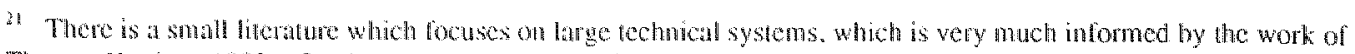
Thomas Hughes (1983). Sec Mayly and Hughes (1988). La Ponte (1991) and Summerton (1094). 


\section{Conclusion}

The stories are waiting to be told. The first - the Operational Strategy of the British Department of Social Security - pushed itself into the previous paragraph. Clearly it is time to turn from discussions about how to describe and analyse technology to the descriptions and analyses themselves. In this chapter, I have effectively set myself four constraints on how these accounts should be presented: incorporate a wide range of factors, adopt a linear narrative, specify scale and scope of the systems and adopt principle of symmetry with regard to explaining success and failure. Of course, constraints can be contradictory: they can also liberate. First, they will be multifaceted. I will not confine myself to technical or economic or political factors in attempting to convey the richness and complexity of the development of three large government IT systems. Awareness of the full range of social and technical factors is required. A second constraint is that the conventions of narrative history will be adopted. The unfolding of events in time is a useful way of organising accounts but, more importantly, the process of structuring occurs in time, as well as in space.

One way I have made life easier for myself is through my choice of middle range technologies. The third constraint of specifying different aspects of the scale and scope of the systems does make the organisation of the stories more difficult. There is an advantage in analysing these large systems, however, because systems involving a range of artefacts and organisations and knowledges bring to the fore my concern with the duality of structure. The fourth constraint is that success and failure have to be analysed in the same terms: recourse to explanations of the variety, 'it just did not work", will not be allowed. Incorporating two stories of failure provides a stronger test of the symmetry principle, which we shall re-visit in the final chapter. 


\section{CHAPTER 4}

\section{THE BRITISH OPERATIONAL STRATEGY}

\section{Introduction}

In 1986, I became unemployed. I was 'between' research contracts. I went to my local unemployment benefit office, a dingy place with peeling paint and harassed staff. There were very high levels of unemployment in Britain at that time, so there was a long wait. I went on a Thursday because that was the day they dealt with people whose last name begins with ' $W$ '. That way, they could ensure all the files had been retrieved from the basement in preparation for the onslaught of unemployed ' $W$ 's. Questions were asked about my plans for seeking further work in the field of technology policy research; lengthy forms were completed. Demonstrating an unusual lack of concern for my own financial self-interest, I was glad I was not eligible for any social security benefits because then I would have had to make more visits to other depressing offices. I eventually received a computer-printed payment book but the payments could only be cashed at my local post office.

Today, should I become unemployed, I would first go to my local Job Centre to register as unemployed. Only then could I go to an Unemployment Benefit Office to claim my unemployment benefits. If I was also eligible for income support or housing benefit, I would still have to go to my local Department of Social Security (DSS) office. In these offices, I might find something very different from what I had experienced a decade earlier. Questions would be asked and forms would be completed but the data entry and processing might be done elsewhere in the country. On later visits, I could go on any day of the week because my records could be accessed on-line. If I needed to telephone, I would dial the local number I had been given but would be connected to someone working in an office in Wigan, Belfast or Glasgow. If I wanted, payment could be made directly to my bank account. These changes over the past decade have been made possible by the implementation of the Operational Strategy, an enomous civil government computing project, initiated in the late 1970 s.

This chapter explores how these changes occurred. The cast is first introduced, including a brief characterisation which seeks to indicate their interests and goals. Then I turn to the project itself, explaining how it unfolded over time. There are a number of theoretical intervals. After introducing the cast, the notions of relevant social groups and their problems and imterests are explored. During the account of the project, the concepts of imterpretative flexibility and closure are examined. These concepts also have a role in this account because they help to make sense of a highly complex process of technical development. Some othel concepts atre already hovering in the wings, shadowy background figures at the moment, making their presence felt in the organisation of the narrative; but they will not be brought centre stage until later chapters. Human actors, material artefacts and linguistic devices are all important in recounting this STS-informed tale of the Operational Strategy. The account below concentrates on what occurred during the $1980 \mathrm{~s}$, so it is first necessary to provide some background information about the 
delivery of social security payments in the UK. The reader should bear in mind Philip Scranton's useful reminder about the purpose of such scene setting: "We do not simply find the right theatre in which to mount our dramas; instead we build it. In so doing, we make (usually implicit) claims that our construction is appropriate, that the things we left out are irrelevant, and so forth.' (1994, p.152, emphasis in original)

\section{A very short history of social security in the UK}

The British social welfare system has emerged over the past 150 years. Within its elaborate regulations and codes can be found traces of the nineteenth century poor laws, the pre-World War One national insurance system and the post-World War Two welfare state. Welfare payments have been administered and delivered using vast numbers of clerical workers. This clerical system has been subject to numerous ad hoc clarifications and amendments over the years.

The Department of Social Security (DSS) is one of the three largest central government departments in the UK, together with the Inland Revenue (responsible for collecting taxes) and the Ministry of Defence. 'They can be considered large along the usual range of indicators: employment, budget and also IT expenditure. During the 1980s and 1990s, approximately twenty percent of civil administration employment was in the DSS; and, social security payments (including unemployment benefits) have accounted for between one third and one half of all government expenditure (CSO, 1990, 1997, 1998).

The Department of Health and Social Security, as the DSS was formerly known ${ }^{2}$, was established in the post-war period following the publication of the Beveridge Report (1942). The terms of reference given to Lord Beveridge were to make recommendations regarding:

* a system of children's allowances;

* a comprehensive health service; and,

* full employment (not addressed in the 1942 report).

He proposed a system of social security to provide higher unemployment benefits, children's allowances, medical attention and pensions. These were to be financed from individuals' and employers' contributions from income (now known as National Insurance contributions). The objective was to prevent an individual's income falling below subsistence level. The Report provided the basis for the Family Allowances Act of 1945 and the National Health Service and National Insurance Acts of 1946. The Beveridge Report is widely regarded as having provided the foundations for the welfare state in the

\footnotetext{
1 The three departments are refered to by colleagues in smaller deparments as the "ugly sistors".

2 Prior to July 1988, there was a joint Department of Healih and Sociall Securily. Provision of heallh care and provision of social security were always quite distinct even when formally part of the same deparment, particularly with respec to the ir information technology strategies. For case of feading. I refer to the 'DS5' throughout this account.
} 
UK, and was an essential element of post-war, pre-Thatcher consensus politics. ${ }^{3}$ The system now incorporates both contributory benefits (including pensions, unemployment and sickness benefits) and direct state-funded payments (including disability allowances, income support, child and housing benefits). The administration of social security in the UK is highly centralised. Although payments are administered locally, all policy decisions are taken centrally, including policy decisions regarding the use of information technology.

The history of IT within the DSS has not been an entirely happy one. It is summarised in Table 4.1 . In the early 1960 s, the government began to plan for the computerisation of social security benefits. Large mainframe-based computer centres were to be established at Livingstone, Crewe, Peterborough and Reading. The Queen officially opened the Reading installation in 1968, but in 1969 it was announced that there would be no firm starting date.

3 Detailed analy sis of the history of the wellare state can be round in Clarke. Cochme and Smant (1987). 


\section{TABLE 4.1 COMPUTERISATION OF SOCIAL SECURITY: CHRONOLOGY OF MAIN EVENTS}

1973 Reading Computer Centre established

$1976 \quad$ Newcastle and Livingstone Computer Centres established

1977 CAMELOT begins

$1980 \quad$ A Strategy for Social Security Operations published

$1981 \quad$ CAMELOT abandioned

$1982 \quad$ 'Operational Strategy' launched

- 14 projects, estimated cost of $2700 \mathrm{~m}$

1984 May Newcastle strike begins

1985 Jan Newcastle strike ends

1986

Development work transferred from Reading to Lytham St Annes

1987 Feb Six week strike at Lytham Computer Centre by senior programming staff

Apr Rolling strikes by public sector IT staff begin; Eric Caines appointed Director of OS

Apr Social Security Refom Act

July Rumours of privatisation following Luxton report; Increased use of consultants to meet deadlines

1988 Feb New Technology, Job Design \& Organisational Sma published

May Business of Service (Moodie report) published

Oct Pilot evaluation study begins

1989 Mar Pilot offices go on-line

July Official cost revised to $£ 1.7 \mathrm{bn}$

Contract awarded to EDS to run Livingstone Computer Centre

Oct National roll-out begins

1990 Apr $^{\circ}$ DSS divided into five agencies - Information Technology Services Agency (ITSA). Benefits Agency, Child Support Agency, Contributions Agency, Resettment Agency

1991 July Roll-out completed 
Progress during the 1970 s was better. A national computer centre for the DSS was established, split between Reading (opened in 1973) and Livingstone (openedin 1976). The sites provided a database for recording information on unemployment and supplementary benefits. In 1976, a computer centre was also created in Newcastle which recorded details of old age pensions, child benefits and the pay of DSS employees. Two years later, a limited index of National Insurance contributions and social security benefits was introduced.

In 1977, the Government announced the start of development work on the Computer Aided MEchanisation of Local Office Tasks (CAMELOT). Local office tasks such as payment, processing and record-keeping were to be automated. It was a very ambitious project for its time, aiming to construct a national data network to link together all local offices. CAMELOT was abandoned in 1981 at a cost of six million pounds. A later investigation by the Central Computer and Telecommunication Agency (CCTA) identified the following problems:

* over-ambitious plans given the extant technology;

* inadequate project control and planning; and,

* a shortage of skilled programmers.

A further problem experienced by the DSS was that turnower of its clerical staff was very high, with a national average of $20 \%$ annually, and $100 \%$ in some parts of London (PAC, 1989, p.viii). Just as Morgan-le-Fay threatened Camelot, these problems would continue to haunt the DSS as it launched the even more ambitious Operational Strategy in the 1980s.

The scene is set. In the late 1970s, the majority of DSS activities were conducted manually. There were no computers in local offices, which were organised benefit by benefit. Different staff dealt with contributory and non-contributory benefits in different parts of the office. As a result, records were replicated, on average, more than five times per claimant. In a typical DSS office, there were 48 places where a claimant's file could legitimately be held. The same information could be recorded up to thirteen times. (Fallon, 1993, p.xi) Further problems were created by the proliferation of non-standard forms. There were estimated to be 8,000 internal and 12,000 external forms. Handwritten files were the norm. Error rates were very high. (Dyerson and Roper, 1989) The next section introduces the cast of characters who attempted to improve this situation during the $1980 \mathrm{~s}$.

\footnotetext{
4. 'Incone support" payments replaced supplementary benelits" in 1987. Both anve the funcion of providing a sately net for people on wery low incomes. The significance of the legislative chamge which brought about this substitution is discussed more fully later in the chapter.
} 


\section{The Operational Strategy: The Cast}

\section{Management at the Department of Social Security (DSS)}

The DSS was responsible for planning monitoring and implementing the Operational Strategy. Two senior committees oversaw the Strategy: the Social Security Management Board, a permanent high level committee and the Operational Strategy Strategy Committee. On a day-to-day basis, the Operational Strategy Directorate planned, developed and controlled the variety of projects that constituted the Sirategy. Each of these three committees was officially committed to the stated ojectives of the Operational Strategy which were to:

1. improve operational efficiency, achieve savings in administrative costs and increase flexibility to respond to changing needs;

2. achieve substantial improvements in quality of service to the public, for example by treating claimants in a less compartmentalised benefit-by-benefit manner as described earlier and more as "whole persons", and by improving the provision of information to the public; and,

3. provide more satisfying jobs for staff. (DSS, 1980)

However, during the course of the project, and under pressure from the Treasury, the Public Accounts Committee, the National Audit Office and the Conservative Government, management within the DSS became increasingly focussed on the first objective only.

\section{Technical staff at the DSS}

The initial intention had been to develop the Operational Strategy using internal expertise. At the height of the development in 1987, however, the development team consisted of approximately seventy-five internal staff, a similar number of contract progranmers and approximately forty consultants from Arthur Andersen. Management was largely exercised by civil servants with help from consultants. Contractors did much of the programming. The use of external staff facilitated the completion of the development work, albeit at a high level of work intensity, but it provoked mixed feelings amongst internal programmers. On the positive side, contact with contractors and consultants gave internal staff access to both project management skills and a wider range of experience with large IT projects. On the negative side, outside staff earned between four and five times as much as internal DSS employees. The implications of using so many external workers for the costs of the Operational Strategy, its timing and its fit with internal DSS procedures are discussed later.

Local office users, the huge numbers of clerical workers who would be using the system to deliver benefits to claimants, were not involved in the devellopment process. Some local office technical staff were co-opted onto development teams but staff with recent experience of the core activity of the DSS were not. Testing of applications was done by other technical staff not directly involved in the particular application; nor were they involved in the daily activities of local office staff. Dyerson and Roper (1989, pp. 14-5) report the example of the 'suspend' key which would have enabled users to move between 
functions. This was lost in an application up-grade because of the lack of awareness by the programmers of the importance of such a function for staff who regularly move between activities.

During the pilot period, the training offered to local office staff was undifferentiated, reflecting the view of the development team that all users are the same. The experience of the pilot period demonstrated the fallacy of that view and subsequent training was tailored more to the needs of different groups of staff. Only during the roll-out period between 1989-91 did technical staff visit local offices.

\section{The National Union of Civil and Public Servants (NUCPS) and the Civil and Public} Servants Association (CPSA) ${ }^{5}$ were the major unions involved, representing local office staff. The First Division Association represents very senior civil servants, such as those people on the most senior management committees mentioned earlier; it did not engage in any public discussion about the Operational Strategy. NUCPS and CPSA, however, published two reports during the 1980s (SCPS, 1987 and 1988). They were concerned with the more than 20,000 jobs $^{6}$ the Operational Strategy required to be lost if it was to achieve the expected financial savings. They expressed concern not only for their members' jobs but also for the implications of such job loss for service quality. The union did not express hostility to the rechnology per se, but rather to its use to cut jobs.

At the same time, there was a general Government policy to restrict public sector pay. Within the public sector as a whole, it has been difficult to retain IT staff because of the relatively buoyant external, highly paid labour market in the IT field. There is a constant shortage of skilled IT staff within the public sector and the DSS. This is one of the reasons why so many external contractors were used, ironically leading to increased expenditure on staff.

The Treasury (what is often called the Ministry of Finance in other countries) is not one of the largest government departments, but it is certainly the most powerful. Its officials work with the Chancellor of the Exchequer to set the annual budget for the country. All large capital projects to be undertaken within central government must be approved by the Treasury. For IT projects, such as the Operational Strategy, it takes advice from the

\footnotetext{
On Janury 1. 1988, the Sociony of Civil and Public Servants (SCPS) merged with the Council for Civil Service Unions (CSU) Io form the National Union of Civil and Public Servants (NUCPS). In 1993. the National Union of Puthlic Employecs (NUPE), the Council of Hoalth Service Employess (COHSE) and the National Association of Lown Governmem Ofhces (NALGO) meged to form UNISON (an anagram of unions). now the largest union of public sector employees. In 1997. NUCPS merged with the Indand Reveme Stafl Federation (IRSF) to torm PTC. Public Services. Tax and Commerce Unono.
}

This represented nearly $20 \%$ (20,000 of 108,000$)$ of the totall DSS workforec. The 1989 NAO report demonsirated how sensive the financial sumgs were to variations bin job loss. The NAO also indicated that the DSS had failed to take into accoun increased demand for social security benclits which occurred throughout the 1980 sand the costs of making staff redundant if job savings could not be achicved via natural wastage. A shortall in job loss of 3432 jobs would put the Strategy in danger of not breaking even by $1998-9$. 
CCTA. The major objective of the Treasury during the 1980 s was to reduce public borrowing and to achieve a high level of value for money in public spending.

The Central Computer and Telecommunications Agency (CCTA) began in 1972 and formally became part of the Treasury in 1981, although the CCTA continues to occupy a separate building away from Whitehall. The CCTA's primary responsibility is to ensure that government departments receive value for money in their IT purchases. Following criticism from the National Audit Office of the ability of the management structure of the Operational Strategy to exercise adequate project control, responsibility for the financial control of the Operational Strategy passed directly to the Treasury. The CCTA continued to provide technical advice, assist in drafting tenders and contracts. It remains responsible for promoting technical standards within the public sector as a whole. The CCTA was represented on the three DSS committees mentioned at the beginning of this section, but financial oversight was conducted by the Treasury itself.

The National Audit Office (NAO), which employs approximately 900 staff, is independent of Government. It certifies the accounts of all Government departments and a range of other public sector bodies. It has the statutory authority to repont to Parliament on the economy, efficiency and effectiveness with which departments and other bodies use their resources. During the 1980 s, the NAO published three major reports regarding the delivery of social security benefits (NAO, 1985, 1988 and 1989) and one focusing on administrative computing in govermment more generally (NAO, 1984).

The Public Accounts Committee (PAC) is a Parliamentary committee, composed of sitting Members of Parliament from all political parties. It examines public expenditure in which task it is assisted by the NAO. The Committee has the authority to summon Ministers and civil servants to answer its questions regarding public spending.

Throughout the 1980s, social security spending in general and the Operational Strategy in particular were scrutinised regularly by PAC. Four reports were published during this period (PAC, 1983, 1986, 1988 and 1989).

\section{Private IT suppliers}

The final estimated cost of developing the Operational Strategy was approximately two billion pounds. Just over half of that was spent on computer and telecommunication equipment and software (PAC, 1989). In itself, this was a lucrative market opportunity for the suppliers of IT hardware and software. Moreover, there was an expectation that at some point in the future, IT operations at the DSS, and elsewhere in government, would be privatised. Thus, private suppliers were keen to be involved in the Operational Strategy, in the belief this would help them to secure contracts to deliver IT equipment and services to the DSS in the future. Major suppliers of the Operational Strategy included ICL, BT, Honeywell, Hewlett Packard, Image Data Systems, Apricot, Logica and the Universities of

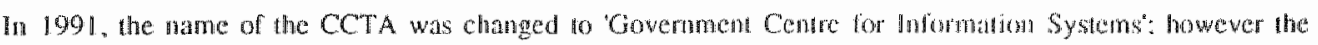
abbrewation of 'CCTA' was kept because il was widely known. 
Lancaster and Surrey as well as Imperial College. In July 1989, a contract was awarded to EDS (Electronic Data Services) to run the DSS computer centre in Livingstone.

\section{Consultants and contractors}

Private consultants were used extensively in the design and project management of the DSS. Contractors were also used in software development. Contractors are the equivalent of temporary office help, but for programming. The use of these forms of external labour, particularly consultants, was a highly contentious issue, discussed at greater length below. Arthur Andersen was the firm of consultants most involved.

The Conservative Party, under the leadership of Margaret Thatcher, was elected in May 1979 (and under John Major was spectacularly voted out of office in May 1997).

Throughout the 1980s, the Conservative Government was committed to achieving a stable monetary environment through, inter alia, the reduction of public sector borrowing. In addition, it wished to reduce the power of trade unions, particularly public sector unions. During this period, a strong thetoric against what Thatcher pejoratively termed the 'nanny state' emerged. This was part of a wider rhetoric against public services generally, in which they were characterised as intrinsically inferior to services provided by the private sector. During the period of Conservative rule, unemployment increased as did the number of people living below the poverty line (defined as half of average income). This led more people to demand social security benefits. In 1976-77, 241 billion was paid in social security benefits; this more than doubled to 288 billion in 1994-95 (in 1994-95 prices). (CSO, 1996)

The views of citizens were never directly sought during the development of the Operational Strategy. This did not prevent some of the groups above from claiming to speak in the name of citizens. The Conservative Party, the Treasury, PAC and the NAO all claimed to speak on behalf of citizens as taxpayers. This provided legitimacy for the emphasis on "vallue for money" which was indeed one of the three aims but it was stressed by these groups to a greater extent. The unions and the NAO $(1989, p .4)$ reminded the DSS of the other two aims, namely improving the quality of service to the public and improwing the quality of working life of DSS staff. Independent research commissioned by the DSS sought the views of welfare rights groups, and concluded the following:

[T]he public would most welcome from the DSS a service which offers the highest standards of speed and accuracy in the processing of claims. In addition they would want to be provided with the fullest information about benefits in order to be able to claim all that they are entitled to, and to have confidence that an approach to the DSS would trigger off claims for other benefits for which there is a potential entillement. They would wish to be able 10 understand clearly how decisions are reached. There was overwhelming support for the notion that staff should deal with claimants with courtesy and understanding, and assess claims with impartiality. In

8 EDS is now an independent, private company, hut began as a subsidiary of Gendal Molors. It is owned by Ross Perot. 
the local office claimants should be dealt with prompty and, on request, have their business conducted in private. Being of service also entaled the provision of clean and comfortable waiting areas. (Adler and Sainsbury, 1991, pp.18-9, emphasis in original)

\section{Relevant social groups - problems and interests}

The description above of the different groups involved in the development of the Operational Strategy hints at some of the events and issues that were later to emerge. Before exploring these more fully, it is time to reflect on the concepts of relevant social groups, their problems and interests. Bellamy (1993) suggests the groups described above can be divided according to their relationship to the development of the Operational Strategy. On the one hand, there are the producers of the Strategy centred around the technical staff within the DSS, the outside consultants who worked with them and the private companies which provided the hardware and software. On the oher hand, there is a more user-oriented group which accepted formal responsibility for integrating the Strategy with the responsibilities and procedures of the DSS. This also included some management consultants but was focused around the 'generalists' in the management and operations groups. Bellamy also points to the emergence of an number of groups, overlapping and intersecting with both of the above, which grew around particular subprojects competing with one another for resources. But there is also a third group, overlooked by Bellamy, with no direct relationship of its own to the Operational Strategy but which was often invoked by proxy as both producer or user. The producers of the Strategy deployed citizens as taxpayers to emphasise the role of the Operational Strategy in improving the efficiency of the DSS. Some of the users, however, deployed citizens as claimants, indirect users of the system, more interested in quality of service.

It is the construction of this third group which highlights some of the limits of Bellamy's neo-plurallist analysis of the emergence of policy networks in the development and implementation of the Operational Strategy. She assumes that public policy emerges from a process of competition between the conflicting needs, values, and priorities of those interests which control the resources necessary for policy issues to be recognised and resolved.' (1993, p.1) She recognises the importance of uneven access to resources, including technology and technical expertise.

This type of analysis exhibits at least four problems. First, technology is treated simply as a resource, and not as constituted by and constitutive of the social groups, or policy communities in Bellamy's terminology. Second, her distinction between producers and users of the Strategy is not one widely used by the actors themselves. Third, it is unable to incorporate 'invisible' groups - in this case, citizens as claimants or taxpayers as mentioned above. Finally, 'interests' are characterised as objective, autonomous entities.

By now it should be clear how I would address the first problem. One of the starting points of this book is that technology is not some neutral object, developed outside of any 
social context. The society-techrology relationship is discussed extensively in Chapter 1 and will be returned to in the Conclusion. In the remainder of this section I focus on the other problems - the identification of relevant social groups and their problems and interests.

Bijker (1995, pp.45-50) clearly outlines the way in which social constructivist analyses of technology conceptualise and identify relevant social groups. The most important feature is that relevant social groups are relevant for both the actors and the analyst. Although actors may not use the term, they utilise the concept to organise their world. Thus, Bijker argues, simply by 'following the actors' it is possible to build up a picture of the groups. engaged in the construction of a technology. The groups engaged in the development of the Operational Strategy, described earlier in this chapter, were identified through reading official reports, press accounts and through interviewing some of the people involved. After a period of time, no new groups emerge and the analyst can feel confident that they have obtained a full list of the characters. There are two advantages to this approach which, it should be emphasised, is simply intended as a heuristic and not as a formulaic methodology; a point to which I shall return in the next Chapter and in the Conciusion. The first advantage is that following the actors makes it more difficult to fall into the trap of giving a Whiggish account because grappling with the actors' versions of problems and events makes visible the constructive nature of both the actors" and analysts" accounts. Secondly, this approach can render visible the powerless and voiceless groups - not necessarily by giving them a voice which they may not have had, but by including them in the cast. For example, citizens as taxpayers or claimants did not have an independent voice in the clevelopment of the Operational Strategy, but they were an important social group which was constructed, deployed and recognised by others." In the later accounts of the development of government networks in the UK and the US, there are also groups with no direct voice of their own but who are essential for understanding the development of those networks.

These voiceless groups are used by others to further their own interests. The treatment of interests is more difficult, and remains unresolved within the sociology of technology as well as within social and political theory more generally. In the early $1980 \mathrm{~s}$, there was a debate in Social Studies of Science about the explanatory power of 'interests' (MacKenzie, 1978 \& 1981; Woolgar 1981a \& b; Barnes, 1981; Callon, 1982). There are two issues on which I think constructivists can agree. First, "to construct an "interest" is a slow historical process, which takes place through complex ideological, discursive and institutional practices. ... "Interests", then, are a social product. (Laclau and Mouffe, 1987, p.118) Second, like social groups, "interests' is a category used by both actors and analysts. But, unlike social groups, this symmetry creates more confusion than clarity. Much of the debate about interests stems from this blurring. To avoid entering the theoretical debates about cause and effect or social and individual determination, 1 shall follow some other social constructivists of technology (Bijker, 1995; Callon, 1987; Hughes, 1983) who use

\footnotetext{
9 One group thave omited, which did play a minor role. is rural postmasters and posimistresses. The cashing of benefit and pension payments was a large part of their activity. They were concence with the plans to increase the wumber of payments made by direc bank transfer.
} 
"interests' as an actors" category and some variant on "problems" as an analysts' category. Many constructivist accounts of technological developments make passing references to 'vested interests' or "conflicting interests'. This is done to aid the narrative flow, and will be done below. Focusing on 'problems' helps the analyst to understand how the technology is seen by the social groups. Problems are, however, also an actors' category. Engineering is often defined as a purposeful, problem-solving enterprise, in which the problems are both social and technical. For analysts, facusing on problems, those moments of disjuncture, helps to illuminate the social nature of technological development by drawing attention to the choices made and the paths not taken when problems were solved.

In the development of the Operational Strategy, the Treasury had the problem of reducing public sector bortowing; the technical staff faced the problem of delivering a working system to a deadline; the unions had a potential problem of one in five of their members losing their jobs. The articulation and resolution of these problems all influenced the way in which the Operational Strategy unfolded as shall be seen in the next section.

\section{The development of the Operational Strategy: Part 1, 1977-86}

In earlier sections of this chapter, I outlined some of the background within which the Operational Strategy was developed and introduced the groups involved. This section summarises the development of the Operational Strategy between 1980 and 1986. This is necessarily a partial account, reconstructed largely through documentary sources. ${ }^{10}$

When discussions began about the Operational Strategy in the late 1970 s, batch systems were held in Newcastle, North Fylde and Livingstone which were updated from paper records sent from local offices. Each benefit - such as child benefit, supplementary benefit and pensions - was held separately. Local offices did not have on-line access to these systems.

In 1977, the Labour Government, under the premietship of James Callaghan, initiated a review of the problems facing the delivery of social security benefus. As mentioned earlier in this chapter, three key ams were stressed, including reduced administrative costs, improved quality of service to the public and increased job satistaction for DSS employees. Costs would be reduced by integrating different benefits, eliminating many of the lowest level clerical jobs and automating the calculation of benefits. Quality of service would be enhanced by reducing error rates and turnaround times. In addition, the integration of different benefits would eliminate the need for separate queues and sometimes even separate offices for contributory and noln contributory benefits. Long queves and high error rates were not only frustrating for clamants but also contributed to

10 Interviews were used much more exsensively as a means of collecling data in the re-constructuon of the development of the GDN and FTS2000, described in the nex Chapter. Some matcriat retevant to the Operational Strategy was gathered during the courst of the GDN research, as many of the groups ate the same. 
low staff morale for those staff who had to cope with angry citizens. Thus, the integration of different benefits was central to the achievement of all three aims.

The preliminary report published by the DSS in 1980, A Strategy for Social Security Operations, expressed concern about rising administrative costs but it assumed that the three major aims - cost reduction, service enhancement and improved job satisfaction could be met together. Much of the report was devoted to exploring ways in which services could be improved, especially via the provision of advice and information to claimants and the integration of benefits. It recommended consultation with local office staff and the establishment of a joint committee with the unions. The foreword to this study was written by Patrick Jenkin, the Minister for Social Services in Margaret Thatcher's first cabinet. The Government was, he wrote, 'determined to make substantial savings in administrative costs and to ensure that the resources released in this way are used in the public interest in the wider sense' (DSS, 1980, Foreword). The main report placed claimants first, assuming happily that the integration of benefits would not only benefit claimants but also result in reduced costs. Jenkin, however, put taxpayers first. For him, the three aims were not equal: cost reduction was the priority. At a DSS management seminar in 1983, a junior social security minister 'stressed that the strategy' was about operations, not about the benefit system itself' (DSS, 1983).

The 1980 report recognised the imminent collapse of the ambitious CAMELOT project and stressed the importance of adopting an incremental approach in any future efforts at local office computerisation. Social Security Operational Strategy: A Framework for the Future was published by the DSS in 1982. It set out the approach to be adopted in the technical and organisational configuration of the system and identified fourteen projects, summarised in Table 4.2. The projects can be divided into those projects that are centrally administered and those that deal with contributory and non-contributory benefits."

As already mentioned, prior to the Operational Strategy, the technicall facilities available to the DSS consisted of a number of mainframe computer sites to which local offices sent paper files. Data from the paper filles was entered manually. It was a batch processing system, not at all uncommon at that time. The 1982 document proposed a system organised around a common database, accessible in real time, consistent with the commitment towards greater integration of benefits. The social security system was organised around more than thirty different benefits, each with its own legislation, administrative code, application form, eligibility rules, payment method and payment cycle. The strategy proposed by the Operations Group, composed largely of general DSS managers and advised by external consultants, was to develop a network. This was resisted by internal technical staff, who were familiar with and committed to batch processing and mainframe computers. They argued that the transition to a fully networked, distributed system would be too difficult, as the costly CAMELOT experience had demonstrated.

11 Contributory benefits are calculated aconding to onc's own contributions through taxation and/or national insurmace. Non-contributory benefits are those which ond receives lhecause of one's state of being, such as disability allowances. 


\section{TABLE 4.2: PROJECTS IN THE OPERATIONAL STRATEGY}

\section{Centrally administered projects}

Infrastructure: The Departmental Central lndex

- to store information on national insurance numbers and benefit claims for the entire population

- to be administered in Newcastle but accessed by all local offices

Specialised benefits, such as war pensions

- to be administered centrally by the North Fylde Centre

Contributory benefits: Pensions and unemployment

- two projects to upgrade the system used to calculate, record and pay retirement pensions (to be transferred from the Department of Employment to the DSS)

- three projects to improve the payment of unemployment benefits

Non-contributory benefits: Income, incapacity and child support

- two projects to assess, record and pay the universal child benefit

- one to calculate and pay incapacity benefits

- four projects to introduce computers in local offices

- to provide advice to the public

- to calculate supplementary benefit (income support), automate direct payment of fuel bills and facilitate location of files (stand-alone systems for llocal offices)

- to assess the payment of supplementary benefit (pilot project for on-line access to regional systems which would calculate benefits and arrange payment)

- to pay supplementary benefits 
A compromise was reached to work towards creating a hierarchical structure in which approximately 35,000 terminals in 1000 local offices would be linked to one of three area computer centres. These would be linked to the mainframe at Newcastle which would maintain the Central Index, mentioned in Table 4.2, holding data on all benefits by National Insurance number. Area computer centres would process benefit claims. Local offices would no longer undertake claims processing, but would focus on information collection; they would not communicate directly with Newcastle, but rather with their designated area computer centre. This simplified the communications software required, as it was not necessary to allow for the possibility of online access to Newcastle by all local offices. Similarly, response times at area computer centres would be faster. The system would be both more robust - in case of failure at one area computer centre, local offices could go to Newcastle via another, and more flexible-additional area centres could be added if necessary. It also had the advantage of not concentrating all technical expertise at a single location. The potential of technical workers to disrupt development was rightly feared, as is seen next.

During 1984-85, DSS management attempted to alter the pattern of shift work in an effort to save $\mathbb{2} 700,000$. Technical staff at the Newcastle computer centre went on strike for eight months, at a final cost to the DSS of 1170 million. To reduce the disruptive potential of future strikes, the number of area computer centres was increased from three to nine.

In 1986, development work for the income support related projects was transferred from Reading to Lytham St Annes. DSS management argued that Lytham had a relatively low turnover of staff and a good record of dellivery.

Later reports by the National Audit Office and the Public Accounts Committee suggested that work on the Operational Strategy between 1982-6 tad proceeded very slowly. Contracis had been awarded to a variety of private companies for the provision of hardware and software and some modifications had been made to the original projects. Each of these is discussed briefly below, before moving on to the watershed year of 1987 .

Contracis were awarded by open tender, with the exception of the contract to ICL for the mainframe computers. ICL had enjoyed a long relationship with the DSS since the opening of the Reading Computer Centre in 1973. Until it was sold to Fujitsu in 1990 (ending a decade of close collaboration), ICL was Britain's only domestic computer manufacturer, and was a favoured supplier in government contracts. All equipment was purpose-built as there was no possibility of buying standard kit for such a large system. ${ }^{12}$

Substantial progress was made towards developing a common hardware platform. However, software development was less smooth. Central to the achievement of the aims

12 There is no evidence to suggest that at this stage suppliers were actively engaged in directing the development of the Operational Strategy. In the past. ICL's contract with the DSS had prowided it with the guaranteed market it needed in order 10 develop a new series of maintrme computers - the Estriel series. 
expressed in the 1982 DSS report was the integration of benefits. Thus, the hierarchical network structure described above was intended to promote functional separation in order to achieve greater integration of benefit delivery. Local offices would concentrate on providing advice to citizens and collecting information from them. Area offices would process claims and arrange payment. Newcastle would store the data. Individuals would no longer have to provide the same information to different staff in different places to claim different benefits. But consultants had persuaded DSS management that rationallising the benefit system would delay the implementation of the Strategy by many years. Thus the software development was undertaken benefit by benefit, by project teams located at different sites. Development on the income support projects was undertaken in Lytham St Annes. The pensions projects and the Central Index were developed in Newcastle. Systems to support the existing mechanisms for delivering benefits separately require different databases, maintaining the traditional system in which data was collected for different benefits, increasing the possibility of duplication and inconsistency, and making cross-referencing via the Central Index more cumbersome.

\section{Interpreting the story of the Operational Strategy}

Let us postpone the discovery of what happens in 1987 , and instead pause to reflect on what has happened so far. The description above is necessarily messy and confusing, because what is being described is not the straightforward development of a single system, albeit a large and complex one. Nor is it a description of a process of systems development following some opaque internal logic. Rather, what is being described is the different interpretations that various social groups had of what became known as the Operational Strategy for the DSS. There are six more or less active social groups, each of which has articulated a problem which they believe the Operational Strategy will enable them to solve.

The key document providing the 'framework for the future' (DSS, 1982) contained rwo versions of the Operational Strategy. One reflected the more consensualist commitment of the Labour Government of the Hate 1970s, the trade unions and the generalist civil serwants at the top of the DSS to reduce costs and improve both service quality and job satisfaction. Achieving these three aims depended upon rationalising the benefit system which had grown up piecemeal since the Poor Laws in the nineteenth century. The Foreword to the 1982 document, however, was written by Margaret Thatcher"s first Minister for Social Services and he emphasised the Conservative Party's commitment to the pre-eminence of the aim to reduce costs. This reflected one of the key problems the Conservatives set themselves to solve, namely to reduce public sector bortowing.

For technical staff within the DSS, the Operational Strategy was not a network. They had endured a humiliating failure with the abandonment of the CAMELOT network. For them, the Operational Strategy was a hierarchical system, at the top of which were some large mainframe systems to be maintained. The problem they faced was the threat to their position posed by the rise of distributed processing, made possible by the increased power and cheaper availability of micro-and mini-computers. For the Newcastle project team, it 
was a system for delivering pencions, and, for the Lytham leam, it was a system for delivering income support.

For middle management at the DSS, it was a source of power for technical staff. It is this last interpretation which has so far had the most visible effect. The decision to increase the number of area computer centres from three to nine was motivated by management"s need to reduce this power source for the technical staff. Industrial relations continued to influence the development of the Operational Strategy, as we shall see in the next section.

This supports the constructivist assumption that the design and content of technical systems is subject to interpretation and negotiation between social groups. The easy constructivist argument, discussed in Chapter 1 , is to recognise that social groups create meanings and interpietations of all sorts of objects, once they have entered the public domain. The young men and women who answer their portable telephones during my lectures ascribe a different meaning to those ringing communication devices than do selfemployed plumbers or telecommunication engineers.

It is more difficult to demonstrate and to accept that prior to the public appearance of an object we recognise as a portable telephone on a car or a nuclear power station, there was also a range of meanings available for use by the social groups involved in the production of the object. But there is no a priori reason why this should be more difficult. As Misa (1992a, p.109) says, within the constructivist research programme, there is nothing in principle that cannot be disputed, negotiated, or reinterpreted". The concept of interpretative flexibility' is centrall to a constructivist analysis. Again, as with 'relevant social groups" and their "problems', interpretative flexibility is both an actors' and an analysts' category. The groups involved in the Operational Strategy are well aware that the other groups have different understandings of what the Strategy can and should be.

For technical systems to achieve any permanence or give the appearance of autonomy in the wider world, their meanings cannot be endlessly interpreted and negotiated by the groups involved. Actors need to enroll others in their vision, to form alliances and to develop a range of strategies in order to solve their problem. It is not yet clear in the Operational Strategy which, if any, group's interpretation of the problem and of the solution will dominate.

Reports by the National Audit Office (NAO) and the Public Accounts Committee (PAC) in 1989 suggested that work on the Operational Strategy between 1982-6 had proceeded very slowly, largely due to inadequate financial and time management. A constructivist analysis would suggest the reason for this slow pace was that no single Strategy was being developed. In other words, there was a high degree of interpretative flexibility. This is not inconsistent with the conclusions drawn by the NAO and PAC, but the way in which they chose to express their conclusions reflects their own interpretation of the Operational Strategy, one which views its implementation as a matter of urgency in order to reduce the costs of delivering social security. Let us now rejoin the story in 1987, a year in which more actors entered but a dominant interpretation emerged. 


\section{The development of the Operational Strategy: Part 2, 1987-91}

In 1987, three events occurred which would prove to be crucial in delivering a version of the Operational Strategy on schedule. First, senior programming staff went on strike at Lytham computer centre in February, followed two months later by rolling strikes of public sector IT staff throughout the country. Second, Eric Caines became Director of the Operational Strategy in April. Third, the Government passed its Social Security Reform Act.

Further industrial action occurred during 1987 because of a bonus awarded to technical staff at the Department of Employment, but not to those in the DSS. The cumulative effect of strike action in 1984-5 and 1987 was to move away from one of the original objectives of developing the Operational Strategy using internal expertise. The pressure to meet deadlines, combined with the Conservative Party's hostility to public sector trade unions, resulted in greater use of non-unionised consultants and contractors. Even though this resulted in higher costs in the short term, ministers argued that it would lead to a more 'stable cost profile' in the longer term (Guardian, 22.7.89, p.2).

The national campaign of rolling strikes begun in April 1987 by public sector IT staff jeopardised the timetable of the Operational Strategy. During this time, Eric Caines became Director of Social Security Operations. Caines had no background in IT but was an experienced project manager with a reputation for not tolerating entrenched interests in the civil service. ${ }^{13}$ He resolved there would be no further delays in the implementation of the Operational Strategy. To this end, he postponed some minor projects, put in place tighter accountability systems and replaced half of the programmers at Lytham with external contractors. In the summer of 1987 , there were press reports that the Strategy would be completely privatised ${ }^{14}$, based on leaked reports of a confidential internal DSS document, known as the Luxton report. It was not until the end of the year that these rumours were categorically denied. It was later revealed that management had explored the possibility of contracting the entire development of the Strategy to a private company but decided it would be too expensive. (NAO, 1989) The transfer of development work from Reading to Lytham in 1986, the replacement of half of the intemal staff with external contractors and rumours of complete privatisation all contributed to a growing feeling of pressure amongst the development team.

The final crucial event of 1987 was the passing onto the statute books of the Social Security Reform Act. This had been announced the year before, four years after the Operational Strategy began and less than two years before it was to be introduced in pilot offices. It is not clear to what extent there was consultation between those involved in the

13 Cumes had been director of regional operations at the DSS in the early 1980 s. whd had vigorously opposed CAMELOT. He was seconded to the Home Office in 1983, where he was responsible for oversecing the prowision of 26 new prisons. 
Operational Strategy and those involved in rewriting the benefit system. The review of the benefit system was driven by the Conservative Government. The main objective was to replace the complicated supplementary benefit system, which was a mixture of discretionary and administrative rules with decisions made by local officials, with a strictly rules-based income support system. In addition, plans to integrate unemployment and local benefit offices were abandoned. The cumulative effect of these changes was to make the software development considerably more straightforward. ${ }^{15}$ The unions argued that this reduced the possibility for service flexibility and integration (SCPS, 1987) and that the DSS would become locked into a rules-based system.

A small example will help to illustrate this. In the mid-1980s, following the privatisation of the gas and electricity utilities, fuel prices rose dramatically. Hypothermia-related deaths amongst old people and babies increased, and were the subject of widespread press reports. The Goveriment responded by introducing cold weather payments for some social security claimants, including families with children under the age of five, pensioners and people with disabilities and long-term illnesses. Obstacles were erected to minimise uptake: claimants had to make a written application and people with personal savings above $\$ 2000$ were excluded. This was prior to the implementation of the Operational Strategy, and the DSS received no notice. They coped by employing additional temporary staff, and by switching permanent staff from less urgent tasks. Applications were processed manually and amendments to payment books were handwritten. Now that the Operational Strategy is in place, ad hoc policy change such as this can no longer occur. All policy changes have to be incorporated within the software, and thus have to be scheduled into the development programme for the Operational Strategy. The cold weather payments have been incorporated, making their payment automatic and standard. Claimants no longer have to make a special application. If the temperature falls below freezing point for more than seven days, payments are made to all income support beneficiaries. (Bellamy, pp.10-11) The capital rule was also abolished, because monitoring that would have required additional data collection and input by local office staff.

These three events decisively shifted the direction of the Operational Strategy. The emphasis was now clearly on administrative rationalisation, with service and job enhancement rarely mentioned. All effort was directed at providing this simpler system, on schedule, using whatever external labour was necessary. 'We'd got almosi nothing written, we had hardly any space, [but] there was a clear sense of direction emerging', said one DSS technical manager. (Dyerson and Roper, 1990, p.4.)

In 1988, the DSS turned its attention to implementation, publishing a report entitled, New Technology, Job Design and Organisational Study Report (DSS, 1988a). There are three

15 In 1990. I was present at a seminat attended by academics and DSS management. Several of ihe academics present suggested that part of the reason for the sacial security reforms. panticularly the move to a rules-based system. was preciscly to hasten development work on the Operaluonal Strategy because codifying a discretionary system like supplementary benefin was simply 100 difficult. The DSS managers present were outraged at this suggestion, denying velemently that techncal exigencies could infuence political choices. 
administrative grades within local DSS offices: Local Office grade one (LOD), Local Office grade two (LOI) and Administrative Assistant (AA). AAs file casepapers, register new cases and prepare forms. LOlls assess claims, trace National Insurance numbers and adjudicate straightforward claims. LOIs handle more complex cases, monitor the work of LOIIs and compile management information. The report recommended a flatter hierarchy following full implementation of the Strategy. Job losses would be borne mainly by AAs because electronic storage of information would render obsolete many of their previous tasks. The calculation of claims, previously done by LOIIs, would also be done by computers in future. It was suggested their jobs would include more data entry but they would be able to devote more time to answering enquiries from claimants and to adjudication. LOIs would take on more management tasks.

A pilot evaluation found, howewer, that there was scope for LOIs to take on more managerial tasks but that staff lacked the training to do so. LOlls became text inputters, and had little time for increased contact with claimants. The tasks available to the few remaining AAs were very tedious, and it was recommended this become an apprenticeship for the LOII grade.

A few months later, another report was published (DSS, 1988b) which examined the organisation of local offices. This report was initiated by a senior civil servant, Margaret Moodie, who was not part of the Operational Strategy team but who based her recommendations on the presumption of the availability of computers in local offices. She suggested adopting a strategy similar to that used by the large British banks in which there would be more but smaller local offices to improve claimant access. All processing work would be done at area computer centres. Local offices would concentrate on providing advice and service to claimants. This echoed suggestions which had been made in the early $1980 \mathrm{~s}$, but which had not been voiced for some time. This report did generate some press attention, but the main focus of interest from PAC and the Treasury was on how the DSS planned to handle job loss.

In 1986, the Permanent Secretary at the DSS (the civil servant in charge) was asked by PAC about the process of negotiations regarding job losses with the unions following full implementation of the Operational Strategy. He replied that negotiations would begin 'once these machines are in and their effect is known' (PAC, 1986, p.19). This statement is remarkably clear in its adherence to a technologically determinist view of the world. Two years later, a new Permanent Secretary was asked the same question by PAC. His reply is quoted more extensively below:

It is only fair...to say that the unions have reservations about the strategy. They see it as fundamentally a cost saving exercise and they are understandably concerned about the future of their members; so are we. We are developing plans for coping with what undoubtedly is a difficult management situation. We shall be reducing staff in our local offices by some 13,000 on 70,000 and that is not an easy situation for anybody to manage or to accept if they are a member of staff.

On the other hand I find increasingly as I go round to local offices that particularly the younger members of staff expect to find information technology in place and 
would wonder what sort of ouffit they were working for if they did not find it. It is in that sense that I am quite sure that we have the full co-operation of our staff and I am encouraged too by the extent to which members of staff make unexpected uses of the technology they already have. (PAC, 1988, pp.4-5)

This reply indicates that there was still no agreement with the unions about redundancy and, moreover, reflects a confusion between job satisfaction and the loss of nearly $20 \%$ of all jobs.

Between October 1989 and July 1991,35,000 terminals were installed in 1000 local offices. The pension and income support systems process eighteen million enquiries each year. Local offuce staff were faced with different screen layouts and different commands for different benefits. The mainframes running the systems held different databases for each benefit. The systems sluared a common hardware platform and the Central Index which maintains a central register of all social security claimants. The system was in place and working, but whether or not the original aims of increasing efficiency, service quality and job satisfaction had been met through the integration of a benefit system which had been baroque in its complexity requires closer examination.

Following the problems experienced in 1987, senior DSS management ensured the Strategy was on schedule by allowing the technicians to proceed with the development at full speed. This was done at the expense of staff and management training and user involvement. The project was driven by the Treasury. The project became closed around its desire to meet the original deadline, because only then could staff reductions and savings begin.

Delays in delivering the Strategy would adversely affect the timely achievement of its aims, and may affect its overa I fnancial viability. ...[1]t is vital that the latest target dates for national implementation...are achieved. ... The achievement of the net present value of $\$ 175$ millian depends crucially on the level of staff savings to be achieved.' (NAO, $1989, \mathrm{p}, 2)$

Success in mesting the financial largets which drove the Strategy during the latter part of the 1980 s has been less obvious. Targets in reducing staff numbers have not yet been met, but it is difficult to ascertain because of the radical reorganisation of the DSS in 1990 .

Dyerson and Roper (1990, p.12) quote one senior DSS mandger who defined the Operational Stategy as the 'provision of different sonts of powerful tools to enable people to do their jobs". The technology was put in place to enable people to do their jobs more quickly with fewer mistakes. They were supposed to react to the technology, at most they were to provide feedback on its performance and reliability. Job satisfaction has improved, however. During the pilot evaluation in 1989, one local office worker said, "if you were to turn around and say "we'll take the computers away, we're going back to clerical work", there would be horror, there would be a hue and cry about it'. Another remarked, with greater aculty, that what we ve got in effect is a few VDUs stuck on the end of a clerical system...that's not what computerisation is all about' (Dyerson and Roper, $1990,0.13$ ) "The unions continued to argue that job design has been driven, not by finding 
ways to improve job satisfaction, but by the more and more pressing need to find the job losses required by Treasury.' (Eagleson, 1991, p.58)

Surveys of claimants also reveal improved service, especially in terms of accuracy and quicker response times. (DSS, 1989) But claimants have limited capacity to exert pressure. This is expressed by a DSS manager as follows. 'If you do not like Marks and Spencer you can go to Littlewoods; if you do not like social security, there is only the appeal tribunal.' (Stewart, 1991, p.52) The appeal tribunal can only deal with an individual complaint. Even though the NAO (1989) expressed concern about lack of attention to service quality, this was in terms of lack of attention to placing a financial value on improvements in quality in order to reduce the widening gap between the costs and benefits the Operational Strategy was expected to deliver.

The Operational Strategy became a tool for controlling costs and reducing jobs. This is partly due to the change in the wider political culture affecting public serwices in Britain throughout the 1980 s in which efficiency and cost saving bectme paramount concerns. But it also reflects a coalition of interests, a solution to the different problems faced by a variety of groups; of the Treasury which wanted something in place so staff reductions could begin; of DSS management who wanted a strike proof structure and a structure that would enable them to abolish thousands of clerical jobs; of technical staff, internal and external, who wanted to keep mainframes; and, of project teams who wanted to develop their own projects.

This resulted in an Operational Strategy which was concerned neither with enhancing service quality nor with improving jobs through integrating benefits and allowing higher levels of contact between local office staff and claimants. Installing 35,000 computer terminals in 1000 locations is a significant achievement, but one which was made possible by narrowing the scope of the project to focus on achieving staff reductions through timely implementation.

\section{Closure}

Following the events of 1987 , which were perceived to be traumatic for many within the DSS, the focus of the Operational Strategy became increasingly narrowed, as did the number of relevant social groups whose voices were heard. This process is captured by the concept of 'closure' in the social construction of technology; a concept borrowed from the sociology of scientific knowledge where it is used to denote the resolution of a scientific controversy. "Closure is achieved when debate and controversy about the form of an artifact is effectively terminated.' (Law, 1987, p.111) It is what happens when the meaning ascribed by one social group becomes dominant across all social groups. In this case, the meaning was shared by the Treasury, NAO, senior management at the DSS and technical staff: the Operational Strategy was a system for reducing staff numbers that could only be achieved by rapid implementation using mainframe computers and organised on a benefit by benefit basis. The voices arguing for better jobs and services did 
not completely disappear, as shall be seen in the next section, but they were not heard in the late $\sqrt{980}$ s.

Closure can be achieved in a wriety of ways, through, for example, externalising problems (Joerges, 1988), rhetorical dewices, redefinition of the problem (Pinch and Bijker, 1987) and organisational innowation (Misa, 1992a). All of these mechanisms were deployed during the course of the Operational Strategy. Through the rhetoric and financial control mechanisms availabile to the Conservative Party, the National Audit Office, the Public Accounts Committee and senior management of the DSS, the problem to be solved becane solely one of delivering a system on time that would enable staff savings to be achieved. To this end, internal and external technical staff were enrolled to deliver a centralised, mainframe system.

The problem with 'closure' as described above is that it has a ring of finality, which is quite deliberate because it is through closure that technologies acquire momentum and the appearance of autonomy. Thus, Bijker (1995) deploys the concept of 'stabilisation', closely linked to closure but which sounds less absolute and allows for degrees of stabilisation. There is a higher degree of stabilisation when interpretative flexibility decreases and the meaning attributed to the technology becomes less ambiguous. (Bijker, $1995, \mathrm{p} .271)$

Other athors have pointed to the contingent and temporary nature of closure. In his discussion of the difference between experimental science and 'real world' technology, Radder (1986, p.669) suggests that it is more difficult to achieve and maintain closure in the latter because the real world introduces greater uncertainty in both conditions of production and effects and involves a wider range of social groups. It is not necessary to enter into discussions of the relative 'real worldliness" of experimental science versus" technology to accept his basic points.

Summerton (1994) argues that technological systems or networks, which would include the Operational Strategy, are dynamic and, therefore, can rarely be closed permanently. She identifies three types of reconfiguration, or the undoing of closure. One type involves, the territorial expansion and interconnection of similar systems across political borders, transforming regional systems into national ones and national systems into transnational ones.' (p.5) A second involves a different type of border crossing in which parts of different systems are tecombined, such as transport with communications. The third type is one of institutional border crossing in which monopoly systems are opened up to competixion, as is happening in many public utilities in western Europe and North America (p.6) (the converse has happened in the past).

All three types of reconfiguration are possible with the Operational Strategy. The European Union is committed to integrating some public administrative systems, including social security because doing so would facilitate the free movement of people throughout the Union (CEC, $1994 a, p .29)$. Recombination of parts of different systems may occur if ideas about integrating different benefits are revived. While the Conservative Party remained the party of Government, it awarded a contract for the operation and 
management of the Livingstone Computer Centre to a private company in 1989 . In the next section, we shall see what steps have been taken to a slightly different form of privatisation.

It is Misa (1992a) who argues nost clearly, however, that not only is closure provisional but that provisionality is necessary for socio-technical change.

Closure must be seen as a contingent achievement of actors and not a necessary outcome of controversies. If achieved, closure implies nore than temporary consensus; it is how facts and artifacts gain their 'hardness' and solidity. As a social process, closure may frequently involve the creating or restructuring of power relationships. Accordingly, this concept should not be seen as being in opposition to change but rather as facilitating the order that makes change possible. (pp.110-1; my emphasis)

\section{Next steps in the Operational Strategy}

In 1988, Margaret Thatcher agveed to what has become known as the "Next Steps" proposals contained in a report from the Efficiency Unit of the Cabinet Office. It recommended that all operational activities of government be delegated to agencies, with only policy-making and strategic management being retained as core civil service activities; and, in the longer term, the possibilities for privatising the former should be expllored. As a result, in 1990, the DSS was divided into five agencies: Benefits, Information Technology Services, Child Support, Contributions and Resettlement. In addition to opening up possibilities for privatisation, this has institutionalised the already existing split between the suppliers of IT services and the internal DSS users. The Operational Strategy affects the workings of the Benefits Agency, the largest of the five agencies. The Strategy itself, however, is developed by the Information Technology Services Agency (ITSA). Negotiations around the provision of IT equipment and services are conducted bilaterally between ITSA and the "user" agencies. ITSA now controls all technical expertise within the DSS and access to external suppliers and consultants.

The Operational Strategy did not deliver the higher levels of integration that had been anticipated in its early days. Large quantities of paper still move between local offices, area computer centres and mainframe sites. Local offices contimue to be organised by benefit. Each benefit has a different interface, therefore it is more difficult for a single member of staff to discuss with clients the range of benefits wo which they are entilled. The Mayhew report (1992), an internal DSS document, returns to the agenda of the Operational Strategy framework document, published a decade earlier. The potential of integrating benefits to improve efficiency, jobs and services is emphasised. There are some new ideas. One is to allow claimants to go to any DSS office, and not to restrict them to the one that is physically nearest to where they live. With a fully integrated, on line system there is no technical obstacle to this, although it is hand to see how it would contribute to improving the quality of interaction between local office staff and clamants. A second new idea is to organise claimants into 'client groups', such as pensioners, single 
parents, long-term ill and disabled, with staff similarly organised. This raises the twin spectre of dividing social security claimants into the deserving and undeserving poor and of moving away from a universal benefit system. It is a form of profiling - discussed in Chapter 2 - which the current socio-technical system at the DSS is as yet unable to support.

The provisional closure of the Operational Strategy achieved in the late 1980s is under threat. But it would be wrong to see this as an example of closure being undone. The closure achieved in the late 1980 s has brought some obduracy to an area that has been contested for more than twenty years. It will structure subsequent changes. There is greater firmness in the socio-technical organisation of the DSS. The post-1990 organisational structure institutionalises some of the social groups and alliances which emerged in the course of the development of the Operational Strategy. ITSA remains committed to the mainframe systems and centralised databases in place, and its relationships with external suppliers are centred on such technologies. The staff remain sceptical about whether an operation as vast as social security could be delivered any other way.

\section{Conclusion}

This chapter has traced the development of the Operational Strategy between the beginning of discussions in 1977 to its full implementation in 1991. The concepts of relevant social groups, their problems and interests, interpretative flexibility and closure were introduced. Throughout the 1980 s, especially following the watershed year of 1987 , the problems which the Strategy sought to solve were simplified by the groups who came to dominate the Strategy, in an effort to deliver some sort of system on schedule. Only then would it be possible to even begin to attempt to achieve the $20 \%$ staffing reduction.

In the early days of the Operational Strategy, there was a high level of interpretative flexibility around its aims. Over time, a high degree of stabilisation occurred, permitting a temporary closure of the Strategy as a centralised, mainframe-based system. A number of events are looming which may challenge this provisional closure, but it has served its purpose. Even if this closure is not permanent, and it is unlikely that it will be, it will serve to structure future developments. The way in which the conceptual building blocks of social constructivism can be used to develop a framework for understanding sociotechncial change is beginning to emerge, a framework moreover which allows for the rhetoric and reality of technological determinism. This account of the Operational Strategy demonstrates how the actions of a variety of social groups led to a narrowing of its interpretative fllexibility and its stabilisation, or provisional closure. The resulting system will structure the options available to social groups in the future.

This chapter also illustrates some of the points made in Chapter 2 which shall be explored more fully in later chapters but which shall be mentioned briefly here. First, with respect to the nature of IT, one of the claims frequently made by IT enthusiasts is that it is a flexible technology. The example of the cold weather payments in which technical 
developments reduced the discretion and flexibility available not only to local officials but also to policy-makers illustrates the limits of that claim. Secondly, Chapter 2 raised three issues posed by the use of IT within public administration. The first, less visible to date, may become more so if the proposals in the Mayhew report concerning clien groups are taken up, concerns privacy. Organising benefit delivery around client groups is a clear case of profiling. The second issue is privatisation and contracting-out. This has clearly been important in the development of the DSS on several different occasions. Finally, a belief in the primacy of the legislative process over mundane operational matters like developing a technical system for delivering social security benefits has been called into doubt, given the timing and importance of the 1987 Social Security Reform Act in relation to the Operational Strategy. The socio-technical embeddedness of the legislative process is beginning to be exposed. 


\section{CHAPTER 5}

\section{THE TYRANNY OF STRUCTURELESSNESS}

\section{Introduction}

During Christmas and New Year of 1995-6, some of the more established large technical systems in Britain were involuntarily opened up to greater public scrutiny. Storms brought down transmission lines in the Shetlands and Hebrides: people were without electricity for at least Christmas Day and Boxing Day. The very cold Christmas was followed by a very rapid thaw. The earth moved, resulting in an unprecedented number of burst domestic pipes and fractured mains pipes. One quarter of a million homes were without water at the beginning of 1996 in the north-east of England; many people were forced to collect their water supplies from tankers in the streets. Parts of the transport system came under attack or were interrupted. The Consumers" Association revealed that in eight out of ten cases its researchers were overcharged between 10 and $100 \%$ for tickets on newly privatised rail lines. In the first week of 1996, closures of parts of London's Underground system lasting for up to eighteen months were announced.

For students of STS, reflecting on the state of the socio-technical infrastructure during Christmas 1995 provided an alternative to the more usual festive pursuits. Over a two week period, the precariousness of large parts of Britain's infrastructure was revealed. Explanations were sought. All of the usual suspects were rounded up: nature, the Conservative Government, (mis)management, (lack of) investment and (lack of) training. Island myths were invoked to reassure people: the indomitable spirit of the British in the face of adversity was praised; Britain's role as the world's first nation to industrialise was heralded.

Closure in these technical systems of electricity, water and transport which, in some cases, had been achieved over a century earlier was at least temporarily undone. Nature was the main culprit in the eyes of many commentators. But in the highly politicised climate in which British utilities operated during the latter years of the Conservative Government, there were many who disputed the authorities' attempts to evade responsibility for system failures by blaming the weather. The then Opposition parties of Labour and the Liberal Democrats, users' and consumers' representatives were quick to blame the economic and political climate which had fostered such failures.

The temporary loss of service revealed not only how dependent we are upon such systems but also what complex ensembles of artefacts, organisations, rules and people they indeed are. Moreover, we were reminded of the variety of natural and social climatic changes to which they can be subject. Most of us take the continuous and reliable working of the technical systems around us completely for granted (except those who regularly travel on the North London Line). The inner workings of well-established technical systems such

Following the eximple of nuclear power. Uhis line was re-named "SilverLink" in 1997. 
as electricty, water and rail transport are only revealed at moments of extrens. The inner workings can be taken for granted because outwardly they continue to function.

In the preceding chapter, the development of an infomation newwork for a single government department - the Operational Strategy of the Department of Social Security was presented. Attention focused on the ways in which different factors and groups interacted during the early stages of the projects specification and development wo shape and construct the system as it emerged. Social and technical issues were crucial in influencing its shape prior to its implementation; issues as varied as the public sector debt, civil service industrial action and the reform of social welfare legistation. In addition, the account drew upon a number of concepts from the social constructivist literature and elsewhere, such as 'relevant social groups', 'interests', 'interpretative flexibility' and 'closure'. This was done in order to deepen both the understanding of the ways in which these systems were constructed as well as the comprehension of the concepts themselves. Just as social order is secured through the enactment of social practices, so too do conceptural tools become more robust through experimentation and repetition.?

In this chapter, the processes through which large technical systems are developed continue to be explored, but the scene shifts fron a single British government department to inter-departmental communications in the UK and the United States. There are differences between these three systems. The Operational Strategy was langely confined to a single department, and is an information system in the fullest sense, incorporating hardware, software and applications. Both the Government Data Network (GDN) and the US Federal Telecommunication System for the year 2000 (FTS2000) aimed to provide a communication infrastructure to be shared by many central government departments. All of these systems are 'large', but in different ways, thus reinforcing the discussion in Chapter 3 regarding the difficulty of defining the scale of technical systems. The Operational Strategy is 'large' when defined according to the number of records and the number of hands-on users. The Government Data Network and the FTS2000 are "large" when defined by the number of major organisations involved in their development and subsequent use. Both of these systems were provided by a third party on the basis of a service contract. Using a third party supplier was a radical change within the UK context, but was common practice in the US. The GDN was about hardware: the network management systems were supposed to be invisible and the applications were superfluous to what came to be understood as the GDN. As we shall see, the lack of attention to applications was simultaneously the reason for the GDN's much more rapid development and for its eventual failure. The US system, FTS2000, provided for integrated voice, data and image communication, whereas the GDN was concerned only with data communication, and moreover only with the required infrastructure. Unlike the GDN, the FTS2000 incorporated some applications within its specification.

There are also differences of policy emphasis between these systems. For the GDN and the Operational Strategy, issues central to British political debate throughout the 1980 s,

${ }^{2}$ For an interesting discussion of what he cals 'bootstrapped induction', sec Barues (1983). 
such as the future of the telecommunications industry, public sector borrowing, the power of civil serwice unions and data protection all played a role in constructing the emerging system. In the US, the political context was dominated by the first of these, together with a longer standing commitment to market competition.

All of these points are explored in greater detail in the remainder of this chapter. But first some contextual information is presented about the structure of the political systems in the two countries, their telecommunication policies and the administrative use of IT within the two governments. The relevant social groups are introduced prior to recounting the genesis of the GDN and the FTS2000. These two stories are presented together in this chapter. Many of the actors are the same for the two British projects, although the relative importance of their parts varies. Also, there was contact between some of the actors involved in the GDN and the FTS2000. Some of the objectives and some of the problems facing the actors are similar. Presenting them together allows us to avoid too much repetition and enables us to see the similarities and differences more easily. There will be a brief pause to reflect again on the notion of "relevant social groups'. Other concepts such as interests, interpretative flexibility, closure and technological frame, will again be deployed but with less obvious reflexion. Questions around success and failure, use and non-use, working and non-working are introduced in the latter part of this chapter, and will be discussed more extensively in Chapter 6 .

\section{Prologue}

Before introducing the cast of characters involved in the development of the Government Data Network and FTS2000, four pieces of scenery need to be described: the structure of the UK and US political systems; British and American telecommunications in the early 1980s; the nature of IT within the rwo administrations; and the difference between computer-driven and telecommunication-driven networks.

\section{The Unired Kingdom}

The United Kingdom is a unitary state, with a highly centralised political structure in which local and sub-national governments have limited autonomy. Geographically, the United Kingdom includes the islands of Great Britain and the north-east corner of Ireland. ${ }^{3}$ Politically it includes the countries of England and Scotland, the principality of Wales and six of the nine counties of the province of Ulster. ${ }^{4}$ The UK has a parliamentary 'first past the post" electoral system in which elections must be held every five years. The party in power is allowed to choose the exact date of elections. The leader of the party receiving the most seats is asked by the Queen to form a government. Since World War II, electoral politics has been dominated by the Labour and Conservative parties.

\footnotetext{
The area of the UK is 244.755 square kilometres: its population is 58 million with $0.3 \%$ annual growth.
}

4 The boundary between Northem Ireland and the Republic of Ireland was decided in the 1920 Government of Iretand Acr. It was confirmed again in 1925. There is no geographic or cultural rationale for including only six of the nine counties of Ulster. If was done solely to ensure a Protestant majorily. 
Scotland and Northern Ireland are often governed by laws different from those operating in England and Wales, but all legislation is passed by elected members of Parliament sitting in Westminster. Wales, Scotland and Northern Ireland do not (yet) have their own parliamentary assemblies, but rather are governed by Ministers based in London. "Local governments are directly elected. They have limited powers of taxation; the bulk of their resources derive from nationally collected taxes, administered by the Department of the Environment. Local government is responsible for the delivery of such matters as primary and secondary education, health care, social services and policing; albeit delivery within nationally determined policies.

The organisations which constitute the UK central state have experienced a radical restructuring in recent years as many administrative functions have been separated into quasi-autonomous and/or fully privatised agencies. ${ }^{6}$ Regardless of their precise relationship, the central state here includes government departments and intermediate agencies which may or may not be staffed by civil servants, but which are directly subject to some form of parliamentary and ministerial overview and constituted by legislation or orders in council.

\section{The United States of America}

The US is a federal republic. It is the fourth largest country in the world, in terms of both area and population. ${ }^{8}$ During the second half of the twentieth century, it has been the most powerful country in the world. Some of that power derives from its technological leadership in many of the key technological developments of this century, including telecommunication and computing as well as defence, space, transport and energy technologies.

There is a constitutional division of power between the federal government and the fifty state governments. Sovereignity is divided between the two, will a complex array of rights and responsibilities of which some are separate and others shared. At the federal level, there is also a division of power between the legislature and the executive, each of which is elected for a fixed term, but based on different electoral mandates. Each branch has its own responsibilities regarding the development and administration of policy, although there is a considerable degree of interdependence. This deliberately complex

\footnotetext{
SFollowing the landslide victory of Now Labour in the 1997 efection. lhis will change. New Labour is wommited to direct representation for the people of Scotand and Walcs. agreed by the wo atcetorates during reforenda held in both parts of the Union in 1997.

This process was initated by Margarel Thacher during the late 1980 and is set out an a repord propared by the Efficiency Unit 1988 ) of the Cabinet Office.
}

Defining the 'cenral state' is a matter of considerable dobate both poltically and within the potitical science literature. For a succinct review, see Dunleawy (1989) who presents his own calcgorisation which. bie argucs, makes it possible to predict which purts of cental government will be given agency status.

* The US is 9.363 .130 square kilometres. It has a population of approximatcly 255 millon people growing at an anmul rate of $0.9 \%$. 
division of power and authority between central and state governments and between the legislature and executive within each can make coordination difficult.

There are two main political parties, the Democrats and the Republicans. ${ }^{9}$ Throughout the 1980 s, during which time the FTS2000 was developed, there was a Republican President, Ronald Reagan, who was elected in 1980 and again in 1984. He was replaced by another Republican, George Bush, in 1988. Ben Bennington, the first director of the FTS2000, remarked upon the significance of this, 'we were very lucky that we got an eight year administration... we only made it under the wire by about a month... Bush is a Republican and so was Reagan but...all bets are off when a new administration comes in'.

\section{The state of US telecommunication}

In Europe, the postal authorities took responsibility for newer forms of communication as they became available. But this did not happen in the US, which has always maintained a separation between the public service of the Post Office and privately provided voice communication. Nonetheless, for much of its history, telecommunication services have been offered by a single supplier, AT\&T. The 'natural monopoly' argument ${ }^{10}$ was used to justify this situation, anomolous in US industry which has a strong commitment to competition, enforced through its anti-trust laws. In order to ensure that AT\&T would not abuse its monopoly position (i.e. by charging excessively high prices or not maintaining investment), the Federal Communications Commission (FCC) was established to regulate its activities. New entrants were not prohibited, but it was believed to be too difficult for them to want to gain entry.

Challenges to AT\&T's dominance have occurred since the late 1940s; initially in the area of terminal equipment, later in the use of the radio spectrum for private communication. At the beginning of the 1980s, AT\&T remained the dominant player. MCI and Sprint had attempted to enter the US voice market throughout the 1970s and 1980s, but had found their efforts obstructed by AT\&T. They sought redress in the courts, accusing AT\&T of failing to prowide them with interconnections, of overcharging them when interconnections were provided or of imposing proprietary technical standards. Following a series of legal challenges, AT\&T agreed to the divestiture of its local exchange companies. In return, the Department of Justice dropped its anti-rrust suit. This resulted in the creation of seven Regional Bell Operating Companies (RBOCs), dividing the US between them, with AT\&T retaining its dominance in long distance and international communication."

\footnotetext{
- As the 1992 Presidemial election demonstrated, it is very diricult for condidates to run who are not members of one of the wo parties. Ross Perol was only able to enter the race as an independently wealhy mawerick.
}

13) 'Natural monopoly' is a tem used by ceonomists 10 debate a situation int which competition would lead to inefficiencies and higher costs. Within neoctassical economics, competition is generally held to the the ideal form of market structure as it is assuned it will lead to greater choice and lower prices for consumers. However. lhey do recognise this is not atwilys the case. For cxample, in electricily supply compctition mould lad 10 a costly probiferation of cables and transtormers. A matural monopoly oceurs when one firm can produce the outpun a lower average cosi than could more than one firm.

t. There is a popular misconception that divestiture is synonymous with compestition. Subsequently. greater competition has been introduced into US telecommunications. However. diwestiture simply left AT\& T as a smaller monopoly with seven regionally based monopolics providing services in their local areas. There has been extensive 
Judge Harold Greene, the US District Court judge who presided over the break-up of AT\&T, was charged with the task of overseeing that other conditions of the divestiture were met. Greater competition has resulted throughout the late $1980 \mathrm{~s}$ and early $1990 \mathrm{~s}$ in the United States. In addition, AT\&T and the RBOCs themselves have sought to expand their globall position or to enter new markets both elsewhere in North America and throughout the world.

\section{The state of UK telecommunication}

The election of a radical Conservative Government in Britain in 1979 and the example of a privately-owned, competitive telecommunication industry in the United States paved the way for restructuring the provision of telecommunication services in Britain. Separation of postal and telephone services in Britain had already been achieved with the 1969 Post Office Act. Nonetheless, telephone services continued to be delivered by a state-owned monopoly until the implementation of the 1981 Telecommunications Act. This Act permitted the licensing of competing network operators. In 1982, Mercury Communications ${ }^{12}$ was awarded a license allowing it to compete with British Telecommunications (BT). The next significant piece of legislation was in 1984: the British Telecommunications Act resulted in the state selling $49 \%$ of its stake in BT to shareholders and in the creation of the Office of Telecommunications (Oftel). Oftel has the task of promoting competition in a market that had been dominated by a single supplier for much of its history. In addition, Oftel,

must secure such telecommunication as satisfies all reasonable demands, providing that the supplier is able to finance these services; promote the interests of consumers, purchasers and all other users in the United Kingdom; ... secure efficiency and economy on the part of the suppliers; promote research and development in the United Kingdom; and enable the United Kingdom telecommunication producers to compete effectively within and outside the United Kingdom. (Mansell, 1993, p.86)

In 1984, Mercury's license was extended to allow it to enter the international voice telephony market. By 1986, it had connected most major British cities to its network and thus was able to offer switched services as well as dedicated leased line services. Nonetheless, it remains heavily dependent on BT for some trunk connections and for the termination of its services. ${ }^{13}$ Despite more than a decade of competition, BT continues to

discussion of the AT\&T divestilure: wo useful sources are Mancel (1993) and Hills (1986. Mansell explores how and why divestiture has been regarded as a lorm of competition.

Recall the discussion in Chapter 3 regarding the difficulty of defining walc. One possibility mooted was the size of the responsible organisations; according to such a definition. the US velcphone system would become instantly smaller following divestuture.

17 Mercury Communications was intially formed by a consortum of Cable wireless. British Petroleum and Barclays Bank. The latter two soon dropped out, but Bell Canada later bought a $20 \%$ share.

13 In more simple terms. Mercury offers an altenative trunk network, connceing major uriban areas. In its early days. customers - usually large businesses - effenvely block-booked pan! of Morcurys trunk nedwork. paying at 
hold more than $95 \%$ of the telecommunications market, although there is somewhat greater competition in certain areas, including international and mobile telephony. The 1991 Duopoly Review permitted other telecommunications operators as well as cable television companies to enter the British market. While there are now more than 150 operators, BT has lost relatively little market share. The regulatory framework has, however, become much more complex. ${ }^{14}$

\section{The state of IT within the UK and US administrations}

In the mid-1980s, the US federal government had more than 27,000 mainframe computers, 170,000 terminals attached to those mainframes and 100,000 microcomputers. State and local governments had more than three times this amount. In sum, the US government possessed the largest stock of computer equipment in the world. (Danziger, 1991, p. 169) Nor was the federal government an insignificant user of tellecommunication equipment and services. Voice communication needs, or standard telephony, were met by the Federal Telecommunication System (FTS) which, in 1980, served approximately 1.3 million users in more than 4000 locations and used more than eleven million miles of transmission lines. These lines were leased from AT\&T. This network was larger than the combined total of the seventeen largest private telephone systems in the US, of corporations such as General Motors, General Electric and Westinghouse.

Data communication needs were met by individual departments or agencies. Procurement was often coordinated centrally by the Government Services Administration, but decisions about specifications and ownership resided with the originating departments. Throughout the $1970 \mathrm{~s}$ and early $1980 \mathrm{~s}$, departments installed different networks at different times in order to meet particular data communication needs.

The US Government has been committed to using IT to improve the operation of its administration since the earliest days of computers. ENIAC, the first computer, was used to process US census data. Since then, IT has been regarded as a usefull tool for coordinating activities throughout its complex administrative structure. The development and use of IT within government remains a priority. Even during the Reagan administration, when many parts of the federal budget were cut in an effort to reduce the US budget deficit, IT expenditure was allowed to grow, as was defense expenditure.

rental fee plus a reduced mate for actual usage. What happened in 1986 was that smaller users, including residenial customers. were able to gun aceess to Metcury's network for long-distance and international calls. This is what is mean by the ferm 'switehed services'.

Mercury does not prowide the finall physical connections from the man trunk network to individual residential or business premises (cxcept for some large businesses). BT is responsible for the provtsion of what is called the 'locat aceess network": thus Mercury is dependent upon BT for these connections, or "terminations". This is the source of much debate between Mencury and BT; with Mercury wanting equal and free access to the local netwoth whereas BT wants to be compensated by Mercury for BT's provision and maintenance of the local access network. In 1991, Ofted decided that neither Mercury nor any other competitor would have 10 pay access deficin charges until BT"s market share had been reduced $1085 \%$. process. Further discussion can be found in Mansell (1993). Hills (1986) and Steinfteld (1993). 
In Britain, central and local government have also been major computer users for decades. For 1994-5, it is estimated that the public sector including central government, defence, health, education and local govermment) represented nearly one quarter of the total UK. expenditure of $\mathcal{E} 3$ I billion on IT. Central govemment, including defence, was the largest single portion of that, accounting for one third (i.e. 12.7 billion). (Swinden, 1995, pp.40-1)

The pattern of IT use by both the British and US governments conforms with Barras's (1986) characterisation of innovation in services, what he refers lo as a 'reverse product cycle, described more fully in Chapter 2 . Since the 1950 s, central government has used mainframe computers for large-scalle data processing, such as payroll. During the 1970 s and 1980 s, various more or less successul attempts were made to use mini and microcomputers in individual offices; by the DSS, for example, to help claimants understand their benefit application forms. Barras predicted that during the 1990s, networks would be used to develop new services and not just to improve the quality and efficiency of delivering existing services. Networks were, however, already in place in various central government departments in the late 1970 s and early $1980 \mathrm{~s}$. As in the US, many departments had several networks of different types which had been instaled over a period of years. For example, Customs \& Excise had a network connecting ports and aimports throughout the country, and the Home Office was responsible for the Police National Computer. There also existed a Government Telephone Service, similar to the internal telephone systems of many large organisations. However, with the exception of defence applications, it was widely believed both within and outside the public sector that it had lost its innovative edge over the private sector. Whereas in the early days of computers, public sector organisations could afford and find uses for mainframes, by the 1980 s they had a relatively impoverished technical and skills resource base. In the mid1980 s, banks and insurance conpanies had more advanced networks in place spanning huge distances, facilitating new divisions of labour and opening up new service possibilities.

\section{Oniy comnect}

In the mid-1970s, computer networking was a young technology. There were a number of academic research networks in use and commercial networks were beginning to follow. As networks grew in number and users came to depend on their services, it became clear that their usefulness would be greater if the different networks were connected, in a process which came to be known as "internetworking". Organisations that tried to do this soon realised that establishing compatibility between systems was not an easy lask, not least because it brought rival networking organisations into conflict.

Three groups were important in defining shape of internet technologies, each representing radically different views and interests:

1. The US Defense Advanced Research Projects Agency (DARPA) introduced it: pioneering ARPANET in 1969.

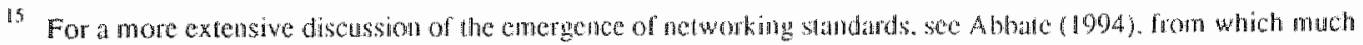
of this section is drawn. 
2. European telephone companies through their own standards body, CCITT (Consultative Committee for International Telephony and Telegraphy) began to think about how to connect computers over telephone links in 1974.

3. The International Standards Organisation (ISO) began to develop 'Open Systems Interconnection' (OSI) in 1977.

By the late 1970s, these three bodies were in conflict over the development of internetworking standards. Each of the three was transformed as a result of their clash.

The 1SO, founded in 1946, is the association for national and international standards bodies for all industrial sectors. Draft standards are created by working groups that are open to interested representatives from government, industry and academia which are circulated amongst all members until there is general approval, at which point they become international standards. The ISO considers itself a spokesperson for users, and believed that by developing the OSI model it was protecting users from big monopolies, IBM for example. Before IBM had a chance to establish its proprietary network system as a de facto standard, the ISO attempted to create abstract standards while internetworking technology was still new. This was a departure from its usual practice of waiting for consensus from the commercial sector. OSI can be understood as an 'ideal type' of what internetworking standards should be. It provided a model, but detailed protocols were not defined, which is where DARPA and CCITT come into conflict.

\section{The Defence Advanced Research Projects Agency (DARPA), an agency of the US} Department of Defence, had a somewhat different set of objectives. Its major goal was to pursue advanced research in areas relevant to military needs. Work began on a countrywide computer network, what became known as ARPANET, in 1967. It had two purposes: first, to allow DARPA contractors to share computer resources; and, second to conduct research about networks themselves. ARPANET was in routine use as early as 1972. Over time, many academic and business networks adopted their standards so they could become part of the large research community connected by ARPANET. The standard developed by the users of ARPANET is called TCP/IP (Transmission Control Protocol/ Internet Protocol).

Meanwhile, the CCITT was also busy. It is a branch of the International Telecommunications Union (ITU), established in $\$ 865$ to coordinate telegraph services between countries. (It became part of the United Nations in 1947.) The CCITT was established in order to research and develop technical standards that would support the structure and practice of the carriers that make up the ITU. It is important to note the membership critiria: it is based on an agreement between countries, not companies. Therefore, for the US, where telephony has always been privately owned, AT\&T could only be present as an observer. However, those countries where public telephone companies existed, i.e. in most of Europe, had voting rights. In other words, throughout the 1970 s and early 1980 s, the CCITT was dominated by European interests, and the US was under-represented.

The state-owned telephone companies of Europe realised that if they wished to extend their telephone monopolies to data communication they would have to provide customers 
with a way to connect computers to public network. DARPA generously offered their standards but were flatly rejected by CCITT. An alternative, led by the then British Post Office and France Telecom, was to develop a standard that allowed computers access 10 public networks. This standard becane known as X.25. Even though the CCTT had done this independently, it soon became associated with the OSI model. Both were official bodies, with shared authority for communication standards. They sent representatives to each other's committees in order to coordinate development. The US feared that the ISO and CCITT had joined tanks to protect European interests against those of the US.

Both TCP/IP and the $X$ series are examples of packet-switched networks. This means the message is divided into little pieces, or packets, which can be sent separately or in groups, to even out traffic. A computer is needed to put the packets back together agan.

There are two techniques for getting data from point $\mathrm{A}$ to point $\mathrm{B}$. One possibility is packet switching, in which the message is divided into litte pieces, or packets, which can be sent separately or in groups. This helps to distribute traffic more evenly across the network. In theory, each packet could take a different route from A to B. Each packet has the address and a number. The receiving computer has the task of recombining the packets in the correct order. This is how newworks using the TCP/IP standards work.

The other possibility is a circuit switched system, in which a unique path is established for a single message. It is similar to a telephone connection, when a line between two points is kept open. This is how the OSI/X.25 series works.

A packet switched system is more robust than a circuit switched one: if part of the network goes down or becomes overloaded, packets are simply sent via a different route. The people who developed this were users of supercomputers. Such a system is much more demanding of the host computers, but it also gives them greater control. It stats from an assumption that the network of commumication links is not robust. This derives from their history of developing a defense network. where robustness in times of war is quite important. This system is biased in favour of computers.

A circuit switched system, on the other hand, assumes the network is robust. This is not surprising, given that the people involved were from BT and its equivalents around the world. The work is done and the complexity is located in the switches in the network. This system is biased in favour of carriers.

Proponents of packet switching and citcuit switching both claim to represent users, albeit different sorts of users. TCP/IP gives users greater control though possibly at the expense of greater complexity. OSI/ X.25 offers greater transparency but less control to end users.

The TCP/IP approach specifies only those functions required for internetworking, namely packet and address formats. This minimises the degree of unifomity needed. DARPA assumed it would be necessary to accommodate many different lypes of systems. which in the US was a reasonable assumption. Following the divestiture of AT\&T, many different 
commercial and government funded networks were being developed. With this diversity, it seemed impossible to convince everyone to use the same thing, so the sensible strategy appeared to be to go for a minimum level of uniformity. Not only was this pragmatic but it also reflected a belief that it was necessary and desirable to have diversity in technological systems.

The X.25 approach favoured by the state-owned telephone companies and the of ficial bodies assumed they would retain monopoly control over data communication. They argued that a standard network would be in the public interest. Manufacturers would be able to build products to a single set of specifications and customers would be able to use equipment to connect to any public network.

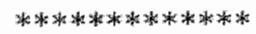

The scene is set. By the mid-1980s, dramatic changes were occurring in the structure of the telecommunication industries throughout the industrialised world, and particularly in Britain and the US. In the US, the basic organisation of private companies regulated by the FCC remained intact, but it was becoming easier for new entrants. The complex federal governmental structure remained committed to using technology to improve its coherence and integration. The UK was also beginning to experience dramatic changes, with new forms of ownership and regulation coming into play. Tentative steps towards the reconfiguration of the organisations of the central state were being taken. Piecemeal and ad hoc IT networks had emerged and continued to be developed in different government departments, but the options for doing so were influenced by the different shape of emerging networking standards in Europe and the US. Only in the unstable telecommunication environments of the UK and the US in the 1980s was it possible to experiment with the arrangements for delivering communication services within government.

In the next sections, we meet the characters who became involved in developing new national communication infrastructures for the UK and the US. In the case of the GDN, some of these groups were also involved in the Operational Strategy and will already be familiar. 


\section{The Government Data Network: The Cast ${ }^{16}$}

\section{The Group of Four (minus one)}

Four of the largest government departments in the UK - Inland Revenue, Social Security, Customs \& Excise and the Home Office - initiated the GDN in 1986. The Home Office is responsible for police, prisons and immigration. For inter-departmental projects, the cooperation of the Inland Revenue, Social Security and the Ministry of Defence (MoD) is usually required. The MoD was not involved in the GDN: it requires secure communication but the GDN was intended for more mundane administrative data transfer. The absence of the MoD is nonetheless significant, not only because it possesses internal expertise in the development of communication systems but also because historically it has always been centrally involved in the development of new communication systens, such as the telegraph, radar and radio.

Customs \& Excise was relatively advanced in its usage of data communication networks, with systems in place that connected points of entry into the UK. It acted as a pilot in the early phases of GDN development. The Home Office, like the MoD, has needs for secure data communication on matters of national security and criminal activity. This was to prove a source of tension between it and the other departments, as will be seen later.

During the tendering process, a Steering Committee was established, including representatives of the four initiating departments. Following the award of the contract, it was replaced by two committees: Management and Operations.

\section{CCTA and the Treasury}

As with the Operational Strategy, both the CCTA (Government Centre for Information Systems) and the Treasury (of which the CCTA is formally a part) were involved. The CCTA was much more active in the GDN development than it was in the Operational Strategy. There is little evidence of direct Treasury involvement, with one significant early exception. Because this was a cross-departmental initiative, the CCTA took on many of the coordinating tasks, not least because the departments did not want a single one of their own group to have that power. The CCTA is responsible for the promotion of technical standards and for ensuring that departments receive value for money in their IT procurement. However, both the CCTA and the Treasury were regarded with suspicion and hostility by other departments, and were referred to during interviews as the CCTA, alias the Treasury' and as groups who 'know the cost of everything but the value of nothing'.

16. Much of the empirical material on which this section is based was collected during the wourse of a project entitled Technological trajectories and the Transfer of Technotiogy from the Public Services". The project was conducted at the then Centre for Business Research, Brighuon Polylechnic (now Centre for Reseduch and Training in Innovation and Management (CENTRIM). University of Brighnon). The project was linancially supported fry the National Advisory Body of the Polytechnics. 


\section{Conservative Party}

The Conservative Party was in power in the United Kingdom between 1979 and 1997 , under the leadership of Margaret Thatcher until 1990 and then under the premiership of John Major. Thatcher's second term, 1983-87, introduced much of the legislation for which she and the Conservative Party are remembered, including the commitments to privatisation and reduction of the public sector borrowing requirement. As has already been discussed, during the 1980 s, the Conservative Government was also committed to introducing competition in telecommunications and to increasing efficiency within the public sector. It was during this term of office that discussions about the GDN began.

The GDN Steering Committee established to oversee the tendering process was chaired by Peter Brooke, then Paymaster General (effectively a junior Treasury minister). He later became Minister of State for Northern Ireland and then chairman of the Party.

\section{The private sector}

Consultants and contractors were not utilised to anything like the same extent as they had been in the Operational Strategy, for reasons which will become obvious later. However, consultants were commissioned by the Steering Committee to prepare a feasibility study, examining the best way of developing a shared data communication network. This will be described more extensively below, but the decision was made to seek a third party supplier from the private sector. A number of companies with data communication expertise, such as BT and Mercury, and a number of others who wished to develop such expertise all submitted tenders for what promised to be an enormous government contract.

The Department for Trade and Industry was not involved in this procurement, despite its responsibility for the health of British industry. Other government departments, including Trade and Industry, subscribed to the GDN after it was in place.

There are a number of other groups, including users and their unions as well as citizens and civil liberties groups, who could conceivably have been involved in the GDN, but were not actually consulted. During the development of the Operational Strategy, these groups were not actively involved, but ideas about their needs and interests were created and deployed by other relevant social groups. In the case of the GDN however, not only were they not actively involved in its development, they were never deployed by participants such as the CCTA or the major government departments. As we shall see, their total invisibility did have a major impact. 


\section{The FTS2000: The Cast ${ }^{17}$}

No single department is solely responsible for IT within the federal government in the US. However, the Office of Management and Budget (OMB), part of the Executive Office of the President, is the single most important organisation, responsible for the development, coordination and implementation of central government IT.

The Government Services Agency (GSA) advises the OMB on all matters concerning the procurement of IT. The GSA is also responsible for developing policies and guidelines to facilitate the sharing of IT resources amongst agencies. Thus, there is a longustanding commitment to share resources and services between departments. The GSA has four main services: Public Buildings, Federal Property Resources, Federal Supply and Information Resources Management. The latter oversees the federal government's local and long distance telecommunication system and its data processing systems. It also has an advisory role to help federal departments to use their IT effectively and efficiently. The GSA has to compete directly with private companies. Departments are not obliged to use its services. Over $95 \%$ of GSA's funding is earned through charges for services, and not through direct funding from the federal budget. It employs more than 19,000 people throughout the country. (GSA Annwal Report, 1989) The GSA was the central player in the development of FTS2000, but in 1987 it was challenged by the group we meet next.

The Government Operations Committee (GOC) oversees government spending generally and the GSA in particular on behalf of Congress. The General Accounting Office (GAO) is responsible for auditing government accounts. Both of these have responsibility for ensuring accounts are in order and that government receives value for money in its procurement.

The emphasis placed by all of the bodies so far described is on value for money. The interests of citizens as taxpayers took precedence over the needs of citizens as users of services.

The Federal Communications Commission is a Congressional committee, responsible for developing and enforcing the regulatory framework. The FCC is governed by five nembers of Congress, who reflect the ballance of power in Congress.

As with the GDN, the large federal departments, including Energy, Agriculture, Employment, the Internal Revenue Service and Health \& Human Services, were the intended users of the FTS2000. They were dissatisfied with the quality of the old FTS, provided by AT\&T, and were keen to have an improved voice communication service.

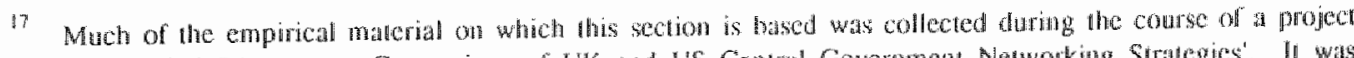

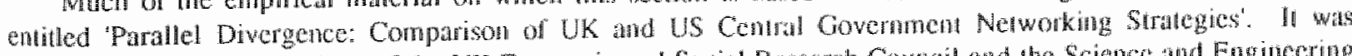

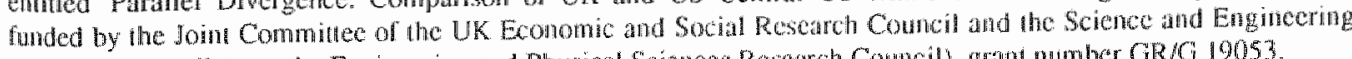
Eresearch Council (now the Engineering and Physical Sciences Rescanch Council). grant number GRe 1905 .
} 
This was true for both management and lower level civil servants. Unions did not play any significant role, neither promoting nor opposing the development of the FTS2000. Notable by their absence, agan similar to the GDN, were the security and defence agencies.

There were several private companies involved in the shaping of the FTS2000. AT\&T, the dominant player in US telecommunications, supplied the old system with its eleven million miles of transmission lines described earlier. Its dominant position in domestic and private commercial voice traffic was replicated in the public sector market. Sprint and MCI, emerging market players, were eager to gain access to the largest single customer in the US, namely the federal government. These private companies used the US lobby system to conwey their viewpoints to the various committees described above, in particular to the Government Operations Committee. Many of the other players, including Bennington, the first director, identified the vendors generally and AT\&T specifically as the driving force behind the F 752000 .

Within the US system of government, there is a constant tension between an individual's right to privacy and government's obligation to freedom of information. Nonetheless, as with the GDN, the FTS2000 did not attract much interest from bodies concerned with civil liberties, such as the American Civil Liberties Union (ACLU).

As with the GDN, the dominant groups in the development of the FTS2000 were senior ciwil servants and private industry. The GSA, however, did play a much more central role than did the CCTA, and through the GOC, politicians became more involved in the US than they ever did in the UK. Users - as citizens or street-level bureaucrats - were marginal. Questions of use will be addressed later, but in the early stages, we shall follow the actors and wait for the users to present themselves.

\section{Social groups - relevant for whom?}

Before beginning the stories, let us puse briefly to reflect upon the status of the relatively invisible groups identified in both the GDN and the FTS2000: the users, whether they be civill servants with direct contact with citizens or the citizens themselves. In the discussion in Chapter 4 about relevant social groups, I endorsed the social constructivist dictum of 'follow the actors'. This makes visible the constructed nature of both actors' and analysts' accounts of a technology and it can provide a space for including relatively powerless and silent groups. Accepting this dictum is to accept that following the actors necessarily leads the analyst to even the quietest and weakest social groups as long as the analyst remains alert. In the case of the Operational Strategy, this was adequate. Following the powerful actors in their deployment of the powerless and voiceless signposted for the analyst the important trophic role of taxpayers and chamants. In the cases of the GDN and the FTS2000, as shall be seen below, it is slightly different. There was an awareness on the part of the more powerful groups of the less powerfull users and citizens. Whereas in the development of the Operational Strategy such groups were constantly brought into the 
frame, at least rhetorically; in the GDN especially, they were kept beyond the boundaries of the system. In some senses, this could be part of the explanation of the eventual failure of the system, but that would be to misunderstand what constitutes success and failure.

Bijker (1992) identifies two methodological problems with the practice of following the actors to identify relevant social groups. First, it is difficult to decide whom to treat as spokespersons; and second there is a danger that only vocal attributions of meaning are analysed. There is an additional worry for analysts dealing with contemporary issues which is that some actors might be overlooked because one simply did not ask the actors the appropriate questions. What one subsequently interprets as a significant absence should more accurately be understood either as a failure in one's own research practice; or, to be more charitable to the analyst, as a genuine difficulty in following the actors. ${ }^{18}$ All forms of interpretative research encounter, in some form or another, the danger of missing sources.

Let us leave aside this perennial problem faced by all researchers, the problem of how to tell the best story one can, consistent with the evidence. Instead let us turn to a problem which some have identified as specific to both actor network and social constructivist accounts of technology. Both approaches have been accused of being 100 mechanistic in their exhortation to follow the actors (Bijsterveld, 1991; Martin and Scott, 1992). We shall return to this general methodological problem in the Conclusion, but let us now examine what it means in practice for the description of the the GDN and the FTS2000.

In the case of the GDN, and to a lesser extent of the FTS2000, if I had simply followed the actors in my attempt to recreate the tendering process, I would never have seen the users. I noticed their absence in my pre-interview reading of the trade press. Years of reading the management of innovation literature as well as the more theoretically informed economics and sociological literature had sensitised me to the importance of users so that I felt justified in raising questions about their role. Users have become a common part of the discourse of technological change, at leasi since Enid Mumford's work on sociotechnical systems and Project SAPPHO. ${ }^{19}$ Following previous analysts led us to ask respondents about what the GDN and the FTS2000 were to be used for and who was to use them. Following the actors is not sufficient, and when Latour (1996) claims this is what he is doing, he is being ironically disingenuous. ${ }^{20}$

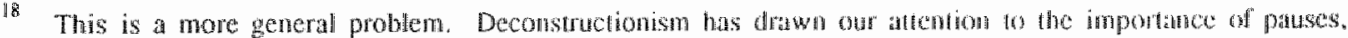
silences and absences. They are indeed significan. But there is of was the worry for the reflexive (insecure) andlysi that it is not that there are major onissions requirtig explamation bul mother that perhaps one simply did not ask the right questions, or not in an appropriate way.
}
For an application of the socio-technich systems approach te compuler design see Mumford and Weir (1979) and Mumford (1981). For details of Projec SAPPHO sece Scicnce Palicy Reseanch Unit (1972) and Rothwell (1974). A summary can also be found in Freman (1982).

20 When Norbert sells the young enginecring studen, "Our job is a cinch. We just lollow the playtess." (Latour. 1996. p.10), he does not really meam it. 
This illustrates the problem with a simple-minded reading of social constructivism. To implore researchers to follow the actors is to give primacy to the actors. One needs to remember another fundamental tenet of social constructivism, namely the principle of symmetry. Truth and falsity, success and failure need to be explained symmetrically. Analysts are also part of the social world, so perhaps the insights of actors and analysts also need to be treated symmetrically. We shall return to this in the Conclusion.

\section{The Government Data Network}

\section{Choosing the route}

In early 1986, a small group of senior officials from the Inland Revenue, Customs \& Excise, the Home Office and the Department of Social Security met together informally to discuss the possibility of developing a single data communication network for their shared use. Prior to this, departments had been developing their own networks as the needs arose. Each department had several different networks, which had been installed at different times to perform different tasks. This group of senior officials wanted to explore whether or not there were economies of scalle to be realised from creating a single network to be used by all.

In May 1986, this informal group was formally constituted as a Steering Committee with a brief to identify the options for developing a shared network. One option would have been for a single department to be entrusted with the task of developing a network, but this option was excluded from the terms of reference given to the consultants commissioned to prepare a feasibility study. A single department, working for the good of all, would have been able to achieve the same economies of scale, but it would not have been acceptable to the other participating departments. Thus, inter-departmental rivalry made it easier to seek a private sector solution. In addition, the Treasury explicitly ruled out the in-house solution on the grounds that no single department would have adequate financial or human resources. However, the Home Office, with its long experience of developing radio, radar and other security-related communication systems believed it had the capacity to develop an appropriate system. It continued to resent being excluded for some years. ${ }^{21}$

Another excluded possibility was to continue with the status quo, with departments developing their own networks. The principle of the 'greater good' was adopted. Even though a department might have been able to develop its own network at a cost lower than its individual contribution to a common facility, it would be for the greater good of government to participate in the development of a shared facility. This was done in spite of the fact that Eryl Thomas of the CCTA, the man responsible for the development of the project, recognised that most communication took place within departments; there was very little communication between departments.

\footnotetext{
21 When asked abou this during inbervicws. the immediate response was, 'you are pressing on some sore spots
} here: 


\section{TABLE 5.1 GDN: THE GOVERNMENT DATA NETWORK: CHRONOLOGY}

1969 Post Office Act

1981 Telecommunications Act

1982 Mercury awarded an interim license

1984 BT Act/creation of Oftel Data Protection Act

1986 informal meetings by senior civil servants to discuss shared data communications facilities

1986 May Steering Committee established/Request for Information issued

1987 Jan Statement of Service Requirement issued

1988 Feb Invitation to Tender issued

1988 May contract awarded to Racal

1990 Racal invited to bid for integrated voice and data service

1991 Duopoly Review 
PACTEL Consultants conducted a feasibility study, comparing two alternative private sector solutions. One solution was to go direclly to BT which had experience in offering similar services to the private sector; the other solution was to seek third party involvement. PACTEL recommended the second as being more cost effective.

Closure around the idea of a private sector solution to meet government's collective data communication needs occurred early. This was despite the Home Office belief it had the necessary expertise; despite the fact that very little inter-departmental communication took place and despite the fact that much communication within departments was speech and not data. ${ }^{22}$ Nonetheless having decided to seek third party involvement in the provision of a shared, data communication infrastructure, there were a number of organisational and contractual possibilities still to be decided. Very simply, the choices were as follows: * To build a network that the CCTA would subsequently own and operate. This would be the usual public sector route.

* To build a network that the CCTA would subsequently own but which the third party would continue to operate. This is known as 'facilities management', a common private sector solution at that time to meeting data communication needs.

To provide a data communication service, paid for on the basis of usage, leaving the design, management and ownership of the physical infrastructure to the third party. This is known as a "service contract', and would be a significant departure from usual civil service practice.

To help them to make their choice, the Steering Committee issued a 'Request for Information' to Computer Science Corporation (CSC - which supplied the network for the US Treasury), EDS (one of the first and most successful facilities management companies) and Cable and Wireless (Mercury's parent company). In addition, members of the Steering Committee themselves visited the United States to examine similar sized networks, especially for the proposed new federal telecommunication system, FTS2000.

The third option, a service contract, was chosen. This was a radical departure for people who like to 'feel, touch and love' their equipment as one Home Office official expressed it. Rather than seeking a contractor who would build a network for the four departments to share, the Steering Committee decided to look for a contractor who would provide a data communication service for the four departments. Choices between black boxes would be left to the contractor.

\section{Choosing a stupplier}

The next task was to produce a Statement of Service Requirement (SSR) which described the service required; the choice of hardware was left to the bidders. The SSR was issued

\footnotetext{
22. The CCTA duriag an interview, estimated that only $10 \%$ of communication within departments involved data. Mhoreover. and the significance of this will become clearer later. the experience within the CCTA and the participating deparments was of voice commenicalion. not data communication.
} 
in January 1987, and over twenty companies made enquiries to the CCTA as a result. The SSR described the service levels required but it did not prescribe the equipment to be used. ${ }^{23}$ The SSR prohibited a single company from bidding on its own and it disallowed BT and Mercury from leading consortia. (Thomas, E, 1988, p.43) Further stabilisation of the technological frame, the goals, problems, strategies, etc. that guide interactions between actors, was being achieved through exploitation of the international rules governing open tendering and open procurement at that time. Both the European Community and the General Agreement on Trade and Tariffs (GATT) require open procurement in public purchasing. At that time, only procurement of goods was covered; services were excluded. ${ }^{24}$ The Steering Committee was thus able to establish its own criteria. ${ }^{25}$ They insisted bids come from consortia because they believed no single organisation could undertake the full range of tasks required and because they believed the danger of being locked into proprietary standards would be greater with a single supplier.

Invitations to Tender were issued in February 1988 to three consortia: Racal with Scicon; Cable and Wireless (Mercury's parent company) with ICL and BT with CSC. On May 19. 1988, it was announced that Racal/Scicon had been awarded the contract. This joint venture subsequently was incorporated as Racal Data Networks Limited (RDNL).

Tenders were evaluated on the basis of price and on an assessment of the ability of the company to deliver. The Racal bid is believed to be two per cent lower than the most expensive. It also offered the most conservative technological solution, an X.25 OSI conforming network. It is claimed that the ICL/Cable and Wireless bid offered a more radical technological solution which aimed to be forward compatible with ISDN, at that time a very unstable technology. In other words, referring back to the earlier discussion about networking, the option chosen reflected a European telecommunication bias conservative in some ways but radical if one really wanted a data network.

This account has emphasised the administrative and legal background to the building of the GDN. I shall argue later that the Steering Committee aimed to construct a new player in the telecommunication market, rather than a network for data communication. There is a significant absence from the account so far: what would this network actually be used for and who would use it? These questions were asked during interviews. (A list of interviewees is included in Appendix III.) The consistent response was that usage was not the concern of either the Steering Group or RDNL. The Steering Group consistently and actively pursued a division of labour: RDNL was charged with the ask of creating a

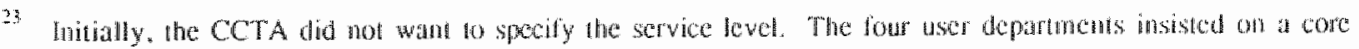
serwice level. against which lenders could be evaluated.

24

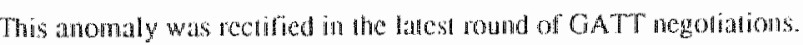

25 Al a public conference in November 1989. Ken Warren. MP and at that the Chair of the Parliamenary Trade and Industry Commitee. stated that the Minstry of Defence should disguise administrative systems as operational Systems in orden to woid EC/GATT rules and that all govenment deparments should break up contracts into amounts less than 1100,000 which woukd also exempt them from interiarional agreements aboul open procurenent. 
nework that enabled data to be transmitted between government offices around the country, described by the CCTA as 'bulk piping". Their job ended at the point in the wall. What was to be connected to these points, what data would be communicated and between whom, were all questions for departments to address after the event. The lask of RDNL and the Steering Commitee was to provide the infrastructure; they assumed the applications would follow, as day follows night.

\section{Finding some urers}

Much had been achieved in a very short space of time: a private company, RDNL, with no previous network management experience had been awarded an opportunity to develop a data communication network infrastructure. BT, reporting industry gossip, suggested that RDNL was "scared when it was awarded the contract.. afraid it would not be able to deliver". Although it did not possess any relevant experience, it was a company with a long history of govermment defence contracts; a civil servant who liaised between the CCTA and RDNL after the contract was awarded was impressed by the political astuteness and ministerial contacts of RDNL. To minimise the technical risk to itself, RDNL used existing technologies to connect users who had no previous access to nor experience of data communication.

The original intention of the Steering Committee was that the four initiating departments should be the only users for the first three years of the contract, in order that they could monitor closely the progress of the network. When the Department for Trade and Industry (DTI) considered its network options in 1987, it enquired about joining the GDN group and was told it could not. This confirms the view that the Steering Committee was not evangelical in its attempt to create a technological frame around shared data communication within govermment. No attempts were made lo entoll a wider range of actors in their vision of a furure of networked public administration.

Athough the Steering Committee semed oblivious not only to the needs of users but more significantly even of the need for users, RDNL was well aware that its long-term profitability depended upon maximising the number of user deparments. The provisional closure achieved by the Steering Committe began to come undone. Because this was a service contract, RDNL was paid according to the amount of usage. During 1989 and 1990 , RDNL devoted considerable marketing effort to getting other departments to sign access agreements. It was successful in this effort: fifteen deparments did sign access agreements." (See Table 5.2) However, the DT1, having been spurned earlier, now found that the GDN did not meet its needs. This success in getting departments to sign is all the more remarkable for two reasons. First, they admitted they did not discuss with departments how such a nework could improve communication, productivity, quality of working life or service delivery: they simply discussed network delivery. Second, the

I6 Sce Wyat (190019) fon at discussion of the factors influencing deparmental choices about whether of not io join the GDN. Fachs can be grenped under thee headings: he nature of the dita (extent fo which data is standardised. time torgent and predictable: wolume: need lor security): organisutional requirements (geographical spread: need for intrideparmental communication) and departments lechological capabilities (in-house expertise: existing facilities). 
departments how such a network could improve communication, productivity, quality of working life or service delivery; they simply discussed network delivery. Second, the 'greater good' argument deployed in the early stages to justify the development of a shared infrastructure was unravelling. It was not only the DTI which found the GDN did not meet its needs. Both the Departments of Employment and the Environment found the GDN to be more expensive than what was availabe via BT; however, both came under strong ministerial pressure to sign up to the GDN.

Many departments did sign access agreements, although doing so did not mean access was actually provided; moreover, a large part of one of the original Group of Four subsequently opted out of the GDN. The police, which come under the auspices of the Home Office, announced they would not use the GDN. They argued it would be politically unwise for the police to use the same physical network as other parts of government, because civil liberties anxieties would be raised by what could be seen as police access to a giant government database. This awareness and deployment of potential public perception of the GDN was unique in its development. In addition, the Home Office claimed the GDN was for administrative data communication; whereas the police had operational needs which would occasionally require access to the network that could be both unpredictable and urgent. Again, albeit in quite a limited way, the Home Office set itself apart from the others by making claims about the nature of its communication needs to exclude itself from the GDN and by raising the spectre of public concern about security. (In a tacit recognition of the importance of enrolling actors in the building of technical systems, the CCTA stated that not only would they need to solve the technical problems of security but they would also need to convince the world that they had solved them'.)

Actual usage of the GDN per se was negligible. Departments simply did not need to communicate with one another very often. Rather than providing a new shared data communication service, RDNL increasingly took on the task of managing existing networks which deparments had already developed themselves for which they subsequently sought extemal network management and operations support. Throughout the 1970s and 1980s, Racal had been a major defence contractor. The contract for the GDN provided it with an opportunity to develop some network management skills which it was able to put to use after the 1991 Duopoly Review, which allowed companies other than BT and Mercury to operate communication services. In the terms of the GDN contract, RDNL is not obliged to pay the British government any royalties based on the technologies developed. It was recognised at the beginning that the technology was not sufficiently novel to warrant this. What RDNL gained was experience. In the early 1990 s, RDNL was awarded a cellular license and has won a major European contract to provide a network to support the Schengen agreement.

Let us recap this story briefly: the GDN was initiated in Britain in the mid-1980s by a small group of senior civil servants from the CCTA and four of the largest departments. 


\section{TABLE 5.2 DEPARTMENTS WHICH \\ SIGNED ACCESS AGREEMENTS FOR THE GDN}

\section{Initial Group of Four:}

Inland Revenue

Customs \& Excise

Social Security

Home Office

\section{Later Signatories}

Employment (February 1989)

Treasury (May 1989)

Office of Population Censuses and Surveys (June 1989)

Her Majesty's Stationery Office (July 1989)

Energy (August 1989)

General Registry Office - Scotland (September 1989)

Intervention Board for Agricultural Policy (September 1989)

Department of Trade and Industry (November 1989)

Welsh Office (February 1990)

Transport (February 1990)

Ordnance Survey (February 1990)

Health (April 1990)

Department for National Savings (May 1990) 
Departing from usual practice, it was decided to award a service contract to a private company, RDNL in May 1988. RDNL had no prior telecommunication experience but it offered the lowest price and the safest technology. It was awarded a contract to provide a network infrastructure; it was not expected to develop applications; no one was. Despite theroic efforts from RDNL to expand the group of departments involved from the original four, usage of the GDN remained negligible, even by the original four. RDNL increasingly took on the management of deparments existing networks, thus was able to gain network management experience.

It did not have to be like this. During the same time period, in the US, individuals and groups with objectives similar to many of those involved in the GDN were also attempting to develop a shared communication infrastructure for use in government. As we see below, this story unwinds rather differently.

\section{The Federal Telecommunications System for the year 2000}

\section{The Early Years}

Since the early 1960s, AT\&T had provided US central government departments with a telephone system, FTS, for their exclusive use; a telephone system that was larger than the sum of the seventeen largest corporate telephone systems in the US. There was growing concern that this system could not meet any further demands placed on it, either in terms of greater use or new services. Moreover, changes in AT\&T's tariff structure in 1981 had resulted in higher prices. As a result, individual agencies were exploring the possibility of buying or leasing telephone services from one of the new entrants in the US telecommunications market. For data communication, individual departments assessed their own needs and made their own procurement decisions. As in the UK, different departments had different networks installed at different times to perform particular tasks.

In 1984, the GSA began to search for a replacement for the FTS, prompted by fears that its existing voice system was becoming overloaded, obsolete and expensive. It also had a general commitment to providing shared services. Initially, it was anticipated that the FTS2000 would simply replace the old FTS, providing a new and improved voice system. At that time, both the GSA, which would oversee any development, and AT\&T, which had provided the old FTS, had vast experience in telephony and relatively little experience in data communication.

The GSA actively sought to involve user departments and vendors during the early stages of discussion between 1984 and 1986. During that time, the GSA was thying to identify all potential problems and the range of solutions available, prior to issuing any call for tender. Four areas of agreement were reached:

1. A service contract would be awarded, in which the GSA would specify the services required and leave the choice of hardware to the contractor. Once in place. government departments would only pay for the services used. The GSA would act as an oversight agency, with the vendor taking responsibility for building and 
mantaining the new work. As with the GDN in the UK, the cost of the network was to be bome by private industry, which would provide the hardware and manage all of the technical aspecis.

2. Rather than simply substituting one voice system for another, the opportunity would be siezed to develop an integrated set of woice, data and video services.

3. The contract would be awarded to a single supplier.

4. Departments would be free to choose whether or not to use the system. It was believed this would ensure competitive pricing, not permitting the supplier to charge monopoly prices if departments were free to go elsewhere.

The aims of the FTS2000 neally fused both political and practical requirements. Rather than an in-house system, priwate industry would provide the government with the solution to its communications needs, the government would pay only for the services provided, and the voluntary nature of the contract would assure competitive prices. On January 7 , 1987, the Request For Procurement (RFP) was released.

\section{Ente Stage Right: The Govermmont Operations Conmitee}

So far, the GSA had been successful in enrolling both users and vendors into a shared vision of the FTS2000, and achieved a provisional closure around the four issues mentioned above. However, they had neglected to enlist the support of Congress. In particular, they had not involved the Government Operations Committee (GOC), the Congressional committee with jurisdiction over virtually everything which affects the operation of the federal government. Its job is to ensure the economy and efficiency of government operations. The Chair of the Committee at that time was Jack Brooks, who had a long-standing interest in and commitment to new technologies. In 1965, he introduced what came to be known as the Brooks Act, suggesting that the best way to improve government service and to reduce costs was to invest in automation. Like the GSA, he also believed that communications services should be shared between federal agencies.

In order to atract the interest of potential vendors, such as AT\&T, US Sprint, MCI and Martin Maretta, GSA lad stated that the contract was worth approximately US\$25 billion. It was potentially the biggest contract any one telecommunications company would ever win. There were, werefore, implications for public policy. AT\&T, the largest telecommunication company in the world, was well entrenched in the field of US federal communications, and thus could be seen to have a significant advantage in the bidding process.

Lobbyists working on behalf of other telecommumications suppliers brought the FTS2000 to the attention of Brooks and his committee. The GOC decided that issues of unfair advantage had to be challenged and proposed that the FTS2000 be sourced by two vendors. But, in order to ensure sufficient traffic volume, a dual sourced system would have to be based on mandatory usage. An extended battle ensued between the GSA and the GOC. As one participant observed, there were knock down, drag out fights in this office and in our conference room and everywhere else for six, seven, eight months'. 
Wanting to be seen to favour competition, AT\&T supported Brooks' two vendor concept. Political expediency dictated the outcome. A presidential election was looming, and unless a compromise could be reached, the FTS2000 concept would never become a reality. On September 25, 1987, the GSA capitulated on two of its previous hard won agreements. Rather than awarding the contract to a single supplier, it was agreed to split the contract between two vendors. Rather than usage being voluntary, any department, agency or bureau funded by Congress would be required to use the FTS2000. It was also agreed that the split between the two vendors should not be equal. Network $A$ would be larger with $60 \%$ of the traffic; Network B would have the remaining $40 \%$, thus ensuring some element of competition in the bidding process.

The technical specifications for the FTS2000 were hastily re-written, and somehow the major shift from one supplier to two, which was agreed between January and September of 1987, was not reflected in the re-write.

When Congress got involved, they decided, well, we'll make it mandatory for all services, and we'll split it into two networks, and we'll have multiple bidders for portions of it. GSA did not come back with a new RFP or amended RFP that says now if data is mandatory, what are your requirements? They left them as they were originally, which were inadequate. (user, Department of Agriculture)

The issue of inter-operability between the two networks was ignored, at the expense of ensuring the robustness of the network. During the 1964 Cuban missile crisis, the old FTS had failed. It was considered vital that such a situation should not be repeated. Both Networks $A$ and $B$ had to be separate from the public switched network so that should a national emergency arise which might increase traffic or result in a failure of the public system, government communication would not be hindered. 


\section{TABLE 5.3 FTS2000: CHRONOLOGY}

1984

1984-6

1987 Jan Sept

1988 Nov Presidential election (George Bush wins)

1988 Dec contracts awwarded (60\% to AT\&T, $40 \%$ to Sprint)

1990

\section{AT\&T divestiture}

talks between GSA, users and vendors

Request for Procurement (RFP) issued

revised RFP issued

voice system completed

Three bids were submitted. The contracts were awarded in December 1988: AT\&T won the contract for Network A and US Sprint won Network B. The resulting networks are incompatible, such that traffic cannot be exchanged between them, somewhat limiting the administration's capacity for internal communication during the much feared and widely touted national emergency.

The concept of re-competition was established. An internal re-competition based on price and quality would occur in years four and seven of the contract. At each re-competition, up to $40 \%$ of either company's share of the network could be awarded to the other vendor. Thus, even if the same company 'lost' each time, there would still be two companies supplying the network, maintaining an element of competition. Quite what this would have meant for users we shall never know, as subsequent developments in internetworking overtook these events.

\section{Using the system}

The FTS $2000^{27}$ is a huge network: by April 1991, only a year after its introduction, it had more than 1.3 million users and in 1992 it handled nearly 3 billion minutes of switchedvoice traffic. The usage of the system is clearly related to its pattern of development as outlined above. The voice side of the network was well understood by the GSA, users and vendors. As a result, the specification was excellent, and the transition of the old voice system was completed in 1990 , eighteen months ahead of schedule.

27 Despite the foregoing discussion about the way in which the FTS2000 becance two networks, I will continue to flollow the actors and refer to it in the singular. 
Voice communication accounted for $87 \%$ of the network's traffic. Voice was regarded as a mature, saturated market, and had been forecast to grow by only $4 \%$ per annum. Within the first year, however, voice traffic increased by $50 \%$. Data communication accounted for $10 \%$ of the remaining volume, making video communication almost non-existent. Before examining the reasons for the relatively low up-take of data communications, the explanations for the massive increase in voice traffic will be outlined.

The first reason relates to the poor quality of the old FTS and the compulsion on agencies to use the new FTS2000. The GSA had underestimated the number of agencies which had been diverting voice traffic away from the old FTS because of its inferior quality. Because they were compelled to use the new FTS2000, growth in voice traffic was far higher than had been anticipated.

Second, the improved quality of service and the lower cost of calls on the FTS2000 ted to greater usage. Also, facsimile (fax) communication appears as voice traffic. In recent. years, the growth of fax communication has increased exponentially, even for internal communication, thus some paper post has effectively been converted to voice traffic.

Finally, the new capacities of the FTS2000 were used to improve the quality of public services. For example, both the Internal Revenue Service (IRS) and Health \& Human Services developed a range of enhanced ' $800^{\prime}$ freephone services, allowing clients to make enquiries via the telephone rather than by visiting an office in person.

There are two possible explanations for the rather limited use made of the available data services. First, departments failed to play a major role in shaping the data side of the system. The revisions to the RFP following the decision to split the contract did not involve changing the technical specifications. Thus the FTS2000 is not tailored to their data needs. Users were sceptical of both the GSA's and the vendors' knowledge of data communication as most of their previous experience had been with voice.

When the FT 2000 contract was negotiated, it really was only negotiated for voice and the data part is just, you know, catch as catch can...the people who did that [GSA] didn't know anything about data. (user, Intemal Revenue Service)

They [AT\&T] do it in a kind of standard way...They have some knowledge of data but they had no concept of what's out there in the real world in a big netwotk like ours. They had no concept. (user, Department of Agriculture)

Second, there had been considerable doubt over whether the FTS2000 would actually happen. Users had anticipated protracted litigation by any unsuccessful bidders. Many departments had been on the verge of committing themselves to new data systems, and then found themselves in the position of having these systems refused by Congress. In some cases, this was further complicated by the deparments having already decided upon their needs and selecting a vendor which could best meet these. The USDA'S DEPNET was a Sprint system, yet the allocation of departments to networks had put USDA into Network A with AT\&T (see GAO, 1991 a). 
The GSA intended to keep related departments, agencies and bureaux on the same network. ${ }^{28}$ Agencies with requirements which could not be met under the terms of the contract for the FTS2000 would be allowed to seek an alternative. Even then, agencies' acquisitions of these requirements must represent value for money, and not adversely affect the cost-effectiveness of the FTS2000. One agency which does not use the FTS2000 is the FBI, which demands a higher level of security than is guaranteed by the FTS2000. (This is similar to the outcome in the UK, where the Hone Office also pleaded special status, based on the security requirements of the police.)

The GDN Steering Conmittee had taken a laisser-faire approach to the ways in which the system might be used. It might be expected that the mandate that departments use the FTS2000 would encourage more and varied use of the system. With a few exceptions, however, use of the system was limited to substitution, replacing the old way of doing something with the new. ${ }^{29}$ Even in the more technologically adwanced departments, there was a reluctance to challenge accepted patterns of organisation, expressed by one respondent as follows:

It looked to us as if Agriculture could make significant savings by coming over to FTS2000. The way they have chosen to do that transition is by what they call the 'mirror image'. You know, they take what they have got, and they implement it onto FTS2000 and then they think about optimising it. That makes the transition easier, but it clearly reduces the benefits. (Government Services Administration)

One justification for contracting private companies to provide the system had been to overcome the shortage of technical staff within government. The lack of innovative use of the system can also be explained by this shortage:

I think the technology thas gone well past our workforce. And what has happened over the past ten years is that the government has lost most or all of its expertise.... and we're depending a lot on companies to do what really should be the government's role ... these companies are really doing most of the jobs that former technical people in the government did. We've lost them all. (member of Government Operations Committee)

Users expected an improvement of quality in service and a reduction in cost. Although the quality of the voice service improved, the price of the service came under attack from user

\footnotetext{
2R Agencies which hat long standing relationships with one of the winning vendors. found themselves inexplicatbly

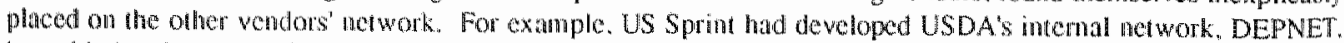
but with the alloestion ol deparments to noworks. USDA was placed on network"
} 
departments, oversight agencies and Congress. ${ }^{50 c a u s e}$ of the economies of scale possible with such a vast system, the GSA expected to be able to maintain lower prices. The old FTS cost up to 40 cents per minute, the FTS2000 cost 11.5 cents, but due to the plummeting cost of telecommunication in the US, the equivalent service in the private sector cost only 9.5 cents. Having failed to meet the price expectation, the long term future of FTS2000 was doubtful.

\section{Reciprocal invisibility: malleability and technological frames}

Here we have two rather curious stories about two attempts to create shared communication networks for some of the major goverment departments in Britain and the US during the late 1980s. There are a number of similarities between the two cases: they took place at similar times in a heady climate of telecommunication re-regulation in both countries; both aimed to improve and alter intra-departmental communication; both used X.25, OSI technology. But there are also a number of key differences, summarised in Table 5.4, 'Characteristics of the GDN and FTS2000. The most curious features of each system can however be very simply expressed: the GDN is an infrastructure in search of some applications, and the FTS2000 became not one network but two incompatible networks. How can we understand these curiosities of non-trivial government expenditure? I will use some ideas previously introduced from both evolutionary economics and the sociology of technology to understand these stories, but first let us retum briefly to the policy issues raised in Chapter 2 , namely privatisation, data protection and the potential threat to the legislative process. In Chapter 4, we saw how central such policy issues were to understanding the development of the Operational Strategy. Clearly, the prevailing climate of privatisation in fin de siecle Britain was also influential in shaping the course of the GDN. Partly this was related to the desire of the Conservative Government to privatise and reduce the size of the public sector. A third party supplier, such as RDNL, reduced the need for technical staff within government deparments. ${ }^{31}$ To a much greater extent, however, the process surrounding the award of the contract for the GDN to RDNL was related to the Government's policy of introducing greater competition and private ownership into the supply of telecommunication services.

Data protection and the primacy of the legislative process played a less visible role in the GDN than they did in the Operational Stategy. Historically in Britain, government departments have not been allowed to exchange data about individuals or other legal entities, with the usual caveats relating to the prevention or solving of crime and to the protection of national security. Even then, the police and security services are required to seek approval from the courts or the Home Secretary each time they wish to gain access to data about a single entity from a variety of sources. This has been enshrined in the UK

\footnotetext{
30 The CAO (1991b) condemned the FTS2000 pricing structure. The report luelled media speculation that support for the system within Congress would be withdrown.

34 See Wyatt and Rush (1989) for a discussion of the skills issues surrounding the development of the GDN, especially the dangers, of not having sufticicht numbers of skilled infornal staft.
} 
Data Protection Act (1984) which incorporates amongst its eight principles that the purposes for which data is being collected must be disclosed at the time of collection and that data collected for one purpose must not be used for another. Data provided to the DSS for the purpose of making a benefit claim cannot be passed by the DSS to the Irlland Revente for the purpose of tax collection. The GDN - a data communication network to be shared between different government departments - could only be used to share data for intra-departmental purposes. Inter-departmental communication is simply not allowed. This serves to underline again the

Steering Committee's preoccupation with the infrastructure. Questions of how it might be used and what data might be exchanged between whom were not questions to which it gave much, if any, consideration. ${ }^{32}$ In the US, competition within the telecommunication service supply industry, following the divestiture of AT\&T in 1984, played a major role in shaping the nature of the system. In addition, the interest and involvement of politicians reinforced the role of the political and legislative processes in what might appear to some as mundane operational matters.

As a result, as with the GDN, the process was successful in providing a relatively new supplier, in this case Sprint, with an opportunity to challenge the power and dominance of the dominant player, AT\&T. FTS2000 was used and it was successful in altering the structure of the telecommunications supply industry but it did not transform the workings of US central government. Exchange of data is not prohibited in the same way as it is in the UK, but in practice departments do not need to communicate with one another.

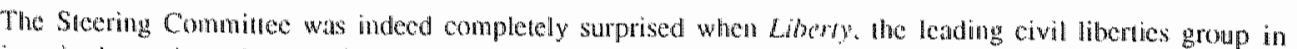

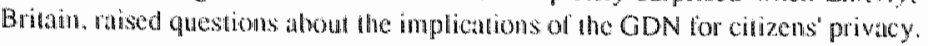




\section{TABLE 5.4 CHARACTERISTICS OF THE GDN AND FTS2000}

\begin{tabular}{|c|c|c|}
\hline Characteristic & $G D N$ & FTS 2000 \\
\hline type of network & data & voice, data, image \\
\hline no. of networks & one & two \\
\hline $\begin{array}{l}\text { compulsion on user } \\
\text { departments }\end{array}$ & voluntary & mandatory \\
\hline $\begin{array}{l}\text { we of } 3 \mathrm{rd} \text { party } \\
\text { contracts }\end{array}$ & radical departure & usual practice \\
\hline $\begin{array}{l}\text { involvement of } \\
\text { politicians }\end{array}$ & negligible & significant, via $\mathrm{GOC}$ \\
\hline restrictions on bidders & $\begin{array}{l}\text { BT \& Mercury } \\
\text { excluded from leading } \\
\text { bid; all bids hadl to } \\
\text { come from consortia }\end{array}$ & none \\
\hline standards & $\mathrm{X} .25, \mathrm{OSI}$ & $\mathrm{X} .25, \mathrm{OSI}$ \\
\hline infrastructure & infrastructure only & $\begin{array}{l}\text { infrastacture plus } \\
\text { applications }\end{array}$ \\
\hline security services & police opted out & FBI excluded \\
\hline decision-making & top-down & top-down \\
\hline
\end{tabular}


The first question to ask about interoperability is how much do these agencies talk to each other? The answer is very, very little. If you ever study the off-net calling even on voice, you'll find that it's a miniscule amount. Agencies talk within agencies. (Sprint, Network B supplier)

It was not our intent...to rewire the West. It is our intent to provide teleconmunication services to the extent that was [already] available...So, if there's no facilities there, there's no facilities there. All we said was we'd go where they go...but if there's no wire there that's not our business. (AT\&T, Network A supplier)

The GDN did not work, it was not used, it was not successful in any commonly used senses of these terms. The account of the GDN presented in this chapter can be interpreted as another example of a technical system which failed through lack of attention to the market, the needs of users or the social relations of its prospective use. Those involved in the development of the GDN consistently expected that use would follow the provision of the cables. There was no Schumpeterian entrepreneur, inventor-entrepreneur, heterogeneous engineer or system builder. It could be seen as another example of what Friedman calls user relations constraints, or of a failure to enrol a variety of actors or of a mismatch between the technology and the market. In the remainder of this section, we shall return to this notion of 'mismatch' which appears in the literature in a variety of guises.

The process of the development, implementation and use of large technical systems in government is an exiremely complex process mediated by technical, social, political and economic factors. Given this, it should not be expected that the implementation of a wide area network within a government administration would lead directly to given, technically determined changes. Nonetheless, that is exactly what was expected by those responsible for the development of these new systems in both the UK and the US. It was assumed that if street-level bureaucrats were provided with a network that spanned the country and included many, if not all, government departments then they would find innovative and useful things to do with it. This assumption was used to justify the pace and direction of change; but expectations were not fulfilled. Christopher Freeman would explain this mismatch between the technology and any new organisational form as being the result of a paradigm shift, in this instance from old electro-mechanical technologies to new technologies based on microelectronics.

Whereas technological change is often very rapid, there is usually a great deal of inertia in social institutions, buttressed by the political power of established interest groups, as well as by slow response times of many individuals and groups. The structurat crisis of the 1980 s is in this perspective a prolonged period of social adaptation to this new paradigm. (Freeman, 1987, p.16)

There are different possible explanations for the inertia of social institutions. Before seeking an explanation in the terms of the social constructivists, let us continue with the ideas of Freeman and other evolutionary economists. In Chapter 2, I suggested that one of 
the defining features of a new techno-economic paradigm is that it has the potential to affect all spheres of economic activity. This would suggest we are in the midst of a paradigm change, one based on the low costs of storing, processing and communicating information. New information technologies permit far more precise control and greater intensification of the flows of data and information central to, inter alia, public administration. These gains have yet to be fully realised because institutions, management styles and working practices are still geared to the old paradigm based on mass production.

One of the distinctive features of IT expounded by its enthusiastic proponents is its malleability. A key element of its alleged transformative potential is its ability to manipulate all sorts of digital signals, representing everything from rave music to stock prices to observations of the moons of Jupiter. It is this malleability, and its pervasiveness, which gives rise to the claims that IT has the potential to alter radically existing sets of social and economic relationships. This was the premise on which the GDN Steering Committee and to a lesser extent the GSA based their expectations: by the relatively simple act of making the infrastructure available, the work of government would be conducted more effectively, new relationships within government and between government and eitizens would emerge and new services would be developed. The GDN Steering Committee was always very clear about this, if not about how it would happen. The GSA did at least incorporate existing communication facilities within the FTS2000 and attempt to include related departments together following the split.

Imagine being confronted with a blank page: the possibilities are endless but it is often very difficult to begin." It is nearly always easier to work with an existing text. With the blank page and pen, those of us brought up in literate societies have some idea of what the expectations are. Imagine being confronted with a pad of paper and pen, never having previously seen either. This was similar to the situation experienced by the thousands of ordinary civil servants who were supposed to sieze the opportunities opened up by the GDN and the FTS2000. Many civil servants had never previously used any type of computer and now they were faced simply with a socket in their office walls. Not surprisingly, the ways in which attaching devices to that socket might alter their working practices were not immediately obvious. There was no equivalent of an already written text with which to negotiate. Infinite choice is no choice at all. It was not possible to alter the working practices of civil servants simply by providing them with an infrastructure or by upgrading their voice network. By ignoring existing working relationships and practices, no space was available for negotiating new relationships. Of course, there is a crucial difference between the two systems: the users of the GDN, in effect, never turned on the switch; whereas the users of the FTS2000 did enjoy the benefits of a seamless substitution.

The concepts of 'technological frame', introduced in Chapter I and of 'reciprocal simplification' can also shed light on these tales of mismatch between technological

33 This is an experience I have had all too lrequently white writmen this bouk. 
opportunity and social actuality. "Technological frame" is used by Wiebe Bijker to include the goals, problems, problem-solving strategies, theories, tacit knowledge, general engineering practice, cultural values, devices, material networks and systems used by social groups to develop an artifact. Technological frames are the product of stabilisation and closure, reflecting reduced interpretative flexibility.

There has been some discussion of this and related concepts within the literature. Bernard Carlson (1992), following Harry Collins and Trevor Pinch (1982), uses 'frame of meaning' to refer to the interaction of cultural beliefs and class interests with business strategy and technological design. 'Such frames ... directly link the inventor's unique artefact with larger social or cultural values.' (Carlson, 1992, p.177) He explicitly identifies the importance of the assumptions designers make about who will use a technology.

Madeleine Akrich and Bruno Latour (1992) use the concept of 'script" to denote the social behaviours that inventors design into an artefact. As Carlson argues, this is too narrow because it emphasises social relations between users and designers but does not take account of how designers draw on a wider cultural frame. Moreover, the notion of 'script' implies some kind of technological determinism. Once the social relations are designed into an artefact, it is not clear if or how they might change. Their concept of 'script' seems to draw upon transactional analysis (although Akrich and Latour do not mention this). In transactional analysis, the potential for personal transformation comes through consciousness, making it possible to change one's future behaviour. It is not clear how any transformations could occur once a particular set of social relations has been inscribed onto an artefact. Thus, this notion of script is peculiarly at odds with much of Latour's other work. Bijker explicitly acknowledges the mutually constitutive nature of the social and technical. Thus, his 'technological frame' is better able to transcend the distinction usually made between the social and the technical, elucidating the single world inhabited by both social groups and technical artefacts. ${ }^{34}$ The notion of mismatch between technologies and social institutions used by Freeman and others is useful, but it also posits a clear distinction between the two which is ultimately not very helpful in understanding the dynamics of socio-technical change.

A technological frame results from a reduction in interpretative flexibility, which occurs when there is greater stabilisation and a reduction in the ambiguity in the meanings surrounding a technology. In the preceding chapter, we saw that process in the construction of the technological frame of the Operational Strategy, one which eventually hardened around a centralised system and cost savings.

In the case of the GDN, we have a slightly different example. Within a very short period of time, three important boundaries were established; first, that it be provided by the

It 1 have chosen wa ignowe the raher wacuous contribution made by Angus Buchanan in the 1991 debate in Technology and Callowe letween historians and sociologists. Buchanan, repesching the historians, suggests that all that Bijker means by technological frame is simply 'team spirit' 1991 , p.371). John Law. responding on behalf of the sociologists. argnes this is a complete misunderstanding. In order to share the same technological frame, it is nof necessary for people 10 like one anoher nor even to know one another. (1991. p.380) 
private sector; second, that only the infrastructure be provided; and third, that it only be used for data communication. This assisted the Steering Committee to meet its two primary goals: to achieve economies of scale through developing a shared infrastructure and to open up the telecommunications market. The problems and goals of other actors are less clear. The supplier, like any private company, wanted to maximise its profits and market share. The users were not given a voice.

It is tempting to regard the FTS2000 story as similar to that of the GDN. Rather than being a serious attempt to transform the operation and delivery of public admimistration, it too was more successful in its effort to transform the telecommunication service supply sector. There are important differences from the GDN, however. One of wheh is that the overlapping and shifting interests of different groups over time is more apparent. The GDN was much more unidirectional. At different moments in the development process for the FTS2000, different groups dominated, new actors were enrolled and new alliances were formed. Later in this section, we shall see how the development process described above can be understood in terms of what Callon (1987) and Law and Callon (1992) call a process of reciprocal simplificarion, simplification simultaneously of the project and of the actors' needs and interests. Moreover, the success of this process depended on the successful deployment by both the GSA and the GOC of the rhetoric of market competition. ${ }^{35}$

Interaction between different actors in the dewelopment stage suggests not only collaborative relationships, but also competitive ones. Each actor is likely to have different interests, imperatives and expectations. Indeed, any one group may have more than one set of objectives, and therefore more than one role in the development of the system. Relationships between the actors are also many and varied. For example, vendorvendor relationships may reasonably be expected to be competitive; whereas vendor-GSA and vendor-CCTA relationships have a shilting pattern of dependency. Over time, these relationships may alter; as a result, the relationships are inherenty unstable, and therefore the development of any large system is at best precarious because stabilisation is not. achiewed for any significant length of time. Both cases suggest that the network did shift its ground, maintaining some of the same elements; but as relationships changed, so did other elements in the sociontechnical ensemble. Analysis of the empirical evidence suggests a pattern in these complex, shifting relationships.

In order to establish a coalition to promote the development of something like the FTS2000, the issue must be simplified to enable different groups to join. Relatively few actors were involved during the initial stages of the development of the system.

Responsibility for this early phase lay with the centrat agency, the GSA. The existing technology was denigrated, ensuring that a search for a replacement system took place. It thus became an acceptable evolution, predicated on the belief that the communications issues faced by the administration could be overcome by the implementation of a wide

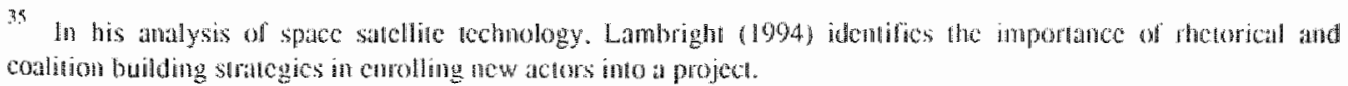


area network. Further, provided the infrastructure was in place, it was assumed it would be used. Such an approach was 'logical' and enabled other relevant social groups, such as vendors and oversight agencies to become involved.

The individuals involved at this early stage were high level IT policy makers and vendors. Although representatives from larger, more technically sophisticated departments were involved in the discussions, differences were minimised: street level users were constructed as a homogeneous group who would build applications to run on the infrastructure provided for them.

For the FTS2000 to develop further, it had to move from this early developmental phase to one of implementation. The involvement of the 'new' group, the Government Operations Committee, resulted in a re-assessment of already agreed principles and of existing relationships. Market competition, which was espoused by GSA as a justification for a voluntary system was challenged by the Committee as potentially tying the government to one network provider, with the concomitant risk of distorting in the broadler telecommunication market. The GSA, the originator of the system, lost its position of unquestionable centrality. A fundamental challenge from within the rhetoric of market competition enabled the project to continue but resulted in a marked change of direction.

'Implementation to use' is another critical phase, with the introduction of new actors, in the form of heterogeneous groups of users. Previously, users had been treated as a homogenous group, whose needs were perceived as being limited to the need to interface easily with the FTS2000; transparency was the goal for the technical specialists. However, the very transparency aspired to by the technical specialists ensured that business simply continued as usual. The centrality of voice communication within the FTS2000 specification reinforced that tendency; and, as we saw earlier the inclusion of data was very much an afterthought.

The Steering Group initially assumed that the provision of a 'transport network' for communications in government would ensure and determine its subseguent use, an assumption barely supported by the calse of the FTS2000, and even less so by that of the GDN. The integration of voice, data and video, though seen as an obvious technological development and attempted with the FTS2000, did not occur in either the US or UK administrations.

Decision-making surrounding the development and implementation of the systems was top-down; with the result that many end-users were unfamiliar with the systems; technological capabilities remained unrecognised, and the systems were understood simply in terms of their ability to generate cost savings.

This was compounded by the aspiration of technical specialists to implement a system with the minimum disturbance to end-users; cut-over should be smooth and the technical interfaces transparent. Systems builders wanted the system to be invisible to users. The reverse was also true: users and their needs were invisible to the putative system builders. Instead of labelling this as a process of 'reciprocal simplification', maybe it is better termed 
'reciprocal invisibility'. But where the ease of use is such that the user barely notices the change, does this not simply compound the strategy of simply substuting new technologies for old, whilst maintaining existing organisational structures? Do users need to overcome 'problems' with a system in order to appreciate its different capacities? An old defininon of technology is that it is something which hurts when you drop it on your foot. Rephrasing the earlier question, do users need to stub their toes in order to realise the existence and potential of a new system?

\section{Conclusion}

The process of closure and the stabilisation of a techological frame around a very narrow vision of the technical infrastructure was perhaps one degree of stabilisation too far. The GDN Steering Committee did not appreciate the heterogeneous nature of a technical system, that what are commonly understood as the social and the technical are mutually constitutive. Focusing on the creation of an infrastructure, using standard hardware, with the expectation that people will find ways of using it once it is in place is to beg disaster. Especially in the design of a communication system, designers also need to be sociologists to understand what people want to communicate to whom, when and why. Rather than understanding the ways in which technologies are actively constructed through the recreation of the social relations of their production and reproduction, the Steering Committee pursued a strategy informed by their technologically deteminist world view, in which applications and uses would automatically follow the introduction of a system.

Is this not being too harsh, ascribing failure simply because no one used the artefacts? This is the conclusion one is forced to draw when following the analysts. From a variety of theoretical perspectives, analysts have repeatedly drawn our attention to the importance and needs of users, or the market. Recall the principle of symmetry discussed in Chapter 3 and its application to method introduced in Chapter 4 . If we shift our viewpoint to follow the major actors, the GDN must be considered a success. It is not widely used; it has not served to transform the workings of public administration but it was successful in introducing a new player onto the stage of the European telecommunication service supply industry. The issue of symmetry in actors' and analysts" concepts will be pursued again in Chapter 6. For the moment, we shall remain with the GDN and FrS2000.

Let us re-adjust the set. There was one set of social relations of which the GDN Steering Committee was very aware, which was astutely deployed and subtly altered. The telecommunication service supply industry was given a new player, RDNL. Rather than building something internally, decisions were taken to ensure that RDNL, a relative unknown in the telecommunication service industry, was provided with an opportunity to develop its network management skills. This it was able to do, not so much through the provision of the GDN itself but through taking over the management and operation of extant networks within central government departments. The Steering Commiltee did not engage with the conventionally understood community of users, lhose groups who might be expected to use the system in their work or about whom data might be communicated or who are paying for the systen. But the Steering Committe did engage with the 
community of telecommunication service suppliers. Obstacles were created to eliminate internat provision of the GDN and regulatory loopholes were exploited to exclude existing dominant players. Through their silences and absences, other actors colluded in this but occasionally the silence was broken, as when the Home Office withdrew claiming its needs were different, not least that it had some user needs to consider.

Similarly with the FTS2000, following both actors and analysts, we initially observed the enthusiasm of many actors to use a single supplier to provide a new voice system, with some data and video communication as an added bonus. This provisional closure was undone when suppliers lobbied Congress to examine more closely the competitive implications of such a solution. The GOC was enrolled; alliances shifted. An attempt was made to stabilise a somewhat different technological frame, one which took the commitment to competition a step further by introducing competition in the provision of a shared infrastructure.

The questions of whether or not the FTS worked, was used or was a success are even more difficult to answer than they are in the case of the GDN. Providing a smooth transition from an old voice system to a new one and making its use compulsory ensured a high level of use. But hoped-for transformations in the operation of government did not occur to any great extent because ways in which the newer facilities of data and video communication might be used were not pursued and political exigencies dictated the bizarre outcome of two incompatible networks. As with the GDN, focusing on the creation of a new infrastructure with the expectation that people will find ways of using it once it is in place is to misconstrue the nature of socio-technical change.

Despite the mandatory nature of the FTS2000, there were remarkably few changes in the operation of the US administration. Indeed, the network has been used primarily to substitute for previous practice. In that respect, the FTS2000 was markedly different from the GDN, in that the former included a new-for-old replacement of the voice network, as well as introducing data and voice services. The take-up, however, has predominantly been of the familiar voice services. Neither the vendors nor the GSA seemed particularly concerned by this. At that time, they were still operating within a culture of voice communication.

This chapter has also explored further some theoretical ideas central to the social constructivist approach. Here they have been used in a more integral fashion, without the conceptual pauses and digressions upon which readers might have stubbed their own toes. To be consistent with the principle of symmetry, I have suggested that in identifying relevant social groups we should not only follow the actors but also the analysts. This chapter has exposed some of the limits of following both actors and analysts which are briefly mentioned below but to which we shall return at greater length in the final chapter. The usefulness of Bijker's concept of technological frame was also identified, especially when compared with similar concepts which do not recognise the duality of the technical and the social. Related to this are the problems and dangers of assuming that IT is infinitely malleable. It may be, but allowing a high level of malleability may be counterproductive. It is only through circumscribing patterns of use that IT will come to be used 
thus limiting the degrees of freedom users may enjoy, but it is only through this circumscription that continuity in the social order can be achieved.

These rather odd little stories raise a number of interesting questions about our understanding of terms often used interchangeably, such as working, use and success as opposed to non-working, non-use and failure. It is tempting to suggest that the technology worked but was not used and was successful only in terms of increasing the number and the market position of players in the wider British and American telecommunications markets. The technology worked - it was standard equipment which worked elsewhere; technology based on the OSI protocols preferred by voice specialists. But this type of argument suggests that whether or not we can speak of technologies 'working' is either a question of whether or not they somehow effect change on the physical world or whether their features derive directly from the physical world.

Winner asserts that the question of use is irrelevant because it implies that any single individual or group has access to a technological process along the whole of its conception, operation and result.' (1977, p.228) On the contrary, he argues, in complex, large-scale systems, individuals can only enjoy (or endure) the final products or services. He prefers the term 'utilisation' as it emphasises the largely passive role most of us have in relation to large, complex technical systems.

It is possible to appreciate the distinction Winner is making, especially as it does resonate with the concern central to this book about the endurance of technological determinism as a way of understanding the relationship between social and technical change. The lack of understanding of and involvement in complex technologies raises many concerns about appropriate and meaningful forms of their governance. But this is not to say that the question of use is irrelevant, nor does the question of use only become important at the end of some linear process of technological development. In the Operational Strategy, the GDN and the FTS2000, it has been demonstrated how essential users and notions of users are in the development of large technical systems. In the case of the Operational Strategy, ideas not only about the possible needs of civil servants, claimants and taxpayers but also ideas about how senior management wished to constrin their relationships all played a role in shaping the development of the system. In the cases of the GDN and the FTS2000, such ideas about users and their relationship to one another were barely in play. To create a large technical system, some notions of the dimensions of largeness, including the extent of the social relationships it is intended to support, have to be present. We shall return to this again in Chapter 6, the Conclusion.

The stories presented here highlight again the principle of symmetry in which it was suggested that success and failure must be explained in similar terms. It is not acceptable to say that technologies work or are successful because of some inherent superiority they possess in relation to the physical world, and that others fail for social reasons, such as lack of financial or political support. Success and fallure have to be explained symmetrically. The GDN illustrates how one can explain failure in social terms extremely well. The GDN draws on standard technologies, that work and were used successfully by British Telecom, Mercury and many other organisations throughout the world. But the 
GDN itself does not work because it was not used and it was not used because no consideration of potential patterns of use had been considered in its development. ${ }^{3.34}$ Thus, I have to disagree with Edward Constant (1984) when he argues that not only does a technology have to work, it also has to fit within its social context. This suggests there is a clearcut distinction in which working can be understood separately from social context, not dissimiliar to Freeman"s notion of social lag or mismatch.

Technologies are not only about artefacts and the knowledge of how to use them, they are also about social relationships. ${ }^{37}$ Creating a new socio-technical system involves creating ideas about how it might be used. In many studies of innovation this is characterised as connecting market research with nore formal R\&D activities. This may be adequate for capturing what is involved in the development of a new product innovation. In the development of a new communication system, however, relationships between users need to be considered in order that it may work. Those involved in the GDN and the FTS2000 failed to realise that a technical system also includes the socio-technical relationships involved in its production and use.

\footnotetext{
36 The GDN story is mot diswimilat to the one teht by Catherine Bertho-Lavenir (1988) about the development of the telephone systen in Fuance between 1879 and 1979. She atcmpts to answer the question of why the French telephone system wits so appalling for so much of its history, and suggests that part of the explanation lies in the separation of RQD from any understanding of user meeds. She identifies three main actors: operators, oquipmen manuficcurers and the state in iis rote as regulator. As with the GDN. the absence of users is notable. But use and ideas about use are not inclevant: on the contrary, they are wital for the success of the system.
}

37 In his study whe US an tratic system. La Pone (1988) suggests that one of the success factors of a network technology is that complex organisational and managerial imperatives are loull ino the system. This is agan a way of suggesting that social refations must be incorporated within the technology. 


\section{CHAPTER 6}

\section{CONCLUSION: TECHNOLOGICAL DETERMINISM \\ IS DEAD; LONG LIVE TECHNOLOGICAL DETERMINISM}

\section{Introduction}

The underlying objective of this book has been to explore the variety of ways we attempt to make sense of the role of technology and the process of technological change in contemporary society. The specific focus has been on the ways in which networks of people, groups, switches, wires, computers and regulations have tried to fix one another, even if only temporarily, in the public administrations of the UK and US. Despite valiant attempts by analysts to kill and bury technological determinism, it remains, Hydra-like in its resistance. It persists in the actions taken and justifications given by many actors; it persists in analysts' use of it to make sense of the introduction of technology in a variety of social settings; it persists in manifold theoretical and abstract accounts of the relationship between the technical and the social; it persists in the responses of policy-makers and politicians to challenges about the need for or appropriateness of new technologies; and it persists in the reactions we all experience when confronted with new machines and new ways of doing things.

This book has demonstrated that we cannot ignore teclinological determinism in the hope that it will disappear and that the world will embrace the indeterminacy and complexity of other types of accounts of the technology-society relationship. In the concluding section of this chapter, I shall argue that we in the STS community cannot simply despair of the endurance of technological determinism and carry on with our more subtle analyses. We must take technological determinism more seriously, disentangle the different types, clarify the purposes for which it is used by social actors in specific circumstances. Moreover, I shall argue that in order to do this we have to recognise the technological determinists within ourselves. Before doing so, I shall summarise the tales of system building: the Operational Strategy and the Goveriment Data Nelwork in the UK and the US Federal Telecommunication System for the year 2000. The major public policy issues identified in Chapter 2 will then be re-visited in light of these tales. Telling these tales has required intervening in the methodological debates of the new sociology of technology. These skirmishes are sketched out before concluding on the common ground of science, technology and society studies and the place technological determinism occupies on that ground. 


\section{Pink, white or gray elephants? Illusion, vainglory or reality in building information networks}

In the preceding two chapters, I have presented three stories about attempts to build information networks. The Operational Strategy of the British Department of Social Security (DSS) was developed, in a long and painful manner, during the late 1970s and throughout the 1980s. It was the second attempt to move the DSS from a system for administering social welfare benefits that required huge amounts of paper and clerical labour to one which could utilise the processing power and speed of information systems. The Operational Strategy initially aimed to improve operational efficiency, quality of service to the public and job satisfaction for DSS staff.

A compromise between a batch processing system, familiar to technical and clerical staff within the DSS, and a fully distributed, networked system was reached. The compromise involved area computer centres, growing from an initial number of three to a final number of nine. Not only did this allow for the development of a more robust network, it also served to reduce the concentration of technical staff in a single location. This latter consideration became more important following successful strike action by technical staff in both 1985 and 1987.

Developing software for the cumbersome social security system was not an easy task. Social security regulations have evolved over decades, containing elements of nineteenth century poor laws, inter-war national insurance rules and post-World War II welfare state provisions. The software development was simplified following the introduction of the 1987 Social Security Reform Act, which replaced the complicated mixture of discretionary and administrative rules with a more straightforward rules-based system. These legislative and organisational changes contributed to shifting the focus of the Operational Strategy towards an emphasis on administrative rationalisation, away from the concerns with quality of service and jobs. Provisional closure was achieved around the desire to finish within the deadline in order to start making financial savings, not least through job reductions.

In the early days of the Operational Strategy, the voices of many groups were heard, from all levels of the DSS. Users, i.e clients, had no direct voice, but most other groups claimed to speak on their behalf. The Operational Strategy did not deliver the high levels of integration promised in its early days. Large quantities of paper still move around between offices; local offices continue to be organised on a benefit by benefit basis. Nonetheless, 35,000 terminals were installed in over 1000 offices in less than two years at the beginning of the 1990s. These are used, and despite many problems and the abandonment of two of the three original objectives, staff would not want them to be removed.

The provisional closure achieved at the end of the 1980s was instrumental in bringing some obduracy to an institution that has been highly contested for at least twenty years 
and continues to be so. This closure was achieved through a series of efforts to simplify objectives and to reduce the number of groups whose voices could be heard. The DSS is committed to a socio-technical organisation which will constrain its subsequent changes. Choices have been made which limit the range of options open to future actors. Some issues will remain open and new strategies for dealing with them may emerge.

The Operational Strategy is a messy and complex story that cannot be adequately represented in a few brief paragraphs, but it is in many ways an everyday story of systems development. It took a long time; it did not deliver all that was expected; it did deliver a few things that were not anticipated. People use it and now cannot imagine life without it. No one ever claimed life would never be the same again following the implementation of the Operational Strategy. Its roll-out was simply one step in a constant, messy process of negotiation between a heterogeneous collection of individuals, groups, legal regulations and electro-mechanical devices.

Chapter 5 presented the rather more curious stories of the British Government Data Network (GDN) and the US Federal Telecommunication System for the year 2000 (FTS2000). The question that really needs to be answered in these cases is not why did these systems fail but rather why did anyone ever think they might succeed? The GDN is the story of a single data communication infrastructure to be shared by departments in a country where exchange of data is forbidden by law. The FTS2000 is the story of how a single integrated network to be shared by government departments became two incompatible networks.

The GDN was initiated in Britain in the mid-1980s by a small group of senior civil servants, from the CCTA and four of the largest government departments, all of whom wished to develop shared data communication facilities. After extensive consultation, largely with external groups, it was decided to award a service contract to a private company, a radical departure from usual practice. BT and Mercury were excluded from leading a bid, though both companies participated in consortia which did make bids. The contract was awarded in May 1988 to RDNL, a company with a history of defence contracts but with no telecommunication experience. It offered the cheapest price and the most conservative technical solution, a network utilising OSI and X.25 standards. RDNL was contracted to provide a network infrastructure. It was not charged with developing applications. No one was. Decisions about what data to communicate between whom were left to the users. For many civil servants, discovering a socket in their office walls was the first exposure they had to the miracle of data communication. Actual usage of the GDN was negligible, despite heroic efforts on the part of RDNL to expand the group of departments with access from the original four. Despite the lack of usage of the GDN per se, RDNL took on the task of managing departments' extant networks and exploited its opportunity to dewelop network management skills; an opportunity from which it has subsequently profited. The GDN Steering Committee pursued a highly technologically determinist strategy: provide an infrastructure and wait for the world to change. It was a short-sighted technological determinism, however. The Committee expected change, but in was not clear what form any change would take. As discussed extensively in the previous 
chapter, the GDN Steering Committee was successful in providing an opportunity for a new player to enter the UK telecommunication market.

The FTS2000 was similar to the GDN in that it also began with a concern to achieve economies of scale through the development of an infrastructure to be shared by different federal departments; again, an infrastructure to be provided by a third party. It differed in two important respects. First, it was an integrated voice, data and image network. Second, it attracted the attention of politicians because of the potential size of the contract (over one million users and worth over US $\$ 25$ billion) and its long-term implications for the telecommunication market in the US. Following lobbying of Congress by smaller telecommunication suppliers, it was decided to split the contract and the network into two unequal parts. This was done in a climate of great political and time pressure, prior to the 1988 presidential elections. Contracts were awarded to AT\&T and Sprint in December 1988. The resulting networks were incompatible. Both conform to OSI standlards, reflecting both companies' experience in voice communication rather than data. The voice side of the networks has been very successful; data and image less so. The FTS2000 worked in terms of substituting new for old means of communicating voice across long distances, but it did not transform the means by which federal agencies conducted their business. As one respondent suggested, "it was not our intent to rewire the West." Perhaps they never meant to alter the workings of government; they wanted a decent telephone service and a company other than AT\&T to have a share of the federal cake.

Questions about how the GDN and FTS2000 might be used to communicate data were not given much attention by the groups responsible for awarding the contracts. Nonetheless, these groups did demonstrate an acute awareness of the changing political and economic climate within which the telecommunication industry operated.

Writing about the GDN and FTS2000 in the late 1990s is rather like trying to describe a flea while ignoring the elephant upon which it rests. Given my concern with understanding scale, this is simultaneously both a completely appropriate and completely inappropriate analogy. It is inappropriate because it implies the GDN and FTS2000 are small systems, whereas I have argued earlier that they are large technical systems on a number of dimensions, including cost, numbers of users, geographical spread. But it remains an appropriate analogy because I have also argued that our understanding of scale has to be specific and contextualised. The elephant in the corner which I have been ignoring so assiduously is, of course, the Internet. Readers familiar with the formative years of this particular elephant will have noticed its brief appearance early in Chapter 5 , when the technical choices confronting those concerned with internetworking were described. The administrative branches of the British and American governments did not pick the winner. On the whole, however, both governments did make an each-way bet. The US Department of Defense and the British National Physical Laboratory were both involved in the development of TCP/IP. The GSA and the CCTA were in good company in their support of OSI over TCP/IP. It was not only official standards bodies such as the ISO and its members who supported OSI. On several occasions, DARPA offered to sell ARPANET to AT\& T. They were refused: AT\&T thought this data communication business would never catch on and that it was incompatible with their core activity of 
voice communication. (Hafner and Lyon, 1996, p.232) The Internet now dominates popular, policy and commercial debates about the emergence of a so-called 'information society. It serves as the focus of many of our dreams and nightmares; presented as a radically new technological system, with both utopian and dystopian possibilities.

This book adopts the perspective of Mr. Gille, the simian of Lal Fontaine's fable: we are concerned with the ants not with the larger creatures. The analysis of the Operational Strategy, the GDN and FTS2000 presented in earlier chapters does help us to understand the Internet phenomenon ${ }^{\prime}$ and related large technical systems. Before re-visicing the general methodological and theoretical concerns of this book, let us approach them more gradually, via a brief detour back to the policy issues raised by the development of IT systems for use in the public sector.

\section{The three Ps: Privacy, primacy and privatisation}

A number of public policy issues, initially identified in Chapter 2, provided part of the context for the development of the three systems. The three issues which have been of most concern, playing roles of varying significance in each of the three stories, are data protection, privatisation and the potential threat to the legislative process.

Data protection laws have been established in most western countries for at least fifteen years, reflecting an acknowledgement of the importance of informational privacy and the need for restraint on the gathering and processing of data about individuals. Unfortunately, as Jeroen van den Hoven (1995) argues,

[O] ur provisional understanding of privacy as implied and codified in these regulations is constantly teased out by information technological innovations ... The lack of a systematic and fundamental understanding of privacy often gives rise to incrementalist public policy, incoherent law and regulations, and difficulties in adjudicating new IT applications. (p. 129)

The Operational Strategy and the GDN both illustrate this confusion and incolerence. The GDN exemplifies the potential for administrations to be inconsistent. Historically, in Britain, government departments have not been allowed to exchange data about individuals or other legal entities, except to aid in the solution or prevention of crime and the protection of national security. Even then, the police and security services are required to seek approval from the courts or the Home Secretary on a case by case basis. In such a legal climate, enshrined in the UK 1984 Data Protection Act, developing a data communication infrastructure to be shared by government departments seems a rather odd project. Data provided to the DSS for the purpose of making a benefit claim cannot simply be transmitted to the Inland Revenue for the purpose of tax collection. The GDN

\footnotetext{
However, in time-honoured fashion. the Intemet is the object of one of my nexl projects. funded under the auspices of the ESRC's "Virtual Sociely?" programme.
} 
Steering Group's preoccupation with the technical infrastructure obscured this legal blot on the landscape of the benefits of sharing.

The Operational Strategy also indicates some level of confusion and difficulty with the concept of privacy. The efficiency gains and quality improvements articulated in the original objectives of the Operational Strategy depended upon a level of data integration previously unknown. This became lost in the haste to get the system up and running, but has returned in the guise of organising benefit delivery around client groups, whether they are single parents, people suffering from disabilities or long-term unemployment and in the less subtle guise of combatting social security fraud.

The Operational Strategy provides at least two examples of how technical developments can undermine the much vaunted (by politicians at least) primacy of the political process over any mundane technical developments; and thus lends support to the notion that technological determinism is often invoked by policy makers to justify particular course of action and also that technological determinism may sometimes have some explanatory power. As already mentioned at the beginning of this chapter, developing software for the cumbersome social security system was not an easy task. The 1987 Social Security Reform Act replaced the complicated mixture of discretionary and administrative rules with a more straightforward rules-based system, thus simplifying the software development task. Some respondents have suggested that some version of the Social Security Reform Act was necessary for the success of the Operational Strategy; the old system simply could not be codified. On a more prosaic level, the system for making cold weather payments to people on income support after periods of prolonged cold weather became fully automated and rules-based, removing discretion not only from local office workers but also from politicians who had previously changed the rules on an almost annual basis. ${ }^{2}$

Privatisation, the leimorif of political life in Britain and the United States throughout the 1980 s, is the most significant influence on all three efforts to develop new technical systems. In the UK, in both the Operational Strategy and the GDN, the desire to reduce dependence on technical staff within the public sector was very strong, especially for the Department of Social Security which had been disrupted by strike action by computer staff during the aborted development of CAMELOT, the precursor to the Operational Strategy, and during the development of the Operational Strategy itself. For the GDN, using a third party supplier such as RDNL reduced the need for technical staff within government departments. To a wery large extent, the process of awarding the contract for the GDN to RDNL was related to the Government's policy of introducing greater competition and private ownership into the supply of telecommunication services.

In the United States, competition within the telecommunication service industry, following the divestiture of AT\& $T$ in 1984, played a major role in shaping the nature of the system.

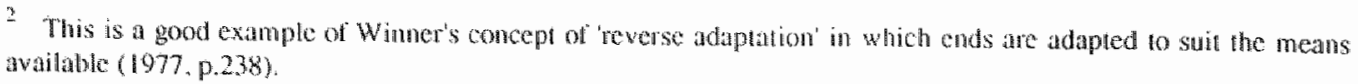


The active interest of politicians in this area strengthened the role of political processes in what might otherwise appear as a mundane operational matter. It was because of the activities of smaller telecommunication companies and of members of Congress that the decision was made to split the contract into two parts, so that some level of competition would necessarily ensue. In order to beat the deadline imposed by a new Administration following the 1988 presidential elections, no one remembered to write into the new tender the need for compatibility between the two networks. Nonetheless, the process was successful in providing a relative newcomer, Sprint, with an opportunity to challenge the power and dominance of AT\&T.

At best, the individuals and groups involved in the development of the GDN and FTS2000 were sanguine about data applications. They assumed the availability of a technical infrastructure would be sufficient to unleash new and creative patterns of data communication across the two countries. They did not treat techmical and social relations symmetrically. Technological determinism continues to be the model with which many social groups operate.

This brief summary of some of the political issues confirms that there is indeed some justification for decision-makers at all levels to continue to work with technological determinism as a model for understanding socio-technical change. Developments in information technology expose gross inadequacies in our data protection regulations. The implementation of a large information system constrains the options available to those responsible for administering and delivering social security. Moreover, in order to implement that system, legislation which conformed to the norms of technical rationality had to be introduced to replace the piecemeal political compromises which preceded it. All of these outcomes lend credence to the notion that where technology leads, political and organisational operations follow.

\section{The elephant and the rhinoceros: Rules of combat}

The stories presented in Chapters 4 and 5 have added a few pieces to the methodological puzzle of how to study the ways in which messy and heterogeneous collections of people, things and knowledges coalesce (or not) into obdurate socio-technical ensembles. Before turning over the big, interlocking symmetry pieces, let us examine some of the smaller pieces. One of the challenges facing the STS community, a challenge that is relevant to actors, analysts and activists, is to find a middle range theory, one that enables a synthesis of the social shaping of technology thesis with the technological shaping of society antithesis. Thomas Misa (1994, p.139) suggests that one way of developing middle range theory is to study middle range actors, such as manufacturers' organisations, standards bodies or engineering consultancy companies. My own suggestion has been to study middle range technologies, networks used by public administration for example. Middle range technologies which are intended to be used by large numbers of people, especially those intended to process information about even larger numbers, facilitate analyses of what Anthony Giddens would refer to as the shifting relations between the production and reproduction of social life, of the ways in which social order is or is not secured; or what 
Wiebe Biker would identify as a technological frame. ${ }^{3}$ Technological frames, if and when they emerge through the interactions of groups and individuals, serve to guide future interactions. In the cases presented here, the actors involved in the Operational Strategy were more successful in creating such a frame than those involved in the GDN or the FTS2000, enabling us to understand how the Operational Strategy served to structure the practices of everyone involved.

The first piece of the puzzle then is to study middle range technologies, but this returns us to the problem of how to define technological scale. If we follow the actors, and I shall return to the difficulties posed by uncritically following actors later in this section, we might discover very different understandings of the scale of the projects discussed here, as exemplified in Joerges"s (1988) discussion of scale, summarised in Chapter 3. For some of the users of the GDN, it was so small as to be virtually invisible. For some of the users of the Operational Strategy and the FTS2000, they were represented by an increasingly familiar computer or already familiar telephones on their desks. For the policy-makers and civil servants, they were sites of huge political significance, given the importance of privatising and re-regulating the telecommunications industry. For those involved with the Internet, the systems discussed here probably appeared as medium-sized networks, similar to thousands of others. The questions remain - how big was it for me and to which actors should I be listening?

All of the systems incorporated different types of equipment, of both hardware and software. They each involved many different groups of actors, including suppliers, users and policy-makers. All were engaged in attempting to alter complex, social processes in order to function, or not. However, attempts to define and delimit the scale, complexity and geographical reach of each of these systems was an important part of the attempt to achieve closure. Defining scale is not only an analytical problem facing the researcher, it is also a practical one for the actors. The resolution of this problem is necessary for the researcher to circumscribe the object of study, but it is also a problem experienced by the actors. In IT systems, there are two areas where closure needs to be achieved. The first is similar to the stabilisation of an artefact - closure in the machine system: definition and agreement of the problems to be solved, of the "best" way of solving them. The second is related to closure in the sociall system: which groups of actors are involved, allowed to identify and define problems and solutions. Of course, this division between the social and the technical is something that needs to be explained. The two aspects of closure are intimately related, and we can see examples of each in the stories presented here. The central actors in the Operational Strategy were successful in marginalising other actors, in order to narrow the objectives of the Operational Strategy, to focus on efficiency and to exclude concerns with job satisfaction and quality of service. As a result, it became much easier to develop a system. In the case of the GDN, closure in the social system was achieved too soon. Leaving the definition and specification of the project to representatives of the four major departments plus the CCTA excluded too many potential

See Chapter I for a fuller discussion of the relationship lelween Giddens on structuration and Bijker on iechnological frames. 
voices. In the FTS2000, there was closure neither in the social nor in the machine systems. Because the system came under political serutiny, more actors served to expand the social system with the result that previous closure in the specification of the machine system was undone.

What have we learned so far? In Chapter 1 , I described the various ways in which people from a variety of perspectives have attempted to understand the place of technology in enabling and constraining social life. In that chapter, I was keen to demonstrate not only that there were a variety of ways of so doing but also to demonstrate that it was an important and worthwhile activity. A gap remains, however, between theorisations of socio-technical relationships and case studies. Drawing on the cases presented in Chapters 4 and 5, I am suggesting that middle range technologies are a valuable source of data and insight about the ways in which technological and social relationships contribute to the production and reproduction of social order. However, one is forced to draw the conclusion that defining middle range teclinologies is not a simple and straightforward task. Questions of scale are difficult and relevant for both actors and analysts and are particularly acute with respect to strategies for achieving closure. But let us retum to this vexed question of following the actors, raised already by the problem of defining scale.

In earlier chapters I have suggested that the stories of systems development recounted here have been informed by two methodological principles: symmetry and follow the actors". Now it is time to bring them together. Understanding the ways in which technical systems are developed and used is an interpretative process. It is not quite so straightforward as Buchanan suggests in his defence of his 'critical narrative approach':

This is 'narrative' in the traditional sense of aiming at the reconstruction of historical events as closely as possible to the way in which they actually happened, and it is "critical" in the sense that it proceeds by pursuing all the available evidence in order to answer certain specific questions and provides the answers to these questions by drawing out a coherent marrative from the evidence, (1991, p.372)

Of course it is essential to attempt to construct a narrative that is consistent with the evidence available, to tell the best story one can. But Buchanan does not question how the questions to be answered might arise; in other words he does not address the crucial interpretative role of the analyst. The exhortation of Latour $(1987,1996)$ and Bijker (1995) to 'follow the actors' has also been criticised for the same reason as I criticise Buchanan - for failing to incorporate the perspective of the analyst. "Follow the actors" is interpreted as a blueprint for writing narratives, a type of 'social constructivism for beginners': identify actors, isolate their problems and interests, pursue the clues they provide to locating other actors until the time comes when no more actors, problems or interests emerge. In such a process the role of the analyst is to record whatever one is told. to index the documents one finds and to construct the best story one can. If that is indeed 
what Bijker and Latour are suggesting, interpretative research could be conducted by an appropriately programmed robot.

Karin Bijsterveld (1991) presents such a critique, based on her own study of debates about the nature of ageing which took place in the Netherlands after World War II. Two discussions took place, one amongst practitioners and another amongst academic gerontologists. They understood the physical and psychological experience of ageing very differently; as a result they offered different solutions to some common problems. Neither group perceived controversy because they were completely unaware of one another. Bijsterveld argues that a strictly observed Latourian 'follow the actors' approach would have resulted in a very partial account of the Dutch debate. Following the actors in one camp would not have led the analyst to the other. Having made this critique she does not offer any way forward, except by implication. The implication is that analysts" knowledge, methods and critiques should be given equal status to those of actors when writing histories of the development of scientific knowledge and technical artefacts.

Brian Martin and Pam Scott (1992) also criticise the 'follow the actors' dictum, based on their analyses of the development of systems for automatic vehicle identification. They adopt the useful technique of analysing the same case study using two different theoretical frameworks: actor network theory as an exemplar of the new sociology of technology and non-decision-making as an exemplar of political economy. They identify a number of potential problems with actor network theory:

It assumes that following actors, reading their texts, and listening to their conversations is a method that can efficiently reveal all that can be known about the sociotechnical world. Actor-network theorists claim that they can carry out their studies without prior conceptual theorizing involving the macrosocial context, but in practice many of their studies appear to draw on concepts of social structure to understand social behaviour and to choose research strategies. ... [There] is the problem of identifying the relevant actors... As Russell (1986,335) points out, groups may be omitted/ 'either because they had no voice in the process or because they were indifferent to the specific options on offer.' It is allso possible that certain actors may be invisible, serving or having their interests served without directly participating. (pp.488-9)

The important dimension that would have been lost in the stories presented here had I not included it is the role of the users, both rhetorically and in practice. I have suggested that the success of technical systems depends upon the ability of people and organisations to find a use for the output or service provided. Histories of the development of technical systems, most notably Hughes (1983) on the history of electricity supply, have emphasised the role of inventor-entrepreneurs - individuals who understand not only the capacities of the technology, but have a vision of the market potential and an ability to involve

The protagonists un Richard Powers' novel, Gahatea 2.2 (1995) could attempe lo design a neural net capable of passing the comprehensive exams in STS at Stanlond, Conell or MT mether than, as fappens in the nowel, to pass the comprehensive exim in English literature at a fictiond tised Princetom. 
financiers and others in that vision. Essential to the success of the socio-technical system is the ability to recognise the importance of users, or the market as it is more usually expressed. It is not only a question of understanding individual users" needs, it is also essential to understand relationships between users.

Often it is possible to define clearly who the users are or will be. But with IT networks in public administration, there can be two sets of users. The first group is those people who are conventionally considered to be the users; employees who use the system to access information in order to perform their job tasks. In many cases, there is a second group of users; clients or customers whom the more direct users ultimately serve with the help of the system.

It is necessary to have two types of 'double vision" to understand the role of users. First, it is important to distinguish between 'real' users in the 'real' world and the images of those users and their relationships theld by systems builders. Second, there might also be users who are served by the system but who do not have any physical contact with it - as with the first type of users, distinctions need to be made about their actual social rellations and the images held of them. Only in the case of the Operational Strategy is it possible to see how social relations between both sorts of users were transformed as a result, at least partially, of the direct involvement of users with direct contact and the rhetorical deployment of the users without direct contact.

The examples of Bijsterveld, Martin and Scotl and my own analysis of the importance of users in the development of the systems under consideration here all highlight the important and obvious fact that, as I argued in Chapter 5 , analysts also inhabit the sociotechnical world they are attempting to study. They will bring to that study their own theoretical frames and will exercise their interpretative skills in their attempts to write narratives. The professor of sociology, Norbert $\mathrm{H}$ and the sociologically naive, young engineering student with no name who were attempting to identify the reasons for the failure of Aramis, a Parisian automated public transport ystem, would have written very different stories iff each had been left to his own devices. (Latour, 1996) Bijker and Latour canl be criticised for not making explicit their commitment to treating actors and analysts symmetrically; their critics could be accused of excessive literal mindedness, a bizarre mistake when reading Latour who makes very clear his conmitment to irony.

'Follow the actors' can be rescued by recourse to the higher principle of symmetry. Actors' and analysts" identification of other actors and their interests should be treated symmetrically. If I had simply followed the actors in attempting to construct the stories of the Operational Strategy, the GDN and FTS2000, we would probably have seen stories of technollogies being developed before their time. It was my inclusion of the concept of 'user' which enabled a fuller picture to emerge. But I certainly do not wish to grant the analyst the status of an omniscient, superior being. In the next and final section, I will return to the persistence of technological determinism and argue that its continued use by actors necessitates that analysts take it more seriously than the have done in recent years. Actors theoretical ideas need to be treated symmetrically with our own, even if they are antithetical to our deeply held views. 
Before filling in those bits of the puzzle shaded with technological determinism, let us explore another part of the principle of symmetry. This is the more conventional application of the principle of symmetry which appears late in Chapter 5 , in the discussion of working and success versus non-working and failure. It is difficult to decide whether the Operational Strategy, the GDN and the FTS2000 were successful and if so, to what extent and in what terms. Unequivocally successful systems do not provide such a rigorous test for Pinch and Bijker's (1984) claim that working is the result and not the cause of a machine becoming a successful artefact. For unequivocally successful systems, such a claim is tautological. The much more ambiguous systems discussed here illustrate how right Pinch and Bijker are, especially if one adds an iterative loop to the statement. The Operational Strategy works and is considered successful. The GDN and FTS2000 worked, were not successful and no longer work. Let us play the postmodern trick of reversing the wording of the claim so that it becomes, 'success is the result and not the cause of a machine becoming a working artefact'. Playing such word games illustrates the importance of Callon's contribution to Table 6.1, most significant is his exhortation to treat the socio-technical divide as a consequence of the stabilisation of socio-technical ensembles. One of the difficulties with the Pinch and Bijker claim is that they presume the existence of that divide in their association of success with the social world and of working with the technical world. One cannot privilege the social as they do by placing 'success" prior to "working". It has to be possible to reverse the claim as I have done here in order to make visible the mutual constitution of the social and the technical but that means that successive extensions of the principle of symmetry have led us back to a position of classical realism. This should not surprise us. The claims of 'success' and 'working' have to be interchangeable to enable us to treat the social and the technical symmetrically. Rather than seeing the bottom items in the columns attributed to Pinch and Bijker and Wyatt as alternatives, they need to be understood as two sides of the same coin. Neither is adequate on its own. There are problems with following the actors, as I have indicated above. Defining scale and success can become messy. Identifying relevant groups who might be invisible to the actors already identified might result in a partial account. As analysts, we have to rely on ourselves and on the research done by others to help us define our concepts and identify relevant groups. Let us continue to take seriously the principle of symmetry. If we allow our own categories and interpretations into the constructions of our stories, we also need to alllow actors' concepts and theories to inform our accounts. Actors and analysts all have access to both the abstract and the real.

\footnotetext{
See Derrida (1976): The significd is always already in the position of the signifier. ofien paraphrased as $X$ is always already $Y$.
} 


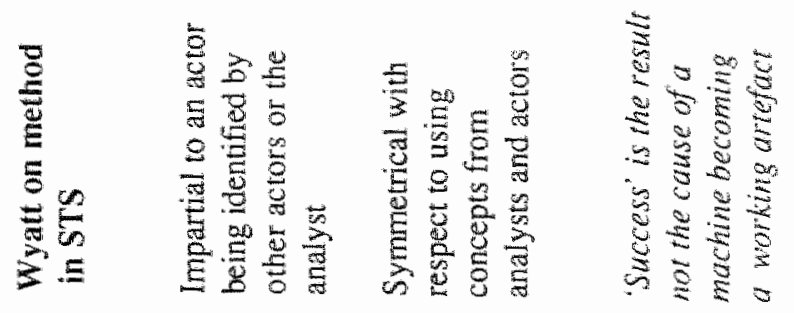
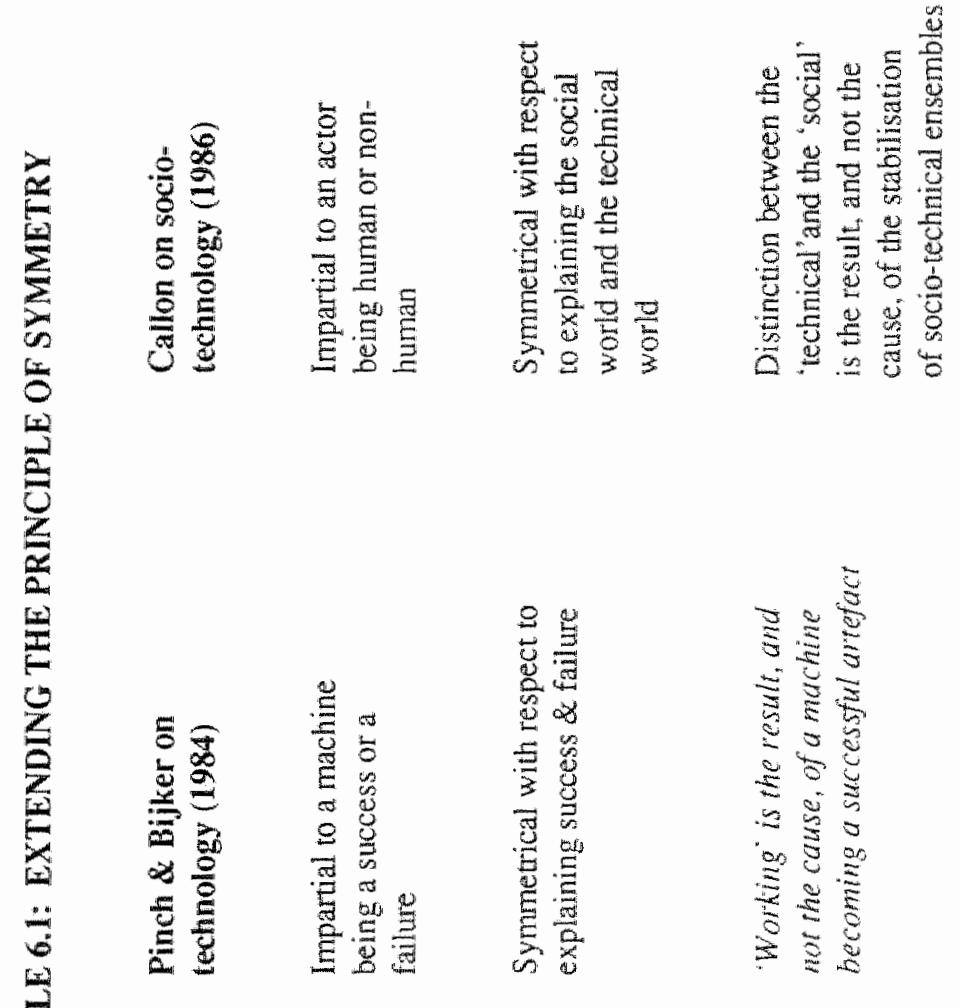

5

D.

$\mathscr{g}$

$\underbrace{2}$

E

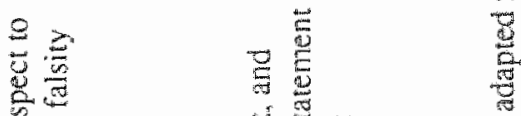

$\Rightarrow \quad 2$

远

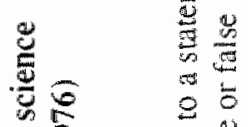

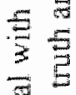

.

50 雪

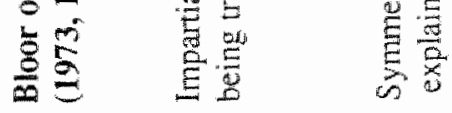

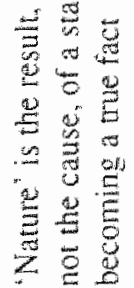

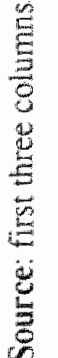




\section{Technological determinism: Elephants live for a very long time}

I have already confessed to ignoring what was at the time a smallish, adolescent Internet elephant, in order to examine the brief lives of the fleas of the GDN and the FTS2000. But many of my colleagues in the social sciences ${ }^{6}$ frequently ignore the equivalent of a thundering herd of elephants when they dismiss the role of technological determinism in shaping the views and actions of actors. Michael L. Smith eloquently expresses a similar view:

We scholars of technology and culture lament the stubborn tenacity of technological determinism, but we rarely try to identify the needs it identifies and attempts to address. On the face of it, our brief against this variety of superstition resembles the academy's response to creationism: How can something so demonstrably wrong-headed continue to sway adherents? (1994, pp.38-9)

Smith is correct to point to the importance of understanding the needs and interests served by a continued adherence to technological determinism, and I will return to that in a moment. He is wrong, however, to dismiss technological determinism (and creationism) as wrong-headed superstition, or as a form of false consciousness. Recall again the principle of symmetry, discussed in Chapter 3 , about the need for impartiality in assessing truth and falsity (Bloor, 1973, 1976; Bijker, 1995). We need to remain impartial in our attempt to explain the persistence of technological determinism in order to understand why it continues to be regarded as true by so many people. Earlier I have argued that the categories deployed by both actors and analysts need to be pursued, in order to justify paying attention to users who might never have been noticed had I naively followed the actors. Now it is time to follow the actors in their continued commitment to technological determinism.

One of the most misleading and dangerous aspects of technological determinism is its equation with progress. In the stories I have told, Ihave demonstrated how messy and ambiguous the process of developing new technological systems can be. But this was not the perspective of some of the actors. In the case of the Operational Strategy, there was a widely shared perception of the difficulty and messiness of the project. With the GDN and FT $\$ 2000$, however, some of the actors, some of the time presented the projects as simple and straightforward. It was necessary for them to adopt this perspective in order to make things happen and to justify their actions. Sometimes socio-technical ensembles work; sometimes they do not. Including stories of systems that did not work or were not used or were not successful provides further armoury in the arsenal to be used against

\footnotetext{
T exempt historians from this criticism, cspecially in light of the publication of Smith and Marx. eds. (1994).
}

"See Leo Marx (1994) for a detailed historical account of the emergence of technology and its relationship lo ideas of progress. 
technological determinism because such stories challenge the equation of technology with progress, though not, of course, if one has an evolutionary perspective on progress. But we should not be under any illusions that it will disappear; and we should recognise that it has a useful function for systems builders.

To conclude, I wish to return to an exploration of the endurance of technological determinism; endurance in the accounts of some analysts, in the actions of systems builders as well as the justifications proferred by policy-makers and other social groups. Despite all of the detailed empirical work of both historical and contemporary examples of the contingency of technological change and despite the nuanced and sophisticated theoretical alternatives that have been proposed, technological determinism persists. In the opening paragraph of this chapter, I likened technological determinism to Hydra: despite repeated attempts to kill it, using a variety of weapons, including rhetorics and empirics, it continues to grow new heads. Despite the seductive symbolism of snakes, appropriate for discussions of technological determinism, let us return to the elephants which have made a number of appearances throughout this book. Recall the proverbial tale presented in Chapter 3 which highlights the importance of perspective and suggests that elephants can serve a wariety of needs, as can both technical systems and technological determinism.

First, let us remind ourselves of what is meant by technological determinism. One of the unfortunate consequences of either stamping on it very hard or ignoring it in the hope it will disappear, is that we do not pay sufficient attention to its subtlety and variety. Sometimes it is a table upon which to thump one's realist credentials; occasionally it can be a rapier to pierce the pretensions of pompous pedants.

The only sustained engagement with technological determinism to be published in recent years is the collection of papers, Does Technology Drive History? The dilemma of technological determinism, edited by Merritt Roe Smith and Leo Marx (1994). All of the contributors are professors of history at US unversities, and the concerns they express are largely those of historians of technology, in their relationship with other historians, and of Americans, with their historic paradigmatic equation of technology with progress and their collective but partial loss of faith with that equation. Nonetheless, the contributors provide a valuable mapping of the terrain of meanings associated with the concept of "technological determinism".

In their introduction, Smith and Marx suggest that technological determinism can take several forms, along a spectrum between hard and soft extremes.

At the "hard' end of the spectrum, agency (the power to effect change) is imputed to technology itself, or to some of its intrinsic attributes; thus the advance of technology leads to a situation of inescapable necessity.... To optimists, such a future is the outcome of many free choices and the realisation of the dream of progress; to pessimists, it is a product of necessity's iron hand, and it points to a totalitarian nightmare. (Smith and Mark, 1994, p.xii) 
At the other extreme of 'soft' deteminism, technology is located, in a far more various and complex social, economic, political, and cultural matrix." (Smith and Marx, 1994, p.xiii) This soft determinism is wague and is not really determinism at all, as it returns us to the stuff of thistory, albeit a history in which technology is taken seriously.

Robert Heilbroner's famous article, 'Do Machines Make History?', originally published in Technology and Culwre in 1967, is reproduced in the collection, together with his own recent reflections on the question. He is the most avowedly technologically determinist of the contributors, in both an ontological and methodological sense. He suggests that a good place to start in the study of an unfamiliar society is to examine the availability of different machines; this will define what it is like to live in a particular place and time. (1994, pp.69-70) He proposes this as a heuristic for investigation, not as a normative prescription. "[T]echnological determinism does not imply that human behaviour must be deprived of its core of consciousness and responsibility.' (1994, p.74)

Bruce Bimber picks up the theme of normative prescription. He distinguishes between three interpretations of technological determinism, what he terms 'normative',

"nomological" and 'unintended consequences' accounts. ${ }^{8}$ "The first he associates with the work of Ellul, Habermas and Winner, amongst others, who suggest that technology can be considered autonomous and determining when the norms by which it is developed have become removed from political and ethical debates. For all of the authors Bimber mentions, the decoupling of technology from political accountability is a matter of great concern. Nomological technological determinism is Bimber's very hard version: 'in light of the past (and current) state of technological development and the laws of nature, there is only one possible future course of social change.' (1994, p.83) To make this even harder, Bimber inposes a very narrow definition of technology: artefacts only. No knowledge of production or use can be incorporated because that would allow social factors to enter this otherwise asocial world. His final category arises from the observation that social actors are unable to anticipate all of the effects of technological change. However, as this is true for many other activities and does not arise from some intrinsic property of technology, Bimber dismisses this as a form of technological determinism."

Thomas Hughes returns to the spirit of the distinctions made by Smith and Marx in their introduction between hard and sof determinism, albeit in different terms and with the explicit objective of establishing 'technological momentum' as 'a concept that can be located somewhere between the poles of technical determinism and social constructivism." For Hughes, 'fal technological system can be botly a cause and an effect; it can shape or be shaped by society. As they grow larger and more complex, systems tend to be more shaping of society and less shaped by it." (Hughes, 1994, p.112) On a methodological These are not dissimiliar to Radder's (1992) distinctions berween methodological, epistemological and
ontological relativism.

Bimber is concerned lo rescue Karl Marx from the accusation of lechnological determinism. This he does by setting up these three accounts: suggesting the nomological is the only true technological determinism and that Marx does not mee the criteria. 
level, he suggests that social constructivist accounts are useful for understanding the emergence and development of technological systems, but momentum is more useful for understanding their subsequent growth and the acquisition of at least the appearance of autonomy. ${ }^{10}$

Earlier in this chapter, Table 3.2 was expanded in order to incorporate some new considerations of the principle of symmetry (see Table 6.1). Now it is time to revise Table 3.1 which outlined ten versions of the linear model. Table 6.2 presents four types of technological determinism which have appeared in this text, what I term: justificatory, descriptive, methodological and normative. Justificatory technological determinism is deployed largely by actors. In the cases presented here, the GDN Steering Committee is the most committed and active. However, we see it all around us. It can be found in policy documents, including the report of the High Level Group on the Information Society which claims, '[t]his revolution adds huge new capacities to human intelligence and constitutes a resource which changes the way we work together and the way we live together.' (CEC, 1994a, p.4) It is the type of technological determinism used by employers to justify redundancies and re-organisations. It is the technological determinism we are all susceptible to when we consider how people's lives have changed in the past 200 years. It is the technological determinism deployed by cinema ticket sellers who claim their automated ticketing system can identify the best seat for all viewers at all times.

Second is the descriptive technological determinism identified by Mackenzie and Wajcman, Misa in his first version and Smith and Marx. These authors eschew technological determinism as modes of explanation for themselves but certainly recognise it when they see it in others. Having recognised it, they rarely attempt to understand the reasons for it. These authors focus on developing richer, more situated explanations of socio-technical change and simply reject technological determinism because of its inadequate explanatory power.

Third, there is the methodological technological determinism of Heilbroner and Hughes. Heilbroner reminds us to start our analyses of societies, and of smaller scale social organisations, by examining the technologies available to them. Hughes's methodological technological determinism is more analytic. But, like Heilbroner, he too is attempting to develop a tool for helping us to understand the place of technology in history. In STS, that is what we are all doing; attempting to understand the role of technology in history and in contemporary sociat life: actor network theory, social constructivism, history of technology and innovation theory all take technology seriously. All of these approaches are regarded as deviant by their parent discplines, because they include technologies in their analyses of the social world, even when, as in actor network theory, much of what they want to understand is how the distinction between the social and the technical is made. Our guilly secret in STS is that we are all technological determinists. If we were not, we would have no object of analysis; our raison d'erre would disappear.

10 To some extent, this formulation of momentum addresses the critique made by Andrew Duvies (1905). Davies is especially critical of what he perceives to be Hughes's falure to incorponate cconomic fores in the shapung of LTS. 


\section{TABLE 6.2: VARIETIES OF TECHNOLOGICAL DETERMINISM}

\section{Justificatory technological determinism}

* GDN Steering Group

* High Level Group on the Information Society (CEC, 1994a)

\section{Explanatory technological deterwinism}

* technology developed independently of social forces (Misa, 1988)

* technology causes social change (Misa, 1988; Smith and Marx, 1994)

* technology developed independently of social forces and causes social change (Mackenzie \& Wajcman, 1985)

\section{Methodological technological determinism}

* 'look to the technologies available to societies, organisations, etc.' (Heilbroner, 1967; 1994)

* 'momentum' (Hughes, 1983; 1994)

\section{Normative technological determinism}

* triumph of technological rationality (Winner, 1977; 1986)

* decoupling of technology from political accountability (Bimber, 1994)

Finally, there is the normative technological determinism identified by Bimber, also by Misa in his second version and implicit in Hughes's concept of momentum. This is the autonomous technology of Langdon Winner. technology that has grown so big and complex that it is no longer amenable to social control. It is this version of technological determinism that has resulted in the intra-STS skirmishes, in which Winner accuses constructivists of abandoning the need to render technology and technological change more accountable. (Winner, 1993; Bijker, 1993)

Does Technology Drive Hisiory? ends with a moving plea from John Staudenmaier to continue to take the history of technology seriously, to treat artefacts, "as crystallized moments of past human vision...each one buffeted by the swirl of passion, contention, celebration, grief and violence that makes up the human condition.' (1994, p.273) Social scientists concerned with understanding the relationship between technology and society share that commitment.

In an earlier chapter, 1 suggested it was time to move from images of things to the things themselves. Now it is time to turn to explanations of things. Just as we treat technology seriously, we must treat technological determinism seriously. It is no longer sufficient to dismiss it for its conceptual crudeness; nor is it enough to dismiss it as false consciousness on the part of actors or as a bleak. Nietzschean outlook for the future of humanity. 
Technological determinism is still here, and unlikely to disappear: it remains in the justifications of actors who are keen to promote a particular direction of change; it remains as a heuristic for organising accounts of technological change; and it remains as part of a broader public discourse which seeks to render technology opaque and beyond political intervention and control.

What I have done in this book is delineate different types of technological determinism, not because I believe it to be an adequate framework for understanding the relationship between the social and technical worlds but because lots of other actors do and therefore we need to understand its different manifestations and functions. We have always treated technology seriously; we have always been concerned with the risks and dangers of autonomous technology. We are not innocent in the ways of methodological and normative technological determinism. But we can no longer afford to be so obtuse in ignoring the justificatory technological determinism of so many actors. Only by taking that type of technological determinism seriously will we be able to deepen our understanding of the dynamics of socio-technical systems and the rhetorical devices of some decision-makers.

The challenges for STS remain: to understand how machines make history in concert with current generations of people; to conceptualise the dialectical relationship between the social shaping of technology and the technical shaping of society; to treat symmetrically the categories of analysts and those of actors even if the latter includes technological determinism, anathema to so much contemporary social science. These dialectics are unresolvable one way or another, but that is as it should be. What is important is to continue to wrestle with them. We need to take seriously the efforts to stabilise and extend the messy and heterogeneous collections of individuals, groups, artefacts, rules and knowledges that make up our socio-technical world. We need to continue to grapple with understanding why sometimes such efforts succeed and sometimes they do not. Only then will people have the tools to participate in creating a more democratic socio-technical order. These may not be issues of import to Jupiter's monkey, but they are as important for humanity as the blade of grass is for the ants.

It is time to close the circle. I have already returned the reader"s attention to La Fontaine's parable which prefaces the text. Now, let us return to the title of this book. "Technology's arrow has two associations, both of which are relevant. The first is with time's arrow, drawing our attention to the historical frame in which socio-technical events occur and to the variety of factors which influence the trajectory of the arrow, including the skills and materials with which it is made and used as well as the prevailing air currents and humidity. The second association is with Cupid's arrow, capturing our fascination and desire not only with explanations of socio-techical change but also with and for technology itself. 


\section{APPENDIX I: ABBREVIATIONS}

$\begin{array}{ll}\text { AA } & \text { Administrative Assistant (UK) } \\ \text { AC } & \text { alternating current } \\ \text { ACLU } & \text { American Civil Liberties Union } \\ \text { ARPANET } & \text { Advanced Research Projects Agency Network (US) } \\ \text { BBC } & \text { British Broadcasting Corporation } \\ \text { CAMELOT } & \text { computer-aided mechanisation of local office tasks } \\ \text { CCrTT } & \text { Consultative Committee for International Telephony and Telegraphy } \\ \text { CCTA } & \text { Government Centre for Information Systems (formerly Central Computer and } \\ & \text { Telecommunication Agency) (UK) } \\ \text { CNC } & \text { computer-numerically controlled } \\ \text { CPSA } & \text { Civil and Public Servants Association (UK) } \\ \text { CSC } & \text { Computer Sciences Corporation (UK) } \\ \text { DARPA } & \text { Defense Advanced Research Projects Agency (US) } \\ \text { DC } & \text { direct current } \\ \text { DSS } & \text { Department of Social Security (UK) } \\ \text { DTI } & \text { Department of Trade and Industry (UK) } \\ \text { EDS } & \text { Electronic Data Services (US) } \\ \text { EU } & \text { European Union } \\ \text { FBI } & \text { Federal Bureau of Investigation (US) } \\ \text { FCC } & \text { Federal Communications Commission (US) } \\ \text { FTS } & \text { Federal Telecommunication System (US) } \\ \text { FTS2000 } & \text { Federal Telecomnunication System for the year 2000 (US) } \\ \text { GAO } & \text { General Accounting Office (US) } \\ \text { GATT } & \text { General Agreement on Trade and Tariffs } \\ \text { GDN } & \text { Government Data Network (UK) } \\ \text { GOC } & \text { Government Operations Committee (US) } \\ \text { GSA } & \text { Govemment Services Administration (US) } \\ \text { ICT } & \text { information and communication technology } \\ \text { IRS } & \text { Internal Revenue Service (US) } \\ \text { ISO } & \text { International Standards Organisation } \\ \text { IT } & \text { information technology } \\ \text { ITSA } & \text { Information Technology Services Agency (UK) } \\ \text { ITU } & \text { International Telecommunications Union } \\ \text { LOI } & \text { Local Office grade one (UK) } \\ \text { LOII } & \text { Local Office grade two (UK) } \\ \text { MoD } & \text { Ministry of Defence (UK) } \\ \text { NAO } & \text { National Audit Office (UK) } \\ \text { NUCPS } & \text { National Union of Civil and Public Servants (UK) } \\ \text { OECD } & \text { Organisation for Economic Co-operation and Development } \\ \text { Oftel } & \text { Office of Telecommunications (UK) } \\ \text { OMB } & \text { Office of Management and Budget (US) } \\ \text { OSI } & \text { Open Systems Interconnection } \\ \text { PA } & \text { public administration } \\ & \end{array}$


PAC Public Accounts Committee (UK)

PC personal computer

PEN Public Electronic Network (US)

R\&D research and development

RBOC Regional Bell Operating Company (US)

RDNL Racal Data Networks Limited

RFP Request for Procurement (US)

SAS Social Assistance System (Denmark)

SCOT social construction of technology

SCPS Society for Civill and Public Servants (UK)

SSR Statement of Service Requirement (UK)

STS science, technology and society

TA technology assessment

TCP/IP Transmission Control Protocol/Intemet Protocol

UK United Kingdom

US United States

USDA United States Department of Agriculture

VCR video cassette recorder

VDU visual display unit 


\section{APPENDIX II: MAP OF THE UK}

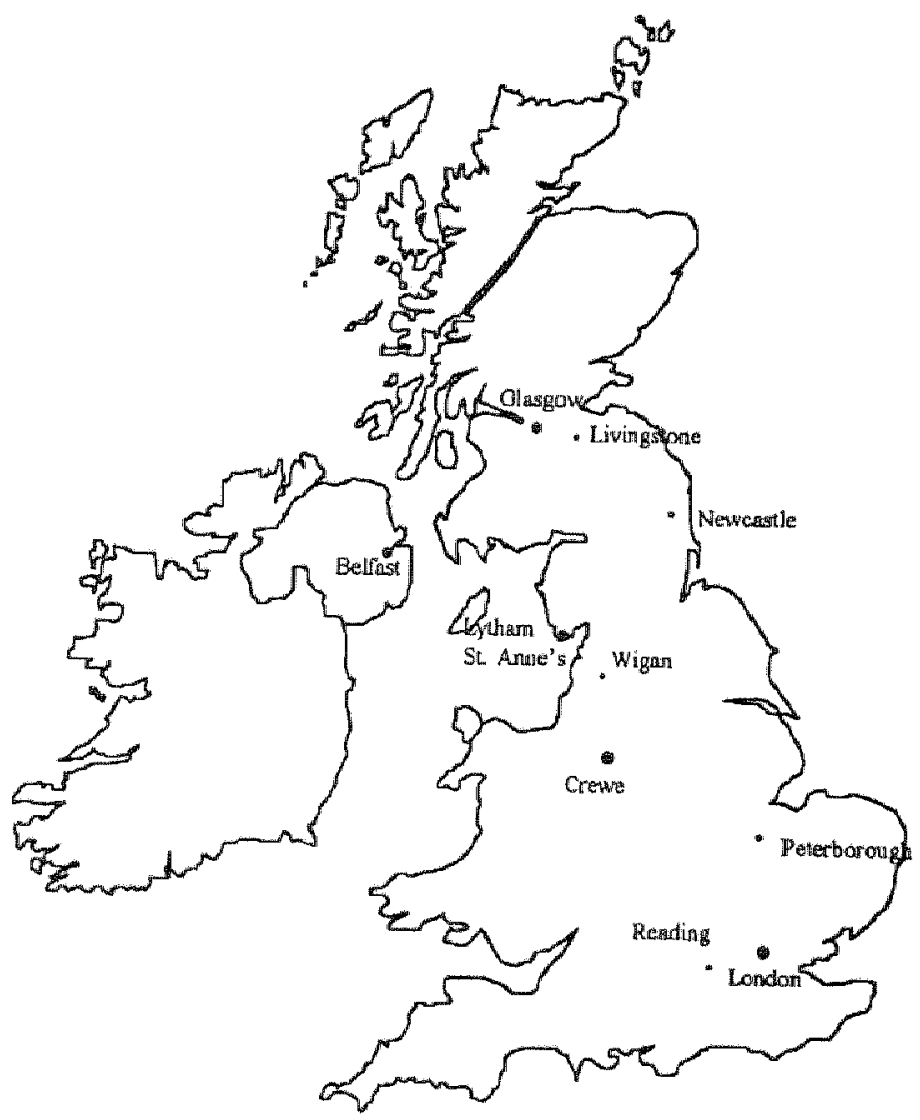




\section{APPENDIX III: LIST OF INTER VIEWEES}

\section{UKK}

Dadd, D. Superintendant, Police Requirements Support Unit. Home Office.

Davidson, S. General Manager. BT Westminister District.

Eaton, R. Networks Branch. Home Office.

Gale, N. National Audit Office.

Gladwyn, M. Head, Central Support Staff. CCTA.

Hughes, R. Networks Branch. Home Office.

Long, J. Chief Superintendant, Police Requirements Support Unit. Home Office.

McKinney, J. Superintendant. Sussex Police.

McKnight, J. Assistant General Secretary. NUCPS.

Minter, J. Telford Development Centre. Inland Revenue.

Morgan, R. Computer Development Officer. House of Commons and House of Lords.

Ryle, E. Deputy Director, Computer Services. Department for Trade and Industry.

Selwood, D. Information Technology Director. Ministry of Agriculture, Fisheries and Food.

Simpkins, E. Customs and Excise.

Skinner, G. Deputy Director, Information Systems Branch. Employment Department.

Stott, A. Information Technology Services Directorate. Department of Social Security.

Stranger, J. Senior Consultant, GOSIP. CCTA.

Stuttard, B. Managing Director. Racal Data Networks Limited.

Sutton, C. Director, Police Requirements Support Unit. Home Office.

Thomas, E. Director of Telecommunications and Security. CCTA. 
Thompson, K. Deputy Director, Information Systems Branch. Employment Department.

Tomlin, E. Computer Centre Manager. Department for Trade and Industry.

West, N. Communications Systems Division. British Telecom.

Winder, P. Computer Services Branch. Sussex Police.

Wooldridge, M. Senior Consultant, Public Sector. SEMA Group.

\section{US}

Beardshear, D. IS Management. USDA.

Beavers, C. Voice Manager. Food \& Nutrition.

Beck, B. Data Manager. Food \& Nutrition.

Bennington, B. Post Office. (first director of FTS2000)

Broadbent, S. Treasury.

Dubay, C. Customs.

Earner, J. FTS2000 Policy Division. AT\&T.

Flyzich, J. Treasury.

Freeman, H. Sales Manager. AT\&T.

Gentili, R. FrS Technical Manager. Forest Service.

Haggard, S. USDA.

Jasionowski, T. Data Manager. Department of Labour.

Leigh, J. Mitre Corporation.

Loh, M. Implementation Team. AT\&T/USDA.

Long, T. Head of Government Telecoms. MCI.

McCarthy, F. Network A Coordinator. GSA. 
McGovern, J. Department of Labour.

McManus, K. Consultant to Jack Brooks.

Martin, W. Department of Labour.

Mason, M. Video Specialist. US Treasury.

Obye, K. FTS Project Manager. Forest Service.

Richmond, N. Implementation Team. AT\&T/USDA.

Rooney, C. Head of FTS2000. Sprint.

Roth, D. Head of FTS2000. AT\&T.

Scott, D. FTS2000 Coordinator. GSA.

Shew, J. Bureau of Labour Statistics.

Smith, D. Network B Technical Advisor. GSA.

Spillman, L. FTS2000 Policy Division. AT\&T.

Stevens, P. Bureau of Labour Statistics.

Summer, B. IS Management. USDA.

Vance, J. FTS2000 Policy Division. AT\&T.

Wheeler, C. Government Operations Committee.

Young, T. Network B Coordinator. GSA.

Zimmerman, T. Internal Revenue Service. 


\section{BIBLIOGRAPHY}

Abbate, Janet. 1994. "The Interne Challenge: Conflict and Compromise in Computer Networking" in Summerion. Jane, ed. 1994 a.

Abram, Philip. 1980. 'History, sociology and historical sociology' Past d Present 87, May. pp.3-16.

Abrams, Philip, 1982 . Historical Sociology. Shepton Mallet: Open Books Publishing.

Adler, M and Sainsbury, R. 1991. "The Social Shaping of Information Technology: Computerisation and the Administration of Social Security" in Adler. Mer al. eds. 1991. The Sociology of Social Security. Edinburgh: Ediriburgh Universily Press.

Adler, Michael and Willians. Robin, eds. 1991. "The social implications of the Operational Strategy' New' Waverley Papers, Social Policy Surves No.4. Edinburgh: University of Edinburgh.

Aitken, Hugh GJ. 1985. The Contmous Wave: Techology and American Radio, 1900-1932. Princeton, NJ: Princeton University Press.

Akrich, Madeleine. 1992. The De-Scription of Technical Objects' in Bijker, Wiebe E and Law, John, Eds. 1992a.

Amsterdamska, Olga. 1990. 'Surcly You Are Joking. Monsieur Latour!' Science, Techology: \& Human Vahes: 15. 4. Fall. pp.495-504.

Arendi, Hannah. 1958. The Human Conditon. Chicago: Universily of Chicago Press.

Aronson, Elliot. 1980. The Soctal Animal. 3rd ed San Francisco: WH Freeman and Co.

Banville, John. 1976. Docros Copermicus. London: Martin Secker \& Warburg.

Banville, John. 1989. The Book of Evidence. London: Martin Secker \& Wartsurg.

Banville, Jolun. 1997. "The European Irishman, review of Independent Spiri by Hubert Butler New Yonk Review of Books June 12, pp.38-41.

Binnes. Barry. 1981. 'On the "Hows" and "Whys" of Cultural Change (Response to Woolgar) Soctal Sindies of Science 11. pp 481-98.

Banes. Batry. 1983. 'Social Life as Bootstrapped Induction' Sociology 17.4. November. pp.524-45.

Barras, Richard. 1986. "Towand a theory of imovation in services" Resedrch Poltoy 15. pp 161-73.

Bell. Dandel. 1973. The Coming of Post-lndustral Sodery. New York: Basic Books.

Bellamy. Claris. 1997. The Informatization of Policy and Policy making for nformatization. The History and Future of the Operational Strategy in the UK Department of Social Security Paper presented at Vmp conference of EGPA's permanen sudy group on Informatisation in Pulblic Administration. Strasbourg. Septenber.

Beniger. Inmes R. 1986. The Control Rewoluton: Technologicat and Economic Origins of the Information Society. Canbridge. MA: Harvard University Press.

Bematt. Colin J. 1992. Regulang Privacy Data Protection and Public Policy in Europe and the United States. Ihaca and London: Comell University Press. 


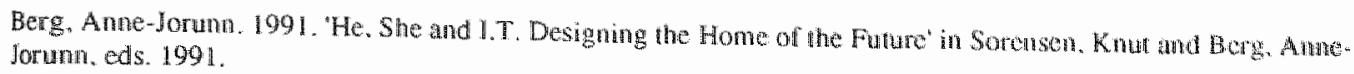

Berkowitz. Leonard and LePage. Anthony. 1967. "Weapons as Aggression-Eliciting Stimuli" Joutwal of Perwowality and Social Psychology 7 . pp. 202-7.

Bertho-Lavenir, Caherine. 1988. The Tetephone in France 1879-1979, Natonal Characterstics and Intmational Infuences in Maynz. Renate and Hughes. Thomas P. eds. 1988.

Beveridge. WH. 1942, Social Insurance and Allied Servicer (aka The Beveridge Repori). London: HMSO.

Bijker, Wiebe E. 1990. The Social Constwoton of Techology. Proefschrint Universiteit Twente.

Bijker. Wiebe E. 1992. "The Social Construction of Fiourescent Lighting, or How an Artifact was Inwented in its Diffusion Stage' in Bijker, Wiche Eand Law John, eds. 1992:

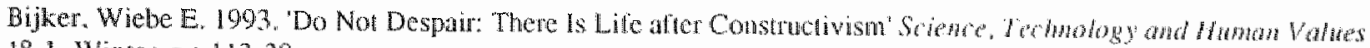
18.1. Winter, pp. 113-38.

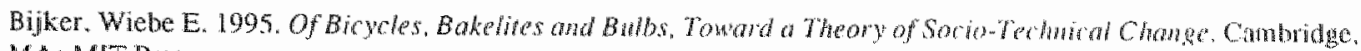
MA: MIT Press.

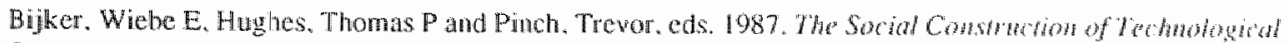
Systems. Cambridge. MA: MIT Press.

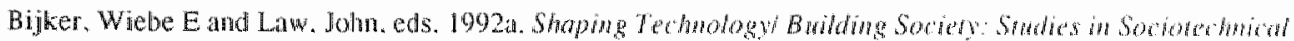
Change. Cambridge. MA: MIT Press.

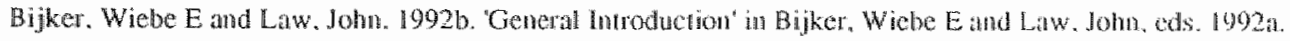

Bjsterveld, Karm. 1991. "The nature of aging. Some problems of "an insider"s perspective" illustrated by Dutch debates about aging (1945-1982)' Paper presented at the Socicty for Social Sudies of Science meeting. Cambridge. Mass. November.

Bimber. Bruce. 1994. 'Three Faces of Technological Determinism' in Smilh, Meritl Roe and Max. Leo. eds. 1994.

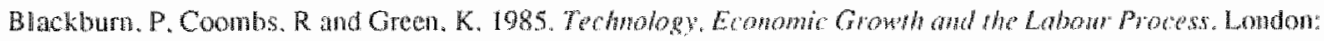
Macmillan.

Bloor. David. 1973. "Wiltgenstem and Manuheim on the Sociology of Mathematics" Sofwites in Hisury" and Philosophy of Science 4 . pp. 173-91.

Bloor, David. 1976. Knowtedge and Soctah Magery. London: Roulledge Be Kegin Paul.

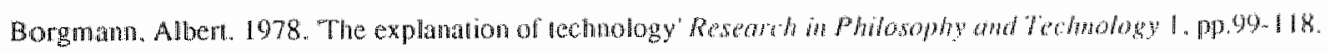

Bourdieu. Piere. 1984. Distincrion. Landon: Routliedge de Kcgan Paul.

Braverman. Hary 1974. Latrow and Mowopoly Caphol New York: Monthly Revicw Press.

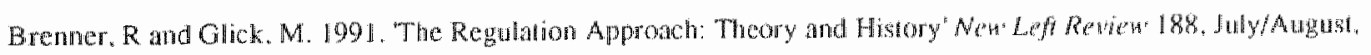
pp. $45 \cdot 119$

Briggs. Asal 1985. The BBC. Whe first fifty years. Oxtord: Oxfond University Press. 
Bruland. Tine and Smith. Keith. 1981. Industrialization. steam power and economic historiography" Ecowomy ame Society 10.1. pp.88-101.

Buchanam. Angus. 1991. Theory and Narrative in the History of Technology Technology and Culhure 32. pp. 36576.

Buckingham. Joama and Wyat, Sally. 1992. 'Central govermmen metworks in the UK and the USA: Impacis by design? Paper presented al the ESRC Sludy Group on Information. Communication and New Technology in Public Administration. London. July.

Burke, John O. 1970. 'Comment: The Complex Nature of Explanations in the Historiography of Technology" Techolology and Culfure 11. 1, January, pp.22-26.

CSO (Central Statistical Oftice). 1990. Anmal Abstract of Siansics, 1990 Edition. London: HMSO.

CSO (Central Slatisical Office). 1996. Social Trends 26. London: HMSO.

CSO (Central Sutustical Orfice), 1997. UK Narional Accomnt, Blue Book. London: HMSO.

CSO (Central Statistical Onice). 1998. Amual Abstract of Sratishics, 1998 Edition. London: HMSO.

Cabina Office (Efriciency Unit). Imyrowng Management in Govewnent: The New Steps. London: HMSO.

Catton, Michel. 1982. 'On lnterests and their Transformation: Enrolment and Counter-Enrolmon' Social Sudies of Serience 12. pp.615-25.

Callon, Michel. 1986. 'Some elements of a sociology of translation: Domestication of the scallops and the fishomen of St. Brieuc Bay' in Law. John, ed. Power, Action and Belief: A New' Sociology of Knowledge? London: Roulledge \& Kegan Paul.

Callon, Michell, 1987. 'Society in the making: the study of rechnology as a tool for sociological analysis' in Bijker. Wiche E. Hughes. Thomas P and Pinch. Trevor, eds. 1987

Castells. Manuel. 1906. The Rise of the Nowork Society: The Information Age volume 1. Oxford: Blackwell.

Carlson, W Bemard. 1992. "Artacts and Fumes of Mesming: Thomas A Edison. His Managers, and the Cultural Construction of Motion Pictures" in Bijker. Wicbe E and Law. John, eds. 1992a.

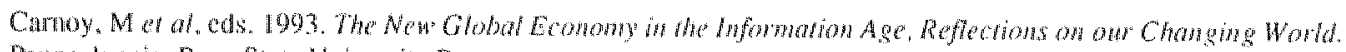
Pennsylvania: Penn State University Press.

Cassell, Philip. 1993. The Giddens Reader. London: Macmillan.

Chamoiseatu, Patrick. 1997. Teraco. London: Granta. (Urans. Rose-Myriam Rejouis and Val Winokurov).

Clanchy, MT, 1993. From Memory ro Wrinten Record, Engtand 1066-1307 2nd cd. Oxiord: Black well.

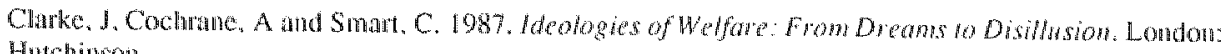
Hutchinsoin.

Cockbum, Cynthia and Ormod, Stsan. 1993. Gender and Tecknology in the Making. London: Sage.

Collingridge, David and Margelts. Helen. 1994. 'Can Government Infomation Systems be Inflexible Techmology'? The Operational Strategy Revisited' Public Admimsmation 72. Spring. pp.55-72. 


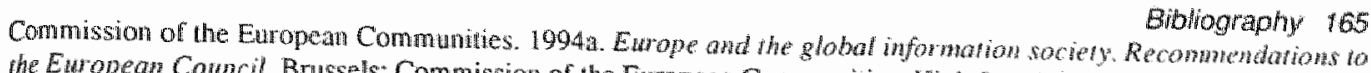
the European Comcil. Brussels: Commission of the European Commumies. High-Level Group on the hiormation Society. (aka The Bangemann Report).

Commission of the European Communities. 1994b. Europe's Way fo the Information Soctey. An Action Plan. COM(94) 347 final. Brussels: Commission of the European Communities.

Compuer Weekly. various issues.

Compuing various issues.

Constant, Edward W II. 1984. 'Communities and Hienarchies: Structure in the Practice of Science and Technology' in Laudan. Rachel. ed. 1984.

Cronberg, Tarja et al eds. 1991. Danish Experiments - Social Conshactions of Technology Copenhagen: New Social Science Monographs.

Csikszentmihalyi M. and Rochberg. Halton. E. 1981 . The meaning of shings, Dontestir symbols ond whe selt. Cambridge: Cambridge University Press.

DSS. 1980. A Strategy for Social Security Operations. London: HMSO.

DSS. 1982. Social Securiry Operationd Srategy: A Framewronk for the Future. London: HMSO.

DSS. 1983. Social Securry Operational Smate gy: Sanmingdade Seminar. Decomber 1982. London: HMSO.

DSS. 1985. Reform of Social Sectity. Green Paper, vols. I and II. London: HMSO.

DSS. 1988a. New Technology, Jab Design and Organisation Sudy Repor. London: HMSO.

DSS. $1988 \mathrm{~b}$. The Busivess of Service (aka The Moodie Report). The Repon of the Regional Organtsation Scruthy. London: HMSO.

DSS. 1989. Operational Strategy Pilat Evaluation Repor, Management Swmmay and Main Report. London: HMSO.

DSS (Benefits Agency). 1992. One Stop: Benefis A gency Sentce Detwery (aka the Malhew Report). internal document.

Daniels. George H. 1970a. 'The Big Questions in the Hishory of Amarican Technology' Techology and Con hit' 11, 1, January. pp.1-21.

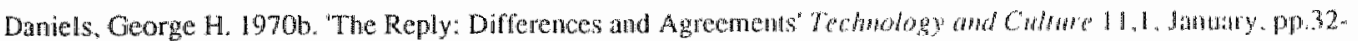
6.

Danziger. IN. 1986. Computers and the political world" Computers and he Social Scidenes 2.4. pp.163.80.

Danziger, JN. 1991. 'Management information systens and intcrorganizational nclations within the Ancrican governmental system Informati-anion and the Puthlic Sector 1.3. pp. 169.87.

Davidson, Roger and White. Phil, eds. 1988. Information and Govermment Studies in the Dyomicr of PolicyMaking. Edinburgh: Edinburgh University Press.

Davies, Andrew, 1995. 'Innovation in Large Technical Systems: The Case of Telecommunications" Working Paper Prepared for CENTRMMSPRU Project on Conplex Product Systems. Brighton: Universitics of Brightomi and Sussex. 
Derrida, Jacques. 1976. Of Grammalogy. Baltimore: Johns Hopkins University Press. (trans. G. Spiwak).

van de Donk, Wirn. 1993. 'Informatization and public policy making' Paper presented at VII ${ }^{\text {th }}$ confenence of EGPAs permantent study group on Informatisation in Public Administration. Strasbourg. September.

Dosi. Giowanni et ah. eds. 1988. Technical Change and Economic Theory. London: Pinter.

Dunileavy, Patrick. 1989. The architecture of the British central state. Part I: Framexwork for analysis' Public Administration 67. Autum, pp.249-75.

Durkheim. Emile. 1982. The rules of sociologicat method, and selected texts on sociology and its nuethod. London: Macmillan. (first published in 1895 ).

Dutton. WH and Guthrie. K. 1991. 'An ccology of games: The political construction of Santa Monica's public electronic nelwork' Informanizanion and the Public Sector 1.4. pp. 279-301.

Dutton, William H. 1992. 'The ecology of games in telecommunications policy' in Sapolsky. Harvey M. al al, eds. The Tevecommuntcations Revolution. Pasi, Present, and Funte. London: Routledge.

Dyerson. Romano and Roper. Michael. 1989. 'Computerisation at the DSS 1977-89: The Operational Strategy' Technology Project Papers 4 London: London Business School.

Dyerson, Romano and Roper. Michael. 1990. "Implementing the Operationall Strategy" Technology Project Papers 8 London: London Business School.

Dyerson. Romano and TRoper. Michael. 1991. 'Implementing the Operational Strategy from Technical Push to User Pull' in Adler, Michnel and Williams. Robin, eds. 1991.

Dyerson, Romano and Roper, Michwel. 1992. 'Large scale information systems in the United Kingdon' in Frissen. PHA er al eds. 1992. European Public Administration and hoformatizaron. Ansterdam: IOS Press.

Eagleson, Rosie. 1991. 'A Trade Union Response" in Adler. Michael and Williams. Robin. eds. 1991.

Efficiency Unit. 1988. Improving management in governmer the nex steps. London: HMSO.

Elkins, Stanley and Mekitrick, Eric. 1994. The Age of Federalism. Oxford: Oxfond University Press.

Elliot Brian. ed 1988. Technology and Soctal Process. Edinburgh: Edinburgh University Press.

Ellul, Jicques. 1964. The Technological Society. New York. NY: Random House torig. La techique on lenjen du sidele. 1954$)$.

Ellut. Jucques. 1980. The Techological 5ystem. New York. NY: Conninum (orig. Le systeme rechaicien. 1977).

Exrahi, Yaron. 1990. The Descent of Lcarus, Science and the Transfomation of Conemparary Democracy. Cambridge, Mass: Harvard University Press.

Fallon, Iwan. 1993. The Paper Chase. A Decade of Change at the DSS. London: Harper Collins.

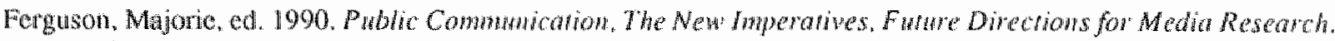
London: Sage.

Financial Times, various issucs.

Finnegan. Ruth, Salaman, Graeme and Thompson, Kenneth, eds. 1987. Information Technology: Social /ssuets, A Readkr. Sevenonks: Hodder \& Stoughton. in association with The Open Universily. 
Forester. Tom. 1993. 'Megatrends or megamistakes. Whatever happened to the Infomation Society?' The Information Society \&. pp.133-46.

Fownain. Jane. 1990. Enacring technology: The effect of organizational logics on informanon perchology suse in governmen organizations. Doctoral dissentation. Yale University.

Freeman. Christopher. 1982. The Economics of Industrial Innowation 2nd ed. London: Frances Pinter.

Freeman, Christopher. 1987. "The case for technological determinism" in Finnegin, Ruth, Sataman, Graeme and Thompson. Kenneth, eds. 1987.

Freeman, Christopher and Soete, Luc. 1993. Infomarion technology and employment. Maastrich: MERTT.

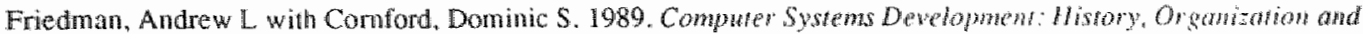
Implementarion. Chichester: John Wiley \& Sons.

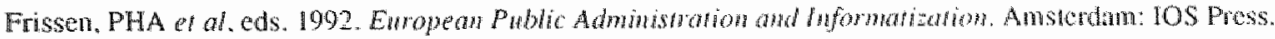

GAO. 1991a. ADP Commmications: HCFA meeds to expedile wansirion to FTS2000. GAOMMTEC-91-10

Washington: US Government Printing Office

GA0. 1991b. FTS2000, GSA must resolve rincal pricing isSues. GAOMMTEC-91-79. Washington: US

Government Printing Office.

GSA. 1989. Anumal Report. Washington: US Government Prining Office.

Galambos, Louts. 1988. 'Looking for the Boundares of Technological Determisism: A Brief History of the U.S. Telephone System' in Mayntz. Renate and Hughes. Thomus P. eds. 1988.

Garnham, Nicholas. 1990. Capinalism and Communication, Global Culture and the Economics of Information. London: Sage.

Giddens. Anthony. 1993. New Rules of Sociological Method, Second Edition. Cambridge. England: Polity. (first edition published by Hutchinson in 1976)

Giddens, Anthony. 1979. Central Problems in Sorkat Theory. London: Macmillan.

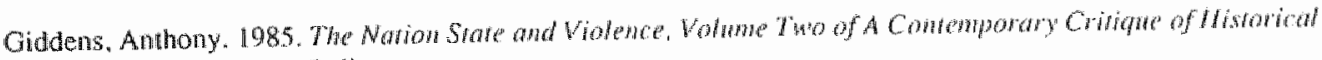
Materialism. Cambridge: Polity.

Giddens. Anthony. 1991. Modernity and Self Identity, Self owd Soctery in the Late Modem Age. Cumbidge: Polity.

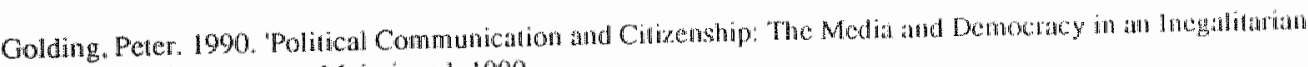
Social Order' in Ferguson. Majorie, ed. 1990.

Guardian various issues.

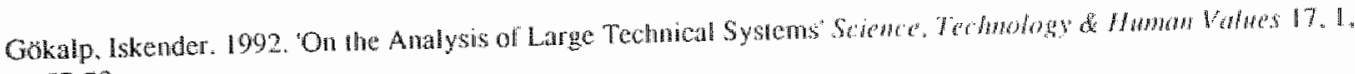
pp. $57-78$.

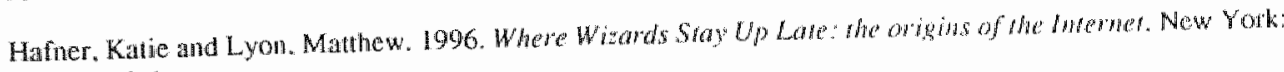
Simon \& Schuster.

Hagendijk, Rob. 1990. 'Structuration theory, constructivism alld scientific chathec' in Cozzens, Susan Eand Gieryn. Thomas F. eds. 1990. Theories of Science in Sochery. Bloomington \& Indianopolis. Indiana Universily Press. 


\section{Bibliography}

Harmon. Michael M and Mayer. Richard T. 1986. Organization Theory for Public Adminishatian. Glenview. Illinois: Scoll, Foresman \& Co.

Harwey, David. 1989. The Condunon of Posmodernity. An Encuiry into the Origins of Cultural Change. Oxford: Basil Blackwell.

Hawkins, Richard. 1996. "Standards for Communication Technologies: Negotiating Institutional Biases in Network. Design' in Manseli, Robin and Silverstone. Roger, eds. 1994.

Heilbroner, Robert L. 1994a. 'Do Machines Make History?' in Snith, Merritl Roe and Marx, Leo, eds. 1994. (originally published in Technology and Cwiture 8. July 1967, pp.335-45.)

Heilbroner. Robert L. 1994b. 'Technological Determinism Revisited' in Smith, Merrit Roe and Marx. Leo. eds. 1994.

Held. Divid, 1989. "The Decline of the Nation State in Hall. Stuart and Jacques. Martin. eds. New Tines. London: Lawrence \& Wishar!.

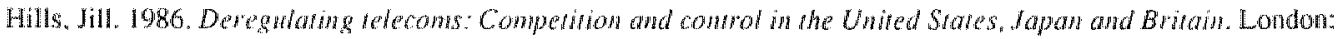
Pinter.

Hobsbawm. EJ. 1968. Industry and Empine: An economic History of Butain since 1750. London: Weidenfeld and Nicolson.

Hoff. Jens, 1992. 'Evaluation of information technology in private and public sector contexts' Informatizarion and the Public Sector $2,4, p p, 307-28$.

Hoff, Jens and Stormgatard. Klaus. 1991. 'Information techology between citizen and administration' Informatization and the Public Sector 1, 3. pp.213-35.

Hood, Christopher. 1986. Admmistrative Anatyis, An Introduchon to Rutes, Enforcement and Organizations. Sussex and New York: Whealsheaf Books and St Marun's Press.

Hood. Christopher and Margets. Helen. 1993. Informatization and public administration trends: Igniting. fuelling Or dampening?" Paper presented at the ESRC Study Group on Information. Communication and New Technology in Public Administration. London. December.

Hoschkil, Perer of ol. 1992. "Teldecooperathon and telepresence: Technical challenges of a government distributed

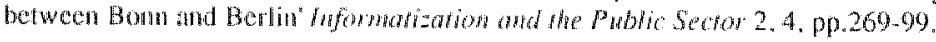

Hoven, Mil van den. 1995. Information I"ethology and Moral Phitosophy, Phitasophical Eviplorations in Compurer Ethics. Proefschrift: Erismus Universileit Ronerdam.

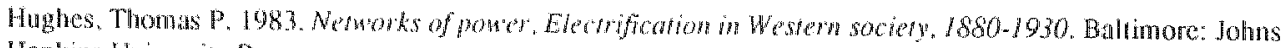
Hopkins University Press.

Hughes, Thomas P. 1994. "Technological Momentum' in Smith, Merritu Roe and Marx, Leo. eds. 1994.

Huxtey, Aldous. 1932. Browe Ne'w World. London: Chatro \& Windus.

Irvine. J. Milles. I and Ewans, J, eds. 1979. Demystifying Social Sfatistics. London: Plluo. Joerges. Bernwird. 1988. Large Technical Systems: Concepts and Issues' in Mayntz, Renate and Hughes, Thornas
P. eds. 1988 . 
Kay. WD. 1994. "Democracy and Super Technologies: The Politics of the Space Shutte and Space Station Freedom" Science, Technology \& Hwman Values 19,2. pp.131-51.

Kraemer, Kenneth. 1991. "Strategic compuing and administrative reform" in Dumlop, C and Kling, R, eds. Conputerisatom and Connroversy. Vahue Conflicts and Social Choices. Boston: Academic Press.

Kuitenbrouwer. Frank. 1990. Wanneer computers koppelen... Ower de noodzad mastad taesich per computer beter re controleren. Dewenter: Kluwer.

Laclau, E with Moufle. C. 1987. Post-Marxism without Apologies New Left Review 166. pp.79-106.

Lambrigh. W Hemry. 1994. "The Political Construction of Space Satlite Technology' Science. Technoldgy de Human Values 19, 1. pp.47-69.

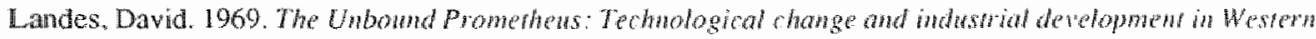
Earope from 1750 o dhe present Cambridge: Cambridge Universily Press.

Landes, David. 1983. Renolytion in Twhe, Clocks and the Making of the Modern World. Cambridge. Mass: Belknap. of Havaud University Press.

La Porte. Todd. 1988. "The United States Air Tramic System: Increasing Reliability in the Madst of Rapid Growth in Maynz. Renate and Hughes. Thomas. P. eds. 1988.

L. Porte. Todd, ed. 1991, Social Responses to Lange Techuical Systenns: Commol or Anticiparion. Dondrech: Kluwer Academic Publishers.

Latour, Bruno. 1987. Sciphe in Action. Hon" to follow sciemists and enginedurs whongh society. Millon Keynes: Open University Press.

Latour, Bruno. 1988. "The Prince for Machines as Well as For Machinations" in Elliot, Brian. ed. 1988.

Latour, Bruno. 1991. "Technology is society made durable' in Law, John, ed. $1991 \mathrm{l}$.

Latour. Brumo. 1996. Aromis, or the Lone of Technology. Cambridge Mass. Harvad Universily Press. (uans. Catherine Porter).

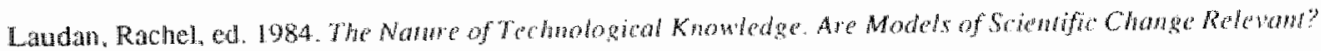
Dordrecht: Kluwer.

Law, John. 1987. "Technology and Heterogeneous Engineering: The Case of Portuguese Expunsion" in Bijker. Wicte E. Hughes, Thomas $P$ and Pincll. Trewor. cds. 1987.

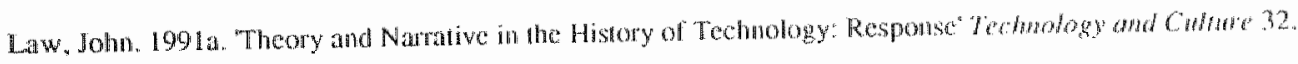
pp. $377-84$.

Law, John, ed. 1991b. A Soriology of Monsters: Eshays on Power, Terhology and Domination. London: Rounledge. Law, John and Bijker, Wiebe E. 1992. 'Postscript: Technology, Stahility, and Social Theory' in Bijker, Wiche Eand Law, John, eds. 1992at.

Law. John and Callon, Michel. 1992. 'The Life and Death of an Aircraft: A Network Analysis of Technical Change' in Bijker, Wiebe E and llaw. John, eds. 1992 a.

Layton. Edwin. 1970. "Comment: The Interaction of Technology and Socicty' Techology and Culute 11.1.

January, pp.27-31. 


\section{Bibliography}

Lewis, Arthur O Ir.a ed. 1963. Of men and machines. New York: EP Duton Co.

Lively. Adam. 1993. Sing the Body Elecric. London: Chatto \& Windus.

Lockwond, D. 1960. "The "New Working Class"' European Journat of Sociology 1, 2. pp. 248-59.

London Ambullance Service. 1993. Report of the Inquiry ino the London Ambulance Service. London: South West Thames Regional Health Authority.

Lyon, Dawid. 1988. The Information Sociery. Cambridge: Polity Press.

Mackay, Hughie and Gillespie, Gareth. 1992. "Extending the social shaping of iechnology approach: Ideology and appropriation" Social Sndies of Science 22 , pp.685-716.

MacKenzie. Donald. 1978. Statistical Theory and Social Interests. A Case Siudy Social Studies of Sciunes. pp.35-83.

Mackenzie. Donald. 1981. 'Interests, Positivism and History' Social Studies of Science 11 . pp.498-504.

Mackenzic. Donald and Wajicman. Judy, eds. 1985. The Social Shaping of Tecthology, How the refrigerator gor its hum. Milron Keynes: Open University Press.

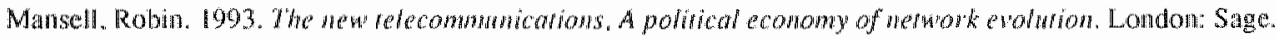

Mansell. Robin and Silverstone. Roger "eds. 1996. Communication by Design. The Politics of Information and Commmication Technologhes. Oxford: Oxford University Press.

Margetts, Helen. 1991. "The Computerization of Social Security: The Way Forward or a Step Backwards?" Public Adrimistration 69. Auiumn, pp.325-43.

Margets. Helen and Willcocks, Leshie. 1992. 'Infornation technology as policy instrument in the UK social security systems: Delivering an Operational Strategy" Inernarional Review of Administrative Sciences 58.3. pp.329-47.

Martin, Brian and Scott. Pam. 1992. "Automatic Vehicle Identificalion: A Test of Theories of Technology' Science. Techwology and Human Values 17.4. pp.48.5-505.

Marx. Kaul and Engets. Frederick. 1965. The Germon Ideosogy. London: Lawrence \& Wishart. (first puthished in 18416)

Marx. Leo and Smith, Merriu Roe. 1994. 'Introduction' in Smith, Merrit Roe and Marx. Leo, eds. 1994.

Mayntz, Revate and Hughes. Thomas P. cds. 1988. The Developmen of Large Techical Systewn. Frankfurt: Campus Verlag.

Maynte. Renate and Schneider, Volker. 1988. The Dymanics of System Development in a Companative Perspective: Internctive Videotex in Germany. France and Britain' in Maynz. Renare and Hughes. Thomas P. eds. 1988.

Meyer, Odette. 1993. The use of so-called beleddsbasis-bestanden in the policy towards minorities of the Municipality of Amsterdam". Paper presented at the meeting of the Infonnalisation theme group. NIAS. Wassenatr. April.

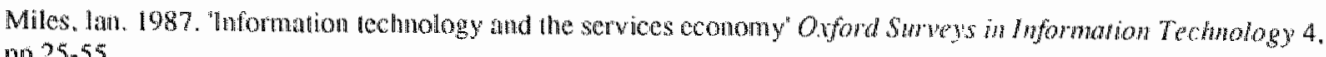
pp. $25-55$.

Miles, Iam. 1988a. 'Intomation technology and information society: Options for the luture' PICT Policy Research Papers 2. London: Economic and Social Reseatch Council. 
Miles, Lan. 1988b. Home Informatics, Infomation Technology and the Transformation of Ener yala Lift. London: Pinter.

Misa. Thomas J. 1988. 'How Machines Make History, and How Historians (and Ohers) Help Them to Do So' Science, Technology \& Haman Vahues 13, 3\&4, pp. 308-31.

Misa. Thomas 1. 1992a. 'Controversy and Closure in Technological Change: Consintucting "Steel"' in Bujker. Wiebe E and Law, John. eds. 1992a.

Misa. Thomas I. 1992b. 'Theories of Technological Change: Parameters and Purposes' Scinuce. Technology d Human Values 17, 1, pp.3-12.

Misa, Thomas J. 1994, "Retrieving Socholechnical Change from Technological Deteminism" in Smim, Merritt Roe and Marx, Leo, eds. 1994.

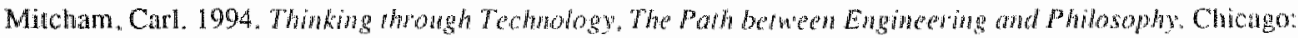
Chicago Universily Press.

Mosco. Vincent. 1996. The Pohtirat Economy of Communication. London: Sage.

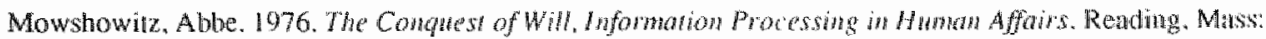
Audison-Wesley.

Mumford, Enid. 1981. Valnes, Technology and Work. The Hague: Marrinus Nijholt.

Mumford, Enid and Weir, M. 1979. Compwter Systems in Work Design. The ETHCS Method: Effective Techical and Human Implementation of Compune-Based Systems. New York: Halsted Press.

Mumford, Lewis. 1961. 'History: Neglected. Clue 10 Technological Change' Technolog: \& Curwe 2, 3, Summer. pp. $230-6$.

Murdock. Graham. 1990. 'Rednawing the Map of the Communications Industrites: Concentration and Ownership in the Era of Privatization" in Ferguson, Mijorie, ed. 1990.

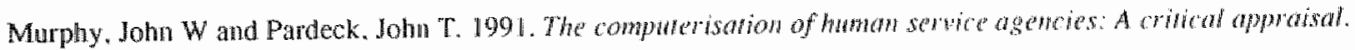
Westport. CT. Auburn House.

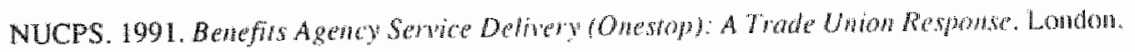

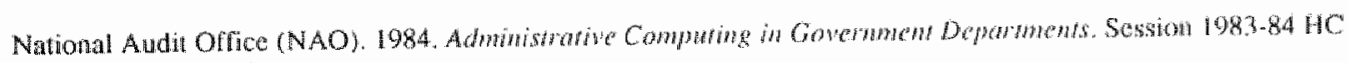
259. London: HMSO.

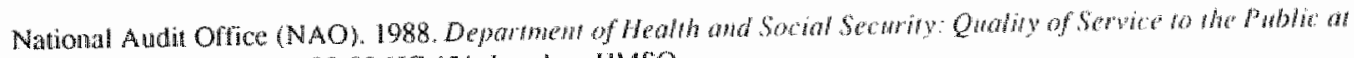
Lacal Offices. Session 1988.89 HC 451 . London: HMSO.

National Audir Office (NAO). 1989. Depatment of Social Securty: Operational Smategy. Session $198 \mathrm{x}-89 \mathrm{HC}$ 11. London: HMSO.

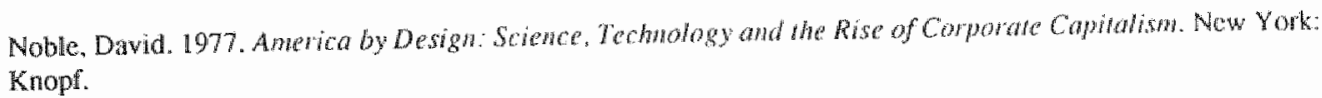

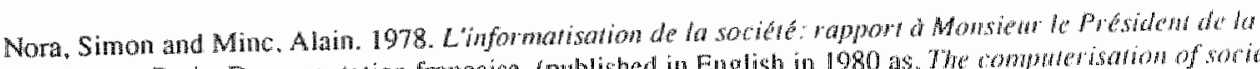
République. Paris: Documentation française. (published in English in 1980 as, The tompute thation of woriety: a report ro the President of Fronce. Combridge. MA: MIT Press.)

Nye, David. 1994. Amorican Technologiral Sibline. Cambridge. Mass: MIT Press. 
Staudenmaier, John M. 1994. Rationaliy versus Contingency in the History of Technogy' in Smith. Merrin Roc and Marx. Leo, eds. 1994.

Steinfield. C. et al 1993. Tetecownmanications in Transihon: Policies, Services and Techologies in the European Economic Commanity. London: Sage.

Stewart, Iair. 1991. 'A Departmenal Response' in Adller, Michael and Willams, Rohin, eds. 1991.

Summerton. Jane, ed. 1994a. Changing Large Technical Systems. Boulder, Colorado: Westview Press.

Summeron. Jauta. 1994b. 'In roductory Essay: The Systems Approach to Technological Change' in Summerton. Jane, ed. 1994a.

Susman, Herben L. 1968. Victorians and the Machine. The Liferary Response to Techology. Cambridge. MA: Harvard Universily Press.

Swinden. Karen. 1995. 'Public systerns - the three Es of T' iTe ar 1.3. pp.40-3.

Sorensen. Knut and Berg. Anne-Jorum, eds. 1991. Technology and Everyday Life: Trajectories and Transformations' Repony No.5: Procededings from a Workshop in Trondhe im, May 28-29. 1990. Oslo: Norwegian Research Council for Science and the Humanities.

Taylor. John A and Willians. Howard. 1991. 'Public andministration and the infomation polity' Prablic Administraton 69. Summer. pp. 171.90.

Teece. David. 1988. "Tcemological change and the nature of the firm' in Dosi. Giowann er at. eds. 1988.

Thomas, Eryl. 1988. "Risk Assessment in Initiating Jurormation Technology Projects" Procededings of Seminor 33. Oxford: Major Projects Association. Templeron College.

Thomas, Frank. 1988. 'The Politics of Growth: The German Telephone System' in Moyntz, Renate and Hughes. Thomas P. eds. 1988.

Thompson, EP. 1967. "Time. Work. Discipline and Industrial Capitalismi' Past \& Presen 38, pp.56-97.

Toyabed, Anold. 1969. Lectures in the industrial retolwion in England, popular addresses, wores and other fragmens. London: David and Charles. (first published in 1884).

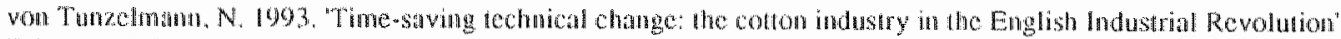
Brighton: Science Poticy Reseanch Unit. mimeo.

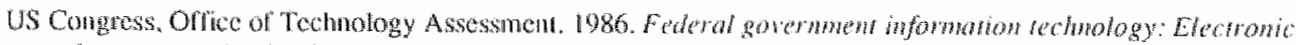

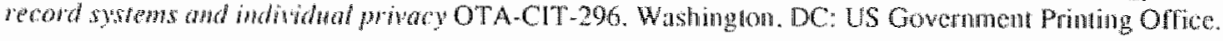

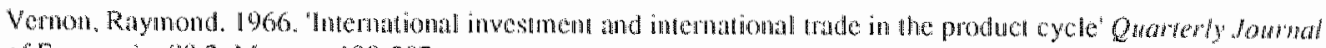
of Economics 80.2. May. pp. 190-207.

Vig. Noman J. 1988. 'Technology. Philosophy and the State: An Overview' in Kalt. Michael E and Vig. Norman 1. ads. Techology and Politics. Durham: Duke University Press.

Wajcman. Judy. 1991 Ferminisun confonds Technology. Pennsylvana: Pennsylvamia State University Press.

Webster. Frank. 1995 . The ries of the Informatom Saxter. London: Roulledge.

Weingar. Peter. 1984. The Structure of Technological Change: Reflections on a Sociological Analysis of Technology' in Laudat. Rachel, ed. 1984. 
Westerberg. H. 1989. 'Managing organisational changes in the Donish tax and customs administranton' $1 \mathrm{CA}$

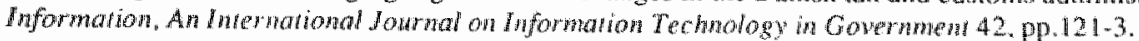

White. Lynn Ir. 1962. Medieval Technology and Social Change. Oxford: Oxford University Press.

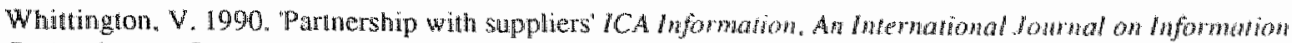
Technology in Goverumen 45. pp.167.72.

Williams. Raymond 1980. Essays in Moterialism and Cwhume. London: Verso.

Williams, Raymond. 1990. Tetevision, Technology and Cuthar Fom 2nd ed. London Routledge.

Wilson. Woodrow. 1887. 'The Siudy of Administration' Polifical Science Quarlenty 2, 2, pp.197-220.

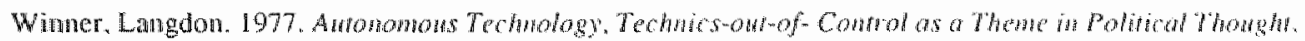
Cambridge. MA: MIT Press.

Winaer. Langdon. 1980. 'Do Artifacts Have Politics?" Daedahs 109. pp.121-36.

Winner. Langdon. 1986a. The Whate and the Reoctor. A Seort for Limits in the Age of High Technohogy. Chicago: Universily of Chicago Press.

Winner. Langdon. 1986b. "The Political Philosophy of Alternative Technology" in Teich. Albert H. ed. Technology and the Future 4th ed. New York: St Martin's Press.

Winner, Langdon. 1993. "Cizen Virtues in a Technological Order' in Winkler. ER and Coombs, JR. eds. Apphed Edhics: A Reader. Oxford: Blackwoll.

Ww inner, Langdon. 1993. 'Upon Opening the Black Box and Finding It Empty: Social Constructivism and whe Philosophy of Technology" Scionce. Techrology and Hwon Vahes 18.3, Summen. pp.362-78.

Woolgar, Steve. 1981 a. 'Interests and Explatiation in the Social Study of Science' Social Srudies of Srience 11. pp. $365-94$.

Woolgar. Steve. 1981b. "Critique and Criticism: Two Readings of Eumomehodology' Social Studies of Science II. pp.504-14.

Wyatt. Sally. 1990a. 'Understanding IT innowation in public services' Anformation Age? 12.1 , pp.3.8.

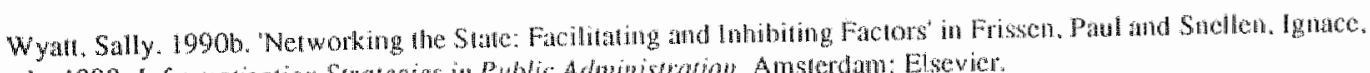

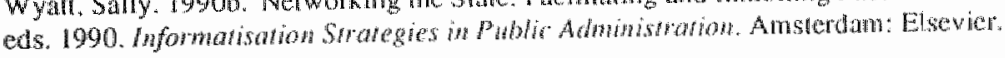

Wyatr. Sally. 1991. 'Webs of Welfare: the Social Security Office Gets Networked' in Adler, Michacl and Williams. Robin, eds. 1991 .

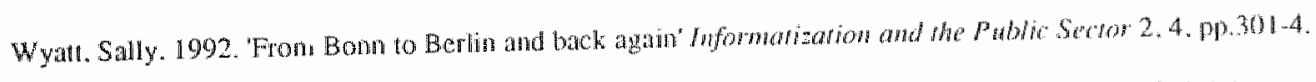

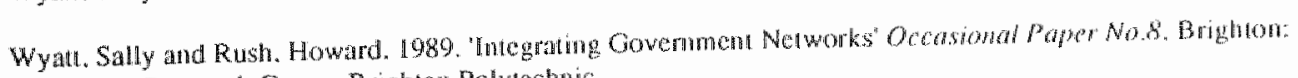
Innovation Reseanch Group. Brighton Pofycchmic.

Young. Robert. 1977. "Science is Social Rekations" Radical Scinno dound 5. pp.65-129,

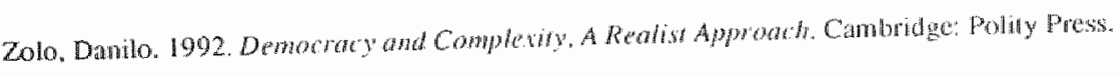

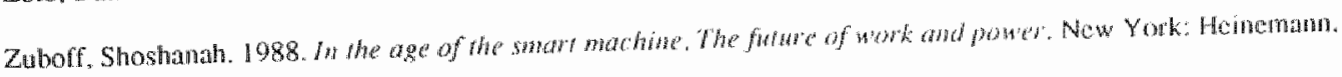


This book demonstrates that we cannot ignore technological determinism in the hope that it will disappear and that the world will embrace the indeterminacy and complexity of other types of accounts of the technology-society relationship. I argue that those of us within the 'science-technology-society' (STS) community cannot simply despair of the endurance of technological determinism and continue with our more subtle analyses. We must take technological determinism more seriously, disentangle the different types, clarify the purposes for which it is used by social actors in specific circumstances. Moreover, I argue that in order to do this we have to recognise the technologicall determinists within ourselves, arising from our conviction that technologies matter. Just as we treat technologies seriously, so we must treat technological determinism seriously. It is no longer sufficient to dismiss it for its conceptual crudeness; nor is it enough to dismiss it as false consciousness on the part of actors or as a bleak outlook for the future of humanity. Technological determinism is still with us, and is unlikely to disappear; it remains in the justifications of actors who are keen to promote a particular direction of change; it remains as a heuristic for organising accounts of technological change; and it remains as part of a broader public discourse which seeks to render technology opaque and beyond political intervention and control. These claims are explored in this book through an analysis of three information technology systems developed during the $1980 \mathrm{~s}$ in the public administrations of the United Kingdom and the United States.

Wild claims are frequently made about the revolutionary potential of the new technologies of information and communication, those "things" that incorporate microprocessors and are connected to one another with wires or cables or via satellites creating that consensual hallucination we now call cyberspace. Such claims usually reflect cheeringly optimistic or despairingly pessimistic visions of the future. The utopian view depicts a future in which we are freed from routine, tedious work in order to enjoy the infinite variety of entertainment and education that is beamed into our homes. The dystopian version emphasises the potential of the technology to increase surveillance and control over every aspect of our lives, not only at home but also at work, in the marketplace and in our dealings with the government.

Information technology (IT) is not the first technology to have such apparently contradictory possibilities and interpretations. The birth control pill freed women from the fear of unwanted pregnancy or led to a decline in family values. The television is welcomed by some for providing a window on the world and extending the distribution of information, and reviled by other for transmitting tawdry scenes of sex, violence and mass consumerism. Such apparently contradictory analyses suggest, at worst, that people thave no choices in the effects new technologies may have, or, at best, that the technologies themselves are inherently neutral and whether they have good or bad effects depends entirely on the choices people make regarding how to use them. 
Chapter 1 outlines the general technology-society problematic- how to make semary world inhabited not only by people but also by the artefacts we and our ancestors have created. Technological determinism, neutral technology and a range of constructivist approaches to understanding technology are introduced. The latter is given most altention, but 1 explore some of the reasons why technological determinism continues to endure, not least of which is that it confirms most people experience of tectunology most of the time.

Chapter 2 narrows the focus by examining the role of IT whin public administration. This is an attempt to redress the balance in the ever-growing literature on the development and use of IT which focuses on manufacturing and private services. Many of the issues are similar, but there are others which are specific to the public sector. Not only is government a major user, it is also involved in the development of $1 T$ through its other roles as, inter alia, regulator and standard-setter. I begin to be more specific about the technologies and their site of development and use in order to situate the particular cases of the development of three government $1 \mathrm{~T}$ systems examined in Chapters 4 and 5 .

Many public policy issues have been raised by the greater use of IT by governments. Three key issues are identified: personal privacy, privatisation of government services and political primacy in the legislative process. To understand these as political problems pushed into public view following the introduction of new lechnologies is only pant of the story. Another part is that perceptions of these problems and how best to resolve them are also used to justify the technical choices made by public sector organisations.

Chapter 3 explores some methodological questions, reaching the following conchusions: First, accounts of systems development need to be mulcifaceted. To convey the richness and complexity of three large govermment IT systems, it is necessary to incorporate technical, economic, political, organisational and social factors. Second, the conventions of narrative history are adopted. The unfolding of events in time proves to be a useful way of organising the accounts. Third, the scale and scope of government IT systems highlights the difficulty of defining scale. However, there is an advantage in analysing these large, complex systems becalse they bring to the fore my concen with the duatity of structure and agency. Finally, the principle of symmetry wim respect to the analysis of success and failure is adopted. Recourse to explanations of the variety, "it just did not work', are not allowed.

Chapter 4 traces the development of the Operational Strategy in the British Department of Social Security between the beginnings of discussions in 1977 to its full implementation in 1991. The concepts of relevant social groups, their problems and interests, interpretave flexibility and closure are discussed. Throughout the 1980 s, the problems which the Strategy sought to solve were simplified by the groups which came to dominate the Strategy, in an effort to deliver some sort of system on schedule. In the early days of the Operational Strategy, there was a high level of interpretative flexibility around its aims. Over time, a high degree of stabilisation occurred, pemitting a temporary closure of the Strategy as a centralised mainframe-based system. Even if the closure was not permanent, 
it did serve to structure future developments. The way in which the conceptual building blocks of social constructivism can be used to develop a framework understanding sociotechuical change emerges; moreover, a framework which allows for the rhetoric and realify of technological determinism.

Chapter 4 illustrates some of the points made in earlier chapters. Attention focuses on the ways in which different factors and groups interacted during the early stages of the projects specification and development to shape and construct the system as it emerged. Social and technical issues were crucial in influencing its shape prior to its implementation; issues as varied as the public sector debt, civil service industrial action and the reform of social welfare legislation. For example, one of the claims frequenty made by IT enthusiasts is that it is a flexible technology. The case of cold weather payments in which technical developments reduced the discretion and flexibility available not only to local officials but also to policy-makers illustrates the limits of that claim. The belief in the primacy of the legislative process over mundane operational matters like developing a technical system for delivering social security benefits is called into doubt, given the timing and importance of the 1987 Social Security Reform Act in relation to the Operational Strategy. The socio-technical embeddedness of the legislative process began to be exposed.

The other two systems which form the empirical focus of this book are described in Chapter 5. The Government Data Network (GDN) and the Federal Telecommunication System (FIS2000) were developed during the 1980s by the central administrations in the UK and the US respectively. The British attempted to develop a data communication network; the US attempted to develop an integrated voice, data and image communication network. Both of these were to be shared by different government deparments and both were to be provided by a third party supplier. Both are very odd stories. The British case is odd because exchange of data across departments is prohibited by law. The US case is odd because what began as a single, integrated network became two incompatible networks provided by two different suppliers.

All three systems can be considered 'large", but in different ways; illustrating the discussion in Chapter 3 about the difficulty of defining the scale of technical systems. The Operational Strategy is 'large' when defined according to the number of records and the number of hands-on users. The GDN and the FIS2000 are 'large' when defined by the number of najor organisations involved in their development and subsequent use. The GDN and the FTS2000 were provided by a third party on the basis of a service contract. Using a third party supplier was a radical change within the UK context, but was common practice in the US. The GDN was about hardware; the network management systems were supposed to be invisible and the applications were superfluous to what came to be understood as the GDN. The lack of attention to applications was simultaneously the reason for the GDN's much more rapid development and for its eventual failure. The US system, FTS2000, provided for integrated voice, data and image communication, whereas the GDN was concerned only with data communication, and noreover only with the 
required telecommunication infrastructure. Unlike the GDN, the FTS2000 incorporated some applications within its specification.

There are also differences of policy emphasis between these systems. For the GDN and the Operational Strategy, issues central to British political debate throughout the 1980s, such as the future of the telecommunication industry, public sector borrowing, the power of civil service unions and data protection all played a role in constructing the emerging system. In the US, the political context was dominated by the first of these, together with a longer standing commitment to market competition.

The process of closure and the stabilisation of a technological frame around a very narrow vision of the technical infrastructure was perhaps one degree of stabilisation too far. The GDN Steering Committee did not appreciate the heterogeneous nature of a technical system, that what are commonly understood as the social and the technical are mutually constitutive. Focusing on the creation of an infrastructure, using standard hardware, with the expectation that people will find ways of using it once it is in place is to beg disaster. Especially in the design of a communication system, designers also need to be sociologists to understand what people want to communicate to whom, when and why. Rather than understanding the ways in which technologies are actively constructed through the recreation of the social and technical relations of their production and reproduction, the Steering Committee pursued a strategy informed by their technologically determinist world view, in which applications and uses would automatically follow the introduction of a system.

I suggest that it is too harsh to ascribe failure simply because no one used the arlefacts. This is the conclusion one is forced to draw when following the analysts. If we shift our viewpoint to follow the major actors, the GDN must be considered a success. It was not widely used; it did not serve to transform the workings of public administration but it was successful in introducing a new player onto the stage of the European telecommunication service supply industry.

The preceding paragraph illustrates how these curious stories raise interesting questions about our understanding of terms often used interchangeably within social consiructivism, such as working, use and success as opposed to non-working, non-use and failure. It is tempting to suggest that the technology worked but was not used and was successful only in terms of increasing the numbers and changing the market share of players in the wider British and American telecommunication markets. The technology worked - il was standard equipment which worked elsewhere; technology based on the OSI protocols preferred by voice specialists. This type of argument suggests that whether or not we can speak of technologies 'working' is either a question of whether or not they somehow effect change of the physical world or whether their features derive directly from the physical world. 
These stories highlight the principle of symmetry which suggests that success and failure must be explained in similar terms. It is not acceptable to say that technologies work or are successful because of some inherent superiority they possess in relation to the physical world, and that others fail for social reasons, such as lack of financial or political support. Success and failure have to be explained symmetrically. The GDN illustrates how one cam explain failure in social terms extremely well. The GDN draws on standard technologies that work and were used successfully by British Telecom, Mercury and many other organisations throughout the world. But the GDN itself does not work because it was not used and it was not used because no consideration of potential patterns of use had been considered in its development.

Chapter 6 summarises the accounts of the systems analysed more fully in Chapters 4 and 5. It also explores the methodological and theoretical contributions of these studies to the analysis of socio-technical change. The major methodological contribution of this book is that actors and analysts can and must learn from one another. If we simply follow the actors, which is what some authors suggest is what the new sociology of technology advocates, we would end up with very partial accounts of technological change. In two of the case studies presented, following the actors would have meant that we would have missed the users, both those people who wse the systems to do their paid work and also those people whose livelihoods depended on the systems. We occasionally found images of users being deployed, but not always even that. Yet, anyone with even a cursory knowledge of the economics and management of innovation literature knows that users are important to the success of projects. These case studies only become comprehensible when the invisibility of users by other social groups is taken into account. Analysts must also learn from the concepts used by actors. In the government IT systems discussed in this book, technological determinism is used by some of the actors as a mode of explanation both to justify courses of action and to mobilise other resources. As part of a strategy, technological determinism can be very effective. Despite valiant attempts by analysts to kill and bury technological determinism, it remains, Hydra-like in its persistent use by actors.

The major theoretical contribution of this book is that technological determinism needs to be treated with more respect and subtlety than has been the case hitherto. Berating technological determinism as a reductionist and inadequate explanation of socio-technical change is not enough. Technological determinism lives! It persists in the actions taken and justifications given by many actors; it persists in analysts" use of it to make sense of the introduction of technology in a variety of social settings; it persists in manifold theoretical and abstract accounts of the relationship between the social and the technical; it persists in the responses of policy-makers and politicians to challenges about the need for or appropriateness of new technologies; and it persists in the reactions we all experience when confronted with new machines and new ways of doing things.

Chapter 6 concludes with a mapping of the varieties of technological determinism found in the words and actions of analysts and actors. Four types are identified: justificatory, 
explanatory, methodological and normative. Taking technological determinism seriously in this way is important for 'big' and "small" politics. In order to be able to intervene in the familiar big politics of public life, we have to understand how technological determinism is used by some actors. An analysis of the types of technological determinism also helps us in the politics of knowledge, to analyse how the dualisms of internal/ external, social/ technical are produced and reproduced.

The challenges of STS remain: to understand how machines make history in concert with current generations of people; to conceptualise the dialectical relationship between the social shaping of technology and the technical shaping of society; to treat symmetrically the categories of analysts and those of actors even if the latter includes technological determinism, anathema to so much contemporary social science. These dialectics cannot be resolved one way or another, but that is as it should be. What is important is to continue to wrestle with them. We need to take seriously the efforts to stabilise and extend the messy and heterogeneous collections of individuals, groups, artefacts, rules and knowledges that make up our socio-technical world. We need to continue to grapple with understanding why sometimes such efforts succeed and sometimes they do not. Only then will people have the tools to participate in creating a more democratic socio-technical order. 


\section{SAMENVATTING}

In dit boek toon ik aan dat we het technisch determinisme niet kunnen negeren in de hoop dat het vanzelf zal verdwijnen, en dat de wereld vervolgens de onbepaaldheid en complexiteit van andere verklaringen wan de techniek-samenleving relatie wel zal omarmen. Ik betoog dat wij als WTS-onderzoekers (WTS: wetenschap, techniek en samenleving) het niet kunnen laten bij onze wanhoop over de volhardendheid van het technisch determinisme, en voortgaan met onze meer subtiele analyses. We moeten technisch determinisme serieuzer nemen, het uiteenleggen in verschillende typen, de doelen verhelderen waarvoor het door maatschappelijke actoren onder bepaalde omstandigheden wordt gebruikt. Bovendien beweer ik dat we hiertoe het technisch determinisme in onszelf moeten erkennen, een gevoel dat voortkomt uit de overtuiging dat techniek ertoe doet. We moeten niet alleen techniek maar ook het technisch determinisme serieus nemen. Het is niet langer voldoende het als inadequaat af te wijzen vanwege zijn conceptuele grofheid; het is evenmin voldoende het als vals bewustzijn van de actoren af te doen; of als cen kil vooruitzicht voor de toekonst der mensheid. Technisch determinisme is er nog steeds en het is onwaarschijnlijk dat het verdwijnt: het blijft als de rechtvaardiging van actoren die verandering in een bepaalde richting willen bepleiten; het blijft als een heuristiek om beschrijvingen van technische verandering te organiseren; en het blijft als deel wan het bredere publieke discours warin techniek ondoorzichtig wordt gemaakt en immuun voor politieke interventie en controle.

Regelmatig worden vèrgaande beweringen gedaan over het revolutionaire potentieel van de nieuwe informatie- en communicatietechnologieën—die "dingen" die microprocessoren bevatten en met elkaar verbonden zijn door snoeren en kabels of met satellieten, om zo die gemeenschappelijke hallucinatie te creëren die we nu "cyberspace" noemen. Zulke beweringen weerspiegelen meestal juichend optimistische of wanhopig pessimistische toekomstvisies. De utopische visie schildert een toekomst waarin we bevrijd zijn van routinemattig, zwaar werk om te genieten van een eindeloze varuëteit aan ontspannings- en onderwijsmogelijkheden die onze huizen wordt ingestraald. De dystopische visie benadrukt het vermogen wan de technologie om elk aspect van ons dagelijks leven te bewaken en te controleren, niet alleen thuis maar ook op het werk, de markt en in onze relaties met de overheid.

Informatietechnologie (IT) is niet de eerste technologie die zuike ogenschijnlijk tegengestelde mogelijkheden heeft. De anticonceptiepil verloste vrouwen van de angst voor ongewenste zwangerschap of leidde tot verval van gezinswaarden. De televisie is door sommigen begroet als een venster op de wereld dat onze horizon verruimt, en door anderen ontmaskerd als een doorgeefluik voor morsige seksbeelden, geweld en massaconsumentisme. Wat deze ogenschijnlijk tegengestelde analyses suggeren is - op zijn slechtst - dat mensen geen invloed hebben op de mogelijke effecten van nieuwe technologie, of - op zijn best - dat de technologie van zichzelf neutraal is en dat de goede of kwade gevolgen volledig afhangen wan de keuzes die mensen maken bij het gebruik van die technologie. 
Hoofdstuk 1 schetst de algemene problematiek van technologie-en-samenleving: hoe een wereld te begrijpen die niet alleen door mensen maar ook door dingen wordt bewoond die wij en onze voorouders gemaakt hebben? In dit hoofdstuk introduceer ik technisch determinisme, neutrale techniek en een spectrum an constructivistische benaderingen van techniek. Die laatste krijgen de meeste aandacht, maar ik bespreek ook enkele van de redenen waarom technisch determinisme zo volhardend is in zijn bestaan; niet de geringste daarvan is, dat het overeenstemt met de ervaring die de meeste mensen meestal met techniek hebben.

Hoofdstuk 2 concentreert de aandacht op de rol van IT in overheidsdiensten. Het is een poging om het evenwicht te herstellen in de nog steeds groeiende hoeveelheid literatuur over de ontwikkeling en het gebruik van IT, waarin een grote nadruk ligt op de domeinen van productie en private dienstverlening. Veel thema's zijn hetzelfde, maar er zijn ook verschillen met de publieke sector. Niet alleen is de overheid een grote gebruiker, zij is ook betrokken bij de ontwikkeling van IT in haar rol als, onder meer, auteur van regels en standaarden. Hoofdstuk 2 biedt specifieke informatie over de technologieèn en hun ontwikkeling en gebruik, teneinde de in hoofdstukken 4 en 5 beschreven gevalstudies van drie IT systemen van de overheid beter in hun context te kunnen plaatsen.

Het toenemende gebruik van IT door de overheid heeft geleid tot talrijke beleidsvagen. Drie kernproblemen zijn geïdentificeerd: persoonlijke privacy, privatisering van overheidsdiensten, en het politieke primaat in de wetgeving. Eén aspect van het verhaal is deze drie te begrijpen als politieke problemen die door de nieuwe technologieen in de openbare schijnwerpers gezet worden. Een tweede aspect is dat percepties van deze problemen en hun mogelijke oplossingen worden gebruikt bij de rechtvaardiging van technische keuzes die gemaakt worden door organisaties in de publieke sector.

Hoofdstuk 3 onderzoekt enkele methodologische kwesties, waaruit de volgende conclusies getrokken worden. Ten eerste dient een beschrijving van de ontwikkeling van systemen veelzijdig te zijn. Om de rijkdom en complexiteit te schetsen wan de ontwikkeling van drie grote IT-projecten in overheidsdiensten is het nodig technische, economische, politieke, organisatorische en sociale factoren in de beschouwingen te betrekken. Ten tweede is gebruik gemaakt van de technieken van de naratieve geschiedsschrijving. Het verloop van gebeurtenissen in de tijd blijkt een bruikbare manier om de beschrijvingen te organiseren. Ten derde onderstreept de reikwijdte van IT-systemen voor de overheid de moeilijkheid hun omvang vast te leggen. Overigens biedt de schaalgrootte van deze systemen ook een voordeel: in deze grote, complexe systemen komt mijn betrokkenheid bij het probleem van de dualiteit van structur en handeling goed naar voren. Tenslotte is met betrekking tot de analyse van succes en falen het symmetrieprincipe gehanteerd. Een beroep op verklaringen als "het werkte gewoon niet" zijn niet toegestatan.

Hoofdstuk 4 beschrijt de ontwikkeling van de Operarional Strategy in het British Department of Social Security vanaf het begin wan de discussies in 1977 tot de volledige invoering in 1991. De concepten "relevante sociale groepen". hun problemen en belangen, "betekenisflexibiliteit" en "sluiten van het debat" worden hier besproken. Tijdens de jaren 80 werden de problemen die de Operational Strategy geacht werd op te 
lossen door de dominante actoren vereenvoudigd, in een poging om tenminste enig werkend systeem op tijd te kunnen afleveren. In de eerste periode van de Operational Strategy hadden zijn doelen een grote betekenisflexibiliteit. Na verloop van tijd ontstond er een hoge mate van stabilisatie, die tot een tijdelijke, effectieve consensus kon leiden over de Operational Strategy als een gecentraliseerd systeem van mainframe-computers. Hoewel deze consensus niet permanent was, structureerde zij toch latere ontwikkelingen. Zo wordt duidelijk hoe de conceptuele elementen van het sociaal-constructivisme gebruikt kurnen worden voor een theoretisch raamwerk om socio-technische verandering te verklaren; een theoretisch raamwerk dat bovendien ruimte biedt voor de retoriek en de realiteit van technisch determinisme.

Hoofdstuk 4 biedt ook enkele illustraties bij de eerdere hoofdstukken. Er is speciale aandacht voor de manieren waarop de wissel werking tussen verschillende factoren en groepen in de eerste specificatie- en ontwikkelingsstadia van het project de latere vorm van het systeem beinvloeden. Sociale en technische vragen speelden een cruciale rol in de vormgeving van het systeem voorafgaand aan zijn implementatie: vragen over het financieringstekort, over stakingsdreiging in overheidsdiensten, en over de hervorming van de sociale zekerheidswetgeving. IT-aanhangers stellen bijvoorbeeld vaak dat IT een flexibele technologie is. De zaak van de koude-uitkeringen, waarin technische ontwikkelingen de beslissingsruimte en de flexibiliteit inperkten van zowel lokale ambtenaren als beleidsmakers, relativeert die stelling. Het geloof in het primaat van de wetgeving over alledaagse uitvoeringszaken als het ontwikkelen van een technisch systeem voor de uitbetaling van uitkeringen wordt evenzo gerelativeerd door het verschijningsmoment en het belang van de Social Security Reform Act (1987) ten opzichte van de Operational Strategy. De sociaal-technische verankering van het wetgevingsproces wordt in dit hoofdstuk zichtbaar.

De twee andere systemen die de empirische basis van dit boek vormen worden beschreven in hoofdstuk 5. Het Governmen Data Network (GDN) en her Federal Telecommunication System for the year 2000 (FTS2000) werden in de jaren 80 ontwikkeld door respectievelijk de centrale overheden van het Verenigd Koninkrijk en de Verenigde Staten. De Britten probeerden een netwerk voor datacommunicatie te ontwikkelen; de Amerikanen een geïntegreerd stem-data-beeld communicatienetwerk. Beide netwerken moesten gebruikt worden door verschillende ministeries en beide zouden door een externe partij geleverd worden. Beide gevallen leveren vreemde verhalen op. Het Britse verhaal is vreend omdat de uitwisseling van gegevens tussen ministeries bij de wet verboden is. Het Amerikaanse geval is vreemd omdat wat begon als een geintegreerd netwerk van én leverancier uiteindelijk leidde tot twee incompatibele netwerken van twee leveranciers.

Alle drie systemen zijn "groot", maar op verschillende manieren; dit illustreert de discussie in hoofdsuk 3 van de moeilijkheid on de omvang van technische systemen precies af te bakenen. De Operational Strategy is groot in termen van het aantal bestanden en het aantal daadwerkelijke gebruikers. Het GDN en het FTS2000 zijn groot in termen van de organisaties die bij hun ontwikkeling en het latere gebruik betrokken zijn. Het GDN en het FTS2000 werden geleverd door een externe partij op basis van een service-contract. Het gebruik van een dergelijke externe leverancier was een radicale 
verandering in de Britse context, maar normale praktijk in de Verenigde Staten. Het GDN ging over hardware; de beheerssystemen van het netwerk moesten onzichtbaar zijn en de toepassings-software was irrelevant voor wat onder het GDN verstaan ging worden. Het gebrek aan aandacht voor toepassings-software was tegelijk de oorzaak van de veel snellere ontwikkeling van het GDN en van het uiteindelijke falen ervan. Het Amerikaanse systeem, FTS2000, leverde geïntegreerde stem-data-beeld communicatie, terwijl het GDN zich alleen bezig hield met datacommunicatie, en dan ook nog uitsluitend met de woor telecommunicatie benodigde infrastructuur. Anders dan bij het GDN waren voor het FT\$2000 wel enkele toepassingen gespecificeerd.

Er zijn ook verschillen in de politieke gevoeligheid wan beide systemen. Bij het GDN en de Operational Srrategy speelden de Britse politieke thema's van de jaren 80 een rol in de ontwikkeling van het systeem: de toekomst van de telecommunicatie-industrie, overheidsfinanciering door leningen, de macht van ambtenarenbonden, en gegevensbescherming. In de VS werd de politieke context gedomineerd door het eerstgenoemde thema, samen met de al langer bestaande nadruk op markiwerking.

Het sluiten van het debat en de stabilisatie van een technisch raum rondom de enge visie van de technische infrastructuur was wellicht één stabilisatie-slap te ver. De GDNstuurgroep wist de heterogene aard van een technisch systeem niet naar watarde te schatten, namelijk het feit dat wat normaal onder "het sociale" en "het technische" wordt verstaan elkaar wederzijds bepaalt. Zich richten op het maken van een infrastructuur met standaardhardware, en verwachten dat mensen wel gebruiksmogelijkheden zullen vinden als het systeem eenmaal geplaatst is, is vragen om problemen. Zeker bij het ontwerpen van een communicatie-systeem moeten ontwerpers ook sociologen zijn om te begrijpen wat, wanneer, waarom en met wie mensen willen communiceren. In plaats van te begrijpen hoe technologieën actief worden geconstrueerd door het herordenen van de sociale relaties van hun productie en reproductie, volgde de GDN-sturgroep een technisch deterministische strategie, waarin toepassing en gebruik automatisch op de introductie van het systeem zouden volgen.

Ik denk dat de mislukking niet eenvoudigweg kan worden afgeleid uit het feit dat niemand de artefacten gebruikte. Die conclusie zou men trekken ats het perspectief van de techniekonderzoekers wordt gekozen. Indien we het perspectief kiezen van de belangrijkste actoren, dan is het GDN een succes. Het werd welis war niet veel gebruikt en het transformeerde niet de praktijk van de overheidsdiensten; matar het slaagde erin een nieuwe speler op de kaart van de Europese telecommunicatiediensten-industrie te plattsen.

De voorgaande alinea illustreet hoe deze geval-studies cen aantal interessante vagen opleveren over de interpretatie van termen die vaak als onderling verwisselbaar worden gehanteerd binnen het sociaal constructivisme; termen zoals "werkend", "gebruik" en "succes" tegenover "niet-werkend", "niet-gebruik", en "mislukking." Het is verleidelijk te suggereren dat de technologie wel werkte maar niet werd gebruikt, en alleen succesvol was in het talrijker en sterker maken van spelers op de Britse en Amerikaanse telecommunicatie-markten. De technologie werkte - het was immers standaardiupparatuur die elders werkte; technologie gebaseerd op de OSI-standaard waaraan de telefoon- 
specialisten de voorkeur gaven. Deze vorm van argumentatie veronderstelt dat het "werken" van een technologie ervan afhangt, of die technologie een effect heeft op de fysieke werkelijkheid, dan wel direct afgeleid is wan die fysieke werkelijkheid.

In deze geval-studies kan ik het symmetrie-principe onderstrepen dat ervoor pleit succes en falen in dezelfde termen te verklaren. Hel is onaanvaardbaar te betogen dat technologieen werken of succesvol zijn vanwege een of andere inherente superioriteit met betrekking tot de fysieke wereld, terwij] andere mislukken vanwege sociale oorzaken zoals gebrek aan financiële of politieke steun. Succes en mislukken moeten symmetrisch verklaard worden. De GDN-casus illustreert hoe mislukken zeer goed kan worden verklaard in sociale termen. Het GDN gebruikt standaardtechnologieèn die goed werken en daadwerkelijk worden gebrukt bij British Telecom, Mercury en vele andere organisaties in de hele wereld. Mar het GDN zelf kan als niet-werkend worden beschouwd omdat het niet werd gebruikt, en het werd niet gebruikt ondat bij de ontwikkeling geen rekening was gehouden met mogelijke gebruikspatronen.

Hoofdstuk 6 vat de geval-studies nog eens samen en bespreekt de methodologische en theoretische bijoragen van de studies an de analyse van socio-technische verandering. De belangrijkste methodologische conclusie van dit boek is dat actoren en onderzoekers van elkaar dienen te leren. Als we eenvoudig de actoren zouden volgen, wat sommige auteurs zien als het adagium van de nieuwe technieksociologie, zou dit een heel eenzijdig verhaal over de technische veranderingen opleveren. In twee van de casus zou dit betekend hebben dat we de gebrükers gemist hadden: zowel de mensen die de systemen gebruiken orm hun betaalde werk te doen, als de mensen die voor hun levensonderhoud van de systemen afhankelijk zijn. Soms vonden we beelden van gebruikers, maar vaak niet eens dat. Toch weet iedereen die ook maar enigszins bekend is met de literatuur op het terrein van economie en innovatie management dat gebruikers van belang zijn voor het succes van een project. Deze twee casus konden dus pas begrepen worden toen $\mathrm{ik}$ als onderzoeker de gebruikers zichtbar had gemaakt, en de onzichtbaarheid van deze gebruikers voor andere actoren had gethematiseerd. Onderzoekers moeten ook lering trekken uit de concepten die door actoren gebruikt worden. In de IT-systemen voor de overheid die in dit boek besproken zijn gat het dan om technisch determinisme, een vorm van verklaring die door sommige actoren word gebruikt on handelen te rechtwardigen en om meer steun te verwerven. Technisch determinisme kan zeer effectief zijn als onderdeel van een strategie. Ondanks moedige pogingen van techniekonderzoekers om het technisch determinisme te doden en te begraven, houdt het stand en blijf het - als het veelkoppige monster Hydra - gebruikt worden door actoren.

De belangrijkste theoretische conclusie van dit boek is dat technisch determinisme met meer respect en nuance moet worden behandeld dan tot nu toe gebuikelijk is. Het te hekelen als een reductionistische en inadequate verklaring is niet voldoende. Technisch determinisme leeft! Het volhardt in het handelen en de zelfechtvardiging van veel actoren; het volhardt in pogingen van onderzoekers om de introductie van technologieën in allerlei sociale omstandigheden te begrijpen; het volhard in velerlei theoretische en abstracte beschrijvingen van de relaties tussen het technische en het sociale; het volhardt in de reacties van beleidsmakers en politici op de uitdagingen ten anzien van de behoefte 
aan of de geschiktheid wan nieuwe technologieèn; en het volhard in de reacties die we allemaal ervaren als we met nieuwe machines en nieuwe procedures worden geconfronteerd.

Ik besluit hoofdstuk 6 met het in kaart brengen van de verschillende varieteiten van technisch determinisme in de woorden en het handelen van onderzoekers en actoren. Vier typen worden onderscheiden: rechtvaardigend, verklarend, methodologisch en normatief technisch determinisme. Het op deze manier ernstig nemen van technisch determinisme is van belang voor "grote" en "kleine" politiek. Om te kunnen deelnemen aan de grote politiek van het openbare leven, moeten we begrijpen hoe technisch determinisme wordt. gebruikt door sommige actoren. Een beter begrip van de typen wan technisch determinisme helpt ook bij de "kleine" kennispolitiek: het leert ons hoe dualismen als intern/extern en sociaal/technisch worden geproduceerd en gereproduceerd.

De uitdaging voor het WTS-onderzoek blijft: begrijpen hoe machines geschiedenis maken, samen met mensen; de dialectische relatie conceptualiseren tussen de sociale constructie van techniek en de technische constructie van de samenleving; de actor-en onderzoekercategorieën symmetrisch behandelen, zelfs als de eerste het technisch determinisme impliceren dat zo haaks staat op veel hedendaagse sociale wetenschap. Deze dialectiek is onoplasbaar, maar zo hoort het ook. Het is belangrijk de worsteling ermee voort te zetten. We moeten serieus ingaan op de pogingen tot stabilisering van de rommelige en heterogene combinaties van individuen, groepen, artefacten, regels en kennis die onze socio-technische wereld vormen. We moeten blijven proberen te begrijpen watarom zulke pogingen soms slagen en soms falen. Alleen dan zullen mensen de middelen krijgen om deel te nemen aan de opbouw van een meer democratische socio-technische orde. 


\section{Curriculum Vitae}

Sally Wyatt was born in North York, Canada on 12 May 1959. She graduated from McGill University, Montreal with a BA (Hons) in Economics in 1979 and from Sussex University, Brighton, England with an MA in the Theory of Economic Policy and Planning in 1980. Between 1980 and 1986, she worked at the Science Policy Research Unit, Sussex University. She moved to the Economic and Social Research Council (ESRC) in 1986 to work with the Central Co-ordinating Unit of the Programme on Information and Communication Technologies. Befween 1988 and 1990 , she was with the Centre for Research into Innovation and Management at Brighton University. She joined the Department of Innovation Studies, University of East London in 1990. In 1993-94, she was a fellow-in-residence at the Netherlands Institute of Advanced Study in the Humanities and Social Sciences.

Sally Wyatt is the co-author, with Gilles Bertin, of Multinationals and Industrial Property, The Control of the World's Technology (1988, Harvester-Wheatsheaf; first published in French: Multinationales et propriété industrielle "Le contrôle de la technologie mondiale, 1986, Presses Universitaires de France). She has published widely in the broad areas of technology policy and technology studies.

Sally Wyatt is the International Comordinator of the MA programme, 'Society, Science and Technology in Europe', involving over ten European universities. She is also a member of the ESRC's Science, Technology and Innovation Studies subject area panel. 